Evandro Fockink da Silva

\title{
EFEITO DA GEOMETRIA NA EBULIÇÃO NUCLEADA DE REFRIGERANTES HALOGENADOS EM TUBOS HORIZONTAIS
}

Tese apresentada à Escola de Engenharia de São Carlos, da Universidade de São Paulo, como parte dos requisitos para obtenção do título de Doutor em Engenharia Mecânica

ORIENTADOR: Prof. Dr. José M. Saiz Jabardo

São Carlos

2005 
Dedico este trabalho a minha esposa Alessandra, minha filha Beatriz, meus pais Manoel e Nilse, pelo amor, constante incentivo e compreensão nas horas difíceis. 


\section{Agradecimentos}

Ao Professor José Maria Saiz Jabardo pela excelente orientação, constante auxílio, amizade e apoio durante a elaboração deste trabalho.

À FAPESP e CAPES pelas bolsas de estudo concedidas.

Aos meus irmãos Diogo e Analice pela amizade e companheirismo.

Ao grupo de ebulição nucleada: Gherhardt Ribatski, Elvio Bugança Stelute e Samuel Freire de Barros pela cooperação na pesquisa.

A todos os amigos do Laboratório de Refrigeração do Departamento de Engenharia Mecânica: José Roberto Bogni, Enio Pedone Bandarra Filho, Paulo Eduardo L. Barbieri, Ana Carolina Evangelista, Elton Ferreira Higino de Cuba, João Roberto Zoghbi Filho, Williams Gonzáles Mamani e Ricardo Mazini.

Aos meus sogros Argeo e Antônia e meus cunhados Eduardo e Aline pelo auxílio e cooperação durante o meu trabalho.

Aos meus amigos Lauro Osiro, Denise Osiro, Fábio Ferraz Jr. e Carlos Eduardo Milhor.

A todos Professores, secretárias do Departamento de Engenharia Mecânica e demais colegas de Pós Graduação pela colaboração. 


\section{$\underline{\text { Índice }}$}

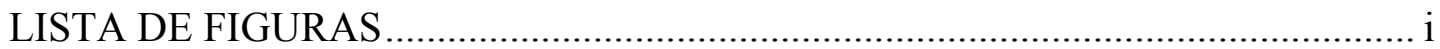

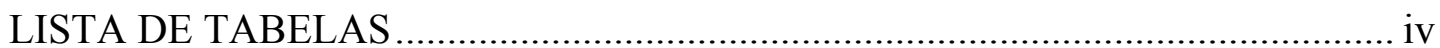

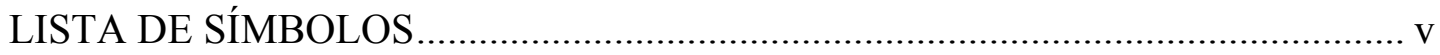

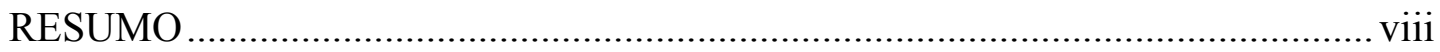

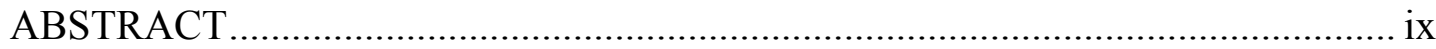

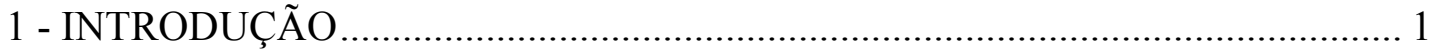

1.1 - Considerações iniciais ............................................................................... 1

1.2 - Objetivos do Trabalho ……………………………............................... 3

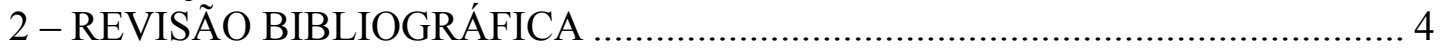

2.1 - Considerações Iniciais .................................................................................... 4

2.2 - Breve análise da influência do diâmetro do tubo na transferência de calor .... 4

2.3 - Fatores que influenciam a ebulição nucleada em banco de tubos ..................... 6

2.3.1 - Configuração do Banco de tubos............................................................ 9

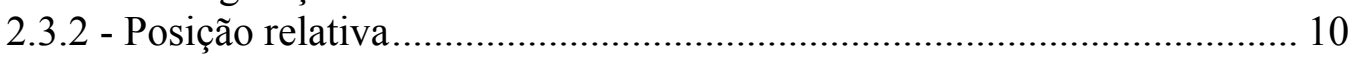

2.3.3 - Espaçamento entre tubos ..................................................................... 12

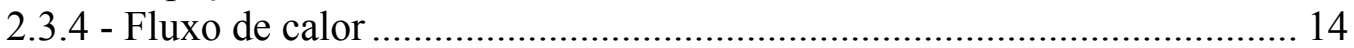

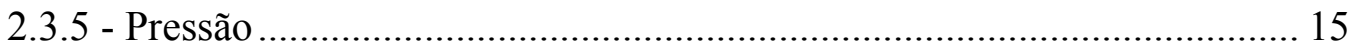

2.3.6 - Efeitos convectivos............................................................................ 16

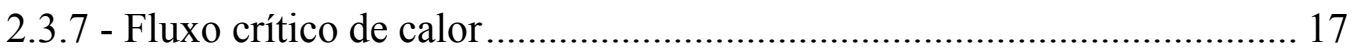

2.4 - Correlações para ebulição............................................................................ 18

2.4.1 - Correlações para escoamento monofásico (líquido) em banco de tubos 19

2.4.2 - Modelos e correlações para ebulição nucleada em um único tubo......... 20

2.4.2.1 - O Modelo de Rohsenow (1952)................................................. 20

2.4.2.2 - Modelo de Foster e Zuber (1955) ................................................. 23

2.4.2.3 - Modelo de Mikic e Rohsenow (1969) ......................................... 25

2.4.3 - Correlações para o coeficiente de transferência de calor médio em banco

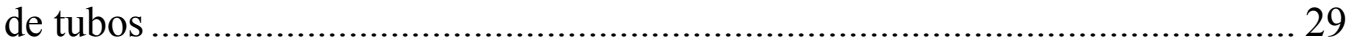

2.4.3.1 - Correlação de Wallner (1971) ………………………………....... 30

2.4.3.2 - Correlação de Rebrov et al (1989).............................................. 31

2.4.3.3 - Correlações de Hsieh et al (2003).................................................. 32

2.4.4 - Correlações para o coeficiente de transferência de calor local em banco

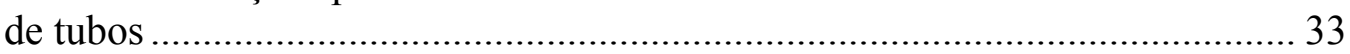

2.4.4.1 - Correlação de Wallner (1971) ………………………………...... 34

2.4.4.2 - Correlação de Hwang e Yao (1986) ............................................ 37

2.4.4.3 - Correlação de Müller (1986) .................................................... 40

2.4.4.4 - Correlação de Danilova et al (1992)............................................ 42

2.4.4.5 - Correlação de Gupta et al (1995)................................................ 44

2.4.5.7 - Correlação de Kumar et al (2002) ............................................. 46

2.4.6 - Resumo das principais correlações para ebulição em banco de tubos .. 50

2.5 - Sumário do estado da arte envolvendo ebulição em banco de tubos.............. 53

2.6 - Conclusões Gerais ..................................................................................... 55 


\section{3 - DESCRIÇÃO DO APARATO EXPERIMENTAL E PROCEDIMENTOS DE}

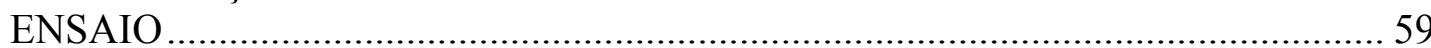

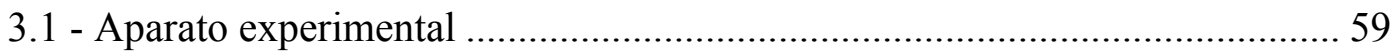

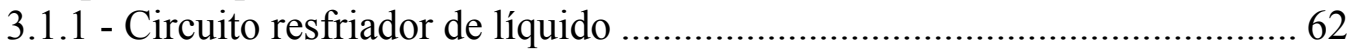

3.1.2 - Circuito de solução anticongelante (etileno-glicol e água) .....................6 62

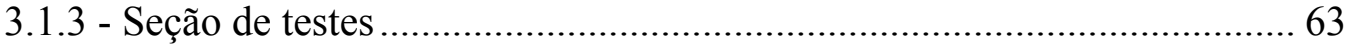

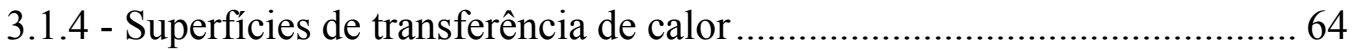

3.1.5 - Sistema de Aquecimento Elétrico....................................................... 70

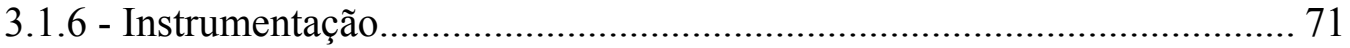

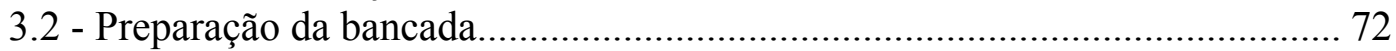

3.2.1 - Carregamento do Sistema ................................................................ 72

3.2.2 - Procedimentos de Ensaio........................................................................ 73

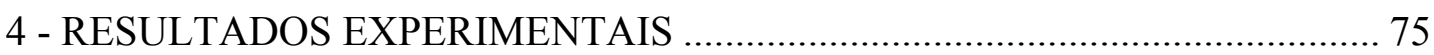

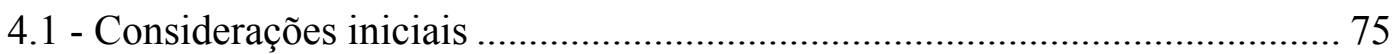

4.2 - Breve análise dos principais fatores que influenciam a ebulição em um único

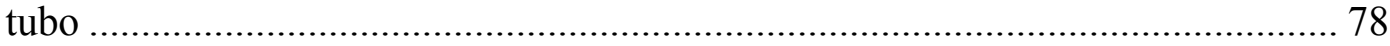

4.2.1 - Influência do acabamento superficial ................................................. 78

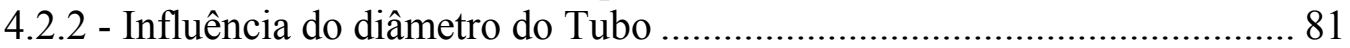

4.3 - Resultados experimentais para banco tubo.............................................. 82

4.3.1 - Comparação entre coeficientes de transferência de calor nos tubos

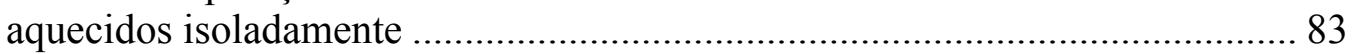

4.3.2 - Fatores que influenciam a ebulição em banco de tubos ......................... 84

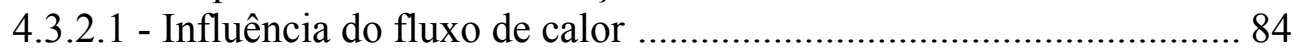

4.3.2.2 - Influência da pressão ............................................................ 87

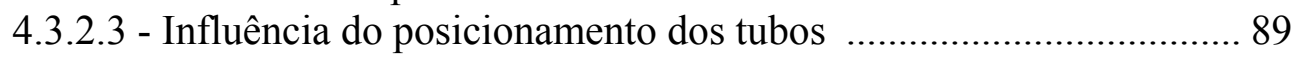

4.3.2.4 - Influência do espaçamento entre tubos ......................................... 90

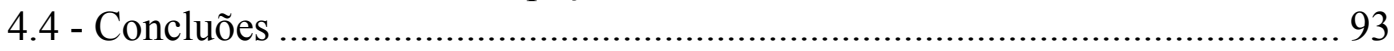

5 - DESENVOLVIMENTO DE UMA CORRELAÇÃO.................................... . 95

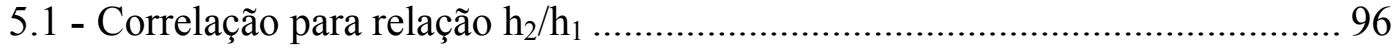

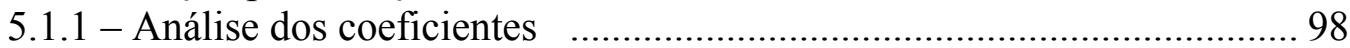

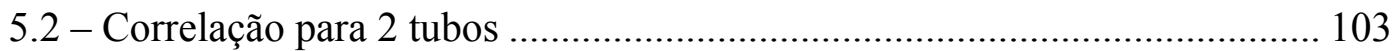

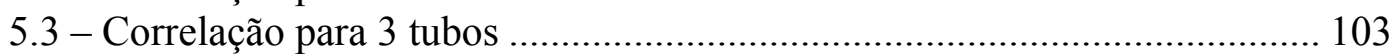

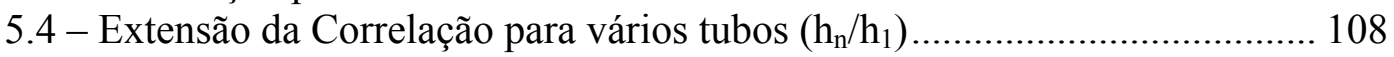

5.5 - Análise dos desvios médios e resíduos .................................................... 113

5.6 - Comparação com resultados da literatura ................................................. 116

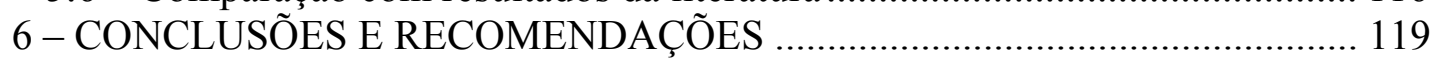

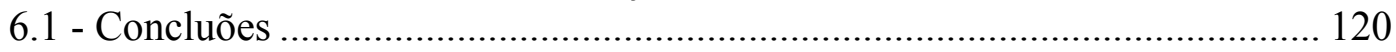

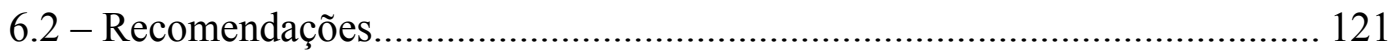

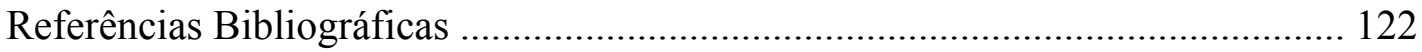

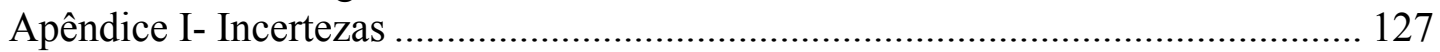

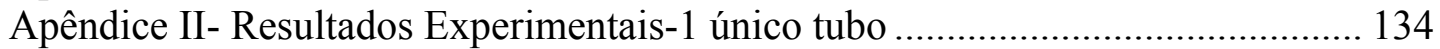




\section{Lista de Figuras}

Figura 1.1 Publicações referentes à ebulição nucleada 2

Figura 1.2 Representação esquemática de um evaporador inundado 2

Figura 2.1 Curva de ebulição, caracterizando os diferentes regimes 8

Figura 2.2 Configurações mais freqüentes de banco de tubos 9

Figura 2.3 Comparação do coeficiente de transferência de calor relativo 10 àquele de um único tubo para as configurações triangular e retangular, Hsieh (2003).

Figura 2.4 Relação entre os coeficientes de transferência de calor do tubo 11 aquecido no banco e isoladamente, Müller (1986)

Figura 2.5 a Relação entre coeficientes de transferência de calor, s/d=1,3 e 14 2,0

Figura 2.5 b Relação entre coeficientes de transferência de calor, s/d=1,6 e 14 2,0 .

Figura 2.6 Relação entre coeficientes de transferência de calor médio para 30 o banco de tubos e para um único tubo vs fluxo de calor. (R$\left.11, \mathrm{P}_{\mathrm{sat}}=100 \mathrm{kPa}\right)$

Figura 2.7 Relação entre coeficientes de transferência de calor médio para 31 o banco de tubos e para um único tubo (Rohsenow modificada) $v s$ fluxo de calor

Figura 2.8 Relação entre coeficientes de transferência de calor médio para distintas configurações e único tubo vs fluxo de calor. (R-134a, $\left.\mathrm{P}_{\mathrm{sat}}=536 \mathrm{kPa}, \mathrm{Ra}=0,06 \mu \mathrm{m}\right)$

Figura 2.9 Valor máximo para o superaquecimento da parede do tubo 37 inferior utilizando a correlação de Wallner (1971)

Figura 2.10 Influência da velocidade mássica no coeficiente de 40 transferência de calor

Figura 2.11 Influência do título local no coeficiente de transferência de 40 calor

Figura 2.12 Resultados experimentais e curvas de $\phi v s h$ obtidas através da 46 correlação de Gupta et al (1995)

$\begin{array}{lll}\text { Figura 3.1 } & \text { Aparato experimental } & 61\end{array}$

Figura 3.2 Fotografia do aparato experimental 62

Figura 3.3 Representação esquemática da seção de testes $\quad 64$

Figura 3.4 Detalhes da superfície de testes, mostrando o posicionamento 66 dos termopares 
Figura 3.5 Montagem da superfície de ensaio

Figura 3.6 Detalhe ilustrativo da tampa lateral para fixação e vedação dos tubos

Figura 3.7 Detalhe ilustrativo do suporte de latão para fixação dos tubos

Figura 3.8 Ilustração do suporte de latão e tampa lateral para fixação dos tubos

Figura 3.9 Fotografia do suporte de latão e tampa lateral para fixação dos tubos

Figura 3.10 Fotografia do banco de tubos. R-123, $\mathrm{p}_{\mathrm{r}}=0,062, \phi=25 \mathrm{~kW} / \mathrm{m}^{2}$ . (Tubo de latão, inferior aquecido)

Figura 3.11 Fotografia do banco de tubos. R-123, $\mathrm{p}_{\mathrm{r}}=0,023, \phi=10 \mathrm{~kW} / \mathrm{m}^{2}$ (Tubos de latão, inferior e intermediário aquecidos)

Figura 4.1 Curvas de ebulição para o R-134a para $\mathrm{p}_{\mathrm{r}}=0,062$, tubo de cobre, $\mathrm{D}_{\text {ext }}=19 \mathrm{~mm}$

Figura 4.2 Curvas de ebulição para o R-123 para $p_{\mathrm{r}}=0,062$, tubo de cobre, 81 $\mathrm{D}_{\text {ext }}=19 \mathrm{~mm}$

Figura 4.3 Variação do coeficiente de transferência de calor (h) com o fluxo de calor específico $(\phi)$ para diversos valores da rugosidade média aritmética $(\mathrm{Ra})$. Superfície de cobre, R-123, $\mathrm{p}_{\mathrm{r}}=0,011$

Figura 4.4 Variação do coeficiente de transferência de calor (h) com o diâmetro do tubo em reduzidos fluxos de calor $(\phi)$. Superfície de latão, R-123, $\mathrm{p}_{\mathrm{r}}=0,023$.

Figura 4.5 Coeficiente de transferência de calor médio $v s$ fluxo de calor para tubos aquecidos isoladamente. R-123, Tubos de latão, Ra $\approx 0,12 \mu \mathrm{m}$

Figura 4.6 Resultados de $\mathrm{h} v s \phi-2$ tubos, R-123, $\mathrm{p}_{\mathrm{r}}=0,023, \mathrm{~s} / \mathrm{d}=2,0$

Figura 4.7 Resultados de $\mathrm{h} v s \phi-3$ tubos, R-123, $\mathrm{p}_{\mathrm{r}}=0,023, \mathrm{~s} / \mathrm{d}=1,32 \quad 86$

Figura 4.8 Fotografias do R-123 em ebulição em tubos de latão, s/d $=87$ 1,53 .

Figura 4.9 Influência da pressão no coeficiente de transferência de calor em banco de tubos. R-123, Tubos de latão aquecidos simultaneamente com igual fluxo de calor

Figura 4.10 Relação entre coeficientes de transferência de calor do tubo superior $\left(h_{2}\right)$ e inferior $\left(h_{1}\right)$ em função da pressão reduzida $\left(\mathrm{p}_{\mathrm{r}}\right)$ e fluxo de calor $(\phi)$. R-123, Tubos de latão, $\mathrm{s} / \mathrm{d}=1,53$

Figura 4.11 Relação entre coeficientes de transferência de calor versus fluxo de calor específico

Figura 4.12 Relação entre coeficientes de transferência de calor do tubo intermediário $\left(\mathrm{h}_{2}\right)$ e inferior $\left(\mathrm{h}_{1}\right)$ versus fluxo de calor

Figura 4.13 Diferença entre a temperatura do fluido junto à superfície do tubo superior (desligado) e fluido afastado dos tubos (saturado) em função do fluxo de calor aplicado nos tubos inferior e intermediário, e relação de espaçamentos entre tubos $(\mathrm{s} / \mathrm{d})$

Figura 5.1 Relação entre coeficientes de transferência de calor do tubo 81 superior e inferior $\left(\mathrm{h}_{2} / \mathrm{h}_{1}\right)$ versus fluxo de calor específico $(\phi)$. $\mathrm{R}-123, \mathrm{p}_{\mathrm{r}}=0,023$ 
Figura 5.2 Relação entre coeficientes de transferência de calor do tubo 98 superior e inferior $\left(\mathrm{h}_{2} / \mathrm{h}_{1}\right)$ versus fluxo de calor específico $(\phi)$. $\mathrm{R}-123, \mathrm{p}_{\mathrm{r}}=0,033$

Figura 5.3 - Relação entre coeficientes de transferência de calor do tubo 98 superior e inferior $\left(\mathrm{h}_{2} / \mathrm{h}_{1}\right)$ versus fluxo de calor específico $(\phi)$. $\mathrm{R}-123, \mathrm{p}_{\mathrm{r}}=0,063$

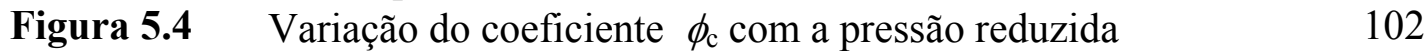

$\begin{array}{lll}\text { Figura 5.5 Variação de } A \operatorname{com} \phi & 103\end{array}$

$\begin{array}{lll}\text { Figura 5.6 Variação de } w \operatorname{com} \phi & 103\end{array}$

$\begin{array}{lll}\text { Figura 5.7 Relação entre } A \text { e } \mathrm{p}_{\mathrm{r}} & 104\end{array}$

$\begin{array}{lll}\text { Figura 5.8 Relação entre } w \text { e } \mathrm{p}_{\mathrm{r}} & 104\end{array}$

Figura 5.9 Relação entre coeficientes de transferência de calor do tubo 105 superior e inferior $\left(\mathrm{h}_{3} / \mathrm{h}_{1}\right)$ versus fluxo de calor específico $(\phi)$. $\mathrm{R}-123, \mathrm{p}_{\mathrm{r}}=0,023$

Figura 5.10 Relação entre coeficientes de transferência de calor do tubo 105 superior e inferior $\left(h_{3} / h_{1}\right)$ versus fluxo de calor específico $(\phi)$. $\mathrm{R}-123, \mathrm{p}_{\mathrm{r}}=0,033$

Figura 5.11 Relação entre coeficientes de transferência de calor do tubo 106 superior e inferior $\left(h_{3} / h_{1}\right)$ versus fluxo de calor específico $(\phi)$. $\mathrm{R}-123, \mathrm{p}_{\mathrm{r}}=0,063$

$\begin{array}{lll}\text { Figura 5.12 Variação de } A_{3} \text { com } \mathrm{p}_{\mathrm{r}} & 108\end{array}$

$\begin{array}{lll}\text { Figura 5.13 Variação de } \phi_{c 3} \text { com } p_{\mathrm{r}} & 108\end{array}$

$\begin{array}{lll}\text { Figura 5.14 Variação de } w_{3} \text { com a } \mathrm{p}_{\mathrm{r}} & 108\end{array}$

$\begin{array}{lll}\text { Figura 5.15 Curva de } h_{n} / h_{1} \text { versus } n & 111\end{array}$

$\begin{array}{lll}\text { Figura 5.16 Curva de } C_{\phi} \text { versus } n & 112\end{array}$

Figura 5.17 Relações entre coeficientes de transferência de calor do n- 113 ésimo tubo e inferior $\left(\mathrm{h}_{\mathrm{n}} / \mathrm{h}_{1}\right)$ correlacionadas versus fluxo de calor específico $(\phi)$

Figura 5.18 Resíduos para os resultados apresentados pela Eq. (5.16) em 116 relação ao banco de dados experimentais

Figura 5.19 Curva comparativa dos resultados experimentais com os 116 proporcionados pela Eq. (5.16)

Figura 5.20 Comparação da correlação de Kumar et al (1992) com a Eq. 117 (5.16); Água, $\mathrm{P}_{\mathrm{sat}}=100 \mathrm{kPa}$

Figura 5.21 Comparação de resultados experimentais obtidos por Hsieh 118 et al (2003) com a Eq. (5.16)

Figura 5.22 Comparação da correlação de Muller et al (1986) com a Eq. 119 (5.16); R11, $\mathrm{P}_{\text {sat }}=100 \mathrm{kPa}, \mathrm{s} / \mathrm{d}=1,6$ 


\section{Lista de Tabelas}

Tabela 2.1 Trabalhos envolvendo a influência do fluxo de calor na relação 15 $\mathrm{h}_{\mathrm{N}} / \mathrm{h}_{1}$

Tabela 2.2 Constante e expoentes para Eq. (2.1) (Collier e Thome (1996)) 19

Tabela 2.3 Valores de C e n para a correlação de Hsieh et al (2003) 32

Tabela 2.4 Coeficientes e expoentes para as Eqs. (2.61) e (2.62) 42

Tabela 2.5 Valores para as constantes da Eq.(2.63) 42

Tabela 2.6 Valores para as constantes da Eq. (2.64) 44

Tabela 2.7 Resumo das principais correlações para ebulição em banco de 51 Tubos

Tabela 2.8 Literatura referente à ebulição em banco de tubos 53

$\begin{array}{lll}\text { Tabela 3.1 Características das superfícies de testes } & 66\end{array}$

Tabela 4.1 Condições experimentais do banco de dados 77

Tabela 5.1 Coeficientes da Eq.5.1 em função da pressão reduzida ajustada a 100 partir dos resultados experimentais

$\begin{array}{lll}\text { Tabela 5.2 Coeficientes da Eq.5.7 em função da pressão reduzida } & 107\end{array}$

Tabela 5.3 Coeficientes da Eq.5.1 ou 5.7 em função do número de tubos 109

Tabela 5.4 Desvios médios absolutos para a relação $h_{2} / h_{1}$ com 2 tubos 115 aquecidos

Tabela 5.5 Desvios médios absolutos para a relação $h_{2} / h_{1}$ com 3 tubos 115 aquecidos.

Tabela 5.6 Desvios médios absolutos para a relação $h_{3} / h_{1}$ com 3 tubos 115 aquecidos 


\section{Lista de Símbolos}

\section{Letras Latinas}
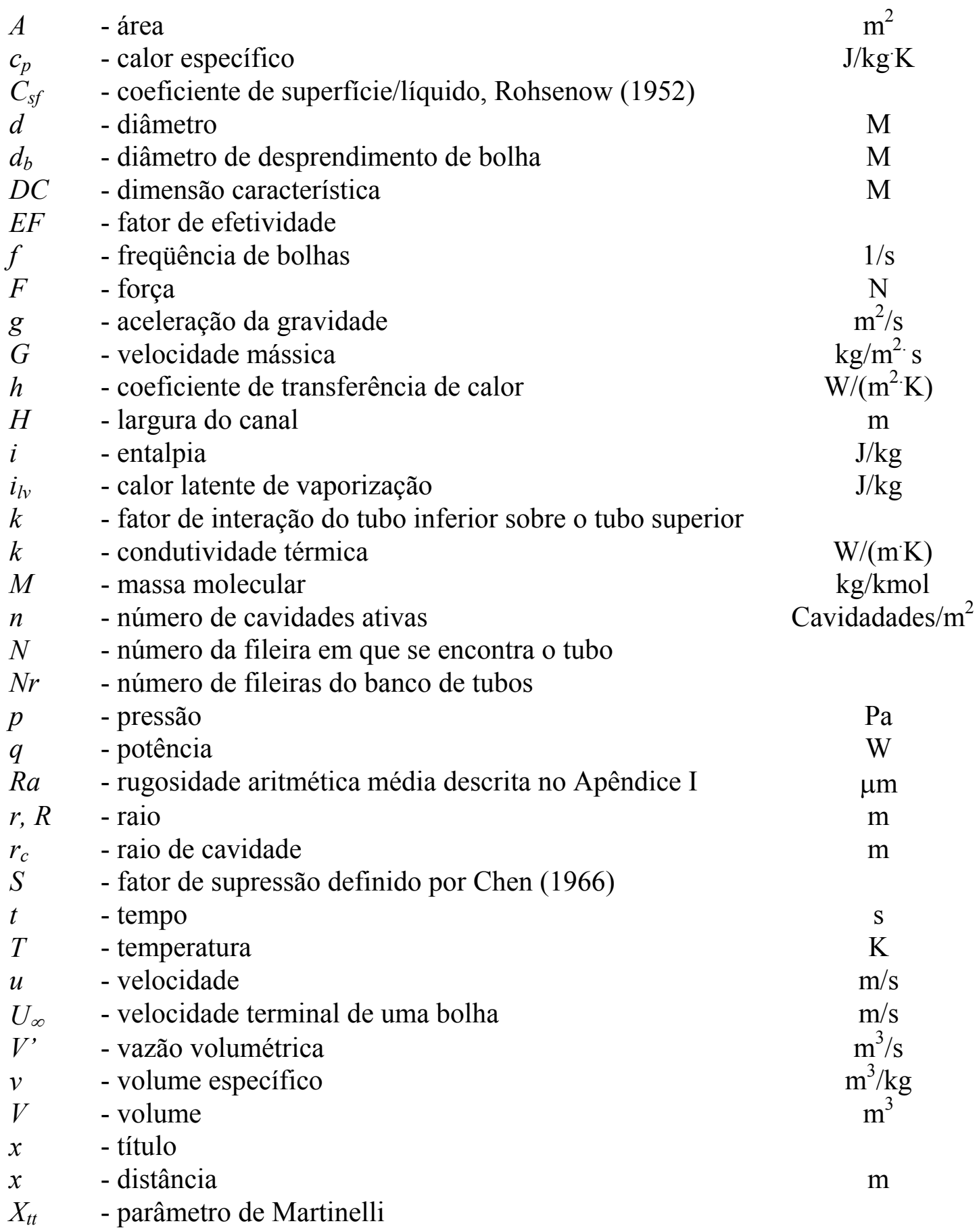


\section{Letras gregas}

$\phi \quad$ - fluxo específico de calor

$\mathrm{W} / \mathrm{m}^{2}$

- viscosidade cinemática

$\mathrm{m}^{2} / \mathrm{s}$

$\mu \quad$ - viscosidade dinâmica

$\Delta T$ - superaquecimento da superfície $\left(T_{p}-T_{\text {sat }}\right)$

$\mathrm{Kg} / \mathrm{s}^{\prime} \mathrm{m}$

$\mathrm{K}$

$\mathrm{m}^{2} / \mathrm{s}$

$\alpha \quad$ - fração de vazio

$\delta \quad$ - espessura

$\mathrm{m}$

$\sigma \quad$ - tensão superficial

$\mathrm{N} / \mathrm{m}$

$\rho \quad$ - densidade

$\mathrm{Kg} / \mathrm{m}^{3}$

$\beta \quad$ - ângulo de contato

graus

$\gamma \quad$ - coeficiente térmico de expanssão volumétrica

$1 / \mathrm{K}$

$\xi$ - relação entre região do tubo e área total

\section{Números adimensionais}

$\begin{array}{ll}\text { Bo } & \text { - número de ebulição } \\ \mathrm{Fr} & \text { - Froude } \\ \mathrm{Gr} & \text { - Grashof } \\ \mathrm{Ja} & \text { - Jakob } \\ \mathrm{Ja}{ }^{*} & \text { - Jakob modificado } \\ \mathrm{Nu} & \text { - Nusselt } \\ \mathrm{Pr} & \text { - Prandtl } \\ \mathrm{Ray} & \text { - Rayleigh } \\ \mathrm{Re} & \text { - Reynolds } \\ \mathrm{St} & \text { - Stanton }\end{array}$

$$
\begin{aligned}
& =\frac{\phi}{G \cdot i_{l v}} \\
& =\frac{G^{2}}{\rho_{l}^{2} \cdot g \cdot D C} \\
& =\frac{g \cdot \gamma \cdot\left(T_{p}-T_{\infty}\right) \cdot L^{3}}{v^{2}} \\
& =\frac{c_{l} \cdot\left(T_{p}-T_{s a t}\right)}{i_{l v}} \\
& =\frac{T_{s a t} \cdot c_{p l} \cdot \rho_{l}}{\rho_{v} \cdot i_{l v}} \\
& =\frac{h \cdot D C}{k} \\
& =\frac{c_{p} \cdot \mu}{k} \\
& =P r \cdot G r \\
& =\frac{u \cdot L}{v} \\
& =\frac{N u}{R e \cdot P r}
\end{aligned}
$$

\section{Subscritos}

$$
\begin{array}{ll}
\text { atm } & \text { - pressão atmosférica normal } \\
b & \text { - bolha } \\
B & \text { - bifásico (líquido e vapor) } \\
B & \text { - banco de tubos } \\
c & \text { - crescimento }
\end{array}
$$




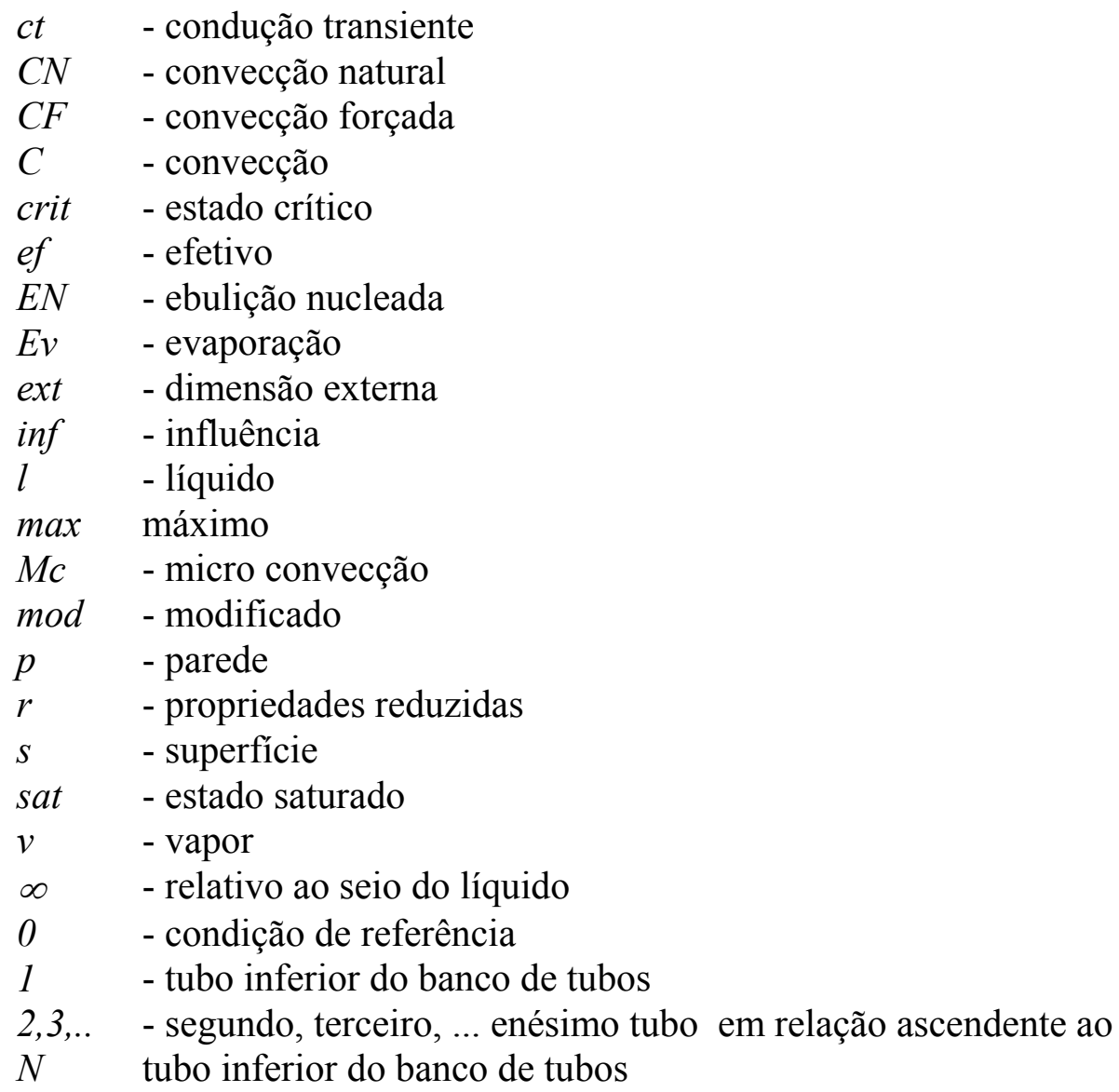




\section{RESUMO}

da Silva, E. F. (2005) Efeito da geometria na ebulição nucleada de refrigerantes halogenados em tubos horizontais. Tese (Doutorado), 143 p. Escola de Engenharia de São Carlos, Universidade de São Paulo, S.P.

O presente estudo envolve a análise teórico-experimental da transferência de calor através do mecanismo de ebulição em um único tubo e em banco com três tubos horizontais. A análise da literatura permitiu levantar os parâmetros que podem influenciar o coeficiente de transferência de calor na ebulição em banco de tubos e algumas correlações. O aparato experimental foi adaptado para realização de ensaios envolvendo refrigerantes halogenados, 3 tubos dispostos em fileiras paralelas e 3 distintos diâmetros. Nos experimentos foram utilizados os refrigerantes R-11, R-123 (baixa pressão) e R-134a (média pressão), tubos de latão aquecidos internamente com resistências elétricas, com fluxo de calor específico variando entre $1 \mathrm{e}$ $40 \mathrm{~kW} / \mathrm{m}^{2}$. Através dos resultados foram observados alguns comportamentos inéditos na influência do acabamento superficial e em banco de tubos. Com base no banco de dados levantado, foi desenvolvida uma correlação para o coeficiente de transferência de calor em ebulição em banco de tubos. Os resultados obtidos por esta correlação apresentaram reduzidos desvios em relação aos experimentais.

Palavras chaves: ebulição nucleada, banco de tubos, refrigerantes halogenados, transferência de calor. 


\begin{abstract}
da Silva, E. F. (2005) Geometry effects in nucleate boiling of halocarbon refrigerants in horizontal tubes. Tese (Doutorado), 143 p. Escola de Engenharia de São Carlos, Universidade de São Paulo, S.P.
\end{abstract}

The research reported herein is a theoretical and experimental investigation of nucleate boiling heat transfer in an isolated tube and a row of three horizontal tubes. The literature review provided enough information to raise the intervening physical parameters and several correlations. The experimental bench has been developed and adapted to perform experiments with several refrigerants, three different tube diameters, and to accommodate a row of three parallel tubes. The experiments have been carried out with refrigerants R-11, R-123 and R-134a. Heating of the brass tubes has been provided by tubular electrical heaters inserted inside the tubes. The heat flux varied from 1 to $40 \mathrm{~kW} / \mathrm{m}^{2}$. Experiments have been carried out by successively heating two and three tubes. Effects of boiling in tubes underneath (lower level) have been investigated. Finally a correlation for the heat transfer coefficient in successive tubes of a tube bank has been developed. The correlation presents good accuracy with respect to data from the present investigation.

Keywords: nucleate boiling, tube bank, halocarbon refrigerants, heat transfer 


\section{1 - INTRODUÇÃO}

A Ebulição Nucleada tem sido objeto de inúmeros trabalhos de pesquisa durante os últimos 50 anos, dentre os quais se destacaram aqueles cujo objetivo eram as aplicações nucleares. Estes dominaram a literatura durante os primeiros 30 anos de pesquisa. Apesar do claro declínio das atividades na área nuclear nos últimos 20 anos, o mecanismo da ebulição nucleada continuou a ser atraente para a comunidade científica, como o demonstra o incremento no número de artigos sobre o tema publicados em periódicos especializados, mostrado na Fig. 1.1. Tal interesse está relacionado não só às aplicações potenciais, mas ao fato de tratar-se de um mecanismo ainda por desbravar.

No caso específico das aplicações frigoríficas, a ebulição nucleada pode ser encontrada em evaporadores inundados para resfriamento de líquidos, como aquele ilustrado na Fig. 1.2, em que o refrigerante líquido permanece na carcaça na forma de um banho no interior do qual estão posicionados os tubos. O líquido que está sendo resfriado circula pelo interior dos mesmos ao passo que o refrigerante se evapora através do mecanismo de ebulição nucleada na superfície exterior dos tubos. Outra aplicação importante da ebulição nucleada em evaporadores ocorre naqueles associados aos sistemas denominados de "recirculação de líquido", onde o refrigerante líquido escoa pelo interior dos tubos de serpentinas sem se evaporar completamente, predominando o regime de ebulição nucleada, neste caso, com escoamento do líquido. 


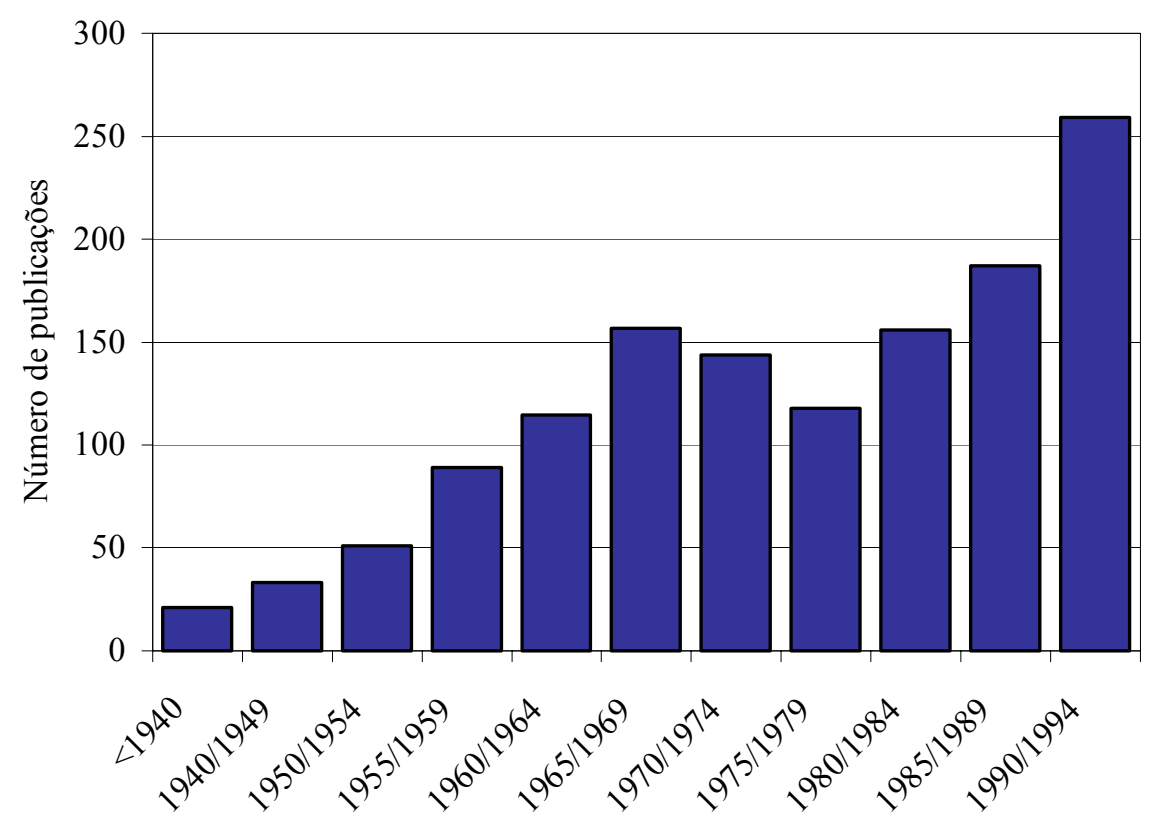

Figura 1.1 Publicações referentes à ebulição nucleada

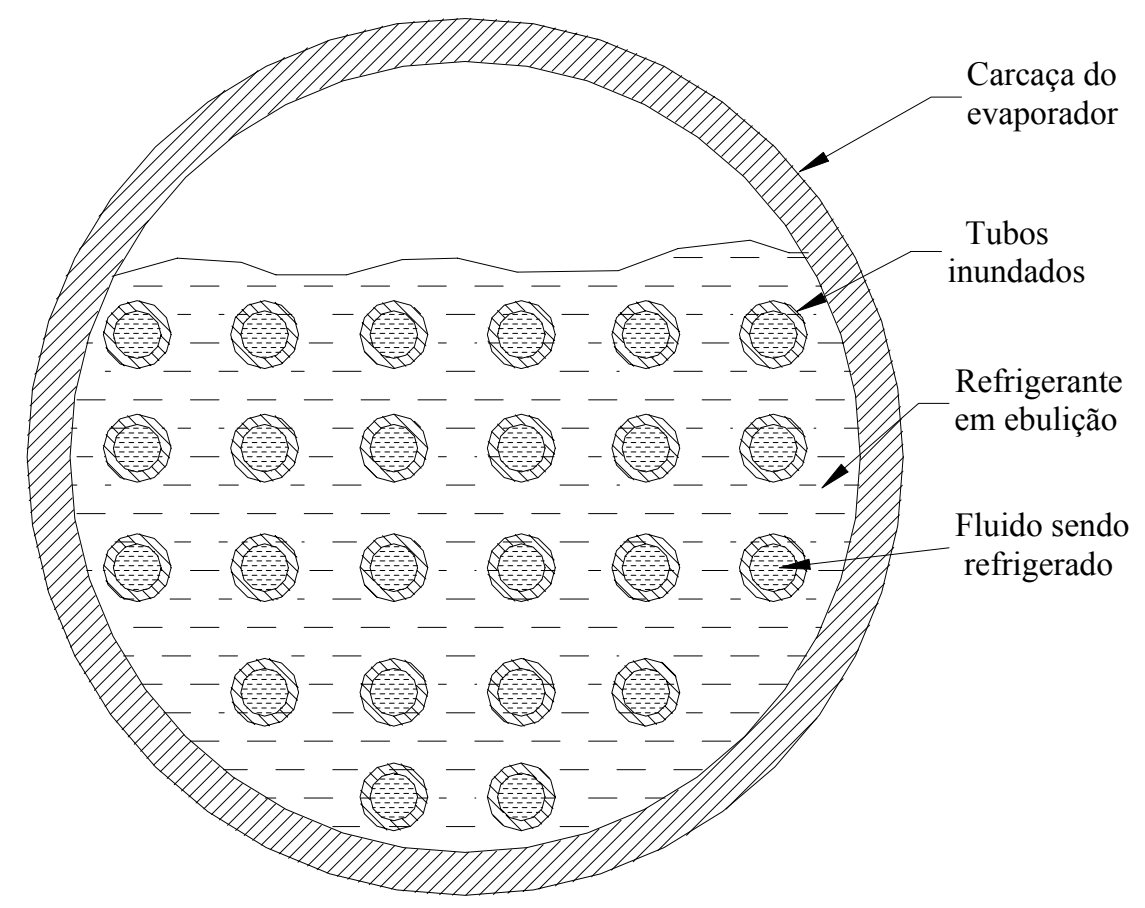

Figura 1.2 Representação esquemática de um evaporador inundado.

Além dos parâmetros que podem afetar a ebulição nucleada em um único tubo como diâmetro e disposição (horizontal ou vertical), material, espessura da superfície, acabamento superficial, ângulo de contato, contaminação, pressão, gravidade local, sub-resfriamento do líquido e gases não condensáveis; outros devem 
ser incorporados no caso de um banco de tubos tais como espaçamento e configuração dos tubos e a circulação de líquido.

\subsection{Objetivos do Trabalho}

O objetivo do presente trabalho está associado aos evaporadores inundados para resfriamento de líquidos, uma vez que aborda a ebulição em banco de tubos, tema que tem sido objeto de pesquisa no passado, visando especificamente o desenvolvimento de correlações que se ajustassem às particulares condições operacionais impostas. Como regra geral, não tem havido um esforço consistente e combinado que inclua a investigação do fenômeno e dos efeitos dos distintos parâmetros físicos/geométricos. Assim, são raros os trabalhos dedicados à investigação, em ebulição nucleada, de efeitos de parâmetros como: diâmetro dos tubos, distância e posicionamento relativo entre tubos e número de fileiras de tubos. Tais parâmetros, relacionados à geometria do banco, podem afetar drasticamente o mecanismo de ebulição nucleada, alterando, em conseqüência, o desempenho do evaporador inundado, por exemplo. Com isso, foram inicialmente levantados resultados da literatura envolvendo a ebulição em banco de tubos. Posteriormente foram levantados resultados experimentais através de duas etapas distintas. A primeira envolvendo um único tubo, analisando brevemente a influência do diâmetro do tubo na ebulição nucleada. A segunda etapa consistiu na análise da ebulição em dois e três tubos dispostos verticalmente em linha (configuração ilustrada na Fig.2.2), envolvendo parâmetros de pressão, diferentes espaçamentos entre tubos, o refrigerante R-123 e ampla faixa de fluxos de calor. Estes resultados experimentais foram inicialmente utilizados na análise dos parâmetros que podem afetar a ebulição em banco de tubos. Posteriormente os resultados experimentais foram utilizados no desenvolvimento de uma correlação semi-empírica para determinação do coeficiente de transferência de calor, que incorpore os parâmetros relevantes na ebulição em banco de tubos e que satisfaça as necessidades das aplicações frigoríficas. 


\section{2 - REVISÃO BIBLIOGRÁFICA}

\section{1 - Considerações Iniciais}

A revisão bibliográfica foi assim organizada:

- Breve análise da influência do diâmetro do tubo na transferência de calor.

- Fatores que influenciam a ebulição em banco de tubos.

- Correlações para ebulição em banco de tubos.

- Breve análise de correlações para ebulição em banco de tubos.

- Resumo dos trabalhos da literatura envolvendo a ebulição em banco de tubos a partir da década de 50 .

- Conclusões gerais.

\subsection{Breve análise da influência do diâmetro do tubo na transferência de calor}

No passado, o efeito do diâmetro do tubo na transferência de calor foi ignorado, tanto nas análises envolvendo modelagem do fenômeno quanto nas empíricas. Atualmente, com a incorporação de superfícies especiais 
(intensificadoras) nos trocadores de calor, o diâmetro do tubo torna-se relevante tanto no aspecto econômico quanto no construtivo.

Alguns trabalhos envolvendo a influência do diâmetro do tubo foram realizados para escoamentos bifásicos internos. Esses trabalhos procuraram analisar a influência do diâmetro sobre o coeficiente de transferência de calor e a perda de carga. Para o lado externo (região de ebulição em piscina) são raros os trabalhos que analisaram a influência do diâmetro do tubo.

Um dos raros trabalhos que analisaram a influência do diâmetro em ebulição em piscina (lado externo do tubo) foi o de Kudritskii e Kolomiets (1995) que investigaram a relação entre $\mathrm{o}$ diâmetro da superfície e $\mathrm{o}$ diâmetro de desprendimento de bolhas, para a água com pressões de saturação entre 20 e 100 $\mathrm{kPa}$. Investigaram superfícies cilíndricas com diâmetros entre 0,5 e 1,5mm, verificando que o tamanho da superfície exerce influência no superaquecimento necessário para o início da ebulição apenas na seguinte condição: $0,1<\frac{d_{s}}{d_{b}}<2,5$

Utilizando correlações para o diâmetro de desprendimento da bolha $\left(d_{b}\right)$ (Fritz (1935), Zuber (1959) Gogorin et al (1978) e Borishansky (1963)), apud Ribatski (2002) observa-se que $d_{b}$ varia entre 0,1 a $2 \mathrm{~mm}$ com a pressão reduzida para o R11. Portanto, a partir da relação anterior, mostra-se que a influência do diâmetro do tubo na ebulição nucleada do R-11 estaria numa faixa de aproximadamente 0,01 a 5 $\mathrm{mm}$.

Kudritskii e Kolomiets (1995) verificaram, também, que, quando a razão entre a área de influência da bolha ${ }^{*}$ e da superfície é superior a 0,5 , a área de influência da bolha aproxima-se da área projetada por esta no seu desprendimento. Deste modo, a região da superfície onde não ocorrem efeitos de ebulição nucleada tem sua área reduzida, resultando no incremento da taxa de transferência de calor.

\footnotetext{
* Han e Griffith (1965b) especificaram a região de influência das bolhas como uma área circular, com centro na cavidade ativa, cujo diâmetro é $2 . d_{b}$. Este procedimento foi justificado através de um experimento, no qual, uma bola de raio $R$ é colocada na região inferior de um tanque cheio de água com o fundo recoberto de giz. Esta bola ao emergir causa distúrbios na camada de pó de giz apenas em uma região circular de diâmetro igual à $4 R$.
} 
A partir da condição em que a área de influência da bolha é igual à da superfície, isto é $d_{b}=d_{S}$, diâmetro da superfície inferiores degradam o coeficiente de transferência de calor, devido ao incremento no tempo de crescimento da bolha, como resultado de efeitos convectivos. A partir destes resultados, qualitativamente, conclui-se que com a diminuição do diâmetro da superfície, o coeficiente de transferência de calor aumenta até um máximo, a partir do qual se reduz.

A partir da breve análise da influência do diâmetro do tubo na transferência de calor, que envolveu apenas superfícies com diâmetros relativamente reduzidos (entre 0,5 e 1,5 mm), mostra-se à necessidade de uma análise mais aprofundada desta influência com a finalidade de se projetarem trocadores de calor mais compactos e eficientes.

\section{3 - Fatores que influenciam a ebulição nucleada em banco de tubos}

Além dos fatores que podem influenciar o mecanismo de transferência de calor em ebulição nucleada em um único tubo como pressão, contaminação do fluido e superfície, acabamento superficial, material, espessura e geometria da superfície aquecida, conforme discutido por Silva (2002), por exemplo, em banco de tubos, outros efeitos podem afetar o mecanismo de transferência de calor. Entre estes, destacam-se: a posição relativa do tubo, o espaçamento entre tubos, a configuração do banco de tubos, o fluxo de calor e a velocidade de circulação do fluido. Os fatores que afetam a ebulição em banco de tubos, ao contrário da ebulição em um único tubo, são dominantes em determinado regime de ebulição, sendo desprezíveis em outros. Estes regimes podem ser identificados na curva de ebulição, que se caracteriza por relacionar o fluxo de calor $(\phi)$ com o superaquecimento da parede $(\Delta \mathrm{T})$. A Figura 2.1 apresenta um exemplo da mesma. Apesar dos limites entre os distintos regimes apresentarem um caráter subjetivo, ou seja, ainda não existe um critério claro e universalmente aceito para a transição entre um regime e outro, é possível classificá-los, segundo Collier e Thome (1996), da seguinte maneira:

AB - Convecção Natural. Caracteriza-se pela remoção do calor da superfície por movimento do líquido promovido por efeitos de empuxo. 
BC - Ebulição Nucleada Parcial. O mecanismo de transferência de calor por convecção natural ainda é o maior responsável pela remoção de calor da superfície, embora já ocorra a formação de bolhas dispersas.

CD - Ebulição Nucleada Plenamente Desenvolvida. Apresenta elevadas variações no fluxo de calor para pequenas variações do superaquecimento, conseqüentemente, a taxa de transferência de calor é alta em comparação com os outros regimes. Nesta região ocorre uma intensa formação de bolhas e, conseqüentemente, a movimentação do líquido frio para junto a parede aquecida.

E - Fluxo Crítico de Calor. A característica física desta condição é a dificuldade de suprimento de líquido à superfície aquecida, resultando um significativo aumento da temperatura da superfície, correspondendo ao limite superior da ebulição nucleada.

\section{EF - Regime de Transição entre Ebulição Nucleada e Ebulição em Película.} Caracteriza-se pela existência de colunas instáveis de vapor sobre a superfície de aquecimento que proporcionam o desprendimento de grandes bolsões de vapor.

FG - Ebulição em Película instável. Esta região é caracterizada por um filme de vapor em torno da superfície. A transferência de calor entre a superfície e o líquido se dá por condução e convecção através do filme de vapor. Esta região existe somente para o caso em que a temperatura é aumentada progressivamente, para o caso do incremento no fluxo de calor a curva de ebulição passa diretamente da região de fluxo crítico para região de película estável.

GH - Ebulição em Película e em Película Estável. Esta região, semelhante a região de película instável, caracteriza-se por um filme de vapor em torno da superfície aquecida. O vapor é removido do filme através de bolhas que se destacam em intervalos regulares. A radiação constitui-se no mecanismo principal de transferência de calor.

A seguir será apresentada uma sumária discussão dos fatores que influenciam a ebulição em banco de tubos. 


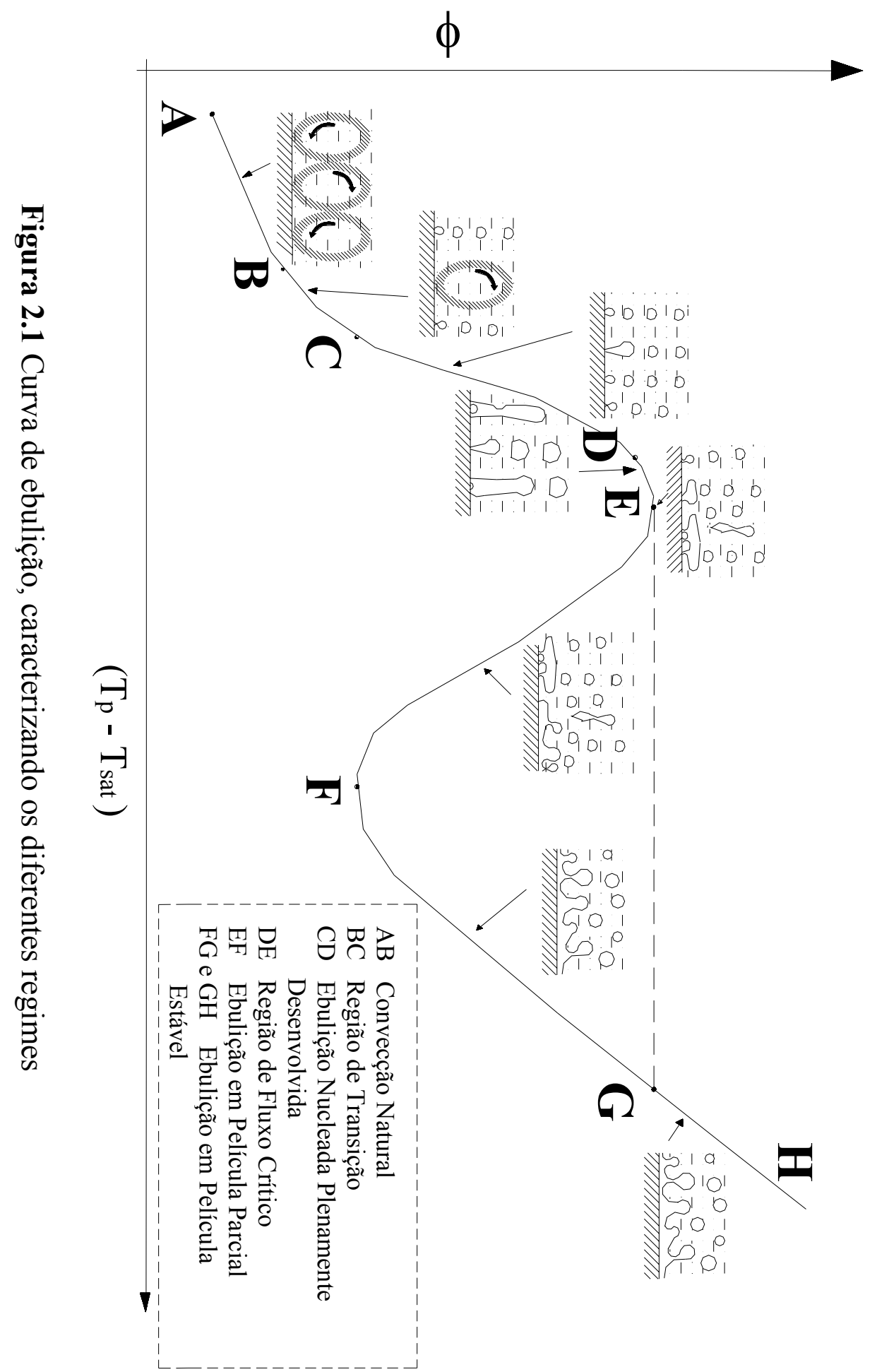




\subsection{1 - Configuração do Banco de tubos}

A configuração do banco de tubos parece influenciar menos o coeficiente de transferência de calor que o espaçamento ente tubos. As configurações mais freqüentes são a horizontal em linha, vertical em linha (não aplicáveis em projetos, mas que proporcionam interpretações físicas), retangular ou quadrangular e triangular (aplicadas em projetos de evaporadores). A Figura 2.2 ilustra estas configurações.

\begin{tabular}{|l|l|l|l|}
\hline Vertical & Horizontal & Retangular & Triangular \\
\hline 0 & & 0 & 0
\end{tabular}

Figura 2.2 Configurações mais freqüentes de banco de tubos

Wallner (1971) investigou a ebulição do R-11 em banco de tubos com configurações triangular e retangular. Mostrou que a configuração triangular apresenta uma melhora na transferência de calor em relação à quadrangular, sendo o coeficiente de transferência de calor médio do banco de tubos triangular aproximadamente $25 \%$ maior que o quadrangular no regime de transição de convecção natural para ebulição nucleada, caracterizado pela formação de algumas bolhas esparsas, conforme definido por Collier e Thome (1996). Para a região de ebulição nucleada plenamente desenvolvida $\left(\phi>10 \mathrm{~kW} / \mathrm{m}^{2}\right.$, para o R-11) esta diferença é desprezível.

Hsieh et al (2003) analisaram a ebulição nucleada do R-134a em banco de tubos constituídos de 15 tubos de cobre lisos e porosos, com diferentes configurações (triangular, retangular, horizontal em linha e vertical em linha) e relação entre distância entre centros (s) e diâmetro do tubo (d), (s/d) =1,5. Os autores mostraram que a diferença entre os coeficientes de transferência de calor médios para os bancos de tubos retangular e triangular é relativamente pequena (máximo de $12 \%$ para $\phi=$ 
$0,5 \mathrm{~kW} / \mathrm{m}^{2}$ ), conforme mostrado na Fig. 2.3, envolvendo a relação entre os coeficientes de transferência de calor médio para o banco de tubos e aquele para um único tubo.

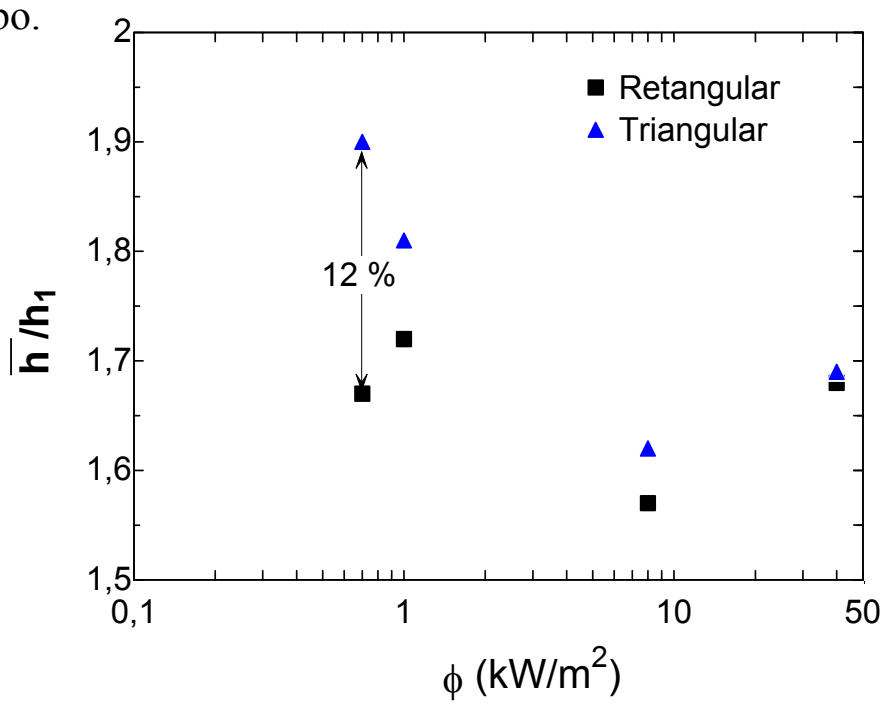

Figura 2.3 Comparação do coeficiente de transferência de calor relativo àquele de um único tubo para as configurações triangular e retangular, Hsieh (2003).

\subsubsection{Posição relativa}

Os coeficientes de transferência de calor para tubos localizados em fileiras superiores são maiores que aqueles para os tubos da fileira inferior do banco de tubos ou a um único tubo sob condições semelhantes, conforme mostrado por Katz (1955), Wallner (1971), Muller (1986), Fujita et al (1987a), Gupta et al (1995), Kumar et al (2002) e Hsieh (2003). Este comportamento é mais pronunciado para região de transição de convecção natural para ebulição nucleada e pode ser considerado desprezível para a região de ebulição nucleada plenamente desenvolvida, conforme mostrado nas Figs 2.4 (a,b e c), e parece estar relacionado aos seguintes fatores:

- As bolhas formadas nos tubos inferiores movimentam-se em sentido ascendente, promovendo a recirculação e agitação do líquido (efeitos convectivos), favorecendo a transferência de calor.

- $\mathrm{O}$ escorregamento das bolhas formadas nos tubos inferiores junto à parede dos tubos superiores facilita novas nucleações e intensifica a transferência de calor.

- Para a região de ebulição nucleada plenamente desenvolvida, os efeitos convectivos são desprezíveis em relação aos efeitos de ebulição nucleada, 
com isso o coeficiente de transferência de calor para elevados fluxos de calor é aproximadamente igual ao dos tubos inferiores ou isolado.
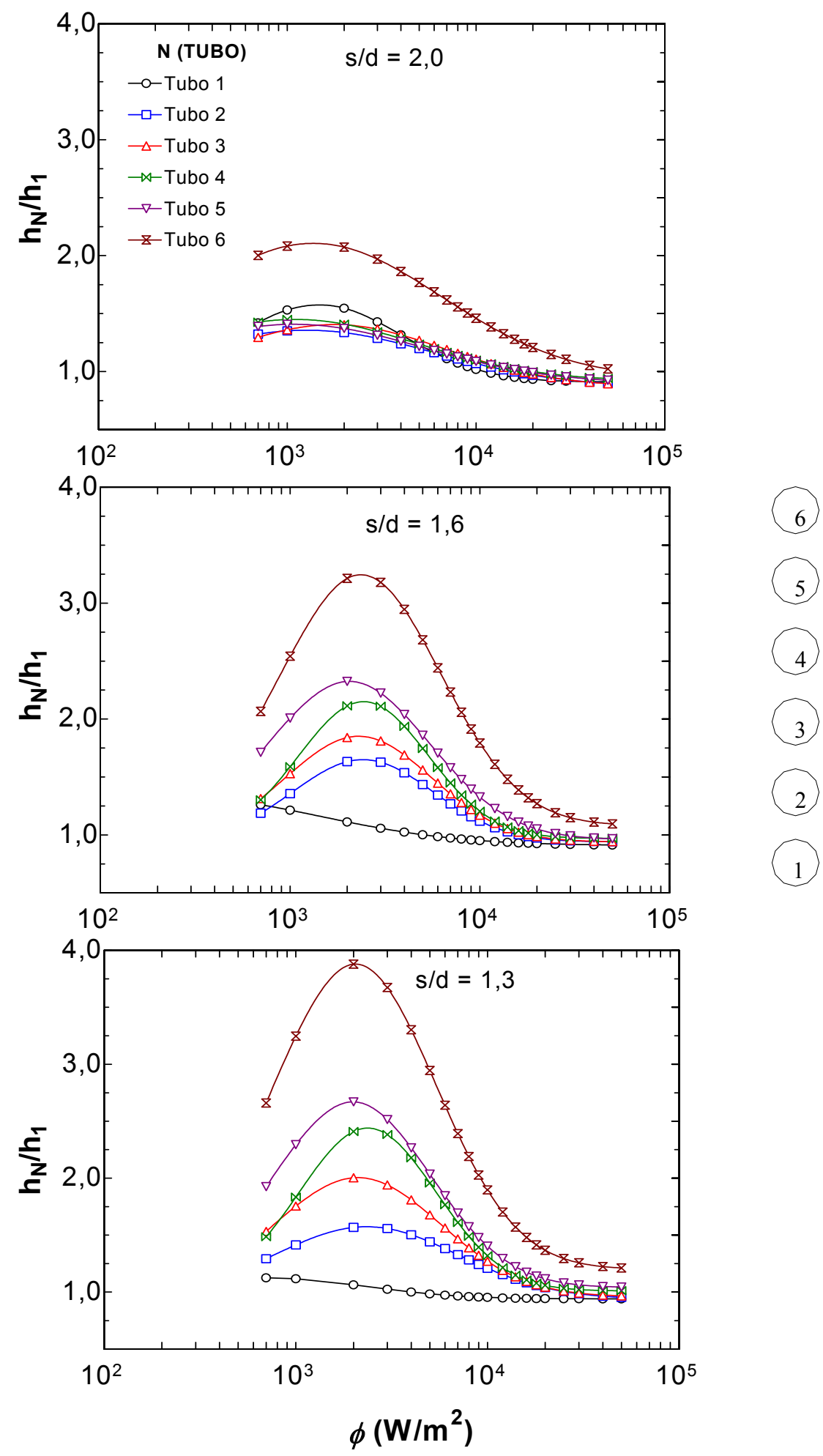

Figuras 2.4 (a), (b) e (c). Relação entre os coeficientes de transferência de calor do tubo aquecido no banco e isoladamente, Müller (1986) 


\subsection{3 - Espaçamento entre tubos}

Apesar de diversos autores terem investigado a influência do espaçamento entre tubos no coeficiente de transferência de calor, ainda existem contradições e lacunas a serem pesquisadas e melhor entendidas, como, por exemplo, o espaçamento ideal para se atingir o valor máximo do coeficiente médio de transferência de calor em banco de tubos. Outra importante influência do espaçamento entre tubos estaria relacionada ao fluxo crítico de calor em ebulição. Diversos autores mostraram que o coeficiente de transferência de calor aumenta com a diminuição do espaçamento entre tubos para regimes de transição (convecção natural para ebulição nucleada), no entanto diminui rapidamente com a elevação do fluxo de calor em regimes de ebulição nucleada plenamente desenvolvida.

Wallner (1971) investigou a influência do espaçamento $(\mathrm{s} / \mathrm{d}=1,33$ e 1,5$) \mathrm{em}$ um banco tubos triangular. Mostrou que a diferença entre os coeficientes de transferência de calor médios no banco para os espaçamentos de 1,33 e 1,5 era muito pequena $(10 \%$ superior para $\mathrm{s} / \mathrm{d}=1,5)$.

Müller (1986) mostrou que a relação entre os coeficientes de transferência de calor dos tubos superiores aquecidos no banco de tubos e do tubo aquecido isoladamente aumenta significativamente com a diminuição do espaçamento entre tubos, conforme mostrado nas Figs. 2.5 (a) e (b). Estas figuras mostram a relação entre os coeficientes de transferência de calor, respectivamente, para s/d =1,3 e 1,6 em relação àquele de 2,0. De acordo com as figuras, para valores de fluxos de calor reduzidos $\left(0,5<\phi<5 \mathrm{~kW} / \mathrm{m}^{2}\right)$, o efeito do espaçamento entre tubos é mais significativo. Para maiores espaçamentos $(\mathrm{s} / \mathrm{d}=2,0)$, o tubo da fileira inferior apresenta coeficiente de transferência de calor superior para os espaçamentos menores $(\mathrm{s} / \mathrm{d}=1,3 \mathrm{e} 1,6)$. Este efeito poderia estar relacionado à maior facilidade de deslocamento das bolhas formadas nos tubos inferiores. Para os tubos das fileiras superiores, no entanto, com o aumento do espaçamento entre tubos, ocorre uma redução no coeficiente de transferência de calor. Segundo o Müller (1986), o incremento no coeficiente de transferência de calor para espaçamentos reduzidos é devido a uma maior agitação do líquido, favorecendo a transferência de calor.

Hahne et al (1991) investigaram a influência do espaçamento entre dois tubos aletados de cobre, semelhantes aos analisados por Müller (1986). As relações s/d 
analisadas foram de 1,05, 1,3 e 3,0. Concluíram, diferentemente de Müller, que o coeficiente de transferência de calor aumentava com a relação de espaçamento na região de transição (convecção natural para ebulição nucleada). Esta divergência pode estar relacionada ao número de fileiras utilizado nos ensaios. O banco de tubos investigado por Müller (1986) era composto por seis fileiras de tubos, enquanto o de Hahne (1991), apenas duas.

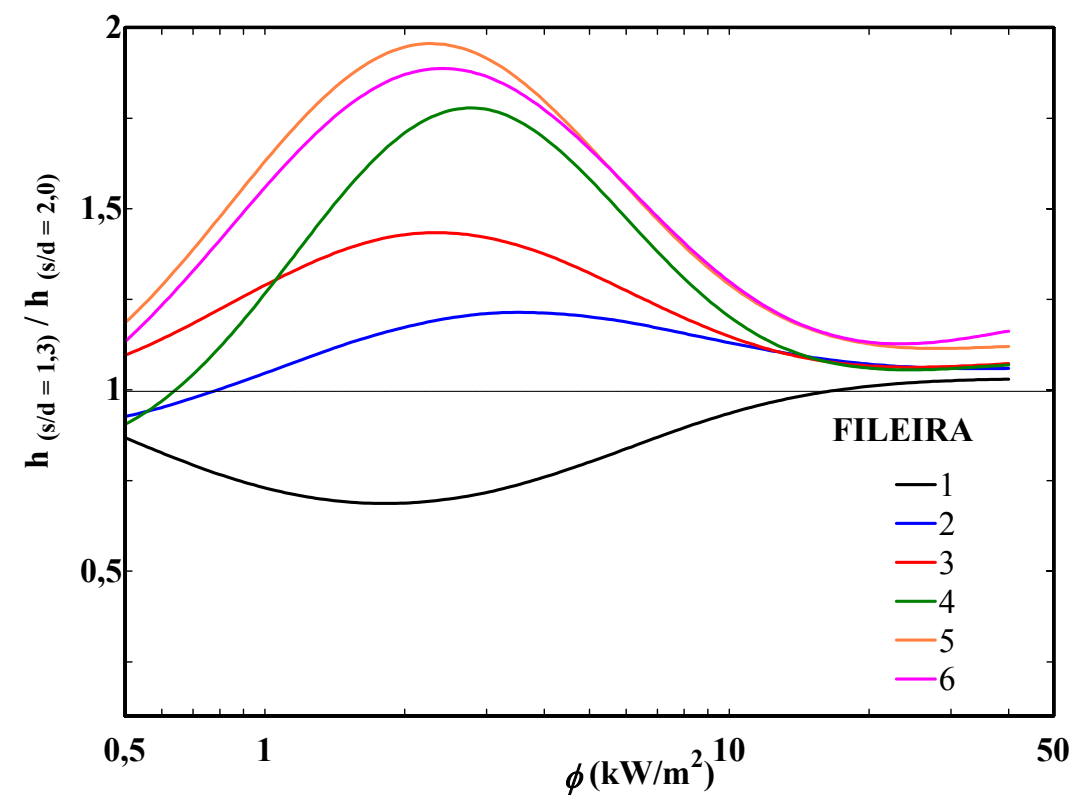

Figura 2.5(a) Relação entre coeficientes de transferência de calor, s/d=1,3 e 2,0.

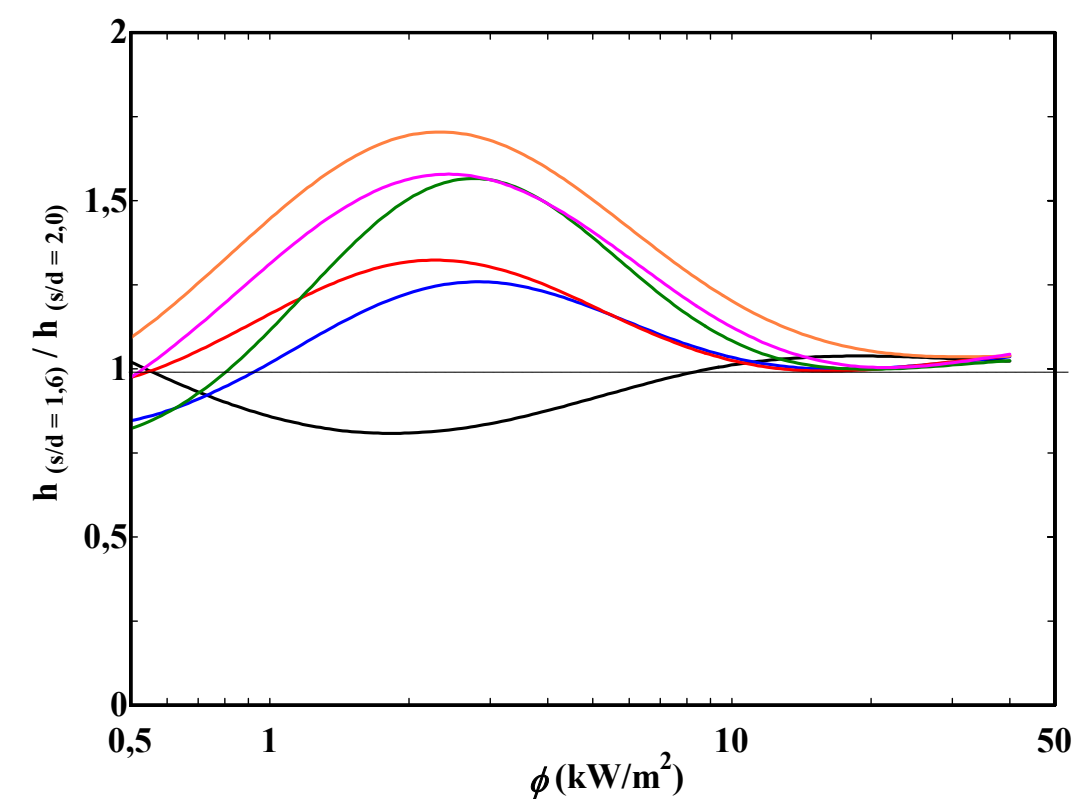

Figura 2.5(b) Relação entre coeficientes de transferência de calor, s/d=1,6 e 2,0. 
Gupta et al (1995) analisaram a influência do espaçamento entre dois tubos lisos de aço inoxidável (AISI 304). As relações s/d analisadas foram de 1,5, 3,0, 4,5 e 6,0. Esses pesquisadores mostraram que o coeficiente de transferência de calor diminui com a relação de espaçamento. Segundo os autores, isto ocorre devido ao menor número de bolhas que intercepta o tubo superior, diminuindo com isso, a transferência de calor em relação a espaçamentos menores.

Liu e Qiu (2002) investigaram a ebulição da água destilada e em uma solução salina em banco de tubos de cobre com espaçamentos relativamente reduzidos $(\mathrm{s} / \mathrm{d}=$ $1,028,1,056$ e 1,22). Os autores mostraram que o coeficiente de transferência de calor aumenta significativamente com a redução entre espaçamento de tubos, podendo, para algumas condições, apresentar um incremento de até 10 vezes no coeficiente de transferência de calor em relação àquele de um único tubo. No entanto, com a diminuição do espaçamento, o fluxo crítico de calor, também, diminui drasticamente (aproximadamente 10 vezes menor que para o tubo aquecido isoladamente). Conseqüentemente, a utilização de banco de tubos com espaçamentos reduzidos $(\mathrm{s} / \mathrm{d}<1,2)$ torna-se imprópria para operações com fluxos de calor elevados $\left(\phi>100 \mathrm{~kW} / \mathrm{m}^{2}\right.$, para a água $)$.

\subsection{4 - Fluxo de calor}

O regime de ebulição, determinado principalmente pelo fluxo de calor, é um fator de grande importância na análise da transferência de calor em banco de tubos. Os autores que investigaram a ebulição em banco de tubos mostraram que o coeficiente de transferência de calor pode ser consideravelmente maior que para um único tubo, em regime de ebulição nucleada parcial ou na transição (convecção natural para ebulição nucleada). Neste regime, as bolhas formadas e que se desprendem dos tubos inferiores influenciam a transferência de calor dos tubos superiores, conforme mencionado anteriormente (influência da posição relativa do tubo). Para a região de ebulição nucleada plenamente desenvolvida (fluxos de calor mais elevados), a maior parte das cavidades dos tubos superiores estão ativas, com isso, a transferência de calor é predominantemente devido aos efeitos de ebulição 
nucleada, portanto, as bolhas formadas nos tubos inferiores têm pouca influência sobre os tubos superiores.

A Tabela 2.1 mostra alguns trabalhos em que se determinou o máximo valor da relação entre o coeficiente de transferência de calor no tubo superior $\left(h_{N}\right)$ e do tubo inferior $\left(h_{1}\right)$ e o correspondente fluxo de calor para a condição.

Tabela 2.1 Trabalhos envolvendo a influência do fluxo de calor na relação $h_{N} / h_{1}$

\begin{tabular}{|c|c|c|c|c|}
\hline $\begin{array}{l}\text { Autor } \\
\text { (Ano) }\end{array}$ & Configuração do banco & $\begin{array}{l}\mathrm{h}_{\mathrm{N}} / \mathrm{h}_{1} \\
\text { máximo }\end{array}$ & $\begin{array}{l}\text { Fluxo de calor }(\phi), \\
k W / m^{2} \text {, para máximo } \\
\text { valor de } h_{N} / \mathbf{h} 1\end{array}$ & $\begin{array}{l}\text { Fluido/ } \\
\text { Pressão } \\
\text { (kPa) }\end{array}$ \\
\hline $\begin{array}{l}\text { Wallner } \\
(1971)\end{array}$ & $\begin{array}{l}\text { Triangular/ } 12 \text { tubos } / \mathrm{N}=4 \text { fileiras } \\
\mathrm{s} / \mathrm{d}=1,33\end{array}$ & 1,5 & 1,0 & $\mathrm{R}-11 / 100$ \\
\hline $\begin{array}{l}\text { Hahne } \quad \text { e } \\
\text { Muller } \\
(1983)\end{array}$ & $\mathrm{N}=2$ fileiras $/ 1$ coluna $/ \mathrm{s} / \mathrm{d}=2,0$ & 1,8 & 4,0 & $\mathrm{R}-11 / 100$ \\
\hline \multirow{2}{*}{$\begin{array}{l}\text { Muller } \\
\text { (1986) }\end{array}$} & $\begin{array}{l}\text { Triangular/ } 18 \text { tubos } / \mathrm{N}=6 \text { fileiras } \\
\mathrm{s} / \mathrm{d}=1,3\end{array}$ & 4,0 & \multirow{2}{*}{2,0} & \multirow{2}{*}{$\mathrm{R}-11 / 100$} \\
\hline & $\begin{array}{l}\mathrm{s} / \mathrm{d}=1,5 \\
\mathrm{~s} / \mathrm{d}=2,0\end{array}$ & $\frac{3,3}{2,2}$ & & \\
\hline $\begin{array}{l}\text { Jensen e Hsu } \\
\text { (1988) }\end{array}$ & $\begin{array}{l}\text { Retangular/ } 135 \text { tubos/ } \\
\mathrm{N}=27 \text { fileiras }\end{array}$ & 2,4 & 2,17 & $\mathrm{R} 113 / 517$ \\
\hline \multirow{2}{*}{$\begin{array}{l}\text { Hahne et al } \\
\text { (1991) }\end{array}$} & $\mathrm{N}=2$ fileiras, 1 coluna $\quad \mathrm{s} / \mathrm{d}=1,05$ & 1,6 & 7,5 & \multirow[b]{2}{*}{$\mathrm{R}-11 / 100$} \\
\hline & $\begin{array}{rr}19 \text { aletas } / \text { pol } & \mathrm{s} / \mathrm{d}=1,3 \\
\mathrm{~s} / \mathrm{d}=3,0\end{array}$ & $\begin{array}{l}1,82 \\
2,0\end{array}$ & $\begin{array}{l}4,0 \\
4,5\end{array}$ & \\
\hline $\begin{array}{l}\text { Gupta et al } \\
\text { (1995) }\end{array}$ & $\begin{array}{l}\mathrm{N}=3 \text { fileiras, } 1 \text { coluna, } \mathrm{s} / \mathrm{d}=3,0 \\
\mathrm{~N}=2 \text { fileiras } 1 \text { coluna } \mathrm{s} / \mathrm{d}=3,0\end{array}$ & $\begin{array}{l}2,2 \\
1,4\end{array}$ & $\begin{array}{l}10 \\
10\end{array}$ & Água/ 100 \\
\hline
\end{tabular}

\subsection{5 - Pressão}

Diversos autores (Cooper (1984), Gorenflo et al (1994), Leiner (1994), Ribatski (2002) e Silva (2002)) mostraram que a pressão afeta significativamente a transferência de calor. Segundo os modelos de nucleação o número de cavidades ativas e a freqüência de desprendimento das bolhas aumentam com a pressão. Conseqüentemente, o coeficiente de transferência de calor aumenta. Para a ebulição em banco de tubos, com o aumento da pressão diminui a relação entre o coeficiente 
médio de transferência de calor do banco de tubos e àquele relativo ao tubo aquecido isoladamente $\left(\bar{h} / h_{1}\right)$. Segundo Fujita et al (1987), este efeito ocorre devido à menor influência das bolhas formadas no tubo inferior que apresentam um diâmetro menor e freqüência de desprendimento maior, diminuindo, com isso, a influência sobre os tubos superiores, devido um menor deslizamento das bolhas sobre os mesmo, bem como uma menor recirculação de da mistura bifásica (líquido e vapor).

\subsection{6 - Efeitos convectivos}

O escoamento bifásico (líquido e vapor) em banco de tubos é um fenômeno muito complexo e depende de diversos fatores, podendo influenciar significativamente a transferência de calor. Chan e Shoukri (1987) investigaram a ebulição do R-113 em um banco de tubos retangular à pressão atmosférica normal $(101,325 \mathrm{kPa})$. Mostraram que ocorre intensa recirculação de líquido no sentido ascendente, sendo que a velocidade superficial do vapor (produto entre velocidade do vapor e fração de vazio) atinge o valor máximo na região superior do banco, para a configuração retangular de 3 fileiras e 3 colunas, e um pouco abaixo dessa região para a configuração de 9 fileiras e 3 colunas. Os autores mostraram que ocorrem dispersões laterais do vapor, favorecendo a circulação no sentido ascendente. Concluíram que a velocidade superficial do vapor está relacionada a dois componentes: a velocidade terminal da bolha e a recirculação do líquido. O aumento da velocidade do vapor favorece a recirculação do líquido e, conseqüentemente, a transferência de calor.

Para escoamento em banco de tubos transversal ("cross-flow"), os trabalhos da literatura mostram que o coeficiente médio de transferência de calor no banco aumenta com a velocidade mássica, G. No entanto, diminui a relação entre os coeficiente de transferência de calor do tubo superior e inferior ou em relação àquele de um único tubo $\left(\mathrm{h}_{\mathrm{N}} / \mathrm{h}_{1}\right)$. Jensen e Hsu (1988) investigaram a ebulição nucleada e convectiva do R-113 em escoamento transversal em um banco de tubos retangular com 27 fileiras e 5 colunas, com pressões variando entre 200 e $500 \mathrm{kPa}$, fluxo de calor entre 1,6 e 44,1 kW/m², velocidades mássicas entre 50 e $675 \mathrm{~kg} / \mathrm{m}^{2} . \mathrm{s}$. Verificaram que a relação entre os coeficientes de transferência de calor do tubo 
superior $\left(\mathrm{h}_{27}\right)$ e inferior $\left(\mathrm{h}_{1}\right)$ é máxima (aproximadamente 2,4) para um fluxo de calor reduzido $\left(\phi=2,17 \mathrm{~kW} / \mathrm{m}^{2}\right)$ e reduzida velocidade mássica $\left(\mathrm{G}=50 \mathrm{~kg} / \mathrm{m}^{2} . \mathrm{s}\right)$. Para elevadas velocidades mássicas esta diferença é mínima (aproximadamente 1). Gupta et al (1995) analisaram o efeito da velocidade mássica ( $G$ variando entre 0 e 10 $\left.\mathrm{kg} / \mathrm{m}^{2} . \mathrm{s}\right)$ na transferência de calor em um banco de tubos $(2 \times 1)$ e também verificaram que a relação entre os coeficientes de transferência de calor do tubo superior e inferior $\left(\mathrm{h}_{2} / \mathrm{h}_{1}\right)$ diminui com a velocidade mássica. Segundo Gupta et al (1995) esta redução ocorre devido à supressão da nucleação na superfície do tubo inferior, resultando, um menor grau de influência das bolhas no tubo superior.

\subsection{7 - Fluxo crítico de calor}

O fluxo crítico de calor se caracteriza pela dificuldade de suprimento de líquido junto à superfície aquecida, resultando em um significativo aumento da temperatura da parede, correspondendo ao limite superior da ebulição nucleada. Em aplicações é inadequado operar sob condições de fluxo crítico de calor devido ao perigo de fusão da superfície sólida.

Para ebulição em banco de tubos, Liu e Qiu (2002) mostraram que o fluxo crítico de calor aumenta com o espaçamento entre tubos, favorecendo, com isso, uma faixa mais ampla de operação do sistema. No entanto, o tamanho do trocador do calor aumenta.

Chan e Shoukri (1987) mostraram que fluxo crítico de calor em um banco de tubos difere do obtido para um único tubo. Para o R-113 em um banco de tubos de configuração retangular $(3 \times 3)$ e s/d $=1,8$, mostraram que o fluxo crítico de calor era aproximadamente $10 \%$ menor no tubo inferior e $15 \%$ maior no tubo superior, quando comparados com um único tubo. A diminuição do fluxo crítico de calor no tubo inferior está relacionada à dificuldade de movimento das bolhas devido a barreira constituída pelo tubo superior. Com isso, segundo os autores, uma alternativa para sistemas que operam em condições próximas ao fluxo crítico de calor seria aumentar o espaçamento entre tubos inferiores em relação ao espaçamento dos tubos superiores. 


\section{4 - Correlações para ebulição}

As correlações para banco de tubos podem ser divididas em dois grupos: aquelas para o coeficiente médio de transferência de calor para o banco de tubos e as locais, em que o coeficiente de transferência de calor é válido para cada tubo ou fileira do banco. As do primeiro grupo são estritamente empíricas, ou seja, resultam de ajustes de resultados experimentais, incorporando coeficientes e expoentes. As do segundo grupo são constituídas por correlações semi-empíricas, que utilizam um modelo físico e ajustam coeficientes e expoentes mediante resultados experimentais.

A maioria dos autores que investigaram o fenômeno da ebulição em banco de tubos mostrou que os tubos da fileira inferior apresentam o coeficiente de transferência de calor próximo ao obtido para um único tubo. No entanto, tubos de fileiras superiores apresentam um incremento no coeficiente de transferência de calor quando comparado com tubos de fileiras inferiores. Apesar do elevado número de correlações para determinação do coeficiente de transferência de calor em banco de tubos, estas são restritas à particular configuração do banco de tubos, fluido refrigerante e condições experimentais.

De forma semelhante à ebulição em escoamento bifásico (líquido e gás) interno, os modelos para ebulição em banco de tubos, geralmente, utilizam correlações monofásicas para a parcela de transferência de calor convectiva, ajustando-as por intermédio de fatores multiplicativos. Para a parcela devido à ebulição nucleada, utilizam-se correlações para um único tubo, corrigidas mediante a incorporação de fatores multiplicativos.

A seguir serão apresentados alguns modelos e correlações para escoamentos monofásicos em banco de tubos, ebulição nucleada envolvendo um único tubo e escoamentos bifásicos internos em dutos que apresentam regimes de ebulição nucleada e convectiva. Estes modelos e correlações serão utilizados mais adiante em correlações para ebulição em banco de tubos, mediante algumas modificações e a incorporação de fatores multiplicativos. 


\subsection{1 - Correlações para escoamento monofásico (líquido) em banco de tubos}

Em banco de tubos, a transferência de calor devido à convecção forçada é governada pela velocidade do escoamento, propriedades termo-físicas do fluido e geometria do banco de tubos. Segundo Collier e Thome (1996), resultados experimentais para escoamento monofásico transversal geralmente são correlacionados por expressões da forma:

$$
N u=c \cdot \operatorname{Re}_{l}^{m} \cdot \operatorname{Pr}_{l}^{n} \cdot\left(\frac{\operatorname{Pr}_{l}}{\operatorname{Pr}_{p}}\right)^{0,25}
$$

onde $c, m$ e $n$ são constante e expoentes empíricos dependentes da configuração do banco de tubos e do número de Reynolds.

Zukauskas e Ulinskas (1985) apud Collier e Thome (1996) obtiveram os valores de $c, m$ e $n$ para uma ampla faixa de Reynolds ( 2 a $2 \times 10^{6}$ ), baseado no diâmetro do tubo, para banco de tubos lisos dispostos na geometria retangular. A Tabela 2.2 mostra os resultados obtidos pelos autores.

Tabela 2.2 Constante e expoentes para Eq. (2.1) (Collier e Thome (1996))

\begin{tabular}{ccccc}
\hline \hline Geometria & Faixa de Re & $\boldsymbol{C}$ & $\boldsymbol{m}$ & $\boldsymbol{n}$ \\
\hline \hline Retangular & $2-50$ & 1,04 & 0,4 & 0,36 \\
& $50-1000$ & 0,71 & 0,5 & 0,36 \\
& $10^{3}-2 \times 10^{5}$ & $0,35\left(\mathrm{~s}_{1} / \mathrm{s}_{2}\right)^{0,2}$ & 0,6 & 0,36 \\
$\mathrm{~s}_{1} / \mathrm{s}_{2}<2$ & 0,4 & 0,6 & 0,36 \\
$\mathrm{~s}_{1} / \mathrm{s}_{2}>2$ & $10^{3}-2 \times 10^{5}$ & 0,4 & 0,8 & 0,4 \\
& $2 \times 10^{5}-2 \times 10^{6}$ & $0,031\left(\mathrm{~s}_{1} / \mathrm{s}_{2}\right)^{0,2}$ & & \\
Em linha & $2-200$ & & 0,4 & 0,36 \\
& $200-850$ & 0,52 & 0,5 & 0,36 \\
& $850-2 \times 10^{5}$ & 0,27 & 0,63 & 0,36 \\
& $2 \times 10^{5}-2 \times$ & 0,033 & 0,8 & 0,4 \\
& $10^{6}$ & & & \\
\hline
\end{tabular}

$\mathrm{s}_{1}$ é a relação entre espaçamentos dos tubos de mesma coluna e linhas adjacentes $\mathrm{s}_{2}$ é a relação entre espaçamentos dos tubos de mesma linha e colunas adjacentes 


\subsection{2 - Modelos e correlações para ebulição nucleada em um único tubo}

Os modelos para ebulição nucleada em piscina de um único tubo descrevem a física do processo parcialmente, pois a transferência de calor durante a ebulição nucleada é resultado da ação concomitante de vários mecanismos, dependendo de condições tais como o fluxo de calor, pressão, ângulo de contato entre a superfície e o líquido em ebulição, acabamento superficial, sub-resfriamento, etc. A seguir serão apresentados alguns dos modelos mais conhecidos para ebulição nucleada de um único tubo, freqüentemente incorporadas nas correlações para banco de tubos.

\subsubsection{O Modelo de Rohsenow (1952)}

Este modelo foi elaborado assumindo como mecanismo responsável pela transferência de calor à agitação do líquido promovida pelo movimento das bolhas. Deste modo, foi possível relacionar a transferência de calor no mecanismo de ebulição nucleada com aquela da convecção forçada. Assim, desde que o mecanismo dominante é o da convecção forçada, da análise dimensional, foi possível relacionar o número de Nusselt aos grupos adimensionais de Reynolds e Prandtl. Para a ebulição nucleada, o número de Reynolds foi associado ao grau de agitação do líquido proporcionado pelo desprendimento das bolhas.

Da análise dimensional, resulta:

$$
N u_{b}=f\left(\operatorname{Re}_{b}, \operatorname{Pr}_{l}\right)
$$

O número de Reynolds, referido ao diâmetro de desprendimento das bolhas, é definido como:

$$
\operatorname{Re}_{b}=\frac{G_{b} \cdot D_{b}}{\mu_{l}}
$$


onde $G_{b}$ é a velocidade mássica média do vapor deixando a superfície, expressa por:

$$
G_{b}=\rho_{v}\left(\frac{\pi \cdot D_{b}^{3}}{6}\right) \cdot f \cdot n
$$

$D_{b}$ é o diâmetro da bolha ao se desprender da superfície aquecida.

Introduzindo a correlação de Fritz (1935) apud Rohsenow (1952) para o diâmetro de desprendimento da bolha que deixa a superfície,

$$
D_{b}=C_{2} \beta \sqrt{\frac{2 \sigma}{g\left(\rho_{l}-\rho_{v}\right)}}
$$

Visto que as bolhas são formadas na superfície aquecida e se desprendem, o aumento da transferência de calor no regime de ebulição nucleada em relação àquele transferido sem mudança de fase foi atribuído à agitação do líquido resultante do movimento das bolhas.

O calor removido pelas bolhas enquanto permanecem na parede é dado por:

$$
(\phi)_{b}=G_{b} \cdot i_{l v}
$$

Rohsenow e Clark apud Saiz Jabardo (1988) provaram experimentalmente que, embora a transferência de calor latente seja muito inferior à de calor sensível, são proporcionais. Pode-se então relacionar o calor latente transferido para o crescimento da bolha com o calor total transferido da superfície aquecida para o líquido e a bolha por:

$$
(\phi)_{b}=C_{1}(\phi)
$$

Substituindo a Eq.(2.7) na Eq.(2.6), obtém-se:

$$
G_{b}=\frac{C_{1} \cdot \phi}{i_{l v}}
$$

Substituindo as Eqs.(2.5) e (2.8) na Eq. (2.3), obtém-se:

$$
\operatorname{Re}_{b}=\sqrt{2} \cdot C_{1} \cdot C_{2} \cdot \beta \cdot \frac{\phi}{\mu \cdot i_{l v}} \cdot \sqrt{\frac{. \sigma}{g\left(\rho_{l}-\rho_{v}\right)}}
$$


O número de Nusselt é definido como:

$N u_{b}=\frac{h \cdot D_{b}}{k_{l}}$

Ao contrário do número de Nusselt, o número de Stanton incorpora o superaquecimento da parede $(\Delta T)$,

$S t=\frac{N u}{\operatorname{Re} \cdot \operatorname{Pr}}$

tendo-se:

$S t=\frac{\frac{h \cdot D_{b}}{k_{l}}}{\frac{G_{b} \cdot D_{b}}{\mu_{l}} \cdot \frac{c_{p l} \cdot \mu_{l}}{k_{l}}}=\frac{h}{G_{b} \cdot c_{p l}}=\frac{\phi}{\Delta T \cdot c_{p l} \cdot G_{b}}=\frac{C_{3} \cdot i_{l v}}{c_{p l} \cdot \Delta T}$

Sendo o número de Nusselt função dos números de Reynolds e Prandtl, e o número de Stanton definido conforme (2.12), pode-se escrever o número de Stanton como função dos números de Reynolds e de Prandtl :

$S t^{-1}=C_{s f} \cdot \operatorname{Re}_{b}^{m} \cdot \operatorname{Pr}_{l}^{n}$

Substituindo as Eqs.(2.9), (2.10) e (2.12) na Eq.(2.13), obtém-se a seguinte expressão:

$\frac{c_{p_{l}} \cdot \Delta T}{i_{l v}}=C_{s f} \cdot\left(\frac{\phi}{\mu_{l} \cdot i_{l v}} \sqrt{\frac{\sigma}{g\left(\rho_{l}-\rho_{v}\right)}}\right)^{m} \cdot\left(\frac{c_{p_{l}} \cdot \mu_{l}}{k_{l}}\right)^{n}$

onde: $C_{s f}=C_{3}\left(\sqrt{2} \cdot C_{1} \cdot C_{2} \cdot \beta\right)^{m}$

O coeficiente $C_{s f}$ depende da combinação superfície/fluido, onde o ângulo de contato $\beta$ é um de seus fatores determinantes. $\mathrm{O}$ expoente $m$, em princípio, também é função da combinação superfície/líquido, incorporando características como material e acabamento superficial. O expoente $n$ é função somente do fluido. Rohsenow 
(1952) obteve os valores para a constante $C_{s f}$ e os expoentes $m$ e $n$ para a água e fluidos orgânicos (benzeno, n-pentano e etanol). Estes valores foram tabelados. Diversos autores (Vachon et al (1968), Sauer et al (1975), Kartsounes (1975), Tewari et al (1986), Liaw e Dhir (1989), Saiz Jabardo e Silva (1991), Pioro (1999)) obtiveram resultados para outros pares superfície/fluido, obtendo-se valores de $C_{s f}, m$ e $n$, tabelados e mostrados por Silva (2002).

Com o objetivo de facilitar a utilização da correlação de Rohsenow (1952) em aplicações envolvendo refrigerantes halogenados; superfícies cilíndricas de cobre, latão e aço inox, diferentes acabamentos superficiais, Silva (2002) propôs uma abordagem generalizada da correlação de Rohsenow, consistindo em utilizar iguais expoentes $m$ e $n$ para todos os pares superfícies/fluidos, incorporando os efeitos da pressão reduzida e da rugosidade média aritmética $(\mathrm{Ra})$ ao valor do coeficiente $C_{s f}$. Silva (2002) propôs para $m$ e $n$, valores respectivamente iguais a 0,28 e 1,55. Para $C_{s f}$ propôs a seguinte relação:

$$
C_{s f}=\ln (R a)^{0,0034 \cdot p_{r}-0,0018}-0,01 \cdot p_{r}+0,0065
$$

\subsubsection{Modelo de Foster e Zuber (1955)}

Foster e Zuber (1955) desenvolveram um modelo baseado na denominada “micro-convecção" como principal mecanismo responsável pela transferência de calor na superfície aquecida. Este mecanismo consiste na remoção de calor através da convecção forçada promovida pelo movimento de expansão da bolha. Em banco de tubos este fator promove o incremento da transferência de calor de tubos de fileiras superiores em relação às fileiras inferiores. O coeficiente de transferência de calor foi definido em termos dos parâmetros adimensionais típicos da convecção forçada, conforme a seguinte equação:

$$
N u=C_{1} \cdot \operatorname{Re}^{r} \cdot \operatorname{Pr}_{l}^{s}
$$


onde: $\operatorname{Re}=\frac{2 . R \cdot \frac{d(R)}{d t}}{v_{l}}$

$$
N u=\frac{h \cdot 2 R}{k_{l}}
$$

O número de Prandtl é o do líquido. Para o cálculo do número de Reynolds, Eq. (2.18a), admitiu-se como dimensão característica o diâmetro instantâneo da bolha. A velocidade característica do líquido foi determinada como função da velocidade de crescimento da bolha. Estas variáveis foram determinadas através das seguintes equações propostas pelos autores:

$$
\begin{aligned}
& d=2 R=2 \cdot J a \cdot\left(\pi \cdot \alpha_{l} \cdot t\right)^{1 / 2} \\
& \frac{d R}{d t}=J a \cdot\left(\frac{\pi \alpha_{l}}{4 t}\right)^{1 / 2}
\end{aligned}
$$

onde o número de Jakob relaciona as taxas de calor latente e sensível transferida durante a mudança de fase.

Determinou-se, assim, através das Eqs.(2.18a) e (2.19), que o número de Reynolds é independente do tempo, o mesmo não ocorrendo com o número de Nusselt. Deste modo, foi definida uma dimensão característica modificada relacionando o raio da bolha em determinado tempo com as pressões interna (vapor) e externa (líquido na vizinhança) da bolha, expressa por:

$$
2 R=R_{0} \cdot\left[\frac{\rho_{l} \cdot\left(R \cdot \frac{d(R)}{d t}\right)^{2}}{2 \cdot \sigma \cdot R_{0}}\right]^{1 / 4}
$$

$R_{0}$ é o raio da bolha obtido da equação de Laplace: 


$$
R_{0}=\frac{2 . \sigma}{p_{v}-p_{l}}
$$

Finalmente, combinando as Eqs. (2.17), (2.18), (2.19) e (2.20) obteve-se a seguinte equação:

$$
\frac{\phi}{\rho_{v} \cdot i_{l v}} \cdot\left(\frac{\pi}{\alpha_{l}}\right)^{1 / 2} \cdot\left[\frac{\rho_{l} \cdot\left(\frac{2 \cdot \sigma}{p_{v}-p_{l}}\right)^{3}}{2 \cdot \sigma}\right]^{1 / 4}=C_{1} \cdot\left[\frac{\rho_{l}}{\mu_{l}} \cdot\left(\frac{\Delta T \cdot k_{l}}{\rho_{v} \cdot i_{l v}}\right)^{2} \cdot \frac{\pi}{a_{l}}\right]^{r} \cdot\left(\frac{c_{p l} \cdot \mu_{l}}{k_{l}}\right)^{s}
$$

Os expoentes $r$ e $s$ foram determinados através da análise de regressão de um banco de dados experimentais, resultando iguais a 5/8 e 1/3, respectivamente. Para o coeficiente $C_{l}$, obteve-se o valor 0,0015 , para a água a pressões variando entre 100 e $5000 \mathrm{kPa}$.

Mediante algumas manipulações algébricas e incluindo os valores de $r$, $s$ e $C_{l}$ a Eq. (2.21) pode ser reduzida à seguinte expressão:

$$
h=0,00122 \cdot\left(\frac{k_{l}^{0,79} \cdot c_{p l}^{0,45} \cdot \rho_{l}^{0,49}}{\sigma^{0,5} \cdot \mu_{l}^{0,29} \cdot i_{l v}^{0,24} \cdot \rho_{l v}^{0,24}}\right) \cdot \Delta T_{s a t}^{0,24} \cdot \Delta p_{s a t}^{0,75}
$$

\subsubsection{Modelo de Mikic e Rohsenow (1969)}

Os autores propuseram um modelo para o mecanismo de transferência de calor em ebulição nucleada, considerando a transferência de calor na superfície aquecida como sendo resultante da superposição de efeitos relacionados à convecção natural (em que não ocorre formação de bolhas) e à ebulição nucleada propriamente dita. Segundo os autores, a transferência de calor em ebulição nucleada se dá por um mecanismo de condução transitória da superfície para a camada de líquido frio. $\mathrm{O}$ modelo admite, ainda, que não haja interação entre zonas de influência das bolhas. Apesar da possível ocorrência de outros mecanismos de transferência de calor, estes foram considerados desprezíveis. Para ebulição em banco de tubos, diversos autores 
adotam a superposição de efeitos, no entanto, além do mecanismo de convecção natural, inclui-se a convecção forçada devido ao movimento das bolhas formadas em tubos inferiores.

Na região de influência de uma bolha, a transferência de calor se dá por um mecanismo de condução transitória da superfície aquecida para a camada de líquido frio que repõe o vapor que se desprendeu com a bolha. Segundo Mikic e Rohsenow (1969) essa área é dada por:

$$
\begin{gathered}
A=\frac{\pi \cdot D_{\text {inf }}^{2}}{4}=\pi \cdot D_{b}^{2} \\
\text { onde: } \quad D_{\text {inf }}=2 \cdot D_{b}
\end{gathered}
$$

Assumindo somente a condução transitória entre a superfície aquecida e o líquido que está na área de influência, modelada como condução num sólido semiinfinito com temperatura superficial constante, a equação que rege o fenômeno assume a seguinte forma:

$\alpha \frac{\partial^{2} T}{\partial x^{2}}=\frac{\partial T}{\partial t}$

Condição inicial:

$T(x, 0)=T_{\text {sat }}$

Condição de contorno no líquido:

$T(0, t)=T_{p}$

Obtendo - se como solução:

$$
\begin{gathered}
\frac{T(x, t)-T_{s a t}}{T_{p}-T_{s a t}}=\operatorname{erf}\left(\frac{x}{2 \sqrt{\alpha \cdot t}}\right) \\
\phi=-\left.k \frac{\partial T}{\partial x}\right|_{x=0}=\frac{k \cdot \Delta T}{\sqrt{\pi \cdot \alpha \cdot t}}
\end{gathered}
$$


De acordo com o modelo, a camada de líquido superaquecida é substituída a uma freqüência $(f)$ correspondente à de formação de bolhas nas cavidades ativas. Assim, o fluxo de calor específico relativo à área de influência assumirá a seguinte expressão:

$$
(\phi)_{m e d, A_{\mathrm{inf}}}=f \cdot \int_{0}^{1 / f} \phi \cdot d t=\frac{2 \cdot k_{l} \cdot \Delta T}{\sqrt{\pi \cdot \frac{k_{l}}{\rho_{l} \cdot c_{p l}}}} \cdot \sqrt{f}
$$

O fluxo de calor transferido da superfície aquecida para o líquido deslocado é dado por:

$(\phi)_{b}=\pi \cdot D_{b}^{2} \cdot n \cdot(\phi)_{\text {med, } A_{\text {inf }}}=2 \cdot \sqrt{\pi \cdot k_{l} \cdot \rho_{l} \cdot c_{p_{l}}} \cdot \sqrt{f} \cdot D_{b}^{2} \cdot n \cdot \Delta T$

onde $n$ é o número de cavidades ativas por unidade de área da parede aquecida.

A partir da equação de Clausius-Clapeyron para gases perfeitos, tem-se:

$r \approx \frac{2 \cdot T_{s a t} \cdot \sigma}{i_{l v} \cdot \rho_{v} \cdot \Delta T}$

Brown (1967) apud Mikic e Rohsenow (1969) investigou a nucleação de bolhas em superfícies com diferentes acabamentos superficiais, constatando que o número de cavidades ativas por unidade de área é inversamente proporcional aos raios das cavidades, tendo proposto a seguinte relação:

$n=C_{1} \cdot\left(\frac{r_{s}}{r}\right)^{m}$

onde $r_{s}$ é o raio para o qual $n$ será igual a 1 por unidade de área.

Das Eqs.(2.29) e (2.17) obtém-se:

$n=C_{1} \cdot r_{s}^{m} \cdot\left(\frac{i_{l v} \cdot \rho_{v}}{2 . T_{\text {sat }} \cdot \sigma}\right)^{m} . \Delta T^{m}$

Substituindo a Eq.(2.31) em (2.28) obtém-se: 


$$
(\phi)_{b}=C_{1} \cdot \frac{r_{s}^{m}}{\sqrt{\pi} \cdot 2^{m-1}} \cdot \sqrt{\left(k_{l} \cdot \rho_{l} \cdot c_{p_{l}}\right)} \cdot\left(\frac{i_{l v} \cdot \rho_{v}}{T_{s a t} \cdot \sigma}\right)^{m} \cdot \sqrt{f} \cdot D_{b}^{2} \cdot \Delta T^{m+1}
$$

O diâmetro de desprendimento da bolha geralmente é obtido com base na correlação proposta por Fritz (1935) apud Rohsenow (1952), que envolve um balanço entre as forças de tensão superficial e as de empuxo. Outros autores utilizam-se de argumentos semelhantes, mas incluem efeitos dinâmicos e do superaquecimento da parede, ajustando a correlação a resultados experimentais. Uma destas correlações foi a proposta por Cole e Rohsenow (1968):

$D_{b}=C_{2} \cdot\left[\frac{\sigma}{g \cdot\left(\rho_{l}-\rho_{v}\right)}\right]^{0,5} \cdot\left(J a^{*}\right)^{1,25}$

onde: $\mathrm{C}_{2}=1,5.10^{-4}$ para a água e

$\mathrm{C}_{2}=4,65 \cdot 10^{-4}$ para outros líquidos

$J a^{*}$ é o número de Jakob modificado, $\frac{T_{s a t} \cdot c_{p l} \cdot \rho_{l}}{\rho_{v} \cdot i_{l v}}$

Para a determinação da freqüência de desprendimento das bolhas utilizou-se a correlação proposta por Zuber (1963):

$$
f . D_{b}=C_{3} \cdot\left[\frac{\sigma \cdot g \cdot\left(p_{l}-\rho_{v}\right)}{\rho_{l}^{2}}\right]^{0,25}
$$

Das Eqs.(2.32), (2.33) e (2.34) resulta o fluxo de calor associado à ebulição nucleada que pode, então, ser expresso em função do superaquecimento da parede e propriedades do fluido de acordo com a seguinte expressão:

$$
\begin{aligned}
& (\phi)_{b}=\frac{C_{1} \cdot C_{2}^{1,5} \cdot C_{3}^{0,5} \cdot r_{s}^{m}}{\sqrt{\pi} \cdot 2^{m-1}} \cdot\left(k_{l} \cdot \rho_{l} \cdot c_{p_{l}}\right)^{0,5} \cdot\left(\frac{i_{l v} \cdot \rho_{v}}{T_{s a t} \cdot \sigma}\right)^{m} \cdot\left(\frac{\sigma \cdot g \cdot \rho_{l v}}{\rho_{l}^{2}}\right)^{0,33} \cdot\left(\frac{\sigma}{g \cdot\left(\rho_{l v)}\right.}\right)^{0,75} \times \\
& \times \cdot\left(J a^{*}\right)^{1,875} \cdot \Delta T^{m+1}
\end{aligned}
$$


Para a região onde ocorre somente influência da convecção natural, a transferência de calor da superfície aquecida é dada por uma relação do tipo:

$N u=f(G r . \operatorname{Pr})=f($ Ray $)$

onde o número de Rayleigh é definido como:

$R a y=G r \cdot \operatorname{Pr}=\frac{g \cdot \gamma_{l} \cdot \Delta T \cdot(D C)^{3}}{v_{l} \cdot \alpha_{l}}$

Sendo a função $f$ dependente da geometria e do regime (laminar ou turbulento).

Uma correlação para o fluxo de calor na região de convecção natural é aquela proposta por Fishenden apud Mikic e Rohsenow (1969):

$(\phi)_{c n}=0,54 \cdot \rho_{l} \cdot c_{p_{l}} \cdot\left[\frac{\gamma \cdot g \cdot \Delta T^{3} \cdot \alpha^{3}}{\sqrt{A_{T}} \cdot v_{l}}\right]^{0,25}$, para regime laminar $10^{5}<\operatorname{Ray}<2 \times 10^{7}(2.38 \mathrm{a})$

$(\phi)_{c n}=0,14 \cdot \rho_{l} \cdot c_{p_{l}} \cdot\left[\frac{\gamma \cdot g \cdot \Delta T^{4} \cdot \alpha^{2}}{v_{l}}\right]^{0,33}$, para regime turbulento.

onde $A_{T}$ é a área total da superfície aquecida.

O fluxo de calor total na parede será então o correspondente à superposição dos dois efeitos, isto é:

$\phi_{T} \cdot A_{T}=\phi_{C N} \cdot A_{C N}+q_{E N}$ ou $\quad \phi_{T}=\left(\frac{A_{C N}}{A_{T}}\right) \cdot(\phi)_{C N}+\phi_{E N}$

\subsection{3 - Correlações para o coeficiente de transferência de calor médio em banco de tubos}

As correlações para o coeficiente de transferência de calor médio em banco de tubos $\left(\overline{h_{B}}\right)$ geralmente são empíricas. Apesar de simples, são restritas a uma faixa muito estreita de condições experimentais, conforme será mostrado a seguir. Para a 
determinação do coeficiente de transferência de calor médio em banco de tubos, geralmente, utiliza-se um circuito de vapor ou água quente passando internamente aos tubos e, através de um balanço de energia, determina-se o coeficiente médio de transferência de calor na região externa (ebulição).

\subsubsection{1 - Correlação de Wallner (1971)}

O autor obteve resultados experimentais para o R-11 a pressão de $100 \mathrm{kPa}$ em ebulição em um banco com 12 tubos em disposição triangular. Ajustou os resultados a uma correlação do tipo $\bar{h}_{B}=C . \phi^{n}$, onde $\bar{h}_{B}$ representa o coeficiente de transferência de calor médio extensivo ao banco de tubos, tendo obtido os seguintes valores: $C=9,5$ e $n=0,55$. Para uma breve análise da correlação empírica de Wallner, foi traçada uma curva obtida através relação entre os coeficientes de transferência de calor médio (obtidos pela correlação de Wallner (1971)) e os coeficientes de transferência de calor para um único tubo (obtidos pela correlação de Rohsenow modificada por Silva (2002)) em função do fluxo de calor, conforme mostrado na Fig. (2.6). Através da Figura (2.6) observa-se que os coeficientes de transferência de calor médio e para um único tubo se aproximam com o fluxo de calor, corroborando a análise de outros autores (Hahne e Muller (1983), Jensen e Hsu (1988), Gupta et al (1995)). Com isso, a correlação proposta por Wallner (1971) parece razoável de ser aplicada às condições semelhantes de operação.

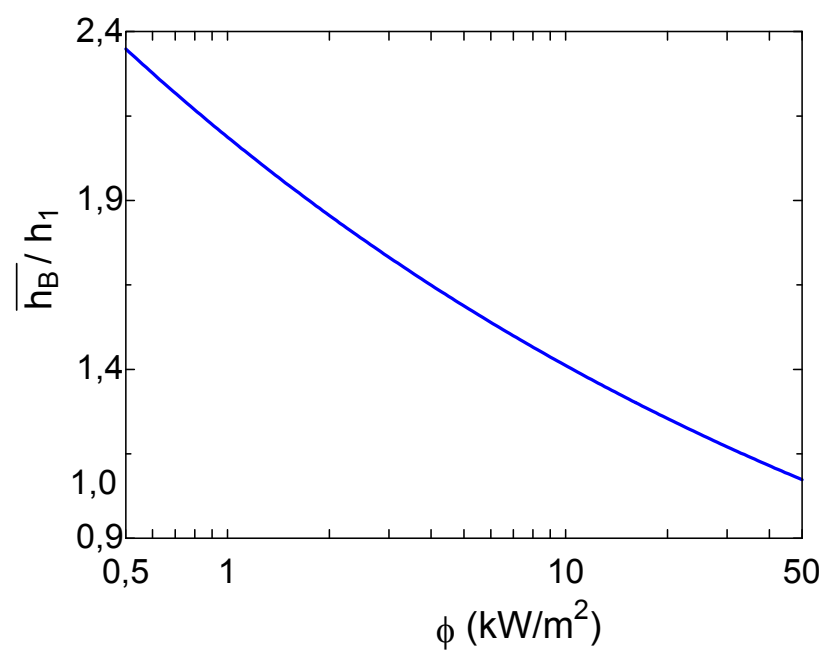

Figura 2.6 Relação entre coeficientes de transferência de calor médio para o banco de tubos e para um único tubo $v s$ fluxo de calor. $\left(\mathrm{R}-11, \mathrm{P}_{\text {sat }}=100 \mathrm{kPa}\right)$ 


\subsubsection{2 - Correlação de Rebrov et al (1989)}

Rebrov et al (1989) investigaram a ebulição do R-12 e R-22 em banco de tubos com 5, 6, 18, 30 e 50 fileiras, relação de espaçamento entre tubos (s/d) de 1,45, fluxo de calor e temperatura de saturação variando, respectivamente, entre 1 a 15 $\mathrm{kW} / \mathrm{m}^{2}$ e -30 a $10{ }^{\circ} \mathrm{C}$. Propuseram uma correlação baseada nos números adimensionais característicos da convecção forçada relacionados à ebulição nucleada, tendo obtido a seguinte expressão pelo ajuste dos resultados experimentais:

$$
\begin{aligned}
& N u=0,04 \cdot e^{0,087 \cdot N} \cdot \operatorname{Re}^{(0,7-0,0078 \cdot N)} \cdot K_{p}^{(0,6-0,0058 \cdot N)} \cdot \operatorname{Pr}_{l}^{0,4} \\
& N u_{l}=\frac{\overline{h_{B}} \cdot\left[\frac{\sigma}{g \cdot\left(\rho_{l}-\rho_{v}\right)}\right]^{0,5}}{k_{l}}, \quad \operatorname{Re}=\left[\frac{\phi \cdot\left(\frac{\sigma}{g \cdot\left(\rho_{l}-\rho_{v}\right)}\right)^{0,5}}{h_{l v} \cdot \rho_{l} \cdot v_{l}}\right], K p=\left\{\frac{P_{s a t}}{\left[\sigma \cdot g \cdot\left(\rho_{l}-\rho_{v}\right)\right]^{0,5}}\right\}
\end{aligned}
$$

onde $N$ representa o número de fileiras do banco de tubos.

Semelhante a comparação feita anteriormente utilizando as correlações de Wallner (1971) e Rohsenow modificada por Silva (2002), foram traçadas curvas das relações entre coeficientes de transferência de calor médio dos bancos de tubos $(1,6$, 30 e 50 fileiras) e um único tubo em função do fluxo de calor, conforme mostrado na Fig. (2.7).

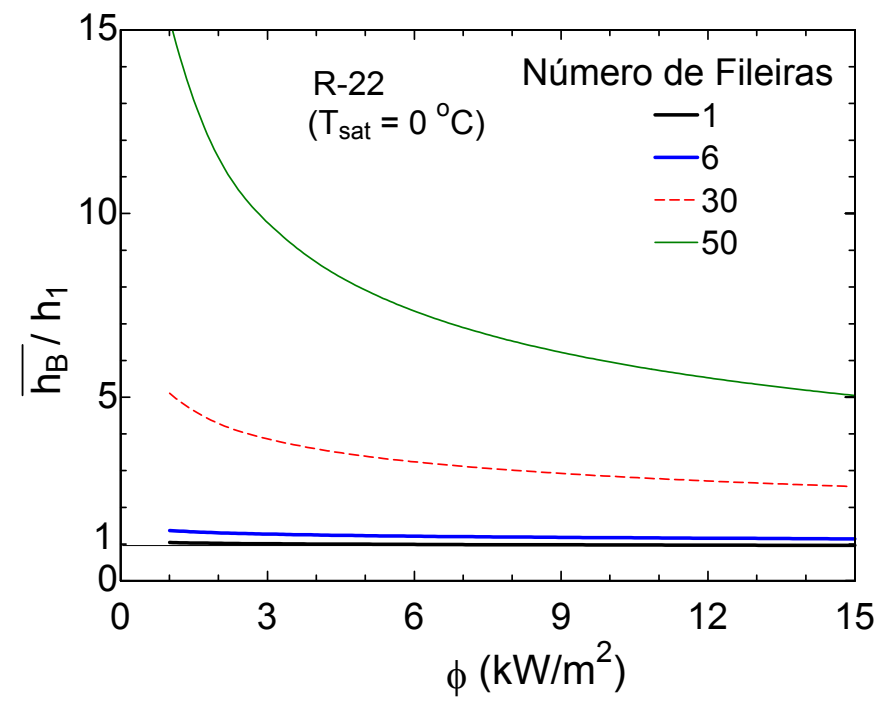

Figura 2.7 Relação entre coeficientes de transferência de calor médio para o banco de tubos e para um único tubo (Rohsenow modificada) vs fluxo de calor 
A partir da Figura 2.7 constata-se que a relação entre os coeficientes de transferência de calor médio do banco de tubos e para um único tubo aumenta com a quantidade de fileiras, e semelhante ao obtido na análise da correlação de Wallner (1971), diminui com o fluxo de calor.

\subsubsection{3 - Correlações de Hsieh et al (2003)}

Hsieh et al (2003), semelhante a Wallner (1971), expressaram os resultados experimentais em correlações empíricas da forma $\bar{h}_{B}=C . \phi^{n}$. A Tabela 2.3 relaciona os distintos valores da constante $C$ e expoente $n$ para as diferentes configurações e número de tubos.

Tabela 2.3 Valores de C e n para a correlação de Hsieh et al (2003)

\begin{tabular}{cccc}
\hline Configuração & $\begin{array}{c}\text { Número de } \\
\text { tubos }\end{array}$ & $\boldsymbol{C}$ & $\boldsymbol{n}$ \\
\hline \hline Vertical em linha & 2 & 4,27 & 0,67 \\
\cline { 2 - 4 } & 3 & 4,29 & 0,66 \\
\hline Horizontal em linha & 2 & 4,04 & 0,72 \\
\cline { 2 - 4 } & 3 & 1,93 & 0,74 \\
\hline \multirow{2}{*}{ Retangular } & 4 & 2,17 & 0,74 \\
\cline { 2 - 4 } Triangular & 6 & 2,60 & 0,71 \\
\cline { 2 - 4 } & 3 & 2,63 & 0,71 \\
\hline
\end{tabular}

A Figura 2.8 ilustra curvas traçadas a partir da relação entre os coeficientes de transferência de calor médio e um único tubo versus fluxo de calor. Observa-se que para reduzidos fluxos de calor $\left(\phi<3 \mathrm{~kW} / \mathrm{m}^{2}\right)$ o coeficiente de transferência de calor médio é superior, em todas configurações, ao de um único tubo. Observa-se ainda 
que a configuração triangular com 6 tubos apresenta desempenho superior às demais, para reduzidos fluxos de calor. Apesar destas tendências, os resultados obtidos para os coeficientes de transferência de calor estão relativamente próximos (diferença máxima de 18\%). Com isso, devido às incertezas de medidas, bem como as associadas às correlações (Hsieh et al (2003) e Rohsenow modificada por Silva (2002)), conclui-se que as configurações investigadas são próximas a um único tubo. Este comportamento parece estar relacionado à reduzida rugosidade $(\mathrm{Ra}=0,06 \mu \mathrm{m})$, que proporciona a formação poucas bolhas com diâmetro reduzido, fazendo com que a influência do tubo inferior sobre os superiores seja relativamente baixa quando comparado a tubos com rugosidade maiores ( $\mathrm{Ra}$ da ordem de $1 \mu \mathrm{m}$ ).

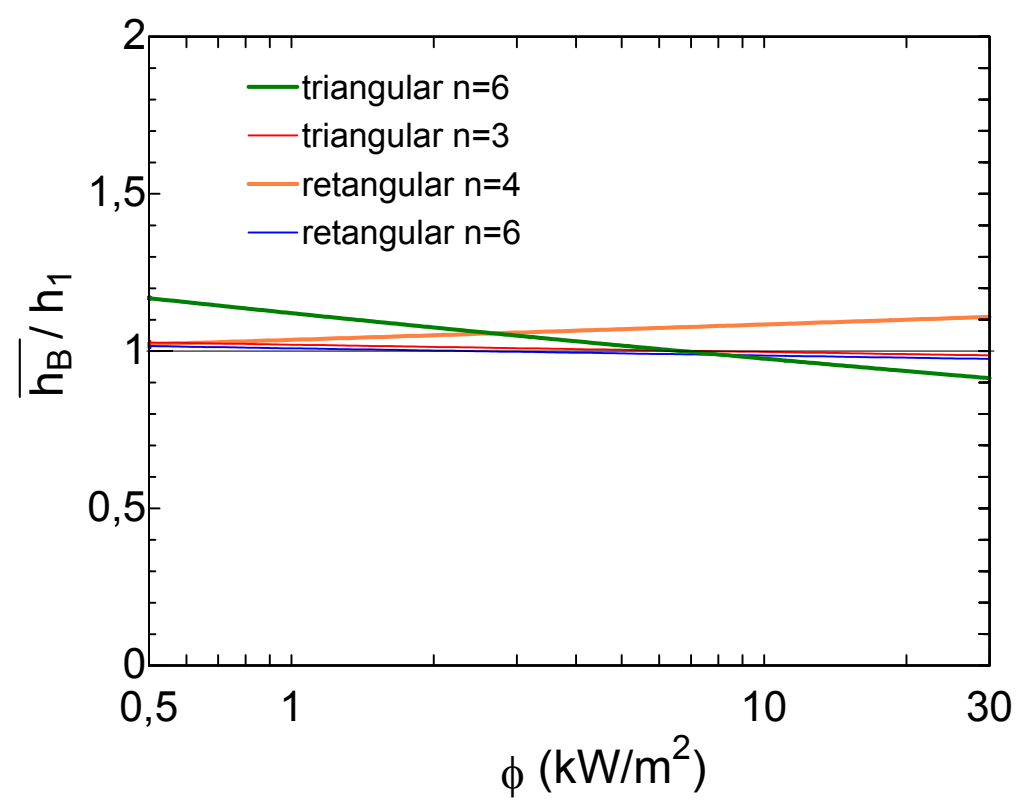

Figura 2.8 Relação entre coeficientes de transferência de calor médio para distintas configurações e único tubo $v$ s fluxo de calor. $\left(\mathrm{R}-134 \mathrm{a}, \mathrm{P}_{\mathrm{sat}}=536 \mathrm{kPa}, \mathrm{Ra}=0,06 \mu \mathrm{m}\right)$

\subsection{4 - Correlações para o coeficiente de transferência de calor local em banco de tubos}

As correlações para determinação do coeficiente de transferência de calor local, geralmente, baseiam-se nos modelos de superposição de efeitos de ebulição convectiva e nucleada, utilizando-se, como base, correlações para ebulição nucleada 
para um único tubo e para ebulição convectiva, de forma análoga à do modelo de Chen (1966) que é baseado na superposição de efeitos de ebulição nucleada e convectiva para escoamentos internos em dutos. Os resultados experimentais geralmente são obtidos por aquecimento elétrico dos tubos.

\subsubsection{1 - Correlação de Wallner (1971)}

Wallner (1971) propôs uma correlação para o coeficiente de transferência de calor do R-11 à pressão de $100 \mathrm{kPa}$ em 2 tubos, baseada no modelo de Han e Griffith (1965b), obtendo as constantes empíricas através de resultados experimentais de Güttinger apud Wallner (1971). No modelo de Han e Griffith (1965b) semelhante ao modelo de Mikic e Rohsenow (1969), conforme mostrado anteriormente, a superfície aquecida (tubo) é dividida em duas regiões: aquela influenciada pelas bolhas e pela convecção natural.

O calor total transferido pode ser expresso por:

$\phi_{T}=\phi_{C . N}+\phi_{E N}$

onde:

$\phi_{C N}=\left(1-\pi \cdot n \cdot R_{\mathrm{inf}}^{2}\right) N u_{C N} \frac{k_{l}}{d} \Delta T$

$\phi_{E N}=2 \rho_{l} c_{p l} . n . f\left[R_{\mathrm{inf}}^{2} \delta_{d}-\frac{R_{d}^{2}}{3}\left(\delta_{d}-\delta_{c}\right)\right]$

$N u_{C N}=0,48 \cdot(G r \cdot \operatorname{Pr})^{0,25}$

Para o R-11, o autor obteve, a partir de resultados experimentais, os seguintes valores para as constantes das Eqs. (2.42) e (2.43): 


$$
\begin{aligned}
& R_{d}=2,5 \times 10^{-3} \mathrm{~m} \\
& R_{\text {inf }}=2 R_{d} \\
& f=521 / \mathrm{s} \\
& \delta_{c}=4 \times 10^{-5} \mathrm{~m} \\
& \delta_{d}=6,4 \times 10^{-5} \mathrm{~m} \\
& n=20 . \Delta T^{4,3}
\end{aligned}
$$

onde $R_{d}$ é o raio da bolha no momento do desprendimento da superfície aquecida, $n$ é o número de cavidades ativas por unidade de área,

$\delta_{c}$ é a espessura da camada limite térmica ao final do período de espera (conforme mostrado por Han e Griffith (1965b),

$\delta_{d}$ é a espessura da camada limite térmica no momento do desprendimento da bolha.

A hipótese assumida por Wallner (1971) para aplicação do modelo de Han e Griffith em 2 ou mais tubos foi considerar um termo de convecção forçada $\left(\phi_{C F}\right)$ no lugar da convecção natural $\left(\phi_{C N}\right)$. A região de convecção forçada é a exposta ao escoamento bifásico originado pelas bolhas formadas no tubo inferior. Com isso, a Eq. (2.41) deve ser reescrita como:

$\phi=\phi_{C F}+\phi_{E N}$

onde:

$$
\phi_{C F}=\left(1-\pi \cdot n \cdot R_{\mathrm{inf}}^{2}\right) N u_{C F} \frac{k_{l}}{d} \Delta T
$$

O número de Nusselt é obtido através da correlação de Bitter (1972) apud Hwang e Yao (1986):

$$
N u_{C F}=0,21 \operatorname{Re}^{0,62} \operatorname{Pr}^{0,38}
$$

As propriedades físicas são referidas ao líquido, o diâmetro para cálculo do número de Reynolds foi considerado igual ao do tubo. Para obtenção do número de Reynolds e posteriormente do Nusselt $\left(N u_{C F}\right)$ é necessária a obtenção da velocidade do escoamento. Através de resultados experimentais, Wallner (1971) mostrou que a velocidade do escoamento quando um único tubo (tubo inferior, (1)) é aquecido, pode ser expressa por: 


$$
u \propto\left(\phi_{1}^{2 / 3}\right)
$$

Quando o tubo superior (2) é aquecido, o fluxo de calor da região superior aquecida contribui com o movimento (velocidade) do escoamento, podendo ser relacionado por:

$u \propto \frac{1}{3}\left(\phi_{2}^{2 / 3}\right)$

Com base nisso, a velocidade do escoamento foi obtida empiricamente através da seguinte expressão:

$u=8 \times 10^{-4}\left(\phi_{1}^{2 / 3}+\frac{1}{3} \phi_{E N 2}^{2 / 3}\right)$

Apesar de correlacionar satisfatoriamente os resultados experimentais, a correlação proposta por Wallner (1971) é limitada a uma determinada faixa de fluxo de calor $(\phi)$, devido ao termo $\left(1-\pi \cdot n \cdot R_{i}^{2}\right)$, que poderá assumir valores negativos, sendo com isso, a correlação inadequada para determinados valores do superaquecimento da parede $(\Delta \mathrm{T})$ e do fluxo de calor. Conforme proposto por Wallner (1971), o número de cavidades ativas (n) depende do superaquecimento da parede e este, por sua vez, do fluxo de calor. A partir disto, traçou-se a curva de $\left(1-\pi . n . R_{i}^{2}\right)$ vs $\Delta \mathrm{T}$, utilizando-se os valores de $n$ e $R_{i}$ sugeridos por Wallner (1971), conforme mostrado na Fig. 2.9. Conclui-se com isso que a correlação proposta por Wallner, a exemplo do modelo de Han e Griffith, é válida apenas para região de ebulição parcial, representada por reduzidos valores do superaquecimento da parede $(\Delta \mathrm{T}<4,5 \mathrm{~K})$. 


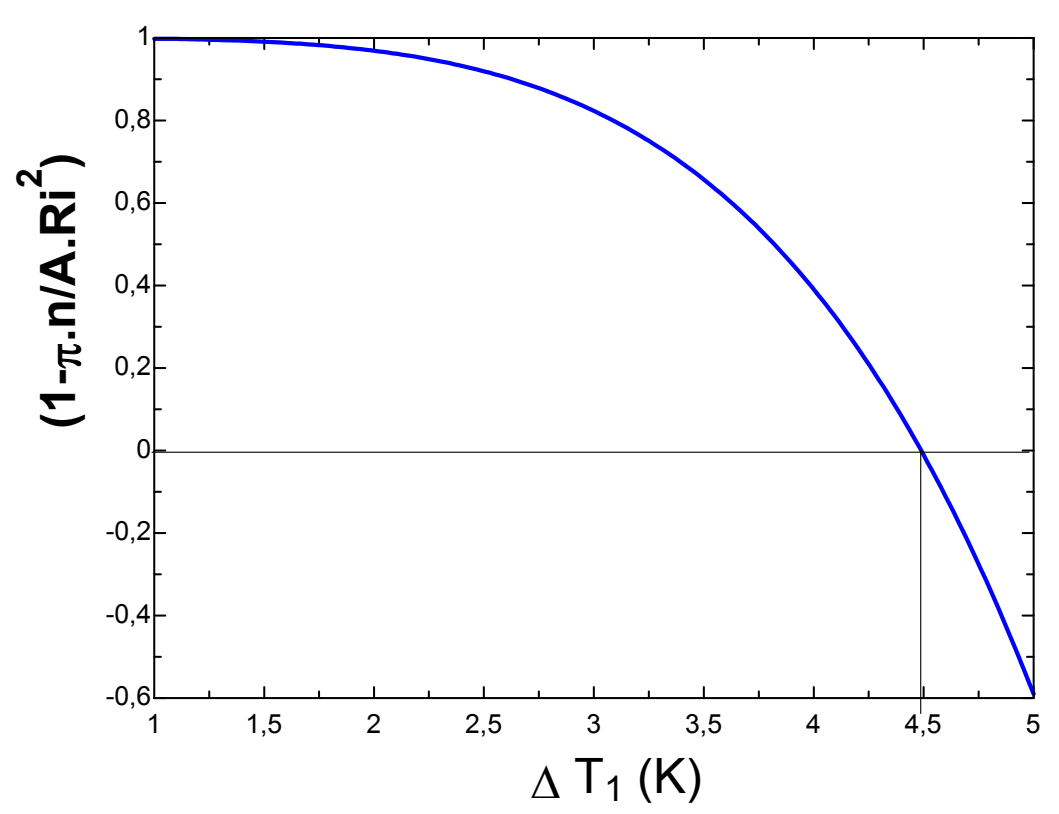

Figura 2.9 - Valor máximo para o superaquecimento da parede do tubo inferior utilizando a correlação de Wallner (1971)

\subsubsection{2 - Correlação de Hwang e Yao (1986)}

Hwang e Yao (1986) investigaram a ebulição do R-113 à pressão atmosférica normal em um banco retangular de tubos de aço inox composto por 48 tubos dispostos em 3 colunas e 16 fileiras. A correlação proposta por Hwang e Yao (1986) foi baseada no princípio da superposição de efeitos de forma semelhante à proposta por Chen (1966):

$h=S \cdot h_{E N}+F h_{l}$

O coeficiente de transferência de calor devido à convecção forçada do líquido $\left(h_{l}\right)$, em escoamento transversal, foi expresso em termos do coeficiente monofásico $\left(h_{c}\right)$, de acordo com a seguinte expressão:

$h_{l}=h_{c} \cdot(1-x)^{0,6}$

O coeficiente de transferência de calor para escoamento monofásico $\left(h_{c}\right)$ foi obtido através da correlação de Bitter (1972) apud Hwang e Yao (1986):

$h_{c}=0,21 \cdot \operatorname{Re}_{d}^{0,62} \cdot \operatorname{Pr}_{l}^{0,38} \cdot\left(\frac{\operatorname{Pr}_{l}}{\operatorname{Pr}_{p}}\right)^{0,25}$ 
onde $\operatorname{Re}_{d}=\frac{U . d}{v}$

$U=U_{\infty} \cdot \frac{H}{H-d}$

$U_{\infty}$ é a velocidade do escoamento na entrada do canal do banco de tubos

$H$ é a largura do canal do banco de tubos

$d$ é o diâmetro dos tubos

O fator $F$ foi obtido empiricamente e correlacionado através da seguinte expressão:

$F=\left(\frac{1}{1-\alpha_{\bmod }}\right)^{0,744}$

onde $\alpha_{\text {mod }}$ é a fração de vazio modificada, expressa pela seguinte equação:

$$
\alpha_{\text {mod }}=\frac{0,833 \cdot x}{x+(1-x) \cdot\left(\frac{\rho_{g}}{\rho_{l}}\right)}
$$

O coeficiente de transferência de calor associado à ebulição nucleada foi obtido empiricamente sendo expresso pela seguinte equação:

$h_{E N}=0,2086 \cdot \phi^{0,75}$

O fator de supressão da ebulição nucleada $(S)$ foi obtido através da correlação proposta por Bennett et al (1980) para escoamento tranversal, sendo expressa por:

$$
S=\frac{k_{l}}{F . h_{l} \cdot Y} \cdot\left[1-\exp \left(\frac{-F \cdot h_{l} \cdot Y}{k_{l}}\right)\right]
$$

onde $Y=0,041 \cdot\left[\frac{\sigma}{g \cdot\left(\rho_{l}-\rho_{g}\right)}\right]^{0,5}$

A correlação de Hwang e Yao (1986) baseia-se no princípio da superposição de efeitos: ebulição nucleada e convecção forçada. Esta correlação pode ser utilizada 
para uma ampla faixa de velocidades mássicas $(G)$ em escoamentos transversais (“cross-flow”) em bancos de tubos. Através da análise dos resultados proporcionados pela correlação desenvolvida para o R-113, pode-se verificar, conforme mostrado nas Figs. (2.10) e (2.11), que:

- A influência da velocidade mássica no coeficiente de transferência de calor é mais pronunciada para reduzidos valores de $\phi$. Este comportamento estaria relacionado ao regime de ebulição parcial ser predominante, com isso a transferência de calor seria principalmente resultante do movimento do líquido. Para elevados valores de $\phi$, os efeitos de ebulição nucleada seriam predominantes, com isso, a influência da velocidade mássica seria desprezível.

- Para reduzidos valores de $\phi$, o coeficiente de transferência de calor local aumenta com o título $(\mathrm{x})$. Este comportamento estaria relacionado à ocorrência de uma maior circulação de mistura na região de maior título (devido à diferença de densidades entre o líquido e o vapor).

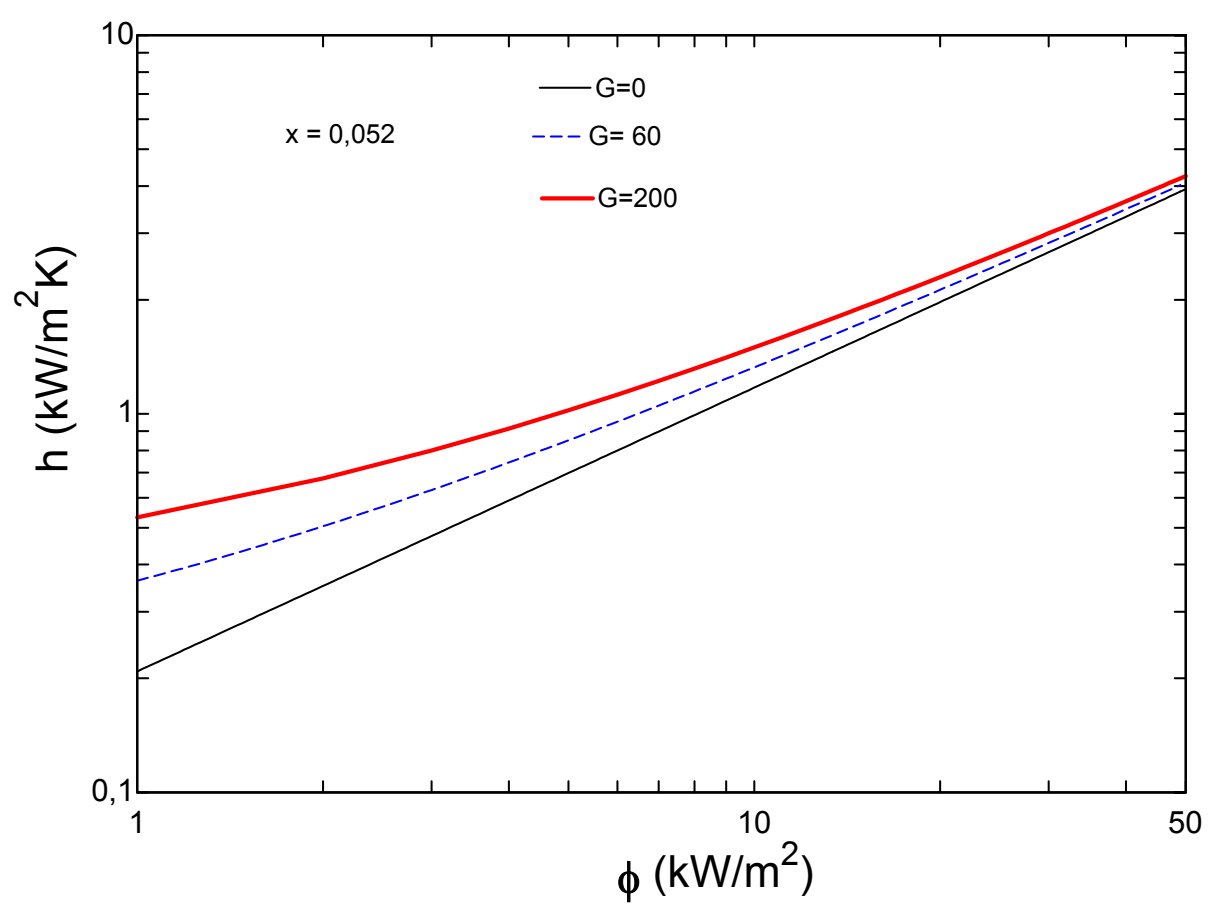

Figura 2.10 Influência da velocidade mássica no coeficiente de transferência de calor. 


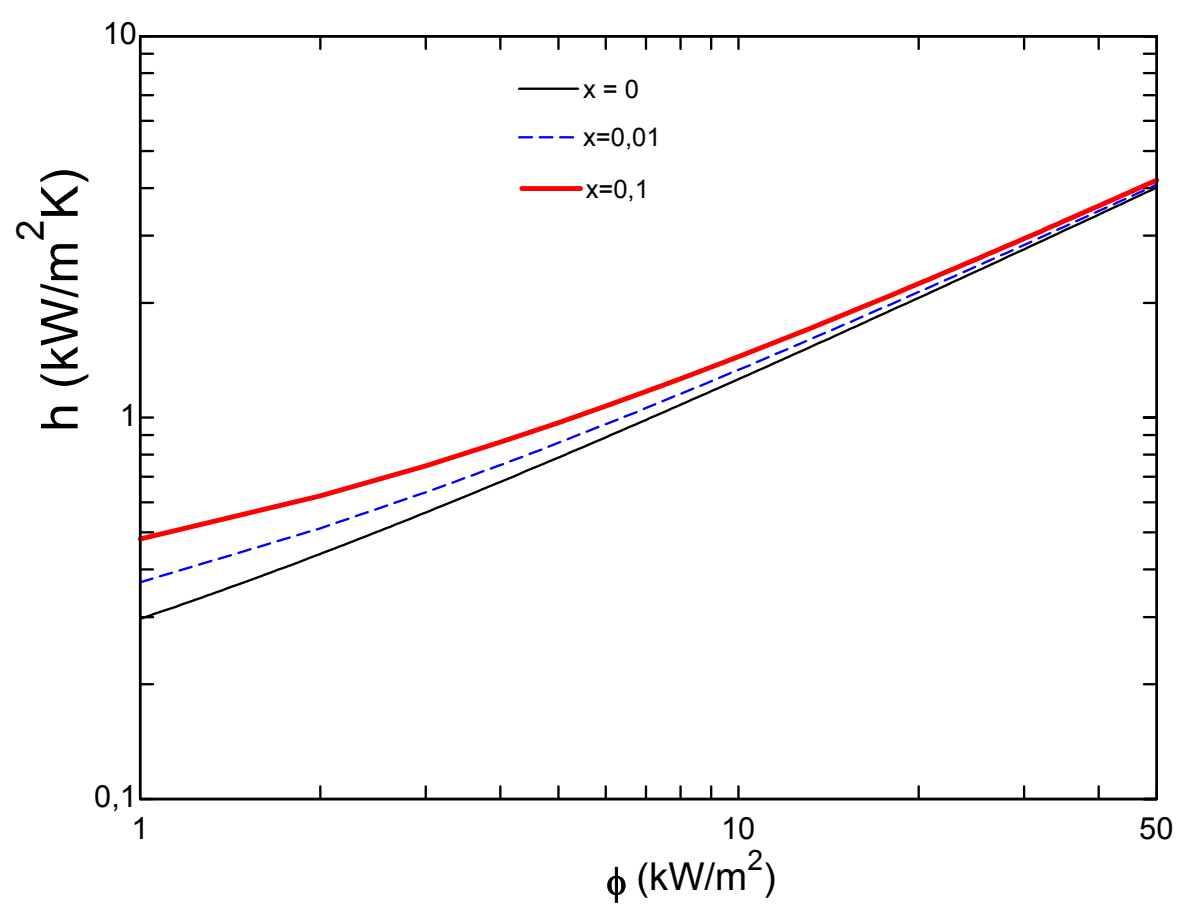

Figura 2.11 Influência do título local no coeficiente de transferência de calor.

\subsubsection{3 - Correlação de Müller (1986)}

Inicialmente, Müller (1986) ajustou os resultados experimentais obtido para cada tubo aquecido separadamente em correlações do tipo:

$h_{1 i}=C_{i} \cdot \phi^{n_{i}}$

$h_{1}=C \cdot \phi^{n}$

onde a Eq. (2.61) representa cada tubo, a Eq. (2.62) representa a média de todos os tubos aquecidos separadamente, o sub-índice $i$ representa o tubo analisado e os coeficientes $C$ e expoentes $n$ estão relacionados na Tabela 2.4.

Posteriormente, Müller (1986) aqueceu os tubos simultaneamente com iguais valores de fluxo de calor, obtendo, a partir dos resultados experimentais, a seguinte 
correlação para a relação entre os coeficientes de transferência de calor associado ao particular tubo no banco e ao tubo isoladamente $\left(h_{N} / h_{l}\right)$ :

$\frac{h_{N}}{h_{1}}=A+B \cdot \exp \left[-C^{2} \cdot(\log \phi-D)^{2}\right]$

onde $A, B, C$ e $D$ são constantes empíricas cujos valores podem ser encontrados nas Tabelas 2.5 (a), (b) e (c).

Com isso, a partir das Eqs.(2.61) ou (2.62) e (2.63), pode-se obter o coeficiente de transferência de calor para cada tubo no banco de tubos em ebulição. Curvas da relação entre o coeficiente de transferência de calor de cada tubo de determinada fileira $(\mathrm{N})$ e aquecido sozinho versus o fluxo de calor $(\phi)$ foram traçadas, conforme mostradas anteriormente nas Figs. 2.4 (a), (b) e (c) e discutidas nas Seções (2.3.2) e (2.3.3).

Tabela 2.4 Coeficientes e expoentes para as Eqs. (2.61) e (2.62)

\begin{tabular}{|c|c|c|c|c|c|c|}
\hline & \multicolumn{2}{|c|}{$0,7<\phi<3 \mathrm{~kW} / \mathrm{m}^{2}$} & \multicolumn{2}{|c|}{$3<\phi<20 \mathrm{~kW} / \mathrm{m}^{2}$} & \multicolumn{2}{|c|}{$20<\phi<50 \mathrm{~kW} / \mathrm{m}^{2}$} \\
\hline & $C$ & $n$ & $C$ & $N$ & $C$ & $n$ \\
\hline \multirow[t]{2}{*}{ Média } & 1,422 & 0,725 & 1,331 & 0,735 & 8,594 & 0,547 \\
\hline & $C_{i}$ & $n_{i}$ & $C_{i}$ & $n_{i}$ & $C_{i}$ & $n_{i}$ \\
\hline 1 & 1,146 & 0,761 & 1,21 & 0,756 & 16,188 & 0,489 \\
\hline 2 & 2,168 & 0,655 & 0,809 & 0,779 & 11,257 & 0,518 \\
\hline 3 & 1,386 & 0,723 & 1,222 & 0,74 & 8,556 & 0,548 \\
\hline 4 & 2,697 & 0,641 & 0,989 & 0,768 & 7,69 & 0,556 \\
\hline 5 & 1,49 & 0,731 & 2,027 & 0,695 & 6,939 & 0,569 \\
\hline 6 & 1,979 & 0,68 & 1,509 & 0,718 & 4,909 & 0,6 \\
\hline
\end{tabular}


Tabela 2.5 (a). Valores para as constantes da Eq.(2.63). Para s/d = 2,0

\begin{tabular}{|l|l|l|l|l|}
\hline TUBO & A & B & C & D \\
\hline 1 & 0,9100 & 0,6678 & 1,6118 & 3,1668 \\
\hline 2 & 0,8700 & 0,4873 & 1,0531 & 3,1028 \\
\hline 3 & 0,8700 & 0,5356 & 1,1988 & 3,2461 \\
\hline 4 & 0,9200 & 0,5301 & 1,0934 & 3,0435 \\
\hline 5 & 0,9000 & 0,5082 & 1,0372 & 3,0379 \\
\hline 6 & 0,9400 & 1,1668 & 1,0431 & 3,1384 \\
\hline
\end{tabular}

Tabela 2.5 (b). Valores para as constantes da Eq.(2.63). Para s/d $=1,6$

\begin{tabular}{|l|l|l|l|l|}
\hline TUBO & A & B & C & D \\
\hline 1 & 0,9100 & 0,4133 & 0,9598 & 2,4212 \\
\hline 2 & 0,9400 & 0,7095 & 1,9033 & 3,3837 \\
\hline 3 & 0,9400 & 0,9111 & 1,8325 & 3,3606 \\
\hline 4 & 0,9700 & 1,1803 & 2,0765 & 3,3872 \\
\hline 5 & 0,9600 & 1,3648 & 1,6596 & 3,3097 \\
\hline 6 & 1,0800 & 2,1645 & 1,6805 & 3,3728 \\
\hline
\end{tabular}

Tabela 2.5 (c). Valores para as constantes da Eq.(2.63). Para s/d=1,3

\begin{tabular}{|l|l|l|l|l|}
\hline TUBO & A & B & C & D \\
\hline 1 & 0,9400 & 0,1855 & 1,4006 & 2,8477 \\
\hline 2 & 0,9400 & 0,6338 & 1,4645 & 3,3677 \\
\hline 3 & 0,9600 & 1,0448 & 1,6253 & 3,322 \\
\hline 4 & 1,0100 & 1,4301 & 1,9796 & 3,3749 \\
\hline 5 & 1,0400 & 1,6301 & 1,7368 & 3,2948 \\
\hline 6 & 1,200 & 2,6793 & 1,6794 & 3,309 \\
\hline
\end{tabular}

\subsubsection{4 - Correlação de Danilova et al (1992)}

Danilova et al (1992) investigaram a ebulição dos refrigerantes R-22 e amônia (R-717) em banco de tubos lisos de aço e tubos porosos de alumínio- 
manganês com configuração triangular com 55 fileiras, para uma faixa de temperatura de saturação entre -20 e $20^{\circ} \mathrm{C}$ e fluxo de calor entre 1 e $10 \mathrm{~kW} / \mathrm{m}^{2}$. Observaram que o coeficiente de transferência de calor aumenta no sentido ascendente das fileiras de tubos, atingindo um valor máximo, a partir do qual mantém-se aproximadamente constante.

Propuseram uma correlação baseada na pressão reduzida $\left(\mathrm{p}_{\mathrm{r}}\right)$, com isso a influência das propriedades de transportes e termodinâmicas nos mecanismos físicos de transferência de calor são reduzidas a uma função da pressão reduzida; incorporaram ainda, o número total de fileiras do banco de tubos $\left(N_{r}\right)$ e a localização da fileira $(N)$ (iniciando da inferior (1)). Propuseram, então, a seguinte correlação

$h=A \cdot \phi^{C_{1}} \cdot N_{r}^{C_{2}} \cdot p_{r}^{C_{3}} \cdot N^{B}$

onde: $h$ é coeficiente de transferência de calor no tubo analisado

$C_{1}, C_{2}, C_{3}$ são constantes, mostradas na Tabela 2.6

$B=f\left(p_{r}, \phi, N_{r}\right)$, mostrado na Tabela 2.6

Tabela 2.6 Valores para as constantes da Eq. (2.64)

\begin{tabular}{|c|c|c|c|c|c|c|}
\hline $\begin{array}{c}\text { Refrigerant } \\
\text { e }\end{array}$ & Regime & $A$ & $C_{1}$ & $C_{2}$ & $C_{3}$ & $B$ \\
\hline $\mathrm{R}-22$ & Eb. Parc. & $\begin{array}{c}24, \\
5\end{array}$ & $\begin{array}{c}0,4 \\
3\end{array}$ & $\begin{array}{c}- \\
0,0 \\
4\end{array}$ & $\begin{array}{c}0,1 \\
3\end{array}$ & $0,31-0,3 \cdot p_{r}-2 \times 10^{-4} \cdot N_{r}$ \\
\hline R-717 & & $\begin{array}{c}28, \\
6\end{array}$ & 0,4 & $\begin{array}{c}0,0 \\
6\end{array}$ & $\begin{array}{c}0,0 \\
9\end{array}$ & $0,39-0,94 \cdot p_{r}-9,1 \times 10^{-4} \cdot N_{r}$ \\
\hline $\mathrm{R}-22$ & Eb.P.Des & $\begin{array}{c}1,0 \\
6\end{array}$ & $\begin{array}{c}0,8 \\
7\end{array}$ & $\begin{array}{c}0,0 \\
5\end{array}$ & $\begin{array}{c}0,2 \\
7\end{array}$ & $0,21-7,6 \times 10^{-6} . \phi-1,3 \times 10^{-3} \cdot N_{r}$ \\
\hline
\end{tabular}

Eb. Parc. : Ebulição parcial

Eb. P. Des. : Ebulição nucleada plenamente desenvolvida 


\subsubsection{5 - Correlação de Gupta et al (1995)}

Estes pesquisadores propuseram uma correlação para o coeficiente de transferência de calor da água destilada em ebulição em banco de tubos, com base no princípio da superposição de efeitos de convecção forçada e ebulição nucleada, de forma semelhante a Chen (1966). O coeficiente de transferência de calor distingue devido a posição relativa dos tubos (inferior e superior)

\section{(a) Tubo inferior}

Para o tubo inferior, que apresenta comportamento semelhante àquele de um único tubo, os autores compararam os resultados experimentais com a correlação para escoamento transversal proposta por Kutateladze (1961) apud Gupta et al (1995), expressa por:

$\frac{h_{1}}{h_{l}}=\left[1+\left(\frac{h_{B E N}}{h_{l}}\right)^{n}\right]^{1 / n}$

onde $h_{l}$ representa o coeficiente de transferência de calor para convecção forçada monofásica de líquido em escoamentos transversais.

Para determinação de $h_{l}$ utilizaram a correlação de Whitaker (1972) apud Gupta et al (1995), expressa por:

$h_{l}=\frac{k_{l}}{d} \cdot\left(0,4 \cdot \operatorname{Re}_{l}^{0,5}+0,06 \cdot \operatorname{Re}_{l}^{2 / 3}\right) \cdot\left(\operatorname{Pr}_{l}\right)^{0,36} \cdot\left(\mu_{l} / \mu_{v}\right)^{0,25}$

O coeficiente de transferência de calor para ebulição nucleada foi obtido através da seguinte relação empírica:

$h_{B E N}=13,035 .\left(\Delta T_{\text {sat }}\right)^{2,881}$

Segundo os autores os resultados experimentais foram satisfatoriamente correlacionados pela Eq. (2.65), para $n=1$, tendo sido obtido um desvio médio absoluto de $\pm 6,8 \%$. 


\section{(b) Tubos Superiores}

Para os tubos superiores, os autores propuseram uma correlação baseada no modelo de Chen (1966), expressa por:

$$
h_{B}=F . h_{l}+h_{B E N}
$$

Conforme sugerido por Bennett et al (1980) apud Gupta et al (1995), o superaquecimento da parede $\left(\Delta T_{s a t}\right)$ utilizado na correlação para ebulição nucleada de um único tubo, em banco de tubos, deve ser substituído pelo superaquecimento efetivo. Com isso, a Eq.(2.67) pode ser expressa por:

$$
h_{B E N}=13,035 .\left(\Delta T_{e f}\right)^{2,881}
$$

Bennett et al (1980) apud Gupta et al (1995) propuseram a seguinte correlação para o superaquecimento efetivo:

$$
\frac{\Delta T_{e f}}{\Delta T_{\text {sat }}}=\frac{k_{l}}{\left(F \cdot h_{l}\right) \cdot Y} \cdot\left[1-\exp \left(-\frac{F \cdot h_{l} \cdot Y}{h_{l}}\right)\right]
$$

onde:

$$
Y=0,041 \cdot\left[\frac{\sigma}{g \cdot\left(\rho_{l}-\rho_{v}\right)}\right]^{0,5}
$$

Com isso, deve-se ainda analisar o fator de incremento da mistura bifásica em relação à monofásica (líquida) $(F)$.

Diversos autores correlacionaram o fator $F$ como função da fração de vazio ( $\alpha$ ) ou com o parâmetro de Martinelli $\left(\mathrm{X}_{\mathrm{tt}}\right)$. Segundo Gupta et al (1995), somente estas funções, $\mathrm{X}_{\mathrm{tt}} \mathrm{e} \alpha$, não são parâmetros físicos adequados. $\mathrm{O}$ fator $F$ em banco de tubos seria função, também, da agitação promovida pelas bolhas formadas nos tubos inferiores, do fluxo de calor, da velocidade do escoamento, da distância entre tubos e do número de fileiras de tubos. Os autores propuseram uma correlação funcional envolvendo estes parâmetros, expressa por:

$F=C_{1} .(B o)^{a} .(s / d)^{b} \cdot(N)^{c}$ 
onde $C_{l}$ é a constante de proporcionalidade

$$
B o=\frac{\phi}{G \cdot i_{l v}}
$$

Empiricamente obtiveram os valores de $C_{l}, a, b$, e $c$, resultando a seguinte expressão:

$$
F=938,53 \cdot(B o)^{0,710} \cdot(s / d)^{-0,186} \cdot(N)^{0,463}
$$

Através da correlação obtiveram-se curvas do coeficiente de transferência de calor versus fluxo de calor, conforme mostrado na Fig. (2.12). A partir de uma análise preliminar constatam-se algumas inconsistências (talvez devido a erro de digitação). A Figura (2.12) ilustra curvas obtidas a partir da correlação e de resultados experimentais obtidos por Gupta et al (1995). Observa-se que há uma diferença relativamente grande entre os resultados.

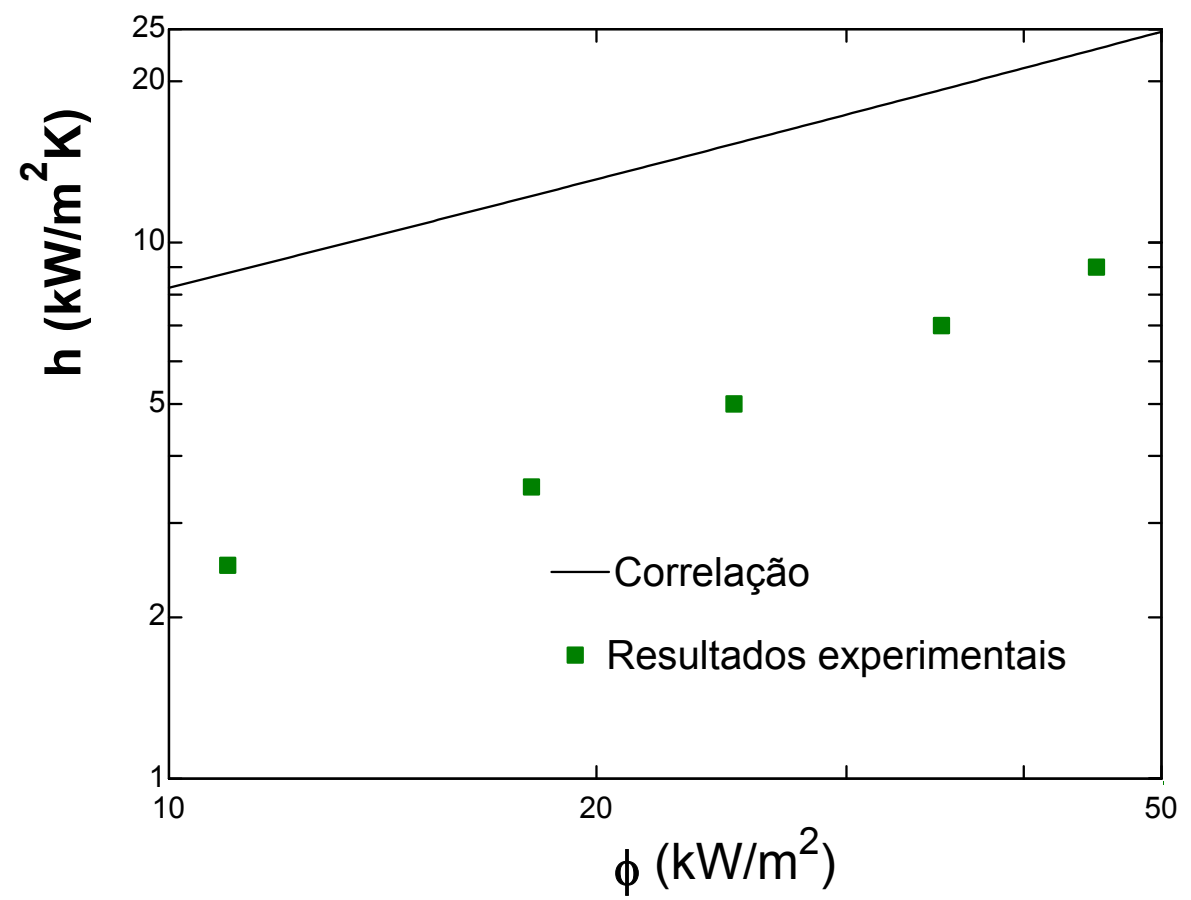

Figura 2.12 Resultados experimentais e curvas de $\phi v_{s} h$ obtidas através da correlação de Gupta et al (1995) 


\subsubsection{7 - Correlação de Kumar et al (2002)}

Kumar at al (2002) propuseram uma correlação empírica para determinação do coeficiente de transferência de calor local para cada tubo, aplicada a banco de tubos com configuração vertical em linha. Obtiveram resultados experimentais para o benzeno, tolueno, água destilada e R-113. As faixas de pressão e fluxo de calor foram respectivamente de 35,36 a $97,5 \mathrm{kPa}$ e 19 a $45 \mathrm{~kW} / \mathrm{m}^{2}$. Utilizaram apenas dois tubos ranhurados de cobre. No entanto, a correlação obtida, segundo os autores, pode ser generalizada a qualquer número de fileiras de tubos.

Inicialmente obtiveram correlações do tipo $h=C . \phi^{n}$ para cada tubo aquecido isoladamente, obtendo-se:

$h_{1}=c_{1} \cdot \phi_{1}^{0,7} \quad$ para o tubo inferior (Tubo 1)

$h_{2}=c_{2} \cdot \phi_{2}^{0,7} \quad$ para o tubo superior (Tubo 2)

Posteriormente aqueceram os dois tubos com fluxos de calor iguais, obtendo:

$h_{1}=c_{1} \cdot \phi_{1}^{0,7} \quad$ para o tubo inferior (Tubo 1)

$h_{2}^{\bullet}=c_{3} \cdot \phi_{1}^{0,55} \quad$ para o tubo superior (Tubo 2)

onde o sobrescrito “•” representa que está ocorrendo influência do tubo inferior sobre o superior.

Quando ambos os tubos foram aquecidos com fluxos de calor diferentes, obtiveram:

$$
\begin{array}{ll}
h_{1}=c_{1} \cdot \phi_{1}^{0,7} & \text { para o tubo inferior (Tubo 1) } \\
h_{2}^{\bullet}=c_{4} \cdot \phi_{1}^{0,3} & \text { para o tubo superior (Tubo 2) }
\end{array}
$$

A partir destes resultados, mostraram que o coeficiente de transferência de calor é função do fluxo de calor aplicado aos tubos superior e inferior, sendo que o coeficiente de transferência de calor no tubo superior depende do fluxo aplicado em ambos os tubos, podendo ser expresso por:

$h_{2}^{\bullet}=c_{5} \cdot \phi_{2}^{m} \cdot \phi_{1}^{n}$ 
ou, a partir da Eq. (2.79), representado por:

$h_{2}^{\bullet}=c_{5} \cdot \phi_{2}^{m} \cdot \phi_{1}^{0,3}$

Para o caso em que ambos os tubos são aquecidos com mesmo fluxo de calor, $\phi_{1}=\phi_{2}$, a Eq.(2.81) pode ser expressa por:

$h_{2}^{\bullet}=c_{5} \cdot \phi_{2}^{m+0,3}$

Igualando a Eq.(2.82) à Eq.(2.77), obtém-se $m=0,25$. Reescrevendo a Eq.(2.80), obtém-se:

$h_{2}^{\bullet}=c_{5} \cdot \phi_{2}^{0,25} \cdot \phi_{1}^{0,3}$

onde $c_{5}$ é uma constante dependente do par superfície/fluido. Para o par água destilada/ superfície aletada de cobre, os autores obtiveram $c_{5}=24,463$, resultando a seguinte expressão:

$h_{2}^{\bullet}=24,463 \phi_{2}^{0,25} \cdot \phi_{1}^{0,3}$

Kumar et al (2002) obtiveram um fator de efetividade do tubo superior, definido como a razão entre os coeficientes de transferência de calor do tubo superior quando aquecido simultaneamente com o tubo inferior e aquecido sozinho, isto é: $E F=\frac{h_{2}^{\bullet}}{h_{2}}$. A partir das Eqs. (2.75) e (2.84) obtiveram:

$E F=\frac{24,463 \cdot \phi_{2}^{0,25} \cdot \phi_{1}^{0,3}}{3,9 \cdot \phi_{2}^{0,7}}=6,27 . . \phi_{2}^{-0,45} \cdot \phi_{1}^{0,3}$

A partir da Eq.(2.85) pode-se observar que $E F$ aumenta com o fluxo de calor no tubo inferior e diminui com o fluxo de calor no tubo superior.

\section{Extensão da correlação para vários tubos}

Em banco de tubos, conforme indicado por diversos autores, os tubos de fileiras superiores apresentam coeficiente de transferência de calor superior aos de fileiras inferiores. Em um único tubo, o coeficiente de transferência de calor aumenta 
com o fluxo de calor. Kumar et al (2002) propuseram um fluxo de calor "virtual" para tubos de fileiras superiores, que seria responsável pelo aumento do coeficiente de transferência de calor. Sendo expresso, para dois tubos, por:

$\phi_{2}^{\bullet}=\phi_{2}+k \cdot \phi_{1}$

onde $k$ representa o fator de interação do tubo inferior sobre o tubo superior.

Quando o tubo superior (Tubo 2) é aquecido isoladamente, tem-se:

$h_{2}^{\bullet}=c_{6} \cdot \phi_{2}^{\bullet 0,7}$

ou

$h_{2}^{\bullet}=c_{6} \cdot\left(\phi_{2}+k \cdot \phi_{1}\right)^{0,7}$

A partir das Eqs.(2.159),(2.149) e (2.161), obtém-se:

$k=\frac{\left(\frac{c_{5}}{c_{6}} \phi_{1}^{0,3} \phi_{2}^{0,25}\right)^{1,43}-\phi_{2}}{\phi_{1}}$,

Para água destilada / tubos aletados de cobre, $c_{5}=24,463$ e $c_{6}=c_{2}=3,9$, com isso:

$k=\frac{\phi_{2}}{\phi_{1}}\left[\left(13,77 \phi_{1}^{0,428} \phi_{2}^{-0,643}\right)-1\right]$

Para o caso em que os fluxos de calor em ambos os tubos são iguais, $\phi_{1}=\phi_{2}=\phi$, a Eq.(2.88) reduz-se a:

$k=\left[\left(13,77 \phi^{-0,215}\right)-1\right]$

Com isso, a partir da Eq. (2.88) ou (2.89) pode-se determinar o "fluxo de calor virtual" do tubo superior.

Para determinar o coeficiente de transferência de calor no tubo superior, utiliza-se o fluxo virtual de calor em correlações para um único tubo. Geralmente, 
em ebulição, correlações envolvendo os adimensionais Nusselt, Reynolds modificado e Prandtl são utilizadas. Estas correlações são expressas na forma:

$$
N u_{b}=c_{7} \cdot\left(\operatorname{Re}_{b}^{\prime}\right)^{0,7} \cdot(\operatorname{Pr})^{0,4}
$$

ou

$$
\frac{h}{k_{l}} \cdot \sqrt{\frac{\sigma}{\left(\rho_{l}-\rho_{v}\right)}}=c_{7} \cdot\left(\frac{\phi}{\mu \cdot h_{l v}} \cdot \sqrt{\frac{\sigma}{\left(\rho_{l}-\rho_{v}\right)}}\right)^{0,7} \cdot\left(\frac{\mu \cdot c_{p}}{k}\right)_{l}^{0,4}
$$

Restando, assim, a determinação do valor da constante $c_{7}$. Este pode ser obtido somente para um único tubo.

\section{Correlação para vários tubos}

A partir dos resultados anteriores pode-se generalizar a correlação para dois tubos, aplicando o mesmo princípio do fluxo de calor virtual.

Para 3 tubos, o fluxo de calor virtual seria dado por:

$\phi_{3}^{\bullet}=\phi_{3}+k \phi_{2}^{\bullet}=\phi_{3}+k\left(\phi_{2}+k \phi_{1}\right)=\phi_{3}+k \phi_{2}+k^{2} \phi_{1}$

Para $n$ tubos, a correlação para o fluxo de calor virtual seria expressa por:

$$
\phi_{n}^{\bullet}=\phi\left(1+k+k^{2}+\ldots .+k^{n-1}\right)=\phi\left(\frac{1-k^{n}}{1-k}\right)
$$

\subsection{6 - Resumo das principais correlações para ebulição em banco de tubos}

Para efeito de comparação das distintas pesquisas envolvendo a ebulição nucleada em banco de tubos foi elaborada a Tabela 2.7, com o resumo das correlações mostradas anteriormente. Nesta tabela são apresentadas de maneira sucinta as principais características experimentais dos distintos estudos como: fluido, número de fileiras do banco de tubos, faixa de pressão, fluxo de calor e espaçamento entre tubos. São feitas, ainda, algumas observações a respeito das correlações. 
Tabela 2.7 - Resumo das principais correlações para ebulição em banco de Tubos

\begin{tabular}{|c|c|c|c|c|c|c|c|}
\hline \multirow[t]{2}{*}{ Autor/ Ano } & \multirow[t]{2}{*}{ Correlação } & \multicolumn{5}{|c|}{ Características Experimentais } & \multirow[t]{2}{*}{ Observações } \\
\hline & & Fluido & $\begin{array}{l}\text { Nr. De tubos } \\
\text { ou fileiras/ } \\
\text { configuração }\end{array}$ & $\begin{array}{l}\text { Faixa } \\
\text { de } P_{\text {sat }} \\
\text { ou } \mathbf{T}_{\text {sat }}\end{array}$ & $\mathbf{s} / \mathbf{d}$ & $\begin{array}{l}\phi \\
\left(\mathrm{kW} / \mathrm{m}^{2}\right)\end{array}$ & \\
\hline $\begin{array}{l}\text { Wallner } \\
(1971)\end{array}$ & $\bar{h}=9,5 \phi^{0,55}$ & R-11 & $\begin{array}{l}12 \text { tubos/ } \\
\text { Triangular }\end{array}$ & $100 \mathrm{kPa}$ & 1,33 & $0,4-20$ & $\begin{array}{l}\text { Estritamente } \\
\text { empírica }\end{array}$ \\
\hline $\begin{array}{l}\text { Rebrov et al } \\
(1989)\end{array}$ & 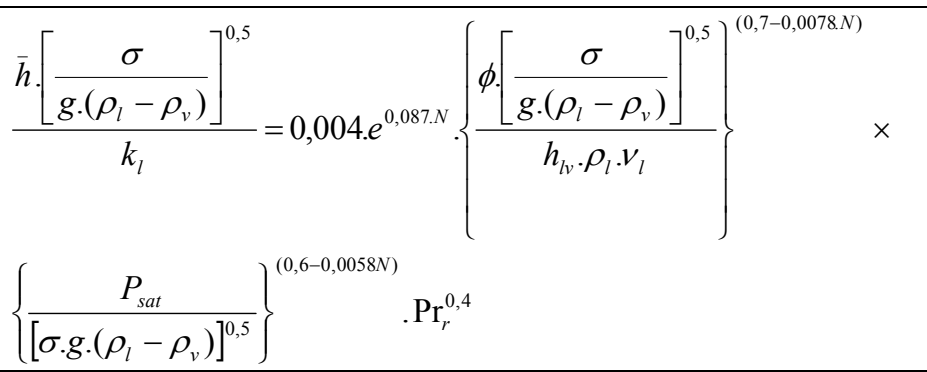 & $\begin{array}{l}\mathrm{R}-12 \\
\mathrm{R}-22\end{array}$ & $\begin{array}{l}\text { 1-50 fileiras/ } \\
\text { Tubos de aço }\end{array}$ & $\begin{array}{l}-30 \mathrm{a} \\
10^{\circ} \mathrm{C}\end{array}$ & 1,45 & $1-15$ & $\begin{array}{lr}\text { Baseada } & \mathrm{em} \\
\text { adimensionais } & \mathrm{de} \\
\text { correlações para } \\
\text { convecção forçada }\end{array}$ \\
\hline $\begin{array}{l}\text { Hsieh et al } \\
(2003)\end{array}$ & $\bar{h}=C \phi^{n}$ (valores de $C$ e $n$ encontram-se na Tabela 2.4) & R-134a & $\begin{array}{l}2,3,4 \text { e } 6 \text { tubos } \\
\text { de cobre/ } \\
\text { Triangular e } \\
\text { quadrangular }\end{array}$ & & 1,5 & & $\begin{array}{l}\text { Estritamente } \\
\text { empíricas }\end{array}$ \\
\hline $\begin{array}{l}\text { Hwang e } \\
\text { Yao (1986) }\end{array}$ & $\begin{array}{l}h=S . h_{E N}+F . h_{C F} \text { (expressões para } S, F, h_{E N} \text { e } h_{C F} \text { encontram- } \\
\text { se na p.37) }\end{array}$ & $\mathrm{R}-113$ & $\begin{array}{l}16 \text { fileiras e } 3 \\
\text { colunas de } \\
\text { tubos de aço } \\
\text { inox }\end{array}$ & $101 \mathrm{kPa}$ & 1,5 & & $\begin{array}{l}\text { Baseada na } \\
\text { superposição de } \\
\text { efeitos (ebulição } \\
\text { nucleada }+ \\
\text { convecção forçada) }\end{array}$ \\
\hline $\begin{array}{l}\text { Muller } \\
(1986)\end{array}$ & $\begin{array}{l}\frac{h_{N}}{h_{1}}=A+B \cdot \exp \left[-C^{2} \cdot(\log \phi-D)^{2}\right] \text { (os valores de } \\
A, B, C \text { e } D \text { encontram-se nas Tabelas } 2.6(\mathrm{a}, \mathrm{b} \text { e c) }\end{array}$ & R-11 & $\begin{array}{l}18 \text { tubos } \\
\text { aletados de } \\
\text { cobre/ } \\
\text { triangular }\end{array}$ & $100 \mathrm{kPa}$ & $\begin{array}{l}1,3 \\
1,6 \mathrm{e} \\
2,0\end{array}$ & $0,7-50$ & $\begin{array}{l}\text { Empírica. Utiliza } \\
\text { comparação com } \\
\text { um único tubo. }\end{array}$ \\
\hline
\end{tabular}




\begin{tabular}{|c|c|c|c|c|c|c|c|}
\hline \multirow[t]{2}{*}{ Autor/Ano } & \multirow[t]{2}{*}{ Correlação } & \multicolumn{5}{|c|}{ Características Experimentais } & \multirow[t]{2}{*}{ Observações } \\
\hline & & Fluido & $\begin{array}{l}\text { Nr. De tubos } \\
\text { ou fileiras/ } \\
\text { configuração }\end{array}$ & $\begin{array}{l}\text { Faixa } \\
\text { de } P_{\text {sat }} \\
\text { ou } \mathbf{T}_{\text {sat }}\end{array}$ & $\mathbf{s} / \mathbf{d}$ & $\begin{array}{l}\phi \\
\left(\mathrm{kW} / \mathrm{m}^{2}\right)\end{array}$ & \\
\hline $\begin{array}{l}\text { Danilova et } \\
\text { al (1992) }\end{array}$ & $\begin{array}{ll}h=24,5 \cdot \phi^{0,43} \cdot N_{r}^{-0,04} \cdot p_{r}^{0,13} \cdot(10 \cdot n)^{B} & \mathrm{p} / \mathrm{R}-22 \\
\text { onde: } B=\left(0,31-0,3 \cdot p_{r}-2 \times 10^{-4} \cdot N_{r}\right) & \\
h=28,6 \cdot \phi^{0,4} \cdot N_{r}^{0,06} \cdot p_{r}^{0,09} \cdot(10 \cdot n)^{B} & \mathrm{p} / \mathrm{R}-717 \\
\text { onde: } B=\left(0,39-0,94 \cdot p_{r}-9,1 \times 10^{-4} \cdot N_{r}\right) & \end{array}$ & R-22 & $\begin{array}{l}55 \text { fileiras } \\
\text { Triangular }\end{array}$ & $\begin{array}{l}-20 \mathrm{a} \\
20^{\circ} \mathrm{C}\end{array}$ & ---- & $1-10$ & $\begin{array}{l}\text { Empírica, baseada } \\
\text { em propriedades } \\
\text { reduzidas. }\end{array}$ \\
\hline $\begin{array}{l}\text { Gupta et al } \\
\text { (1995) }\end{array}$ & $\begin{array}{l}h_{B}=F \cdot h_{l}+h_{B E N}, \text { onde: } \\
F=938,53 \cdot(B o)^{0,710} \cdot(s / d)^{-0,186} \cdot(N)^{0,463} \\
h_{B E N}=13,035 \cdot\left(\Delta T_{s a t}\right)^{2,881} \\
h_{l}=\frac{k_{l}}{d} \cdot\left(0,4 \cdot \operatorname{Re}_{l}^{0,5}+0,06 \cdot \operatorname{Re}_{l}^{2 / 3}\right) \cdot\left(\operatorname{Pr}_{l}\right)^{0,36} \cdot\left(\mu_{l} / \mu_{v}\right)^{0,25}\end{array}$ & $\begin{array}{l}\text { Água } \\
\text { destilada }\end{array}$ & $\begin{array}{l}3 \text { tubos aço } \\
\text { inox }\end{array}$ & $\begin{array}{l}100,19 \\
\mathrm{kPa}\end{array}$ & $\begin{array}{l}1,5 \\
3,0 \\
4,5 \\
6,0\end{array}$ & $10-40$ & $\begin{array}{l}\text { Baseada na } \\
\text { superposição de } \\
\text { efeitos (tipo Chen) }\end{array}$ \\
\hline $\begin{array}{l}\text { Kumar et al } \\
(2002)\end{array}$ & $\begin{array}{l}\phi_{n}^{\bullet}=\phi \cdot\left(\frac{1-k^{n}}{1-k}\right) \quad k=\cdot\left[\left(13,77 \cdot \phi^{-0,215}\right)-1\right] \\
\frac{h_{N}}{k_{l}} \cdot \sqrt{\frac{\sigma}{\left(\rho_{l}-\rho_{v}\right)}}=c_{7} \cdot\left(\frac{\phi_{n}^{\bullet}}{\mu \cdot h_{l v}} \cdot \sqrt{\frac{\sigma}{\left(\rho_{l}-\rho_{v}\right)}}\right)^{0,7} \cdot\left(\frac{\mu \cdot c_{p}}{k}\right)_{l}^{0,4}\end{array}$ & $\begin{array}{l}\text { Água } \\
\text { destilada }\end{array}$ & $\begin{array}{l}2 \text { tubos } \\
\text { aletados de } \\
\text { cobre }\end{array}$ & $\begin{array}{l}35,36 \mathrm{a} \\
97,5 \\
\mathrm{kPa}\end{array}$ & ---- & $19-45$ & $\begin{array}{l}\text { Empírica. Baseada } \\
\text { no efeito do fluxo } \\
\text { de calor do tubo } \\
\text { inferior sobre o } \\
\text { superior. }\end{array}$ \\
\hline
\end{tabular}




\section{5 - Sumário do estado da arte envolvendo ebulição em banco de tubos}

A Tabela 2.8 apresenta um resumo das principais publicações sobre ebulição em banco de tubos a partir da década de 50. Constata-se que a maioria dos pesquisadores dedicou-se aos estudos dos refrigerantes R-11 e R-113 que são da família dos CFC's, que, conforme firmado em 1986 no protocolo de Montreal, deverão ser retirados do mercado. Com isso, torna-se relevante o estudo da ebulição com refrigerantes substitutos para os CFC's. Também é interessante destacar o reduzido número de trabalhos de otimização do desempenho de banco de tubos, através da análise da influência de parâmetros, tais como: espaçamento entre tubos, fluxo de calor, pressão, velocidade mássica, que podem afetar drasticamente o coeficiente de transferência de calor. Verifica-se, ainda, que a maioria dos trabalhos apresentou condições experimentais limitadas, com reduzidas variações na pressão e no fluxo de calor.

Tabela 2.8 Literatura referente à ebulição em banco de tubos

\begin{tabular}{|c|c|c|c|}
\hline Autor & Ano & Características Experimentais & Fluido / $p_{\text {sat }}$ ou $T_{\text {sat }}$ \\
\hline Katz & 1955 & 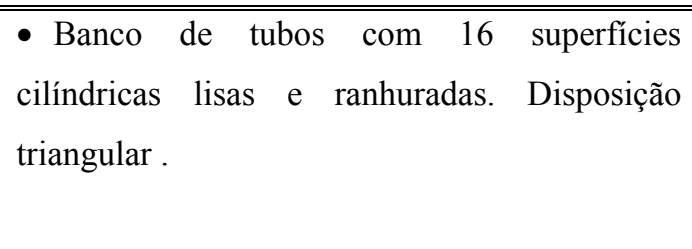 & $\begin{array}{l}\text { Propano/ } 10,55{ }^{\circ} \mathrm{C} \\
\text { n-butano } / 13,9{ }^{\circ} \mathrm{C} \\
\text { R-12/ } 12,8{ }^{\circ} \mathrm{C} \\
\text { Dióxido de enxofre/ } 5,6{ }^{\circ} \mathrm{C}\end{array}$ \\
\hline Czikk et al & 1970 & $\begin{array}{l}\text { - banco de tubos com } 20 \text { superfícies lisas de } \\
\text { cobre, } D_{e x t}=19 \mathrm{~mm} \\
\text { - banco de tubos com } 18 \text { superfícies } \\
\text { corrugadas de cobre e recobertas com material } \\
\text { poroso, também de cobre, } D_{e x t}=25,4 \mathrm{~mm}\end{array}$ & $\mathrm{R}-11 / 1,11^{\circ} \mathrm{C}$ \\
\hline Wallner & 1971 & $\begin{array}{l}\text { - banco } 4 \text { fileiras e } 12 \text { tubos, } D_{e x}=10 \mathrm{~mm} \text {. } \\
\text { Disposição triangular, relação de espaçamento } \\
\text { entre tubos e diâmetro }(\mathrm{s} / \mathrm{d})=1,33 \text { e } 1,50\end{array}$ & $\mathrm{R} 11 / 100 \mathrm{kPa}$ \\
\hline
\end{tabular}


Tabela 2.8 (continuação) Literatura referente à ebulição em banco de tubos

\begin{tabular}{|c|c|c|c|}
\hline Autor & Ano & Características Experimentais & Fluido / $p_{\text {sat }}$ ou $T_{\text {sat }}$ \\
\hline $\begin{array}{l}\text { Danilova e } \\
\text { Dyundin }\end{array}$ & 1972 & $\begin{array}{l}\text { - banco de tubos com } 19 \text { superfícies de cobre } \\
\text { com } 639 \text { aletas } / \mathrm{m}, D_{e x t}=20,9 \mathrm{~mm} \\
\text { - banco de tubos com } 19 \text { superfícies de cobre } \\
\text { com } 2092 \text { aletas } / \mathrm{m}, D_{e x t}=19,15 \mathrm{~mm}\end{array}$ & $\begin{array}{l}\text { R-12 e R-22 puros e para } \\
\text { misturas destes } \\
\text { refrigerantes com óleo de } \\
\text { lubrificação } /-20{ }^{\circ} \mathrm{C}<T_{\text {sat }} \\
<30{ }^{\circ} \mathrm{C}\end{array}$ \\
\hline Arai et al & 1977 & $\begin{array}{l}\text { - banco de tubos com } 225 \text { superfícies } \\
\text { comerciais Termoexcel-HE, } D_{\text {ext }}=16,4 \mathrm{~mm} \\
\text { - banco de tubos com } 225 \text { superfícies aletadas, } \\
748 \text { aletas } / \mathrm{m}, D_{e x t}=18 \mathrm{~mm}\end{array}$ & $\begin{array}{l}\mathrm{R}-12 \text { e } \mathrm{R}-12 \text { com óleo } \\
\text { lubrificante. } / 0 \text { e } 2^{\circ} \mathrm{C}\end{array}$ \\
\hline $\begin{array}{l}\text { Cornwell e } \\
\text { Schüller }\end{array}$ & 1982 & $\begin{array}{c}\text { - banco de tubos com } 241 \text { superfícies lisas, } \\
D_{e x t}=19 \mathrm{~mm}\end{array}$ & R-113 / $1 \mathrm{~atm}$ \\
\hline Hahne e Müller & 1983 & $\begin{array}{l}\text { - ensaios com } 2 \text { e } 18 \text { tubos para superfícies de } \\
\text { cobre com densidades de aletas iguais a } 767 \\
\text { aletas } / \mathrm{m}, D_{e x t}=18,9 \mathrm{~mm}\end{array}$ & $\mathrm{R}-11 / 1$ bar \\
\hline Hwang e Yao & 1986 & $\begin{array}{l}\text { - banco de tubos composto por superfícies de } \\
\text { aço inoxidável, com } R p=0,3 \mu \mathrm{m} \text { alinhadas } \\
\text { verticalmente e distribuídas em } 3 \text { colunas e } 16 \\
\text { fileiras, } D_{e x t}=19,1 \mathrm{~mm}\end{array}$ & R-113/ 1atm \\
\hline Muller & 1986 & $\begin{array}{l}\text { - Banco com } 18 \text { tubos de cobre ranhurados. } \\
\text { Diâmetro externo superior }=18,9 \mathrm{~mm} \text {, } \\
\text { diâmetro externo inferior }=15,9 \mathrm{~mm} \text {. } \\
\text { Configurações triangular e retangular. Relação } \\
\text { de espaçamento entre tubos }(\mathrm{s} / \mathrm{d}) \text { de } 1,3,1,6 \text { e } \\
\text { 2,0. Fluxo de calor, } \phi \text {, entre } 0,7 \text { e } 50 \mathrm{~kW} / \mathrm{m}^{2} \text {. }\end{array}$ & $\mathrm{R}-11 / 100 \mathrm{kPa}$ \\
\hline Fujita et al & 1987 & $\begin{array}{l}\text { - Banco com } 2 \text { e } 3 \text { tubos de cobre alinhados } \\
\text { verticalmente. } D_{e x t}=25 \mathrm{~mm} \text {. }\end{array}$ & $\begin{array}{l}\mathrm{R}-113 / \\
100,200,500 \text { e } 1000 \mathrm{kPa}\end{array}$ \\
\hline Chan e Shoukri & 1987 & $\begin{array}{l}\text { - superfícies tubulares lisas de alumínio } \\
\text { dispostas conforme as seguintes configurações: } \\
3 \text { tubos verticalmente alinhados; nove } \\
\text { superfícies distribuídas em três linhas e três } \\
\text { colunas; } 27 \text { superfícies distribuídas em nove } \\
\text { linhas e três colunas, } D_{e x t}=19,1 \mathrm{~mm}\end{array}$ & $\mathrm{R}-113$ / $1 \mathrm{~atm}$ \\
\hline Jensen e Hsu & 1988 & $\begin{array}{l}\text { - } 135 \text { tubos de aço inoxidável verticalmente } \\
\text { alinhados distribuídos em } 5 \text { colunas e } 27 \\
\text { linhas, } D_{e x t}=7,94 \mathrm{~mm}\end{array}$ & $\begin{array}{l}\mathrm{R}-113 \mathrm{p} / p_{\text {sat }} \text { igual a } 200, \\
400 \text { e } 500 \mathrm{kPa}\end{array}$ \\
\hline
\end{tabular}


Tabela 2.8 (continuação) Literatura referente à ebulição em banco de tubos

\begin{tabular}{|c|c|c|c|}
\hline Autor & Ano & Características Experimentais & Fluido / $p_{\text {sat }}$ ou $T_{\text {sat }}$ \\
\hline Cornwell & 1990 & $\begin{array}{l}\text { - banco com } 90 \text { tubos de latão, } D_{e x t}=25,4 \mathrm{~mm} \text {, } \\
\mathrm{s} / \mathrm{d}=1,25\end{array}$ & $\mathrm{R}-113 / 1 \mathrm{~atm}$ \\
\hline Hahne et al & 1991 & $\begin{array}{l}\text { - banco com } 2 \text { tubos aletados de cobre, } \\
\mathrm{s} / \mathrm{d}=1,05 \text { e } 3,0\end{array}$ & $\mathrm{R}-11 / 100 \mathrm{kPa}$ \\
\hline Zhang e Orozco & 1991 & $\begin{array}{l}\text { - Banco com } 4 \text { tubos de cobre verticalmente } \\
\text { espaçados. } D_{e x t}=12,7 \mathrm{~mm} \text {. }\end{array}$ & $\mathrm{R}-113 / 1 \mathrm{~atm}$ \\
\hline Danilova et al & 1992 & $\begin{array}{l}\text { - banco de tubos compostos por superfícies de } \\
\text { aço lisas } \\
\text { - banco de tubos composto por superfícies } \\
\text { porosas recobertas com } \mathrm{Al} \text { e } \mathrm{Mg} \text {. } \\
\text { para ambas as configurações os } 12 \text { tubos foram } \\
\text { dispostos segundo triângulos equiláteros em } 5 \\
\text { linhas, } D_{e x t}=20,0 \mathrm{~mm}\end{array}$ & $\begin{array}{l}\text { amônia } \quad \mathrm{e} \\
-20^{\circ} \mathrm{C}<T_{\text {sat }}<20^{\circ} \mathrm{C}\end{array}$ \\
\hline $\begin{array}{l}\text { Marto e } \\
\text { Anderson }\end{array}$ & 1992 & $\begin{array}{l}\text { - banco de tubos formado por } 35 \text { superfícies } \\
\text { de cobre lisas dispostas segundo triângulos } \\
\text { equiláteros distribuídas em } 10 \text { linhas, } D_{e x t}=15,9 \\
\text { mm }\end{array}$ & R-113 / 1atm \\
\hline Gupte & 1992 & $\begin{array}{l}\text { - banco de tubos composto por superfícies } \\
\text { Turbo-B } \\
\text { - banco de tubos composto por superfícies } \\
\text { GEWA-SE. } \\
\text { - banco de tubos composto por superfícies } \\
\text { aletadas com densidade de aletas igual a } 1023 \\
\text { aletas/m } \\
\text { cada banco era composto de } 21 \text { superfícies, } \\
\text { distribuídas segundo triângulos equiláteros em } \\
5 \text { linhas, com } D_{e x t}=19,0 \text { mm }\end{array}$ & $\begin{array}{l}\mathrm{R}-11, \mathrm{R}-123 \text { e R-134a / } \\
4,4^{\circ} \mathrm{C} \text { e } 26,7^{\circ} \mathrm{C}\end{array}$ \\
\hline Memory et al & 1994 & $\begin{array}{l}\text { - banco de tubos formado por } 15 \text { superfícies } \\
\text { Turbo-B localizadas na região central do } \\
\text { banco, e } 20 \text { superfícies lisas localizadas nas } \\
\text { laterais. São dispostas segundo triângulos } \\
\text { equiláteros, num total de } 10 \text { linhas, } D_{\text {ext }}=15,9 \\
\text { mm }\end{array}$ & R-113 / 1atm \\
\hline Webb e Chien & 1994 & $\begin{array}{l}\text { - } 21 \text { superfícies de cobre lisas distribuídas em } \\
6 \text { linhas e posicionados segundo triângulos } \\
\text { equiláteros, } D_{e x t}=16,8 \mathrm{~mm}\end{array}$ & $\begin{array}{l}\mathrm{R}-113 \text { e } \mathrm{R}-123 / 18.9^{\circ} \mathrm{C} \text { e } \\
37.8^{\circ} \mathrm{C}\end{array}$ \\
\hline
\end{tabular}


Tabela 2.8 (continuação) Literatura referente à ebulição em banco de tubos

\begin{tabular}{|c|c|c|c|}
\hline Autor & Ano & Características Experimentais & Fluido / $p_{\text {sat }}$ ou $T_{\text {sat }}$ \\
\hline Li e Hahne & 1995 & $\begin{array}{l}\text { - banco de tubos composto por superfícies } \\
\text { de cobre com densidade de aletas igual a } \\
1023 \text { aletas } / \mathrm{m} \text {, posicionadas em linha } \\
\text { verticalmente distribuídas em } 3 \text { colunas e } 6 \\
\text { linhas, } D_{\text {ext }}=18,8 \mathrm{~mm}\end{array}$ & $\mathrm{R}-11 / 100 \mathrm{kPa}$ \\
\hline Gupta et al & 1995 & $\begin{array}{l}\text { - Banco com } 2 \text { e } 3 \text { tubos de aço inox. } \\
D_{\text {ext }}=19,05 \mathrm{~mm}, \mathrm{~s} / \mathrm{d} \text { entre } 1,5 \text { e } 6,0\end{array}$ & $\begin{array}{l}\text { Água desitlada/ } \\
100,19 \mathrm{kPa}\end{array}$ \\
\hline Cheung et al & 1995 & $\begin{array}{l}\text { - Banco com } 7 \text { tubos de cobre aletados, } \\
\text { configuração triangular. } D_{e x t}=19 \mathrm{~mm}\end{array}$ & $\mathrm{R}-134 \mathrm{a} / 20^{\circ} \mathrm{C}$ \\
\hline Memory et al & $1995 b$ & $\begin{array}{l}\text { - banco de tubos composto por superfícies } \\
\text { GEWA-K } D_{e x t}=12,9 \mathrm{~mm} \\
\text { - banco de tubos composto por superfícies } \\
\text { Turbo B, } D_{e x t}=15,9 \mathrm{~mm} \text {. } \\
\text { - banco de tubos composto por superfícies } \\
\text { HighFlux, } D_{e x t}=15,7 \mathrm{~mm} \\
\text { cada banco de tubos é formado por } 15 \\
\text { superfícies intensificadoras localizadas na } \\
\text { região central do banco, e } 20 \text { superfícies lisas } \\
\text { localizadas nas laterais, cujo } D_{\text {ext }}=15,9 \text { mm. } \\
\text { São dispostas segundo triângulos equiláteros, } \\
\text { num total de } 10 \text { linhas. }\end{array}$ & $\begin{array}{l}\text { R-114, e mistura composta } \\
\text { por R-114 e óleo } \\
\text { lubrificante / } 1 \text { atm }\end{array}$ \\
\hline Roser et al & 1999 & $\begin{array}{l}\text { - banco de tubos composto por } 45 \\
\text { superfícies de cobre com } R_{a}=0,4 \mu \mathrm{m} \\
\text { distribuídas em } 18 \text { linhas e cinco colunas } \\
\text { arranjadas segundo triângulos eqüiláteros }\end{array}$ & $\begin{array}{l}\text { n-pentano/ 200, } 300 \quad \mathrm{e} \\
500 \mathrm{kPa}\end{array}$ \\
\hline Liu e Qiu & 2002 & $\begin{array}{l}\text { - Banco de tubos composto por tubos de } \\
\text { cobre lisos e ranhurados. Diâmetro } \\
\text { externo }=18 \mathrm{~mm} \text {, comprimento } \\
\text { aquecido }=100 \mathrm{~mm} .17 \text { tubos em } \\
\text { configuração triangular. Espaçamento } \\
\text { entre tubos de } 0,5,1 \text { e } 4 \mathrm{~mm} \text { ( } / \mathrm{d}= \\
1,028,1,056 \text { e } 1,22) \text {. Fluxo de calor, } \phi \\
\text { entre } 3 \text { e } 300 \mathrm{~kW} / \mathrm{m}^{2} \text {. }\end{array}$ & $\begin{array}{l}\text { Água destilada / 101,325 } \\
\mathrm{kPa} \\
\text { Água com NaCl (10\% em } \\
\text { massa) }\end{array}$ \\
\hline
\end{tabular}


Tabela 2.8 (continuação) Literatura referente à ebulição em banco de tubos

\begin{tabular}{|c|c|c|c|}
\hline Autor & Ano & Características Experimentais & Fluido / $p_{\text {sat }}$ ou $T_{\text {sat }}$ \\
\hline Kumar et al & 2002 & $\begin{array}{l}\text { - Banco de tubos com duas superfícies } \\
\text { cilíndricas de cobre ranhuradas. Diâmetro } \\
\text { externo de } 32 \mathrm{~mm} \text {, comprimento aquecido } \\
\text { de } 100 \mathrm{~mm} \text {, dispostos verticalmente em } \\
\text { linha., fluxo de calor, } \phi \text {, entre 19-45 } \\
\mathrm{kW} / \mathrm{m}^{2} \text {. }\end{array}$ & $\begin{array}{l}\text { Benzeno } \\
\text { Tolueno } \\
\text { Água destilada / 35,36- } \\
97,5 \mathrm{kPa} \\
\text { R-113 }\end{array}$ \\
\hline Hsieh et al & 2003 & $\begin{array}{l}\text { - banco de tubos compostos de superfícies } \\
\text { cilíndricas de cobre lisas }(\mathrm{Ra}=0,07 \mu \mathrm{m}) \mathrm{e} \\
\text { porosas. } 15 \text { tubos em configurações } \\
\text { triangular, retangular, horizontal e vertical } \\
\text { em linha. } 6 \text { tubos aquecidos. Espaçamento } \\
\text { entre tubos, } \mathrm{s} / \mathrm{d}=1,5 \text {. Fluxo de calor, } \phi, \\
\text { entre } 0,1 \text { e } 30 \mathrm{~kW} / \mathrm{m}^{2} \text {. }\end{array}$ & $\mathrm{R}-134 \mathrm{a} . / 536,06 \mathrm{kPa}$ \\
\hline Silva & 2005 & $\begin{array}{l}\text { - Banco de tubos com } 3 \text { superfícies de cobre } \\
\text { lisas }(\mathrm{Ra}=0,12 \mu \mathrm{m}) \text {. Espaçamentos entre } \\
\text { tubos, s/d }=1,32 ; 1,53 \text { e } 2,00 \text {. Fluxo de } \\
\text { calor, } \phi \text {, entre } 1 \text { e } 40 \mathrm{~kW} / \mathrm{m}^{2} \text {. }\end{array}$ & $\begin{array}{l}\mathrm{R}-123 / \quad 84,4 ; 128,4 \mathrm{e} \\
231,1 \mathrm{kPa}\end{array}$ \\
\hline
\end{tabular}

\subsection{Conclusões Gerais}

Com base na presente revisão bibliográfica envolvendo a análise da influência do diâmetro do tubo no coeficiente de transferência de calor, os fatores que podem influenciar a ebulição em banco de tubos e as correlações para o coeficiente de transferência de calor, foi possível extrair as seguintes conclusões:

- A influência do diâmetro do tubo no coeficiente de transferência de calor tem sido pouco estudada, sendo raros os trabalhos analisando este parâmetro.

- Em ebulição em banco de tubos, a região de ebulição nucleada parcial, onde o fluxo de calor é relativamente baixo, parece ser mais influenciada pelo posicionamento dos tubos. Nesta região, todos autores mostraram que tubos 
de fileiras superiores apresentam desempenho superior àquele da fileira inferior. Para região de ebulição nucleada plenamente desenvolvida, representada por fluxos de calor elevados, o coeficiente de transferência de calor é aproximadamente igual para todos os tubos, independente da localização.

- Ainda existem algumas divergências qualitativas e quantitativas a respeito da influência do espaçamento entre tubos, podendo este parâmetro afetar significativamente a transferência de calor.

- Os autores, apesar de poucos, que analisaram a influência da configuração do banco de tubos, mostraram que este parâmetro afeta de forma limitada o coeficiente de transferência de calor.

- Para a ebulição em banco de tubos, com o aumento da pressão, diminui a relação entre o coeficiente de transferência de calor médio e aquele a um tubo aquecido isoladamente $\left(\overline{h_{B}} / h_{1}\right)$.

- Os trabalhos da literatura mostram que o coeficiente de transferência de calor médio aumenta com a velocidade mássica $(G)$. No entanto, os coeficientes de transferência de calor de tubos de distintas fileiras são próximos. 


\section{3 - DESCRIÇÃO DO APARATO EXPERIMENTAL E PROCEDIMENTOS DE ENSAIO}

\subsection{Aparato experimental}

$\mathrm{O}$ aparato experimental utilizado foi desenvolvido com a finalidade de estudar e analisar a transferência de calor em ebulição nucleada. A bancada atual permite a realização dos seguintes ensaios:

- Ensaios envolvendo diferentes refrigerantes para uma ampla faixa de pressões.

- Análise do efeito do óleo de lubrificação na ebulição nucleada de refrigerantes.

- Estudo dos mecanismos de transferência de calor em ebulição nucleada para um único tubo e para banco de tubos.

- Estudos envolvendo a visualização do fenômeno, através de filmagens e fotografias.

- Análise do desempenho térmico de superfícies com diferentes acabamentos superficiais e diâmetros.

O aparato experimental é composto basicamente por três sistemas de rejeição de calor (dois para resfriamento da mistura de etileno-glicol e água, e um para estudo da ebulição nucleada) e um conjunto de auto transformadores (variacs) para a alimentação das resistências elétricas. A Figura 3.1 ilustra um diagrama esquemático e a Fig. 3.2 ilustra uma fotografia do aparato experimental utilizado para estudo de ebulição de um único tubo. A seguir serão descritos os distintos componentes do mesmo. 


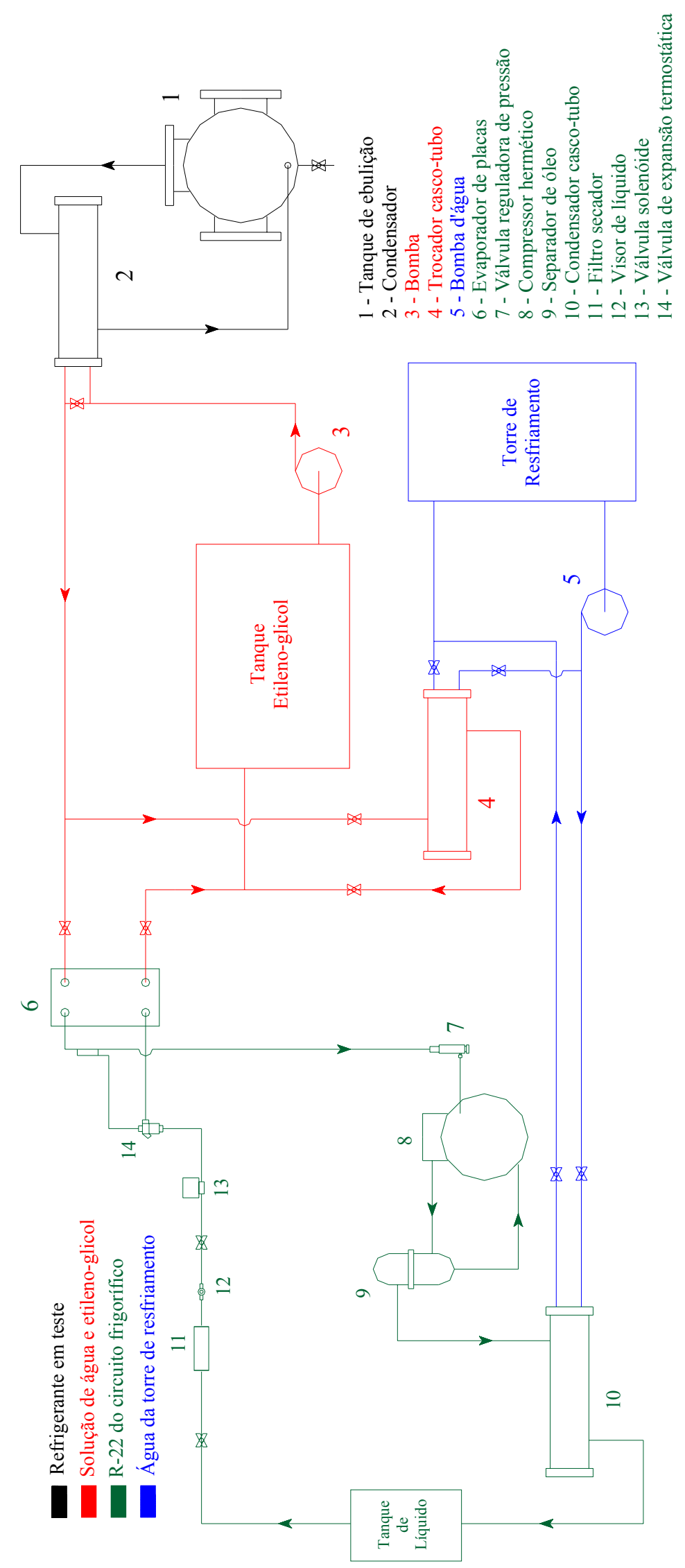

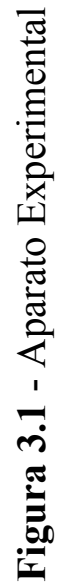




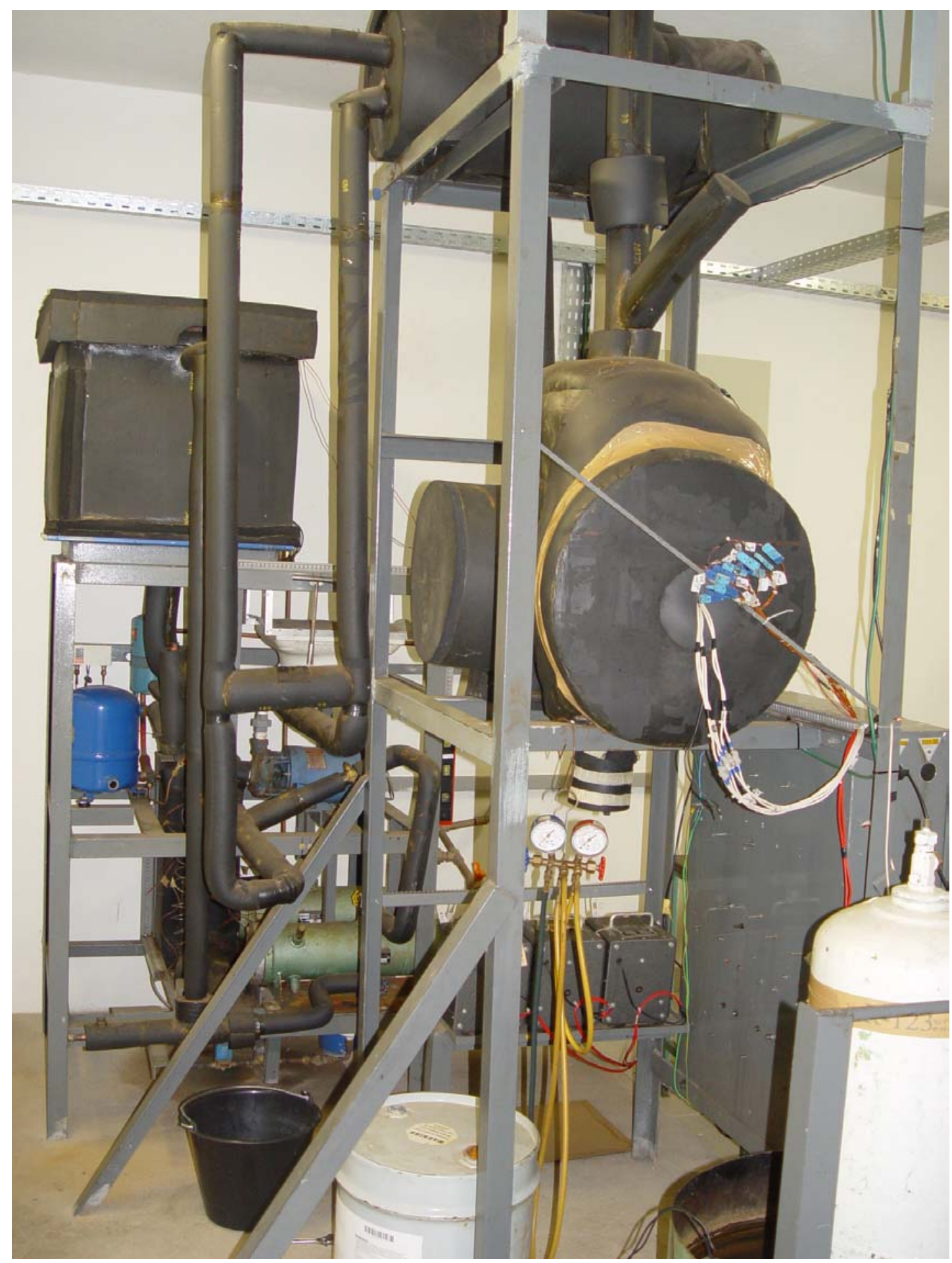

Figura 3.2 Fotografia do aparato experimental 


\subsubsection{Circuito resfriador de líquido}

Seu objetivo é resfriar a solução de água e etileno-glicol e, conseqüentemente, permitir a condensação do vapor gerado no tanque de ebulição. Este sistema pode ser dividido em dois sub-sistemas que atuam alternadamente através de manobra de válvulas: o primeiro, consistindo de um circuito frigorífico que opera para temperaturas reduzidas na cuba de ebulição, composto basicamente por condensador e evaporador do tipo placas, uma válvula de expansão, um compressor hermético com capacidade de $1,7 \mathrm{~kW}$ a $-23^{\circ} \mathrm{C}$ e uma válvula reguladora de pressão, localizada na linha de sucção do compressor, com a função de protegê-lo quando em condições de pressão elevada no evaporador. A condensação do refrigerante ocorre no condensador secundário, com a utilização de água proveniente de uma torre de resfriamento. O refrigerante utilizado é o R-22. O segundo subsistema opera em temperaturas elevadas na cuba de ebulição, sendo composto basicamente por um trocador tipo casco-tubo, que resfria a solução anti congelante com água proveniente da torre de resfriamento. A vazão de água, neste trocador, é controlada através do fechamento e abertura de uma válvula de agulha. Em paralelo a esta válvula, encontra-se uma válvula de esfera utilizada para resfriamentos rápidos da solução anti-congelante.

\subsubsection{Circuito de solução anticongelante (etileno-glicol e água)}

No interior deste circuito circula uma mistura composta por etileno-glicol ( $40 \%$ em volume) e água ( $60 \%$ em volume), podendo-se, com isso, atingir uma temperatura de aproximadamente $-25^{\circ} \mathrm{C}$. A função deste circuito é a de condensar o vapor gerado no tanque de ebulição. É composto por um tanque com capacidade de armazenamento de 100 litros, uma bomba e tubulações de cobre com diâmetro de 3/4". No interior do tanque, foram instalados uma resistência elétrica(5000W/220V) e uma termo resistência de platina (pt100). Estes componentes estão conectados a um 
controlador eletrônico, que permite controlar a temperatura da mistura e conseqüentemente a pressão do refrigerante na cuba de ebulição.

\subsubsection{Seção de testes}

A seção de testes é ilustrada na Fig. 3.3, sendo composta basicamente pela cuba de ebulição (isolada termicamente e com duas janelas de vidro para a visualização dos fenômenos), superfície de troca de calor (que pode ser alterada), um condensador e tubulações. Todos os componentes estão isolados termicamente.

A cuba de ebulição foi construída em aço carbono, tendo sido testada hidrostaticamente para uma pressão de 3,1 MPa. A Figura 3.3 ilustra um esquema da seção de testes; podendo-se visualizar o condensador, a cuba de ebulição, a superfície de testes, entrada e saída da solução anticongelante, fios para ligação da resistência elétrica interna da superfície de teste ao autotransformador (variac) e o dreno para enchimento e esvaziamento do circuito.

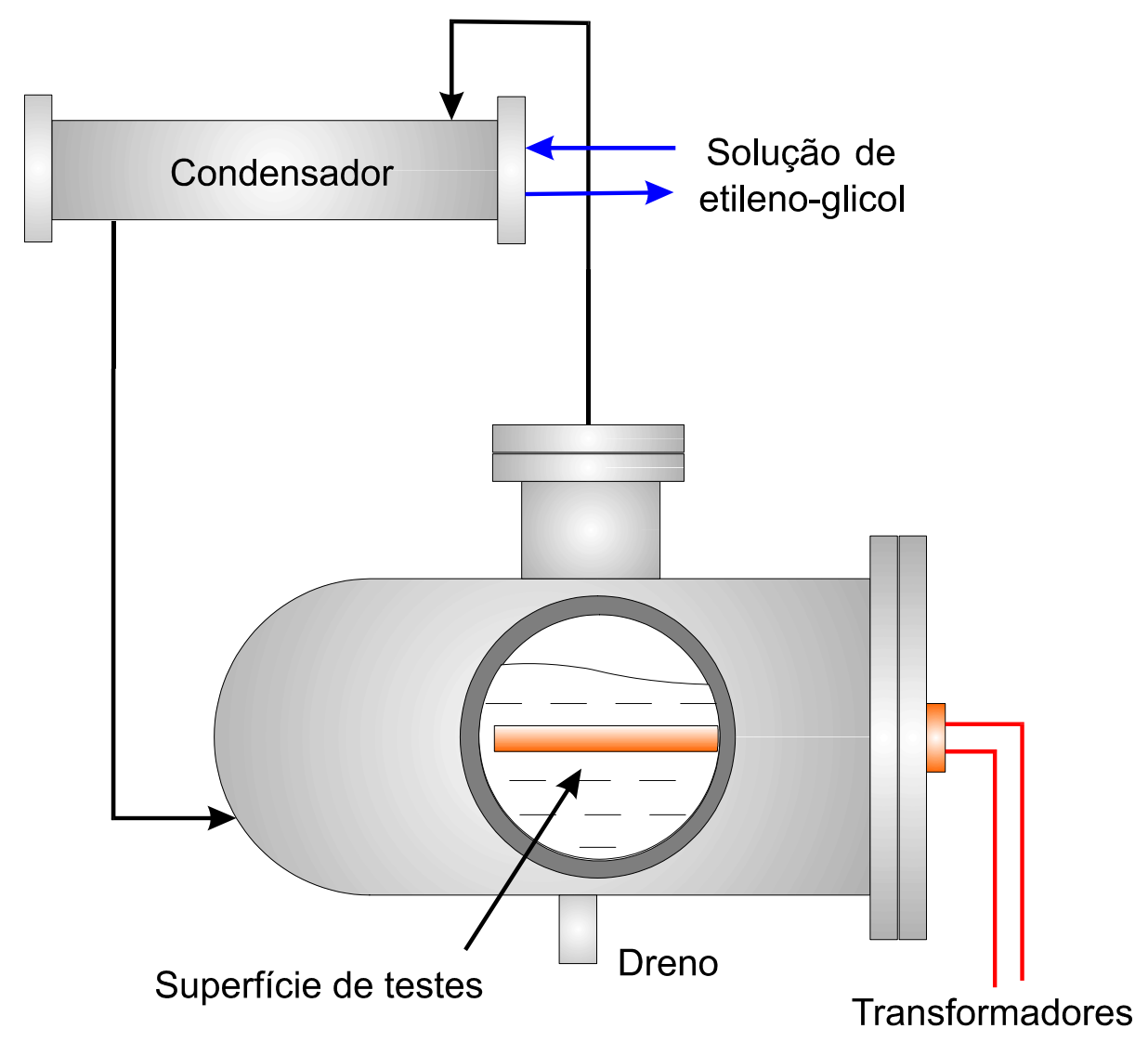

Figura 3.3 Representação esquemática da seção de testes 
A tubulação interligando a cuba de ebulição e o condensador principal foi construída em cobre, sendo dotada de válvulas de esfera que permitem isolar estes componentes. No condensador e na cuba de ebulição foram conectadas válvulas de segurança do tipo plugue, "fusível", selecionadas para uma temperatura de saturação algo superior à máxima de ensaios. Para os refrigerantes mais voláteis, optou-se por válvulas que atuam para uma temperatura de $73^{\mathrm{O}} \mathrm{C}$, correspondendo, para o R-22, um refrigerante de alta pressão, um valor de $p_{\text {sat }}$ de aproximadamente $3 \mathrm{MPa}$, adequando-se ao equipamento e aos objetivos deste trabalho. Já, para ensaios com refrigerantes pouco voláteis, optou-se por válvulas que atuam a uma temperatura de $103^{\circ} \mathrm{C}$, permitindo, desta forma, levantar resultados experimentais para pressões superiores.

Uma resistência elétrica de $1500 \mathrm{~W} / 220 \mathrm{~V}$, acessível através da tampa da cuba, foi instalada com o objetivo de auxiliar a retirada do refrigerante do circuito e permitir, no caso de ensaios com temperaturas elevadas, um rápido aquecimento do refrigerante.

\subsubsection{Superfícies de transferência de calor}

Foram construídas três diferentes superfícies de testes com o objetivo de analisar os efeitos do diâmetro do tubo no coeficiente de transferência de calor em ebulição. Internamente, estas superfícies apresentam ranhuras obtidas através do processo de eletro-erosão. Termopares do tipo T de cobre-constantan, utilizados para a medida da temperatura superficial, são fixados nas ranhuras através de um "cimento térmico".

Nas superfícies testadas anteriormente (Silva 2002) foram abertos um total de oito canais, sendo fixados oito termopares. O objetivo foi o de avaliar efeitos de condução axial e verificar diferenças de temperaturas para uma mesma seção, ao longo da superfície externa do tubo, resultantes do mecanismo de ebulição nucleada. A partir desta avaliação constatou-se que, como seria esperado, os termopares na região central do tubo apresentaram menores perdas longitudinais, conforme 
mostrado por Ribatski (2002). Com isso, as superfícies posteriores foram construídas somente com quatro ranhuras, onde se fixaram os termopares na região central dos tubos. A Tabela 3.1 e a Fig.3.4 apresentam as características das superfícies de testes e as posições onde se encontram alojados os termopares.

No interior da superfície de testes foi alocada a resistência elétrica, do tipo cartucho, responsável pelo aquecimento da superfície de ensaio. Após fixar a resistência elétrica, o espaço livre em uma das extremidades da superfície de testes foi preenchido com giz (com objetivo de reduzir as perdas longitudinais), soldandose, em seguida, uma chapa de material semelhante ao da superfície de teste, que tinha, desta forma, vedada uma das suas extremidades.

Tabela 3.1 Características das superfícies de testes

\begin{tabular}{|c|c|c|c|}
\hline Dimensões (mm) & Superfície 1 & Superfície 2 & Superfície 3 \\
\hline A & 255 & 180 & 255 \\
\hline B & 35 & 35 & 15 \\
\hline C & 105 & 66 & 109 \\
\hline D & 105 & 65 & 111 \\
\hline$\phi_{\text {ext }}$ & 19,05 & 12,7 & 22 \\
\hline
\end{tabular}

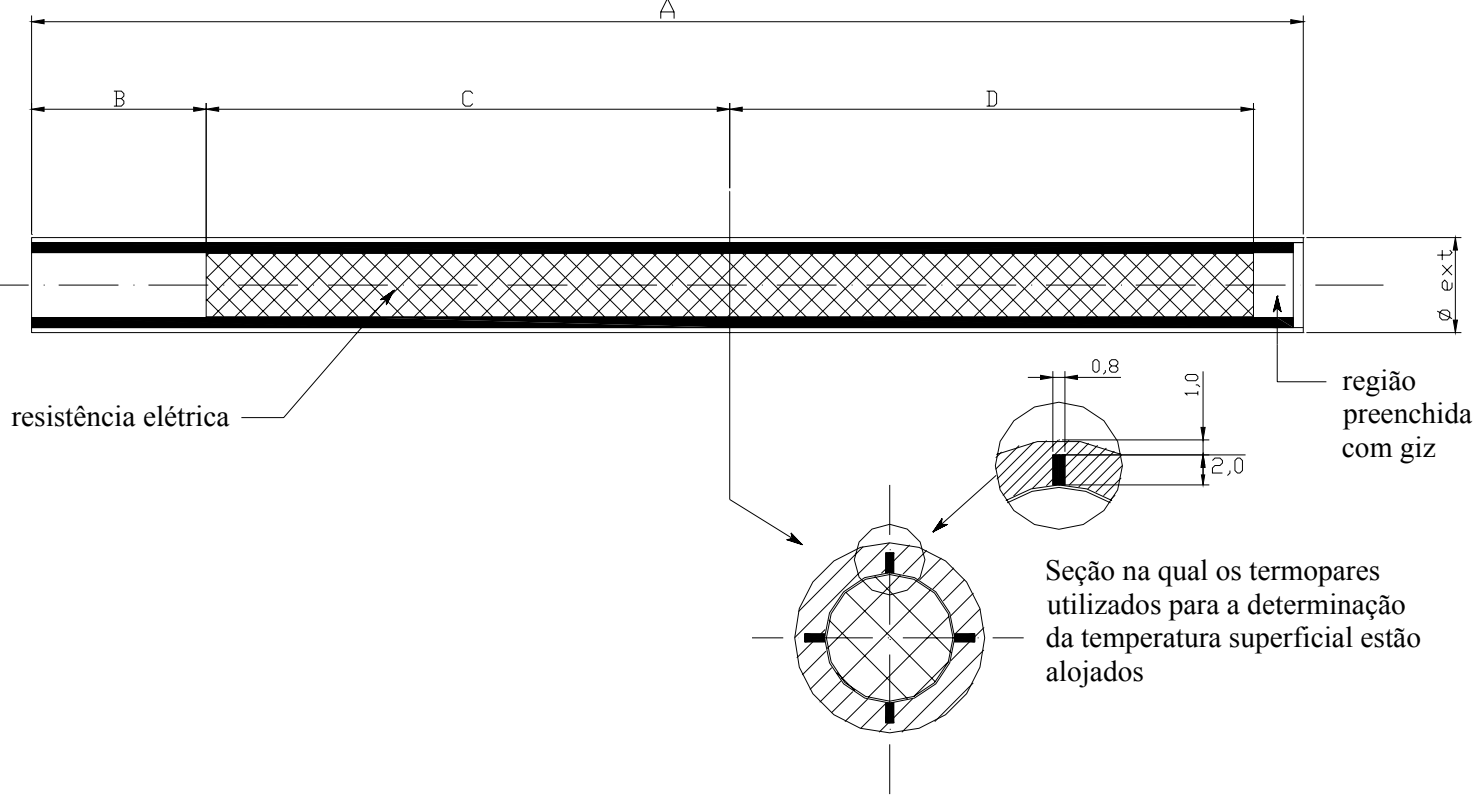

Figura 3.4 Detalhes da superfície de testes, mostrando o posicionamento dos termopares. 
A sustentação da superfície de testes foi feita através de um suporte de latão dotado de um flange e fixado por intermédio de parafusos à tampa da cuba. A superfície de teste foi fixada neste suporte, através de dispositivo composto por uma peça de latão externa e um anel de teflon, com uma das extremidades chanfrada. Este, além de reduzir a condução axial de calor da superfície de testes para o suporte, tinha o papel de junta de vedação ao ser pressionado contra a superfície cônica interna do suporte, através da peça externa. A montagem da superfície de testes no suporte e sua fixação no interior da cuba de ebulição são, esquematicamente, ilustrados na Fig. 3.5.

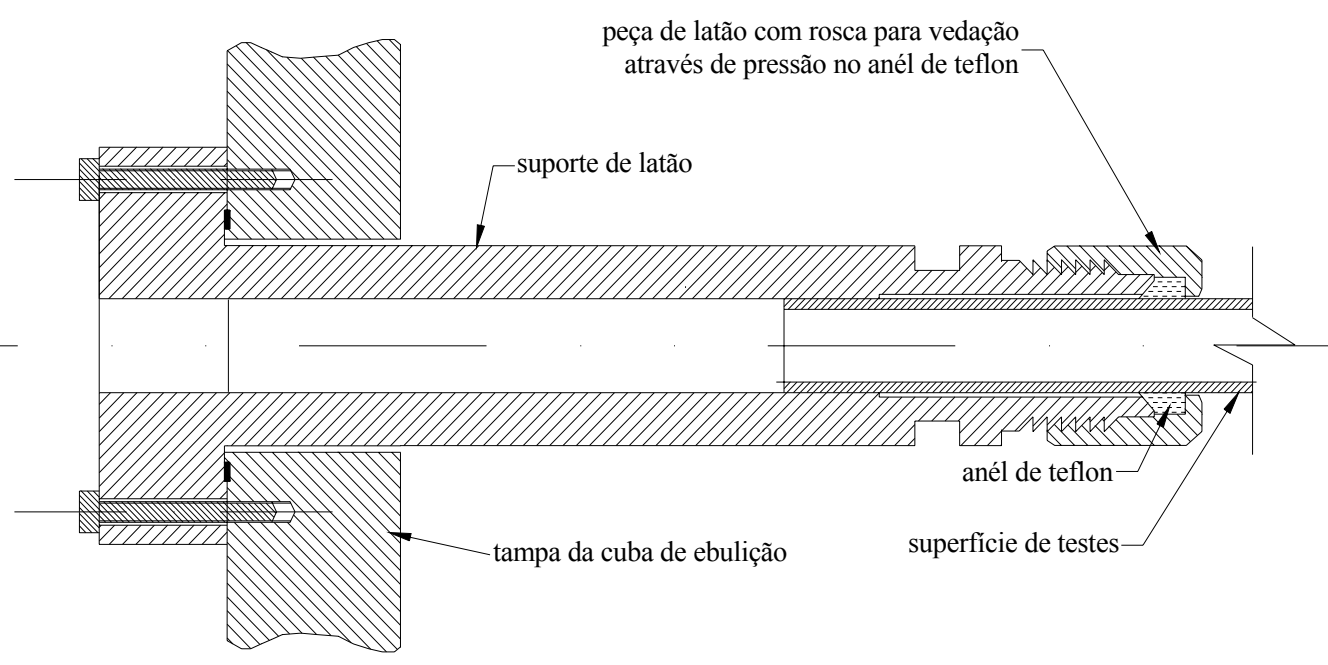

Figura 3.5 Montagem da superfície de ensaio

\section{Banco de tubos}

Para a investigação em mais de um tubo (banco de tubos) foram utilizados tubos de latão com dimensões iguais à da superfície 1 mostrada na Tabela 3.1. Foi construído um suporte em latão para fixação dos tubos semelhante ao utilizado para um único tubo, com diâmetro maior, conforme ilustrado nas Figs. 3.6, 3.7, 3.8, 3.9, 3.10 e 3.11. Optou-se por construir um suporte com noves furos, dos quais três são fixados os tubos de ensaios e nos restantes são fixados tubos com comprimentos 
menores $(60 \mathrm{~mm})$, com a finalidade de investigar a influência do espaçamento entre tubos, tornando o suporte construtivamente mais econômico e versátil. Na Figura 3.6, observa-se que as distâncias entre centros dos furos alinhados são iguais, mas diferem de um alinhamento para outro. Com isso, em cada bateria de teste, são inseridos 2 ou 3 tubos alinhados, sendo os furos restantes vedados através de pseudos tubos (tubos com comprimento igual a $20 \mathrm{~mm}$ ), de modo que não influenciem nos testes. Para vedação e posicionamento correto dos tubos, utilizou-se uma tampa lateral de latão chanfrada nos furos, fixada no suporte através de parafusos de aço inoxidável, conforme mostrado nas Figs. 3.7 e 3.8. Nesses chanfros são inseridos anéis de teflon, com a finalidade de vedacão e alinhamento dos tubos.

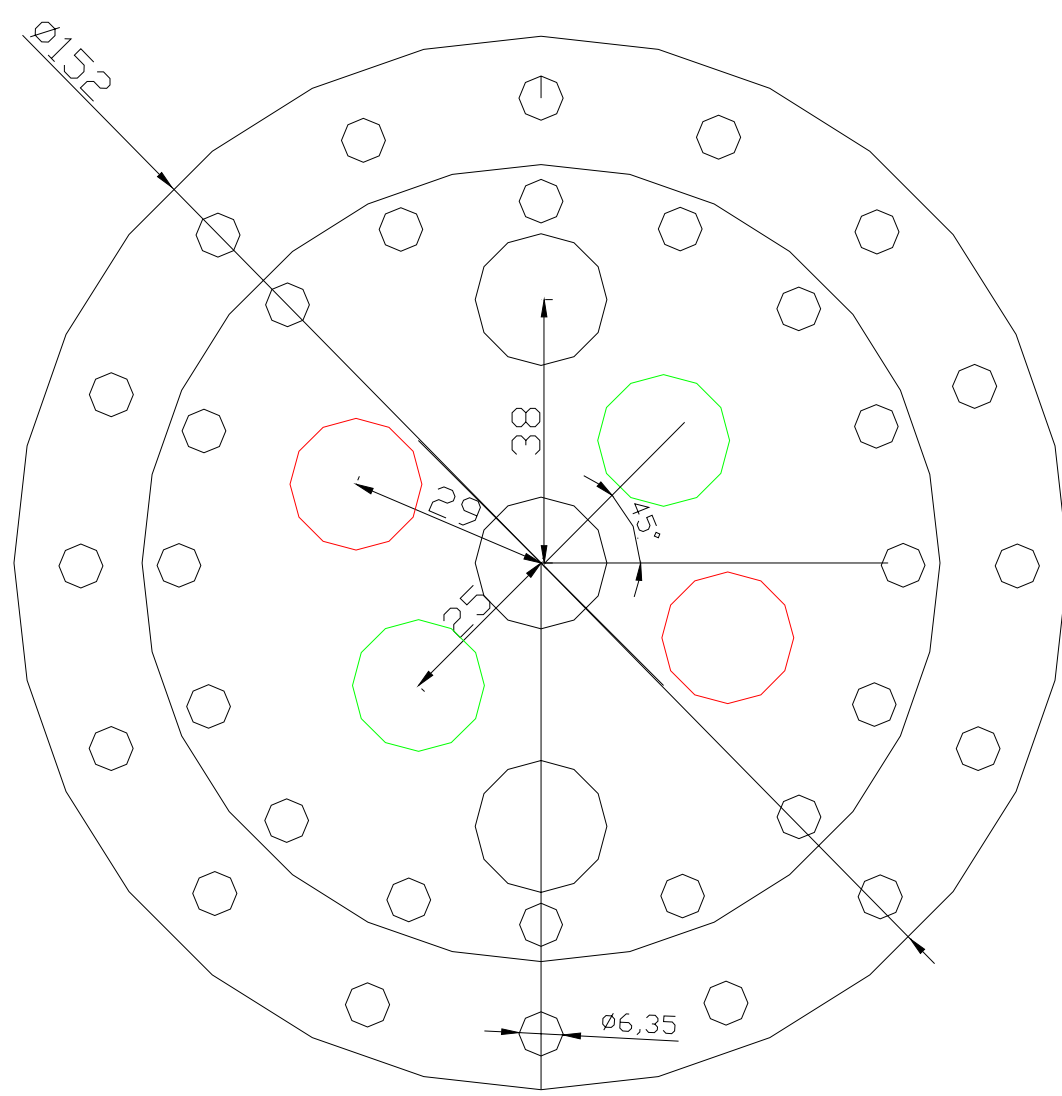

Figura 3.6 Detalhe ilustrativo da tampa lateral para fixação e vedação dos tubos. 

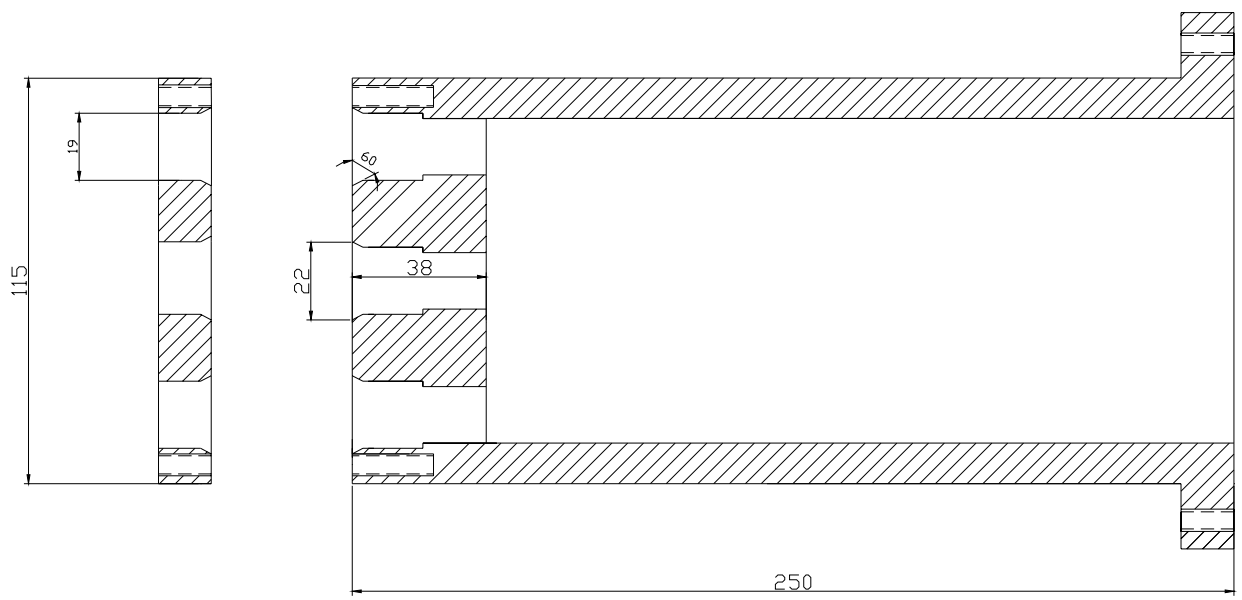

Figura 3.7 Detalhe ilustrativo do suporte de latão para fixação dos tubos.

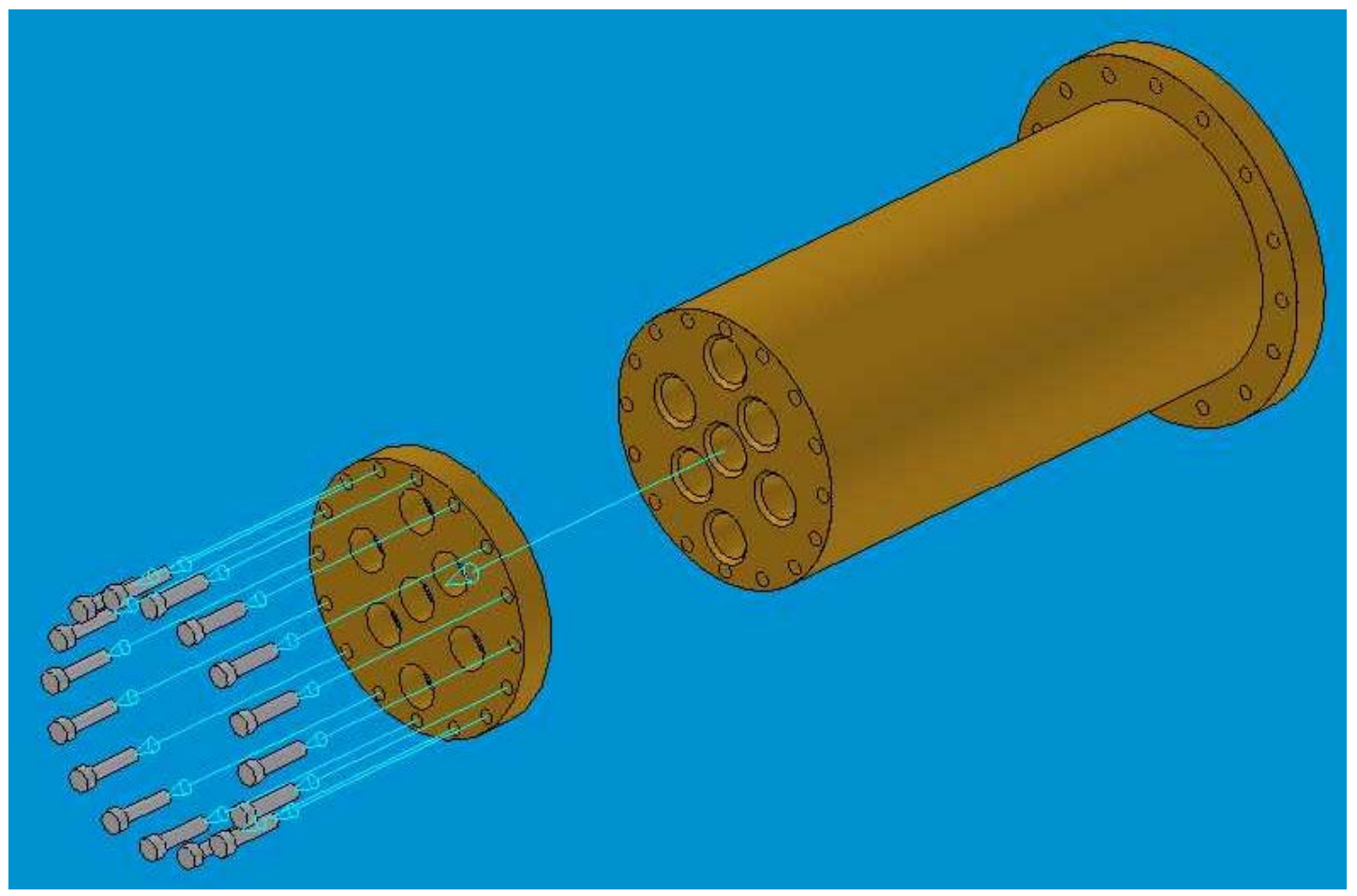

Figura 3.8 Ilustração do suporte de latão e tampa lateral para fixação dos tubos 


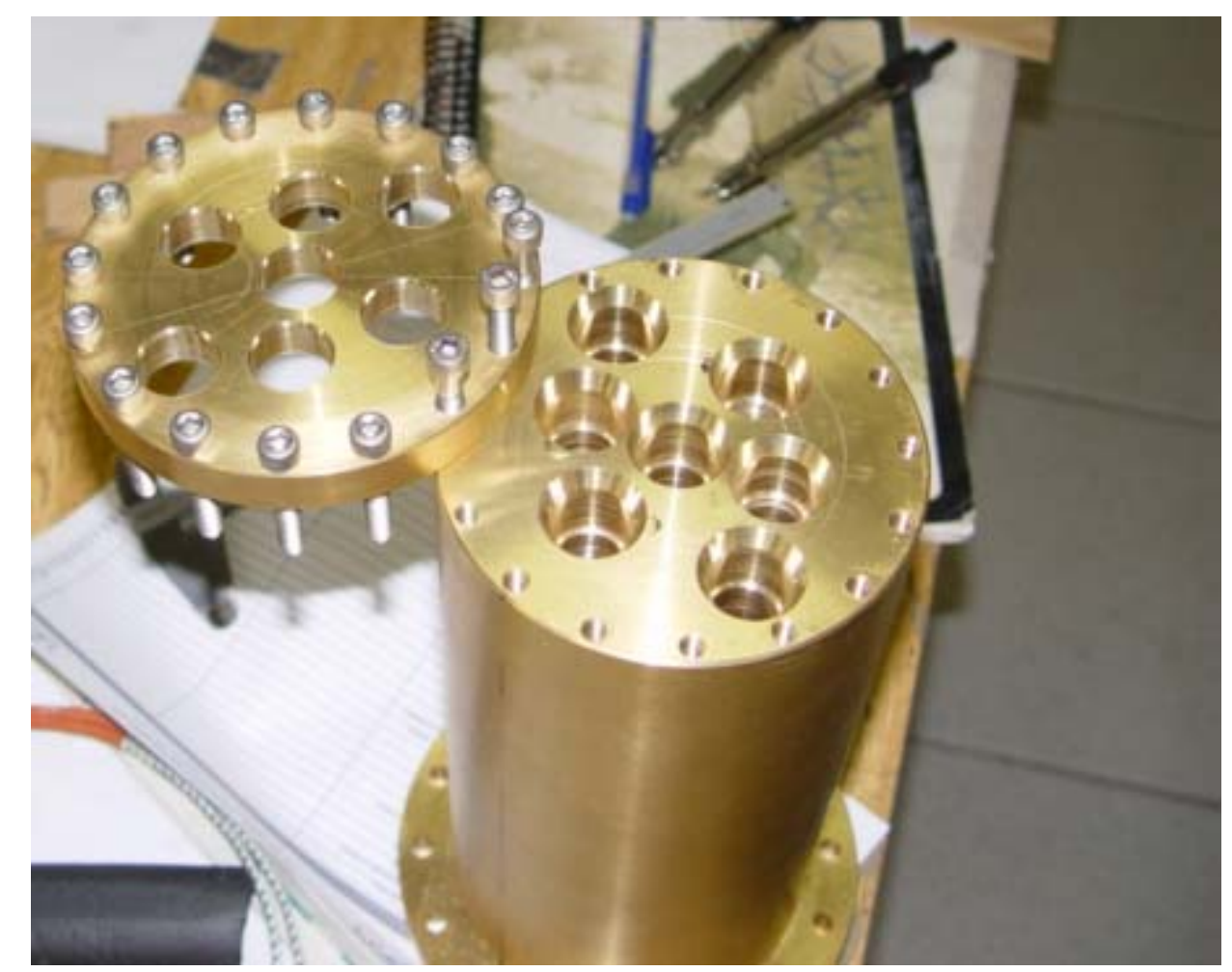

Figura 3.9 Fotografia do suporte de latão e tampa lateral para fixação dos tubos

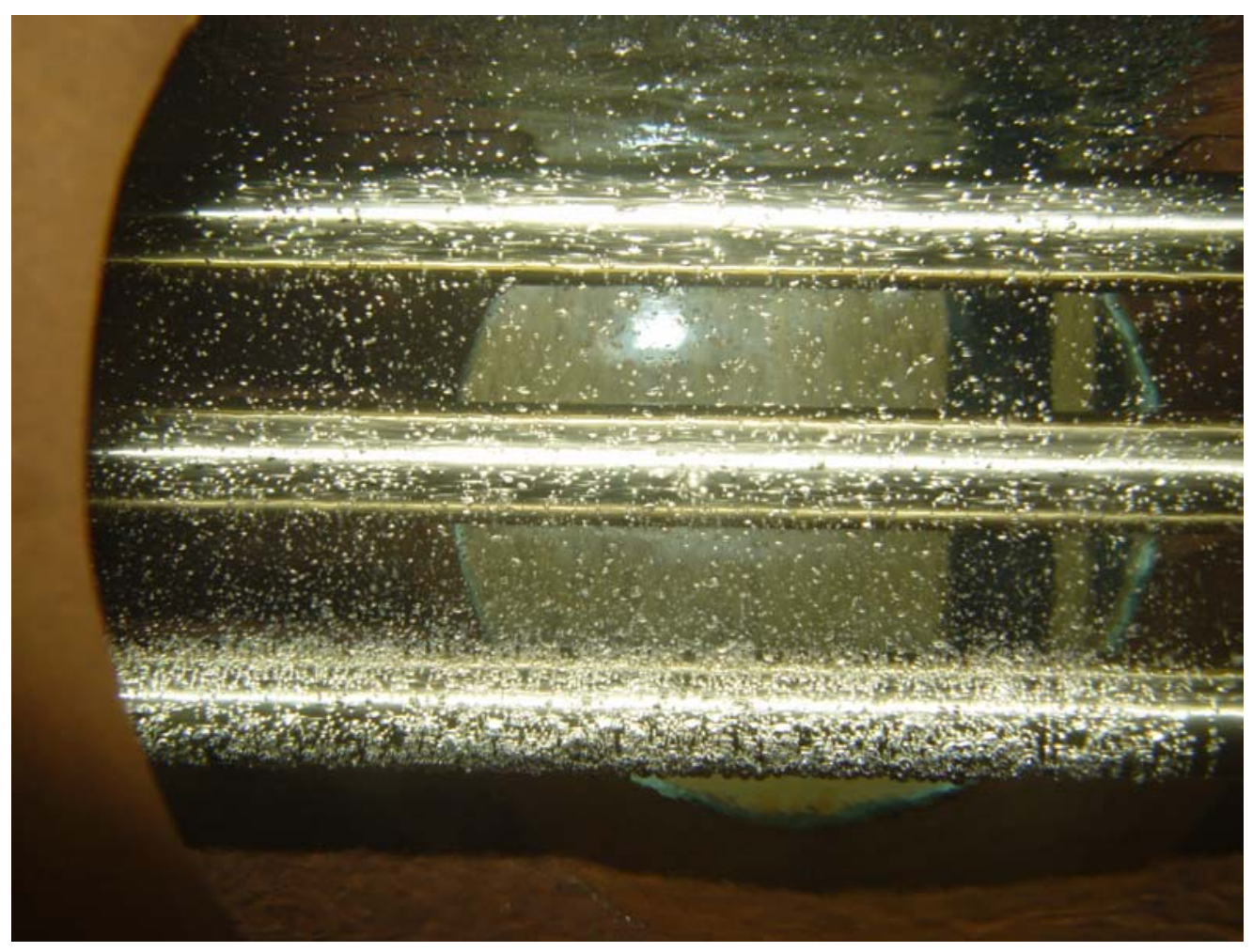

Figura 3.10 Fotografia do banco de tubos. R-123, $\mathrm{p}_{\mathrm{r}}=0,062, \phi=25 \mathrm{~kW} / \mathrm{m}^{2}$ (Tubo de latão, inferior aquecido) 


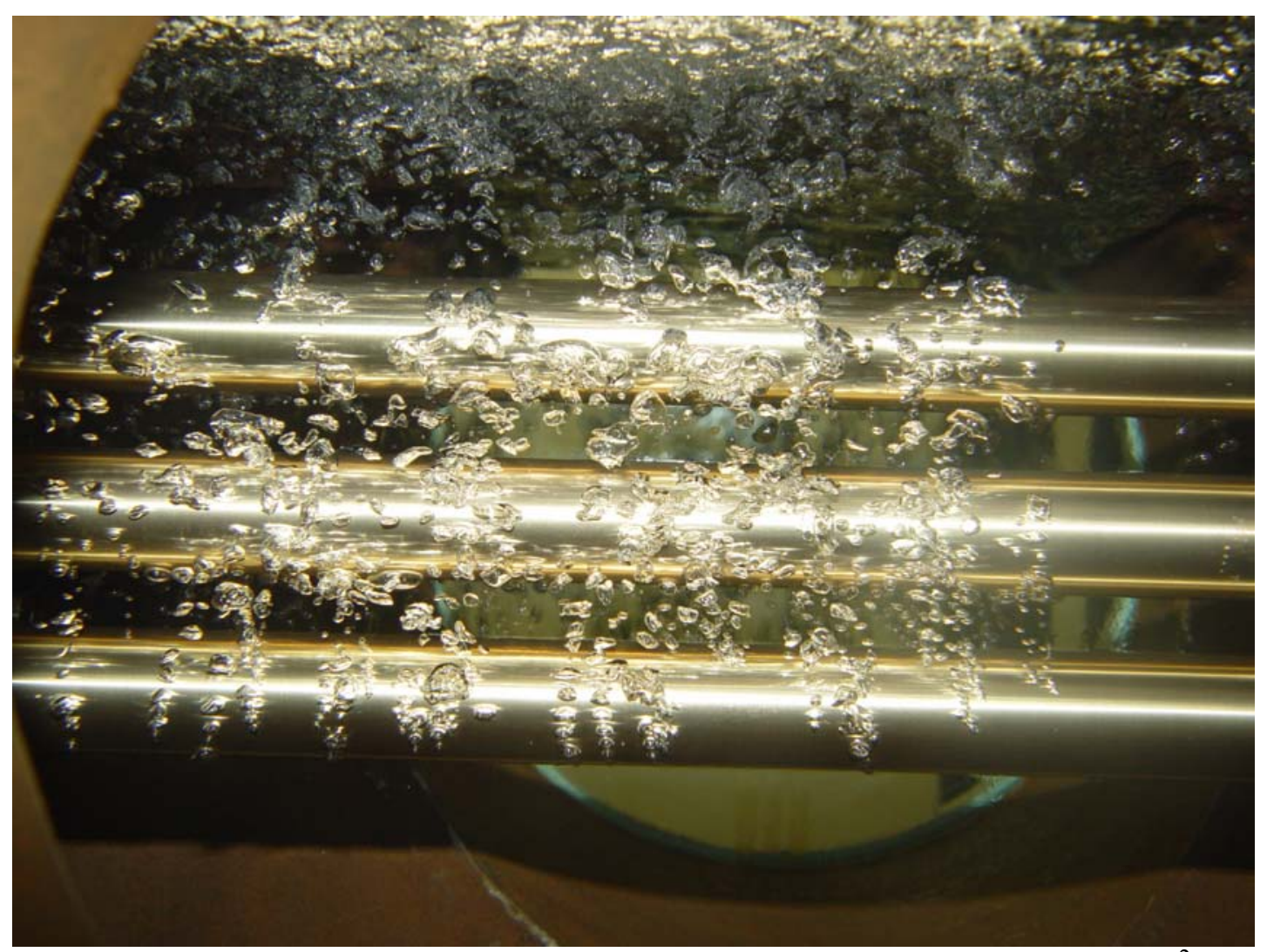

Figura 3.11 Fotografia do banco de tubos. R-123, $\mathrm{p}_{\mathrm{r}}=0,023, \phi=10 \mathrm{~kW} / \mathrm{m}^{2}$ (Tubos de latão, inferior e intermediário aquecidos)

\subsection{5 - Sistema de Aquecimento Elétrico}

O fluxo de calor, através da superfície de ensaio foi determinado por um autotransformador que alimenta a resistência elétrica. No presente trabalho, o fluxo de calor específico máximo na superfície de testes foi estabelecido como sendo da ordem de 90 e $120 \mathrm{~kW} / \mathrm{m}^{2}$, respectivamente, para os tubos de latão e cobre aquecidos isoladamente e $40 \mathrm{~kW} / \mathrm{m}^{2}$ para o banco de tubos. Efeitos de campo elétrico na superfície externa foram eliminados através do aterramento direto da superfície de cobre, localizada entre a resistência elétrica e a superfície de testes. Este procedimento foi adotado, pois tanto a resina de epoxi quanto a graxa condutora, substâncias que evitam o contato físico direto com o equipamento, apresentam características de isolamento elétrico. 


\subsection{6 - Instrumentação}

O conjunto de equipamentos para instrumentação visa, basicamente, a determinação do superaquecimento da parede e a potência fornecida às superfícies de transferência de calor. Isto permite o levantamento das curvas de ebulição (fluxo de calor vs superaquecimento da superfície) para uma determinada pressão. Para as medidas de temperatura foram utilizados termopares do tipo T (cobre-constantan), adequados às aplicações deste trabalho. Os fios dos termopares para determinação da temperatura na superfície de testes apresentam diâmetro igual a $1 \mathrm{~mm}$, sendo encapados com material plástico. A temperatura nas regiões inundada (líquida) e seca (vapor) da cuba de ebulição, são obtidas através de termopares blindados com isolação mineral. São 14 o total de pontos de medida de temperatura diretamente relacionados com o presente estudo. Foi também determinada a temperatura no interior do reservatório da solução de etileno-glicol e água. Os resultados fornecidos pelos termopares blindados (embora possam apresentar pequena diferença devido ao efeito de coluna do refrigerante) podem ser contrastados com a temperatura de saturação, avaliada por intermédio da pressão na cuba, lida através do transdutor de pressão, com fundo de escala de $1300 \mathrm{kPa}$.

A medida da potência elétrica e, indiretamente, do fluxo de calor, é efetuada por intermédio de um amperímetro e um voltímetro de precisão.

Os sinais elétricos resultantes dos transdutores são processados por um sistema de aquisição de dados da marca STRAWBERRY TREE, USA, incluindo 2 terminais de temperatura para 8 canais cada um (12 bits de resolução), 1 terminal para sinais elétricos com 8 canais e 2 placas conversoras A/D, de 16 canais cada uma, além do "software" "Work Bench for Windows 3.11". Os sinais provenientes das placas conversoras são processados por um computador modelo IBM PC 486 DX4 100Mhz. 


\subsection{Preparação da bancada}

Diversas precauções eram tomadas antecedendo os testes experimentais. Entre estas, destacam-se: a limpeza do sistema, garantia de ausência de ar, determinação das características superficiais (rugosidade) e paralelismo entre tubos.

\subsubsection{Carregamento do Sistema}

Antes do enchimento da cuba de ebulição com o refrigerante, foram tomados cuidados relativos à limpeza do sistema e à possível ocorrência de vazamentos. A existência, tanto de óleo como de partículas sólidas, pode alterar os resultados. A verificação da existência de vazamentos foi efetuada não só para evitar fugas de refrigerante mas também para não permitir uma possível entrada de ar no sistema. Isto ocorreria para o caso de ensaios com refrigerantes pouco voláteis, para os quais a operação pode envolver pressões inferiores à atmosférica. Para esta situação, a pressão na cuba seria igual à soma das pressões parciais do refrigerante e do ar existente no sistema, resultando em uma estimativa errônea da pressão de saturação.

Previamente a cada condição de ensaio, caracterizada pelo refrigerante, a superfície de testes e seu acabamento superficial, lavava-se a cuba de ebulição com R-11. Em seguida, ela era vedada através da fixação da sua tampa e do suporte no qual encontra-se fixada a superfície de testes. A seguir era realizado vácuo no sistema (cuba de ebulição e condensador) até uma pressão absoluta de $2 \mathrm{kPa}$. Concomitantemente, para facilitar a eliminação da umidade e do ar existentes no sistema, circulava-se a solução anti-congelante pelo condensador principal com uma temperatura igual a $80^{\circ} \mathrm{C}$. $\mathrm{O}$ vácuo era mantido durante um período superior a 12 horas, após o que se carregava o sistema com $\mathrm{N}_{2}$ até uma pressão de $800 \mathrm{kPa}$, para verificação de possíveis vazamentos. A seguir, realizava-se um novo vácuo e o sistema era carregado com o refrigerante no estado de vapor a partir das garrafas (ou depósitos) comerciais. Como resultado da diferença de pressão entre a cuba e o reservatório, o refrigerante evaporava e circulava através de mangueiras até a cuba. 
Já no interior do sistema, o refrigerante condensava ao entrar em contato com a superfície interna do condensador principal, no qual circulava a solução anticongelante com temperatura reduzida. Tal processo, similar a uma destilação, evitava que partículas estranhas, eventualmente existentes no refrigerante, fossem transportadas até a cuba e depositadas na superfície de testes. Quando o refrigerante atingia um nível de aproximadamente $35 \mathrm{~mm}$ acima da superfície de teste, o registro de entrada era fechado e cessava o carregamento.

Após a realização dos ensaios para determinado par refrigerante/superfície de transferência de calor, caracterizada pelo seu acabamento superficial, material, diâmetro e espaçamento entre tubos, o sistema era drenado e a superfície de testes retirada. No caso da permanência do sistema inativo por períodos prolongados, tampava-se com uma flange a região onde era fixado o suporte da superfície de testes, seguida da realização de vácuo no sistema e de seu preenchimento com $\mathrm{N}_{2}$ até uma pressão de $600 \mathrm{kPa}$. Tal procedimento evitava o contato do interior da cuba de ebulição com o ar externo, o que resultaria sua oxidação. Quando o reinicio dos testes era imediato, a superfície era novamente preparada ou substituída e o procedimento descrito neste item repetido.

Verificava-se a existência de gases não condensáveis, comparando, para a condição de equilíbrio, as temperaturas dos termopares blindados e a pressão da cuba com os valores de $T_{\text {sat }}$ e $p_{\text {sat }}$ tabelados no Handbook of Fundamentals (1997) da ASHRAE. No caso da não correspondência destes valores, o refrigerante no interior da cuba era aquecido e realizava-se uma purga no condensador principal através da qual tais gases eram eliminados. Esta purga era realizada de modo a não provocar alterações significativas no nível de refrigerante. A seguir, a superfície de testes era submetida a um fluxo específico de calor em torno de $60 \mathrm{~kW} / \mathrm{m}^{2}$, durante um período de 4 horas, para a remoção de gases ainda existentes nas reentrâncias da superfície.

\subsection{2 - Procedimentos de Ensaio}

Uma vez realizadas as etapas descritas anteriormente, ou seja, instaladas as superfícies e carregado o sistema, eram levantadas as curvas de ebulição para 
diferentes valores de $p_{\text {sat }}$. Tanto a escolha do $p_{\text {sat }}$ inicial como a ordem de acréscimo ou decréscimo no seu valor era aleatória. Repetia-se a condição inicial após a determinação das curvas de ebulição para os diferentes valores de $p_{\text {sat }}$ verificando-se, através da coincidência de resultados, a não alteração das características superficiais. A pressão no interior da cuba era determinada através do ajuste da temperatura da solução de etileno-glicol, atuando-se nos seguintes dispositivos: controlador eletrônico de temperatura, válvula de controle da capacidade de refrigeração para valores reduzidos de $T_{\text {sat }}$ e da válvula de agulha, no caso de valores elevados de $T_{\text {sat }}$.

Diariamente, antes do início dos testes, com o objetivo de evitar possíveis erros nas medidas de temperatura devido à oxidação das conexões dos termopares, eram verificadas as diferenças entre as temperaturas dos termopares inundados (termopares na superfície de teste e o termopar blindado e inundado), que deveriam ser inferiores a $0,2 \mathrm{~K}$, valor adotado arbitrariamente.

A aquisição dos dados era efetuada com condições fixas de pressão e fluxo específico de calor. Este último parâmetro tinha seu valor elevado gradativamente até um máximo e, em seguida, reduzido. Os testes visando apenas a análise da ebulição nucleada foram realizados somente para a redução do fluxo de calor a partir de um valor máximo. A pressão no interior da cuba era mantida constante, independente do fluxo de calor, com o ajuste da temperatura da solução anti-congelante através dos dispositivos de controle citados anteriormente. Adotou-se como critério para o início da aquisição uma variação inferior a $0,2 \mathrm{~K}$ nas temperaturas fornecidas pelos termopares durante um período de 10 minutos. O sistema de aquisição foi ajustado de forma a gravar uma leitura (conjunto de medidas de todas as variáveis) a cada $1 \mathrm{~s}$, utilizando uma freqüência de aquisição de $11 \mathrm{~Hz}$. Os resultados foram extraídos da média de 60 leituras consecutivas, ou seja, da média dos valores lidos em um intervalo de 60 segundos. Para cada condição experimental foram realizadas as seguintes medições:

i. Tensão e corrente elétricas fornecidas para as resistências do tipo cartucho;

ii. Temperatura nas superfícies de testes;

iii. Temperatura e pressão do refrigerante. 


\section{4 - RESULTADOS EXPERIMENTAIS}

\section{1 - Considerações iniciais}

Foram realizados ensaios experimentais envolvendo os refrigerantes R11, R123, R134a; com tubos cilíndricos de cobre, aço inox e latão com 3 diâmetros distintos em banco de tubos (2 e 3 tubos verticalmente alinhados), ampla faixa de pressões e acabamentos superficiais (caracterizados pela rugosidade média aritmética, Ra). As condições experimentais se encontram resumidas na Tabela 4.1. Nesta Tabela são mostrados resultados obtidos anteriormente, na pesquisa de mestrado, Silva (2002), e aqueles obtidos no presente trabalho, conforme indicado na legenda da tabela.

Em uma primeira etapa, foi brevemente analisada a influência do acabamento superficial. Posteriormente, abordou-se a influência do diâmetro do tubo. Numa segunda etapa foram obtidos resultados experimentais envolvendo a ebulição do R123 em banco de tubos, sendo analisada a influências do fluxo de calor, pressão, posicionamento, interação e espaçamento entre tubos. A partir dos resultados, foi proposta uma correlação semi-empírica. 
Tabela 4.1 Condições experimentais do banco de dados

material /
faixa de $\phi$
$\left(\mathrm{kW} / \mathrm{m}^{2}\right)$

$\left(\mathrm{kW} / \mathrm{m}^{2}\right)$

\begin{tabular}{|c|c|c|c|c|}
\hline \multirow{19}{*}{$\begin{array}{c}\text { cobre/ } \\
0,7 \leq \phi \leq 116,5\end{array}$} & \multirow{4}{*}{$\mathrm{R}-11$} & \multirow{4}{*}{$1 / 19,0$} & 0,17 & 0,$011 ; 0,023 ; 0,035 ; 0,064 ; 0,092 ; 0,12$ \\
\hline & & & 0,45 & 0,$011 ; 0,023 ; 0,035 ; 0,064 ; 0,092 ; 0,12$ \\
\hline & & & 2,3 & 0,$011 ; 0,023 ; 0,035 ; 0,064 ; 0,092 ; 0,12$ \\
\hline & & & 4,6 & 0,$023 ; 0,035 ; 0,064 ; 0,092 ; 0,12$ \\
\hline & \multirow{5}{*}{$\mathrm{R}-123$} & \multirow{5}{*}{$1 / 19,0$} & 0,16 & 0,$011 ; 0,023 ; 0,035 ; 0,064 ; 0,092 ; 0,12$ \\
\hline & & & 0,47 & 0,$011 ; 0,023 ; 0,035 ; 0,064 ; 0,092 ; 0,12$ \\
\hline & & & 3,3 & 0,$011 ; 0,023 ; 0,035 ; 0,064 ; 0,092 ; 0,12$ \\
\hline & & & 4,6 & 0,$023 ; 0,035 ; 0,064 ; 0,092 ; 0,12$ \\
\hline & & & 10,5 & 0,$023 ; 0,035 ; 0,064 ; 0,092 ; 0,12$ \\
\hline & \multirow[t]{2}{*}{$\mathrm{R}-12$} & \multirow{2}{*}{$1 / 19,0$} & 0,06 & 0,$050 ; 0,064 ; 0,092 ; 0,12 ; 0,20 ; 0,26$ \\
\hline & & & 0,51 & 0,$050 ; 0,064 ; 0,092 ; 0,12 ; 0,20 ; 0,26$ \\
\hline & \multirow{3}{*}{$\mathrm{R}-22$} & \multirow{3}{*}{$1 / 19,0$} & 0,07 & 0,$064 ; 0,092 ; 0,12 ; 0,15 ; 0,18 ; 0,20$ \\
\hline & & & 0,47 & 0,$064 ; 0,092 ; 0,12 ; 0,15 ; 0,18 ; 0,20$ \\
\hline & & & 2,6 & 0,$064 ; 0,092 ; 0,12 ; 0,15 ; 0,18 ; 0,20$ \\
\hline & \multirow{5}{*}{$\mathrm{R}-134 \mathrm{a}$} & \multirow{5}{*}{$1 / 19,0$} & 0,07 & 0,$050 ; 0,064 ; 0,092 ; 0,12 ; 0,20 ; 0,26$ \\
\hline & & & 0,50 & 0,$050 ; 0,064 ; 0,092 ; 0,12 ; 0,20 ; 0,26$ \\
\hline & & & 2,5 & 0,$050 ; 0,064 ; 0,092 ; 0,12 ; 0,20 ; 0,26$ \\
\hline & & & 4,6 & 0,$064 ; 0,092 ; 0,12 ; 0,18 ; 0,20 ; 0,26$ \\
\hline & & & 10,3 & 0,$064 ; 0,092 ; 0,12 ; 0,18 ; 0,20 ; 0,26$ \\
\hline \multirow{13}{*}{$\begin{array}{c}\text { aço inoxidável / } \\
0,7 \leq \phi \leq 64,0\end{array}$} & \multirow[t]{2}{*}{ R-11 } & \multirow{2}{*}{$1 / 19,0$} & 0,02 & 0,$011 ; 0,023 ; 0,035 ; 0,064 ; 0,092 ; 0,12$ \\
\hline & & & 0,16 & 0,$011 ; 0,023 ; 0,035 ; 0,064 ; 0,092 ; 0,12$ \\
\hline & \multirow[t]{2}{*}{$\mathrm{R}-123$} & \multirow[t]{2}{*}{$1 / 19,0$} & 0,16 & 0,$011 ; 0,023 ; 0,035 ; 0,064 ; 0,092 ; 0,12$ \\
\hline & & & 0,50 & 0,$023 ; 0,035 ; 0,064 ; 0,092 ; 0,12$ \\
\hline & \multirow{9}{*}{$\mathrm{R}-134 \mathrm{a}$} & \multirow{9}{*}{$1 / 19,0$} & 0,08 & 0,$064 ; 0,092 ; 0,12 ; 0,18 ; 0,20 ; 0,26$ \\
\hline & & & 0,03 & 0,$063 ; 0,12 ; 0,26$ \\
\hline & & & 0,16 & 0,$063 ; 0,12 ; 0,26$ \\
\hline & & & 0,45 & 0,$063 ; 0,12 ; 0,26$ \\
\hline & & & 0,90 & 0,$063 ; 0,12 ; 0,26$ \\
\hline & & & 1,1 & 0,$063 ; 0,12 ; 0,26$ \\
\hline & & & 1,45 & 0,$063 ; 0,12 ; 0,26$ \\
\hline & & & 2,0 & 0,$063 ; 0,12 ; 0,26$ \\
\hline & & & 2,5 & 0,$063 ; 0,12 ; 0,26$ \\
\hline
\end{tabular}


Tabela 4.1( continuação) Condições experimentais do banco de dados

\begin{tabular}{|c|c|c|c|c|c|}
\hline $\begin{array}{c}\text { material / } \\
\text { faixa de } \phi \\
\left(\mathrm{kW} / \mathbf{m}^{2}\right)\end{array}$ & $\begin{array}{c}\text { Fluido } \\
\text { refrigerante }\end{array}$ & $\begin{array}{c}\text { Número de } \\
\text { Tubos / } \\
\text { Diâmetro } \\
(\mathbf{m m}) \\
\end{array}$ & $\begin{array}{c}\text { Relação de } \\
\text { espaçamento } \\
(\mathrm{s} / \mathrm{d})\end{array}$ & $\begin{array}{c}\boldsymbol{R a} \\
(\mu \mathbf{m})\end{array}$ & $p_{r}$ \\
\hline \multirow{21}{*}{$\begin{array}{c}\text { latão / } \\
0,7 \leq \phi \leq 84,4\end{array}$} & R-11 & $1 / 19,0$ & & 0,15 & $\begin{array}{l}0,011 ; 0,023 ; 0,035 ; 0,064 ; 0,092 \text {; } \\
0,12\end{array}$ \\
\hline & \multirow{9}{*}{$\mathrm{R}-123$} & $1 / 19,0$ & & 0,16 & $\begin{array}{l}0,011 ; 0,023 ; 0,035 ; 0,064 ; 0,092 ; \\
0,12\end{array}$ \\
\hline & & $1 / 12,5$ & & 0,16 & 0,$023 ; 0,035 ; 0,064 ; 0,092 ; 0,12$ \\
\hline & & $1 / 22,0$ & & 0,16 & 0,$023 ; 0,035 ; 0,064 ; 0,092 ; 0,12$ \\
\hline & & \multirow{3}{*}{$2 / 19,0$} & 1,32 & 0,12 & 0,$023 ; 0,035 ; 0,064$ \\
\hline & & & 1,53 & 0,12 & 0,$023 ; 0,035 ; 0,064$ \\
\hline & & & 2,00 & 0,12 & 0,$023 ; 0,035 ; 0,064$ \\
\hline & & \multirow{3}{*}{$3 / 19,0$} & 1,32 & 0,12 & 0,$023 ; 0,035 ; 0,064$ \\
\hline & & & 1,53 & 0,12 & 0,$023 ; 0,035 ; 0,064$ \\
\hline & & & 2,00 & 0,12 & 0,$023 ; 0,035 ; 0,064$ \\
\hline & $\mathrm{R}-12$ & $1 / 19,0$ & & 0,08 & $\begin{array}{l}0,050 ; 0,064 ; 0,092 ; 0,12 ; 0,18 ; \\
0,20 ; 0,26\end{array}$ \\
\hline & $\mathrm{R}-22$ & $1 / 19,0$ & & 0,08 & 0,$064 ; 0,092 ; 0,12 ; 0,15 ; 0,18 ; 0,20$ \\
\hline & \multirow{9}{*}{$\mathrm{R}-134 \mathrm{a}$} & $1 / 19,0$ & & 0,08 & $\begin{array}{l}0,050 ; 0,064 ; 0,092 ; 0,12 ; 0,18 ; \\
0,20 ; 0,26\end{array}$ \\
\hline & & \multirow{6}{*}{$1 / 19,0$} & & 0,9 & 0,$063 ; 0,12 ; 0,26$ \\
\hline & & & & 1,2 & 0,$063 ; 0,12 ; 0,26$ \\
\hline & & & & 1,4 & 0,$063 ; 0,12 ; 0,26$ \\
\hline & & & & 1,8 & 0,$063 ; 0,12 ; 0,26$ \\
\hline & & & & 3,0 & 0,$063 ; 0,12 ; 0,26$ \\
\hline & & & & 3,5 & 0,$063 ; 0,12 ; 0,26$ \\
\hline & & $1 / 12,5$ & & 0,08 & 0,$064 ; 0,092 ; 0,12 ; 0,18 ; 0,20$ \\
\hline & & $1 / 22,0$ & & 0,08 & 0,$064 ; 0,092 ; 0,12 ; 0,18 ; 0,20$ \\
\hline
\end{tabular}




\section{2 - Breve análise dos principais fatores que influenciam a ebulição em um único tubo}

Conforme mostrado por Silva (2002) e Ribatski (2002), diversos parâmetros podem influenciar o mecanismo de transferência de calor em ebulição nucleada. Entre os principais, já estudados, destaca-se a pressão (geralmente dependente das condições operacionais) e o acabamento superficial (parâmetro obtido na fase de projeto e construção do equipamento). Conforme mostrado na revisão bibliográfica, a influência do diâmetro do tubo é desprezada na transferência de calor em ebulição nucleada.

\subsection{1 - Influência do acabamento superficial}

O acabamento superficial apresenta grande influência no coeficiente de transferência de calor em ebulição nucleada, conforme mostrado por Silva (2002), Ribatski (2002) e Stelute (2004).

No presente trabalho, inicialmente, fez-se uma análise geral da influência do acabamento superficial no coeficiente de transferência de calor para uma ampla faixa de fluxos de calor (entre 0,7 e $120 \mathrm{~kW} / \mathrm{m}^{2}$ ). Posteriormente, levando em consideração a operação de equipamentos frigoríficos, bem como à faixa em que fatores geométricos em banco de tubos apresentam maior influência (região de transição entre convecção natural e ebulição nucleada), optou-se por uma análise envolvendo valores relativamente reduzidos de fluxo de calor (inferiores a $40 \mathrm{~kW} / \mathrm{m}^{2}$ ).

Foram obtidos resultados experimentais para superfícies de cobre e latão, refrigerantes R-11, R-123 e R134a, fluxo de calor variando entre 0,7 e 120 kW/m², pressões reduzidas variando entre 0,011 e 0,27 . As Figuras 4.1 a 4.3 ilustram alguns resultados para superfície de cobre com refrigerantes R-123 e R-134a, mostrando o efeito do acabamento superficial, caracterizado pela rugosidade média aritmética (Ra), que variou entre 0,07 e 10,5 $\mu \mathrm{m}$. Sua análise permite concluir o deslocamento da curva para a esquerda com o aumento de Ra, para a faixa entre 0,07 e 3,3 $\mu \mathrm{m}$. 
Este comportamento parece ser determinado pela maior densidade de cavidades ativas proporcionada pela superfície rugosa. Analogamente ao comportamento observado por Ribatski (2002), Silva (2002) e Stelute (2004), com o incremento de Ra, verifica-se uma certa atenuação do efeito do acabamento superficial na transferência de calor. $\mathrm{O}$ incremento da rugosidade seria acompanhado por uma elevação da densidade de cavidades ativas, o que resultaria no aumento do coeficiente de transferência de calor. Para o R-123 e R-134a, com Ra de 4,6 $\mu$ m, a curva de ebulição se desloca para a direita, correspondendo a uma redução no coeficiente de transferência de calor em relação a rugosidades inferiores. Este comportamento mostra que existiria um valor de Ra para o qual o coeficiente de transferência de calor seria máximo. Valores superiores de Ra causariam uma redução na transferência de calor. Este fenômeno pode estar relacionado à presença de cavidades menores (micro cavidades) no interior de cavidades maiores, sendo que nem todas estas micro-cavidades seriam ativas. As bolhas formadas nas microcavidades ativas poderiam, ainda, desfavorecer a nucleação de cavidades vizinhas. Com isso, apesar da elevada rugosidade, a superfície se comportaria como uma superfície menos rugosa, comprometendo a transferência de calor.

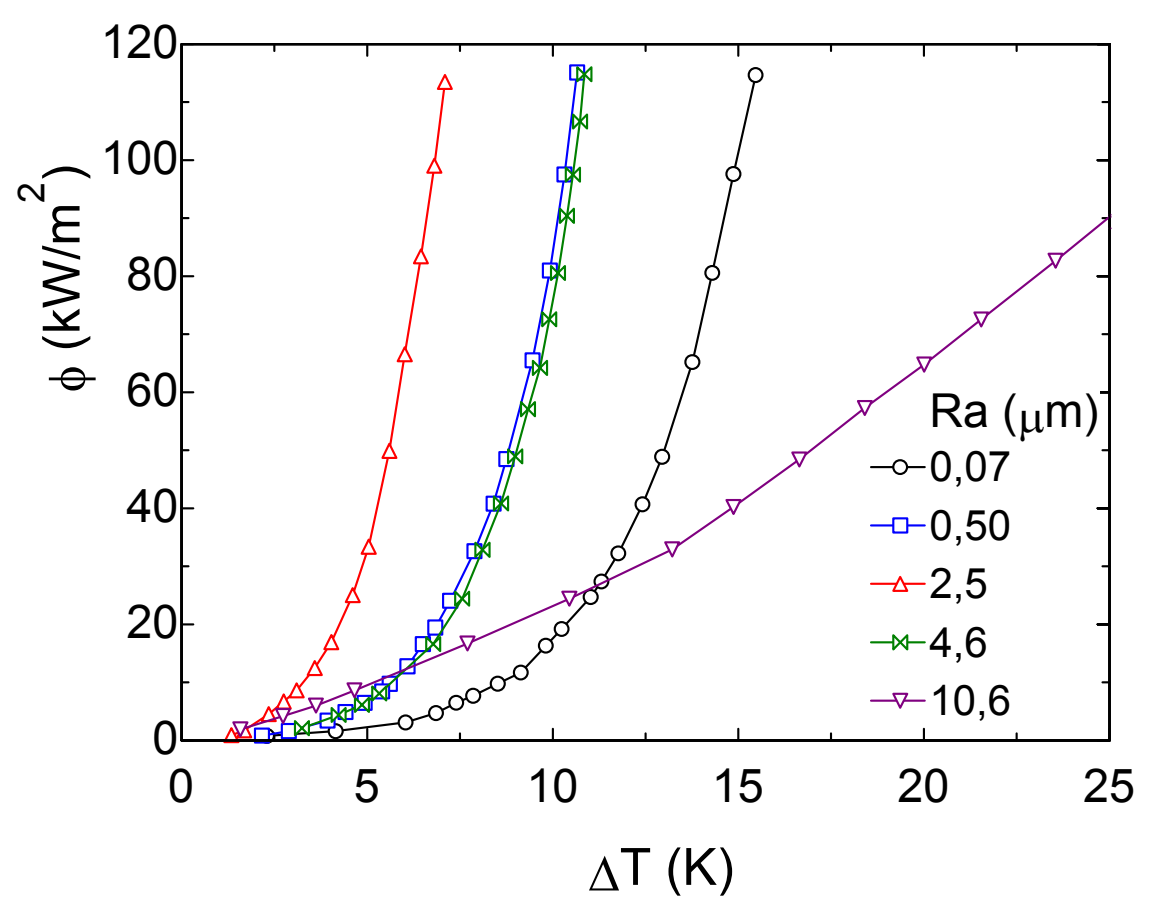

Figura 4.1 Curvas de ebulição para o R-134a para $\mathrm{p}_{\mathrm{r}}=0,062$, tubo de cobre, $\mathrm{D}_{\mathrm{ext}}=19 \mathrm{~mm}$. 


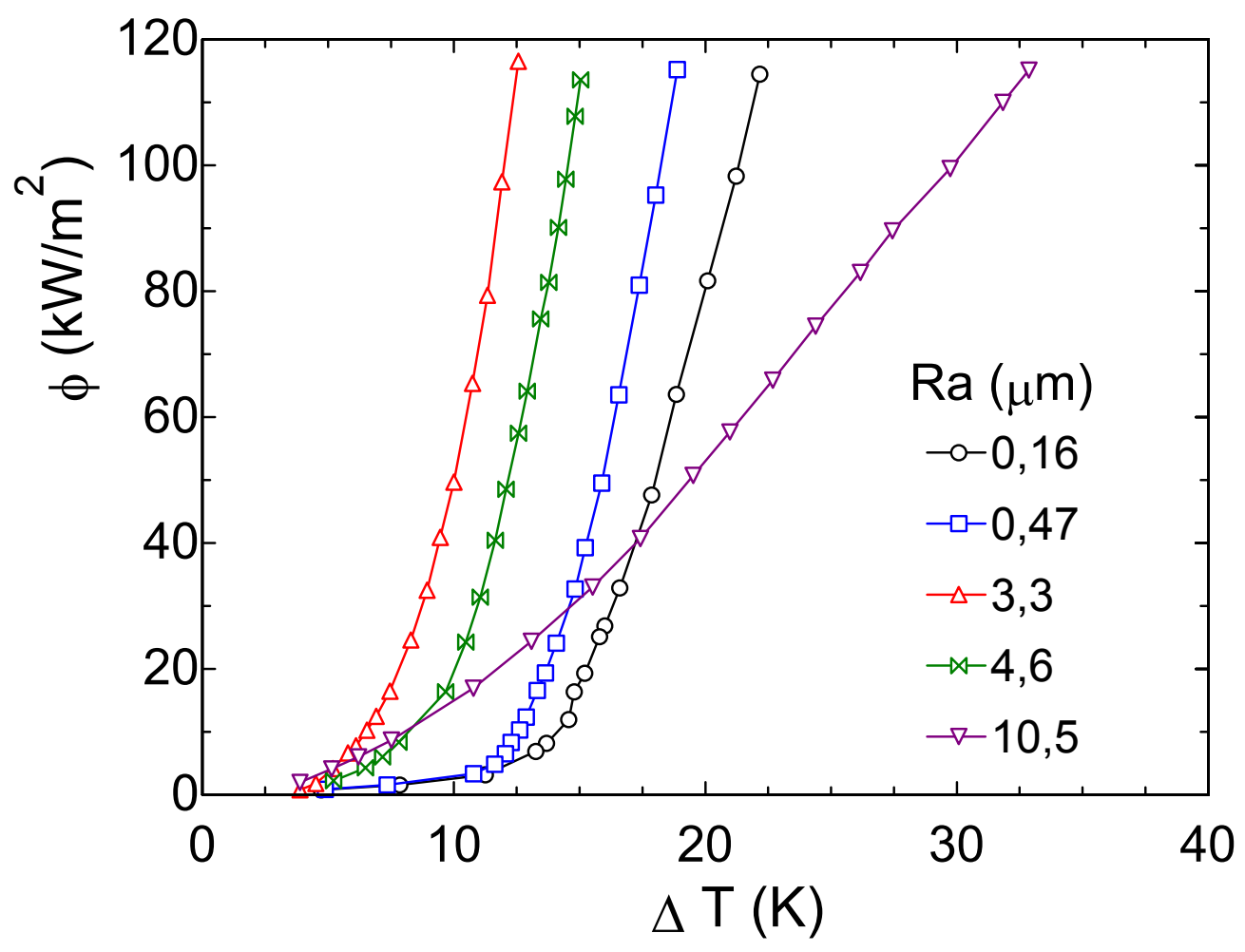

Figura 4.2 Curvas de ebulição para o R-123 para $p_{\mathrm{r}}=0,062$, tubo de cobre,

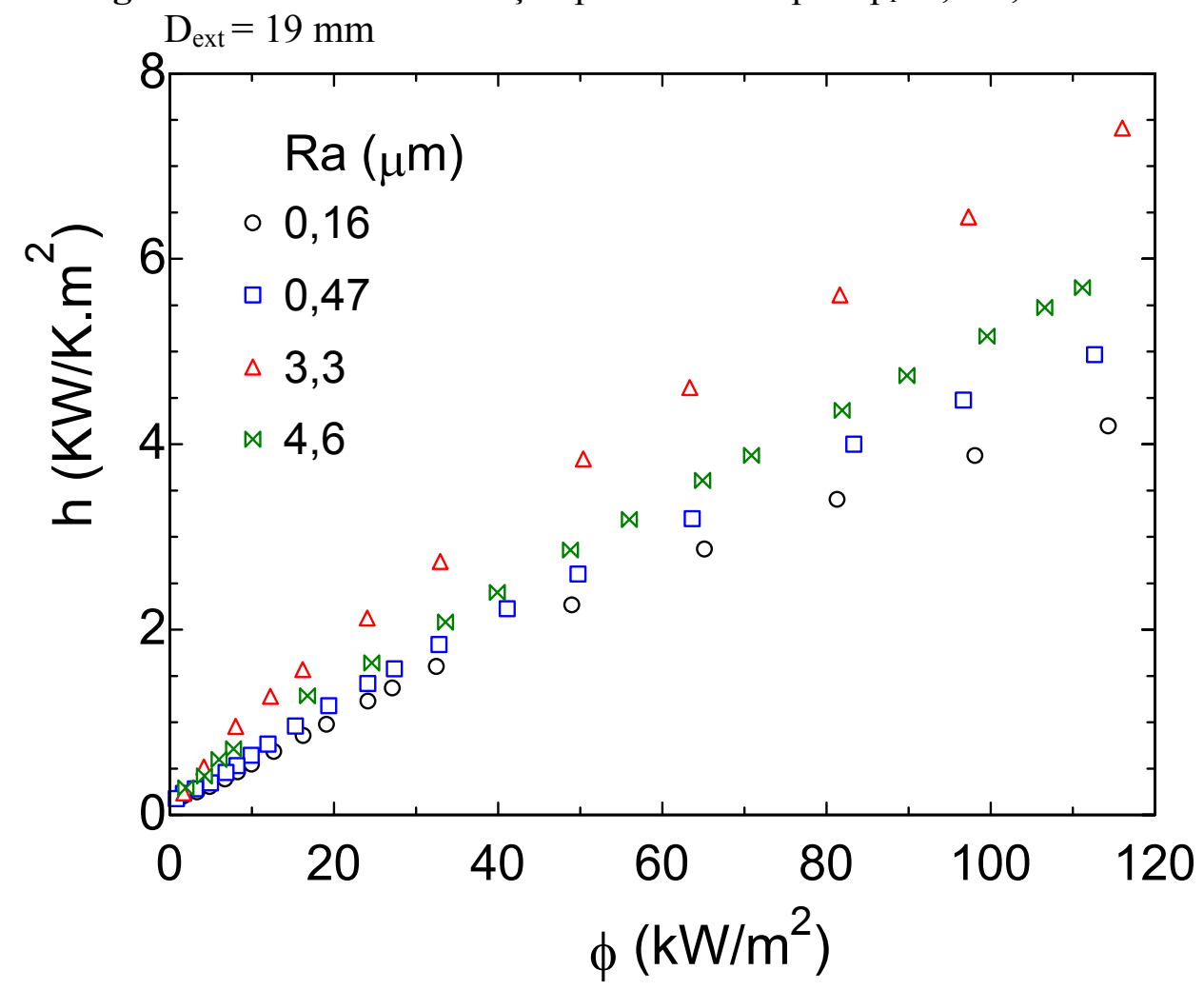

Figura 4.3 Variação do coeficiente de transferência de calor (h) com o fluxo de calor específico $(\phi)$ para diversos valores da rugosidade média aritmética (Ra). Superfície de cobre, $\mathrm{R}-123, \mathrm{p}_{\mathrm{r}}=0,011$. 


\subsubsection{Influência do diâmetro do tubo}

A investigação da influência do diâmetro do tubo para dimensões usuais na refrigeração (diâmetros da ordem de dezenas de milímetros) é um tema pouco explorado. Da literatura verifica-se que os trabalhos envolvendo a ebulição nucleada não incorporam o diâmetro do tubo. Conforme mostrado na revisão bibliográfica um dos raros trabalhos que analisaram a influência do diâmetro na ebulição em piscina foi o de Kudritskii e Kolomiets (1995). No entanto, os autores utilizaram fios aquecidos de dimensões ainda pouco usuais (diâmetro entre 0,5 a 1,5 mm). Verificaram que o diâmetro do tubo influencia a ebulição nucleada somente em reduzidas dimensões (para o R-123 à pressão atmosférica este valor é em torno de $0,01$ a $5 \mathrm{~mm})$.

Através dos resultados experimentais foram obtidas curvas do coeficiente de transferência de calor em função do fluxo de calor específico, Fig. (4.4), para 3 distintos diâmetros $(12,5 ; 19,0$ e 22,0 mm). Com base nas curvas da Fig (4.3) (influência do acabamento superficial) e Fig. (4.4) (influência do diâmetro), constatase que, em superfícies em ebulição, o diâmetro do tubo apresenta reduzida influência no coeficiente de transferência de calor, quando comparado à influência do acabamento superficial. Através dos resultados e barras de incertezas, conclui-se que os coeficientes de transferência de calor para tubos com os diâmetros investigados ( $D_{\text {ext }}$ entre 12,5 e $22 \mathrm{~mm}$ ), que são usualmente utilizados em aplicações práticas de sistemas frigoríficos convencionais, pode ser considerado aproximadamente iguais para mesma condição. No entanto, para algumas aplicações que utilizam superfícies especiais com reduzidas ou elevadas dimensões, novas pesquisas devem ser consideradas com a finalidade de uma melhor avaliação da influência do diâmetro na transferência de calor em ebulição nucleada. 


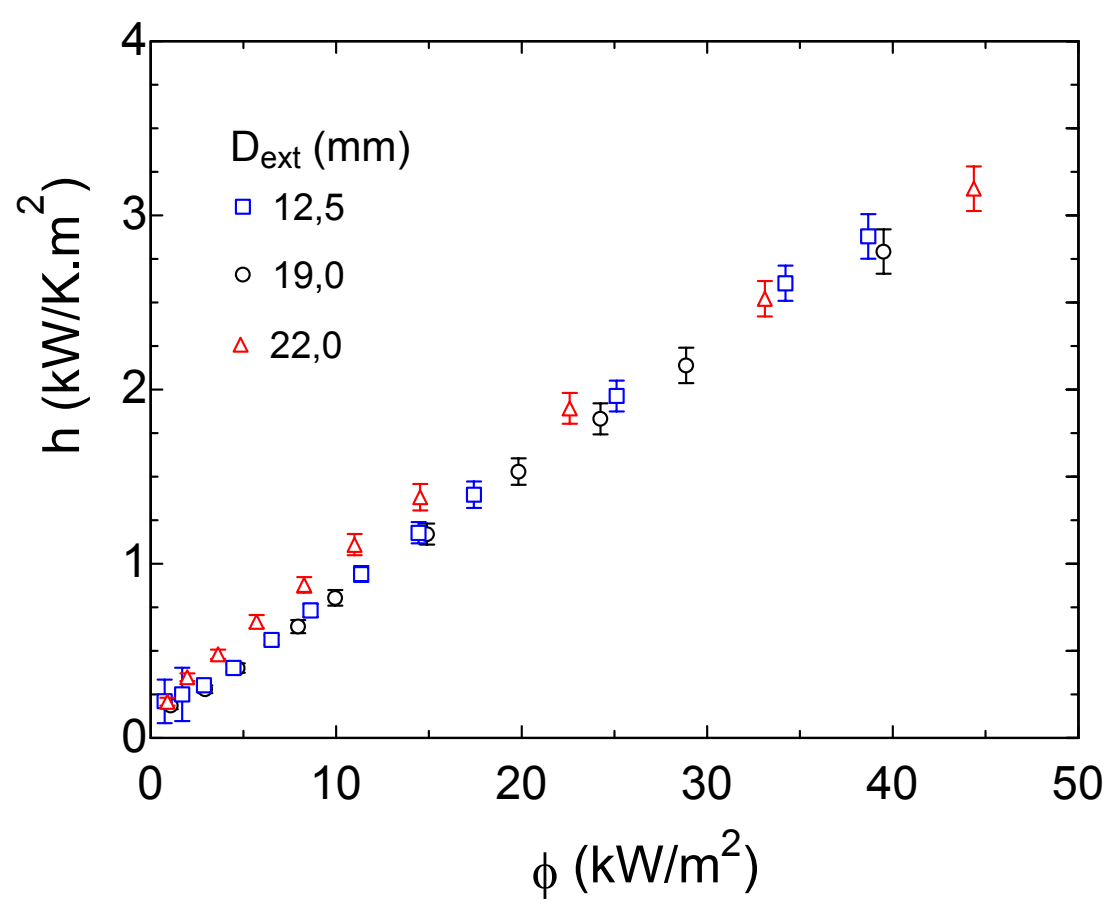

Figura 4.4 Variação do coeficiente de transferência de calor (h) com o diâmetro do tubo em reduzidos fluxos de calor $(\phi)$. Superfície de latão, R-123, $\mathrm{p}_{\mathrm{r}}=0,023$.

\section{3 -Resultados experimentais para banco de tubos}

Os resultados experimentais envolvendo a transferência de calor em banco de tubos são analisados nesta seção. Inicialmente foram obtidos resultados experimentais para cada um dos tubos do banco aquecido isoladamente. Tais ensaios tiveram por objetivo a verificação de possíveis erros de medida da temperatura na parede dos tubos em virtude da fixação dos termopares, conforme mostrado por Ribatski (2002). Posteriormente, é realizada uma investigação dos efeitos, no coeficiente de transferência de calor, dos seguintes parâmetros: fluxo de calor, pressão, posicionamento e espaçamento entre tubos, com 2 e 3 tubos aquecidos simultaneamente com mesmo fluxo de calor. Tal investigação é realizada com base no banco de dados levantado e na análise da literatura.

\subsubsection{Comparação entre coeficientes de transferência de calor nos tubos aquecidos isoladamente}

O coeficiente de transferência de calor médio em cada tubo pode ser obtido da Lei de resfriamento de Newton, escrita em termos do fluxo específico de calor e 
da diferença média de temperatura entre aquela da superfície do tubo e a do banho, que podem ser avaliadas segundo as seguintes relações:

$$
\begin{aligned}
& \Delta T=\left(T_{\text {parede }}-T_{\text {banho }}\right) \\
& \Delta T_{\text {med }}=\frac{\Delta T_{l e}+\Delta T_{l d}+\Delta T_{i}+\Delta T_{s}}{4} \\
& h=\frac{\phi}{\Delta T_{\text {med }}}
\end{aligned}
$$

onde $l e, l d$, i e s referem-se aos termopares lateral esquerdo, lateral direito, inferior e superior, respectivamente.

A Figura 4.5 ilustra os resultados obtidos para cada tubo aquecido isoladamente. Constata-se que a diferença entre os coeficientes de transferência de calor dos tubos aquecidos isoladamente está dentro da faixa de incerteza. Com isso, para uma comparação entre os coeficientes de transferência de calor médio em cada tubo no banco (tubos aquecidos simultaneamente), os erros e outros fatores que possam influenciar (por exemplo: coluna de líquido), podem ser considerados dentro da margem de incerteza.

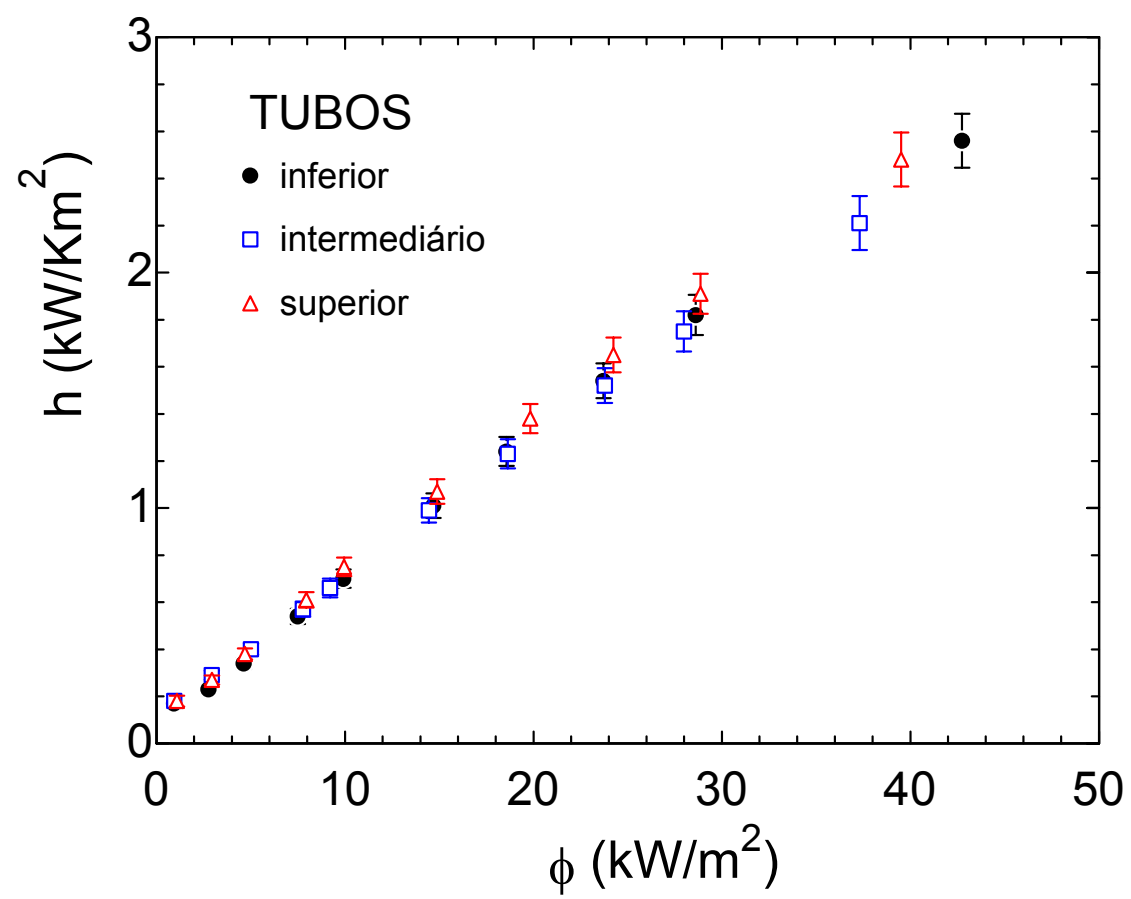

Figura 4.5 Coeficiente de transferência de calor médio $v s$ fluxo de calor para tubos aquecidos isoladamente. R-123, Tubos de latão, $\mathrm{Ra} \approx 0,12 \mu \mathrm{m}$. 


\subsection{2 - Fatores que influenciam a ebulição em banco de tubos}

\subsubsection{1 - Influência do fluxo de calor}

Conforme mostrado na revisão bibliográfica, o coeficiente de transferência de calor para distintos tubos difere especialmente para as condições de transição entre os regimes de convecção natural e ebulição nucleada, que podem ser caracterizados através do fluxo de calor, pressão e propriedades termofísicas do fluido. Na literatura sugere-se que, para ebulição nucleada parcial, o coeficiente de transferência de calor (h) aumenta no sentido ascendente na fileira de tubos. Em ebulição nucleada plenamente desenvolvida, o desempenho dos tubos (independentemente do posicionamento) é aproximadamente igual àquele de um único tubo aquecido.

As Figuras 4.6 e 4.7 mostram curvas do coeficiente de transferência de calor médio (h) versus fluxo de calor específico $(\phi)$ para 2 e 3 tubos aquecidos simultaneamente. As Figuras 4.8 (a) a (f) ilustram fotografias obtidas sob condições de mesma pressão, para distintos fluxos de calor, quando o tubo inferior e o intermediário são aquecidos simultaneamente com o mesmo fluxo de calor.

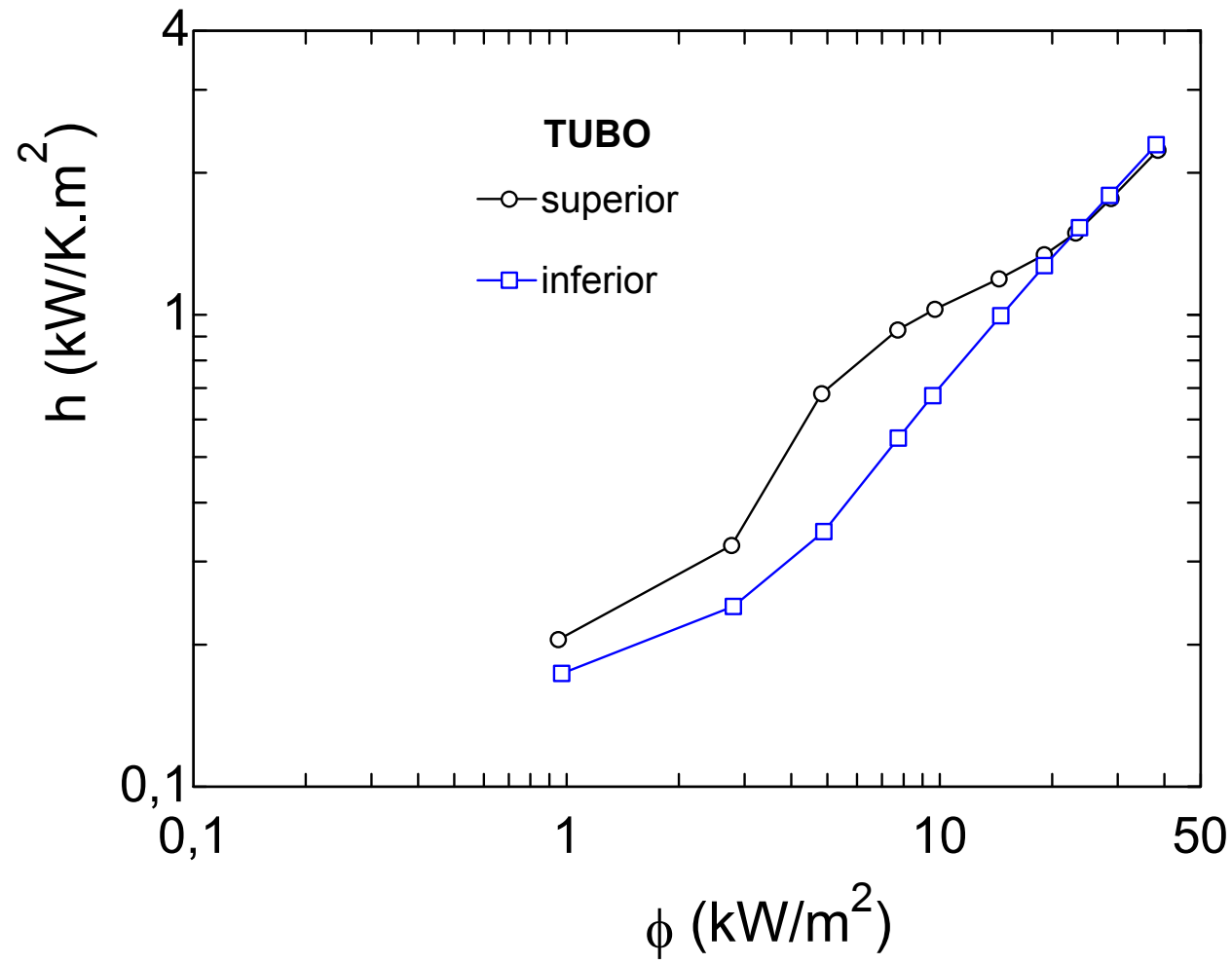

Figura 4.6 - Resultados de $\mathrm{h} v s \phi-2$ tubos, R-123, $\mathrm{p}_{\mathrm{r}}=0,023, \mathrm{~s} / \mathrm{d}=2,0$. 


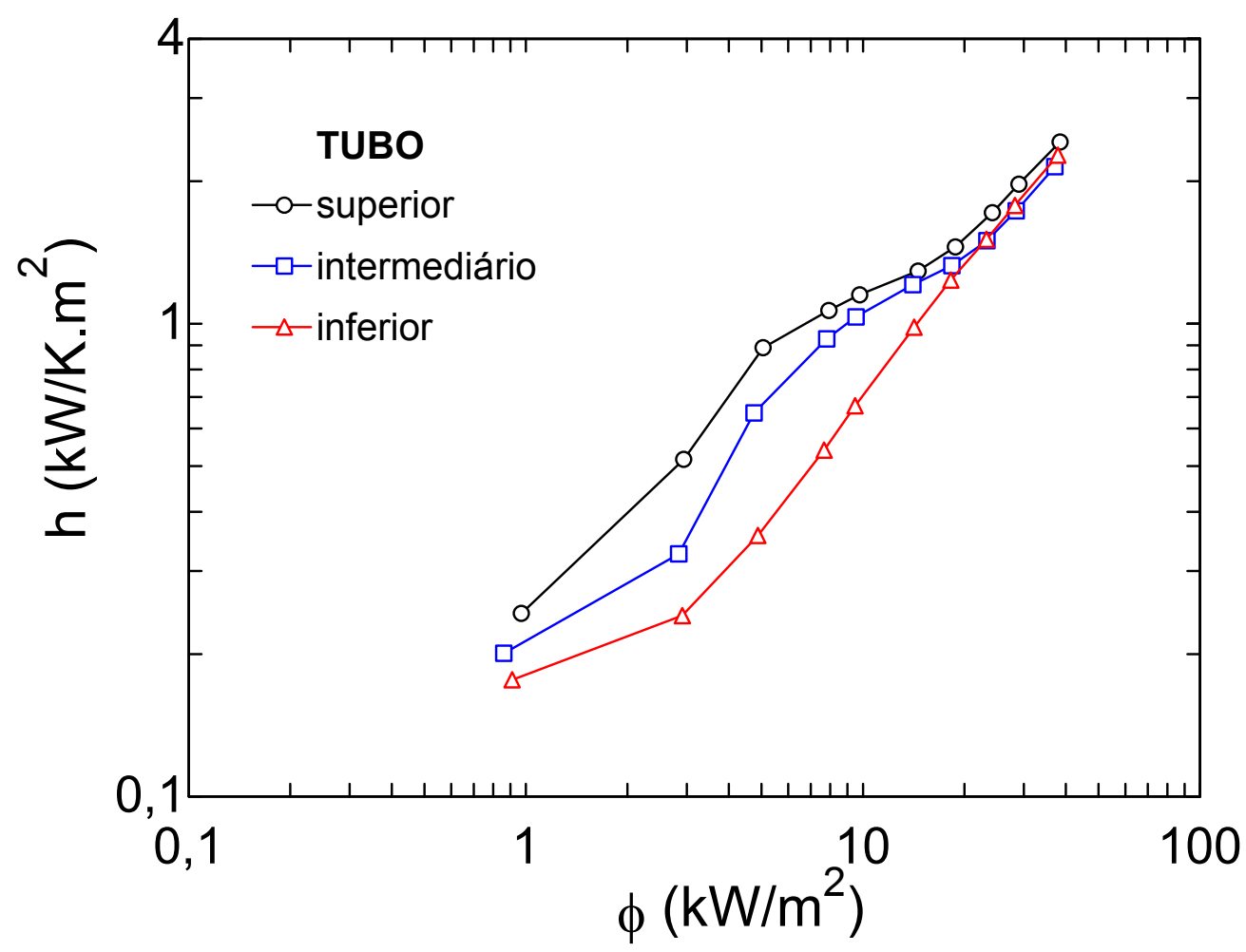

Figura 4.7 - Resultados de h $v s \phi-3$ tubos, R-123, $\mathrm{p}_{\mathrm{r}}=0,023, \mathrm{~s} / \mathrm{d}=1,32$.

Os resultados ilustrados nas Figs. 4.6 e 4.7 corroboram de forma geral os da literatura. Mostra-se que para o R-123 à pressão reduzida de 0,023, os tubos apresentam desempenho semelhante para fluxos de calor acima de $20 \mathrm{~kW} / \mathrm{m}^{2}$ (região de ebulição nucleada plenamente desenvolvida). Para fluxos de calor entre aproximadamente 5 e $10 \mathrm{~kW} / \mathrm{m}^{2}$ o desempenho do tubo superior é consideravelmente superior ao tubo inferior (aproximadamente de um fator de 2). Este efeito está relacionado à superposição de efeitos de ebulição nucleada e convecção promovida pelo desprendimento e movimento das bolhas formadas nos tubos inferiores, que favorecem a circulação de líquido frio junto à parede dos tubos superiores. Em condições de ebulição nucleada plenamente desenvolvida, a superfície do tubo superior é completamente tomada pelas bolhas. Com isso, as bolhas formadas nos tubos inferiores não influenciam a transferência de calor nos tubos superiores, ou seja, os efeitos convectivos podem ser considerados desprezíveis em relação aos efeitos de ebulição nucleada e, conseqüentemente, os tubos inferiores e superiores apresentaram desempenho semelhante. 


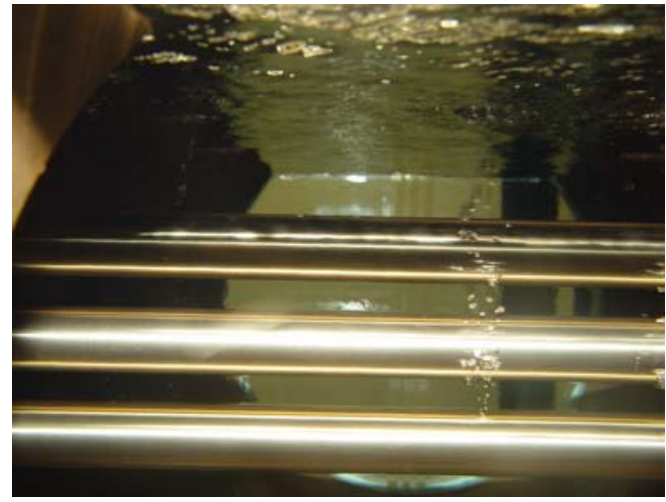

(a) $\phi=2 \mathrm{~kW} / \mathrm{m}^{2}, \mathrm{p}_{\mathrm{r}}=0,023$

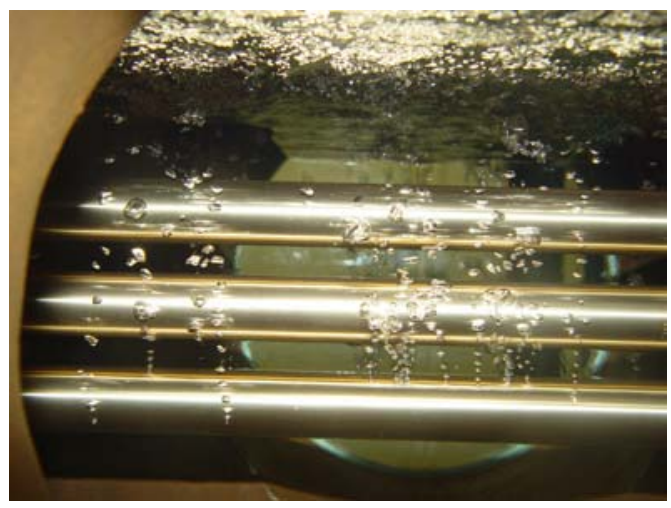

(c) $\phi=5 \mathrm{~kW} / \mathrm{m}^{2}, \mathrm{p}_{\mathrm{r}}=0,023$

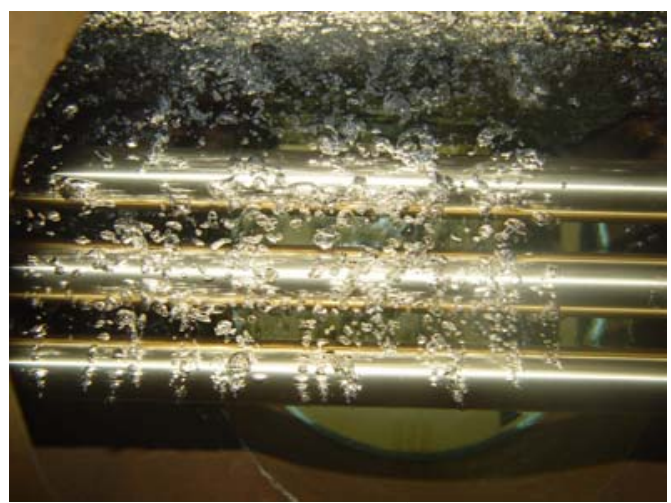

(e) $\phi=10 \mathrm{~kW} / \mathrm{m}^{2}, \mathrm{p}_{\mathrm{r}}=0,023$

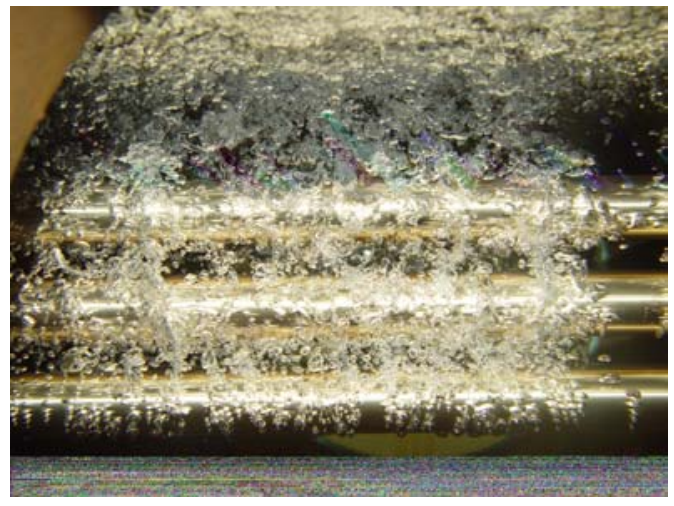

$(\mathrm{g}) \phi=25 \mathrm{~kW} / \mathrm{m}^{2}, \mathrm{p}_{\mathrm{r}}=0,023$

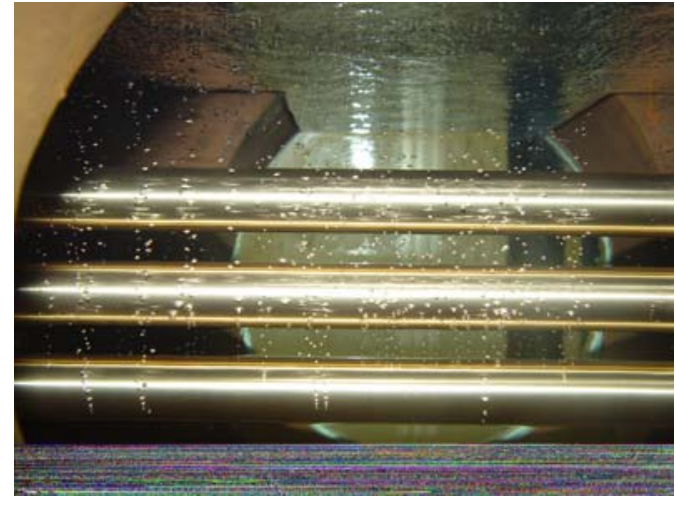

(b) $\phi=2 \mathrm{~kW} / \mathrm{m}^{2}, \mathrm{p}_{\mathrm{r}}=0,062$

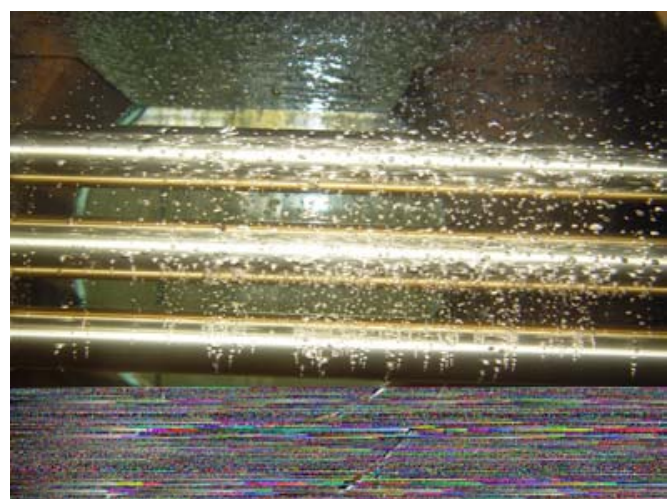

(d) $\phi=5 \mathrm{~kW} / \mathrm{m}^{2}, \mathrm{p}_{\mathrm{r}}=0,062$

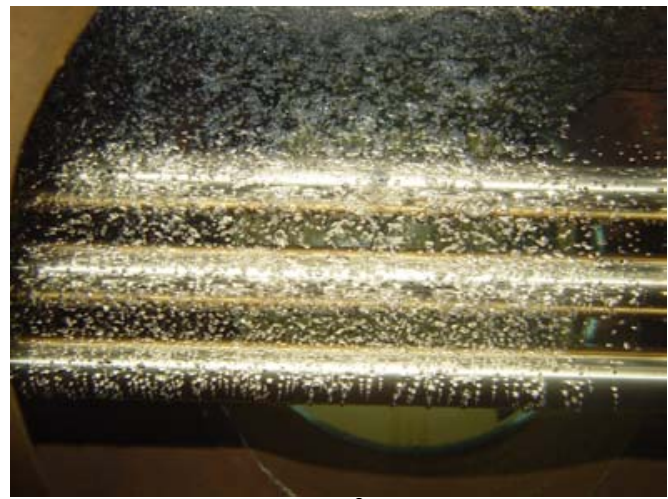

(f) $\phi=10 \mathrm{~kW} / \mathrm{m}^{2}, \mathrm{p}_{\mathrm{r}}=0,062$

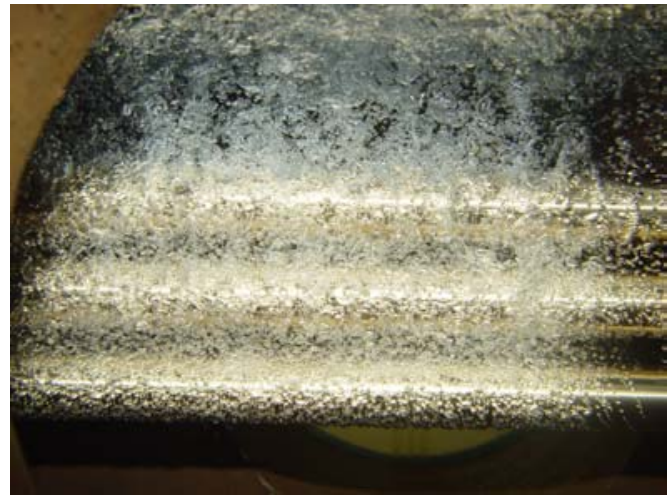

(h) $\phi=25 \mathrm{~kW} / \mathrm{m}^{2}, \mathrm{p}_{\mathrm{r}}=0,062$

Figura 4.8 Fotografias do R-123 em ebulição em tubos de latão, s/d=1,53. 


\subsubsection{2 - Influência da pressão}

Na ebulição de um único tubo, mostrou-se que o coeficiente de transferência de calor aumenta com a pressão, Silva (2002). Em banco de tubos, o coeficiente de transferência de calor também aumenta com a pressão. No entanto, a diferença entre os desempenhos do tubo superior e o inferior diminui, conforme é possível verificar nas Fig. (4.9) e (4.10). Este efeito, provavelmente, se deve a dois fatores: (1) menor influência das bolhas formadas nos tubos inferiores sobre os tubos superiores e (2) aumento do número de cavidades ativas com a pressão e o fluxo de calor. O primeiro fator ocorre devido à redução do diâmetro das bolhas e aumento da freqüência de desprendimento com a pressão. A região do tubo superior influenciada pelas bolhas formadas nos tubos inferiores seria proporcional ao diâmetro das mesmas, como sugerido por Fujita et al (1987). Nesta região de influência ocorre intensificação da transferência de calor. A redução no diâmetro da bolha seria responsável, ainda, por uma menor circulação da mistura bifásica (líquido e vapor) e conseqüentemente, redução de efeitos convectivos. O segundo fator, aumento no número de cavidades ativas com a pressão, é responsável pela redução do fluxo de calor necessário para transição do regime de ebulição parcial para ebulição nucleada plenamente desenvolvida. Em conseqüência, o máximo valor assumido pela relação entre os coeficientes de transferência de calor do tubo superior e inferior deverá ser menor e ocorrer com um menor fluxo de calor, conforme mostrado na Fig. (4.10). Este comportamento pode ser comprovado, ainda, comparando, por exemplo, as Figs. 4.8 (c) e (d), onde se percebe que, para um mesmo fluxo de calor, o número de bolhas aumenta e o seu tamanho diminui com a pressão. 


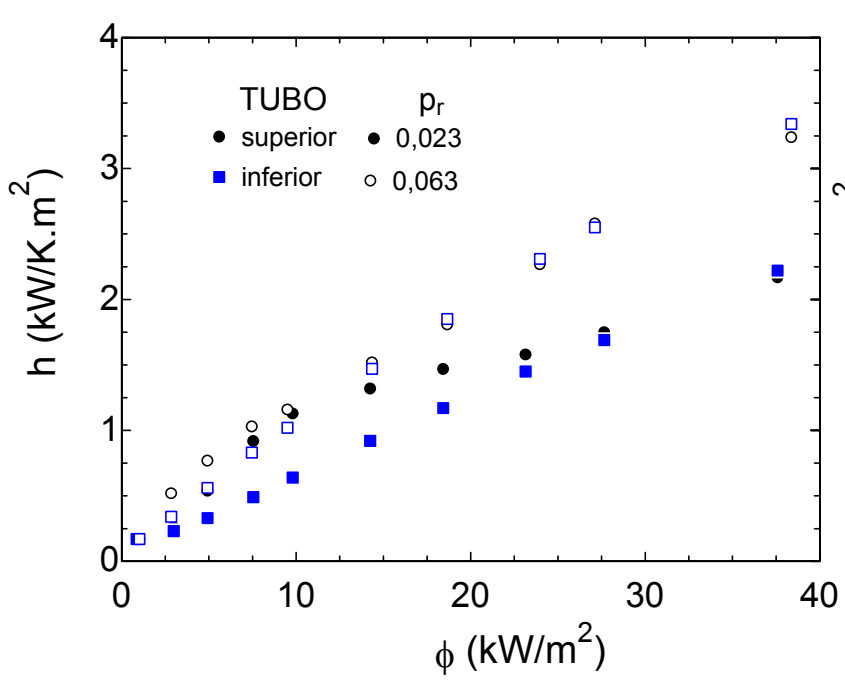

(a) $\mathrm{s} / \mathrm{d}=1,32$

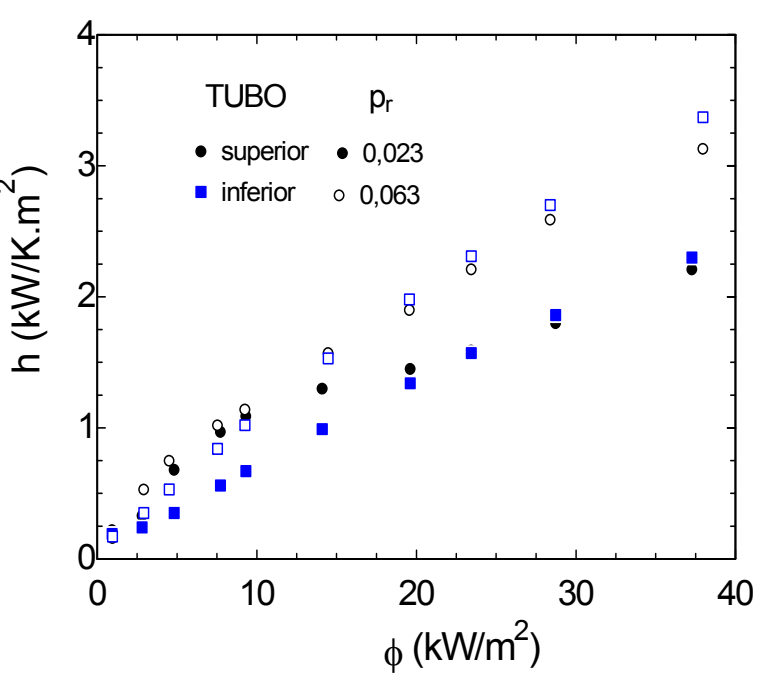

(b) $\mathrm{s} / \mathrm{d}=1,53$

Figura 4.9 Influência da pressão no coeficiente de transferência de calor em banco de tubos. R-123, Tubos de latão aquecidos simultaneamente com igual fluxo de calor.

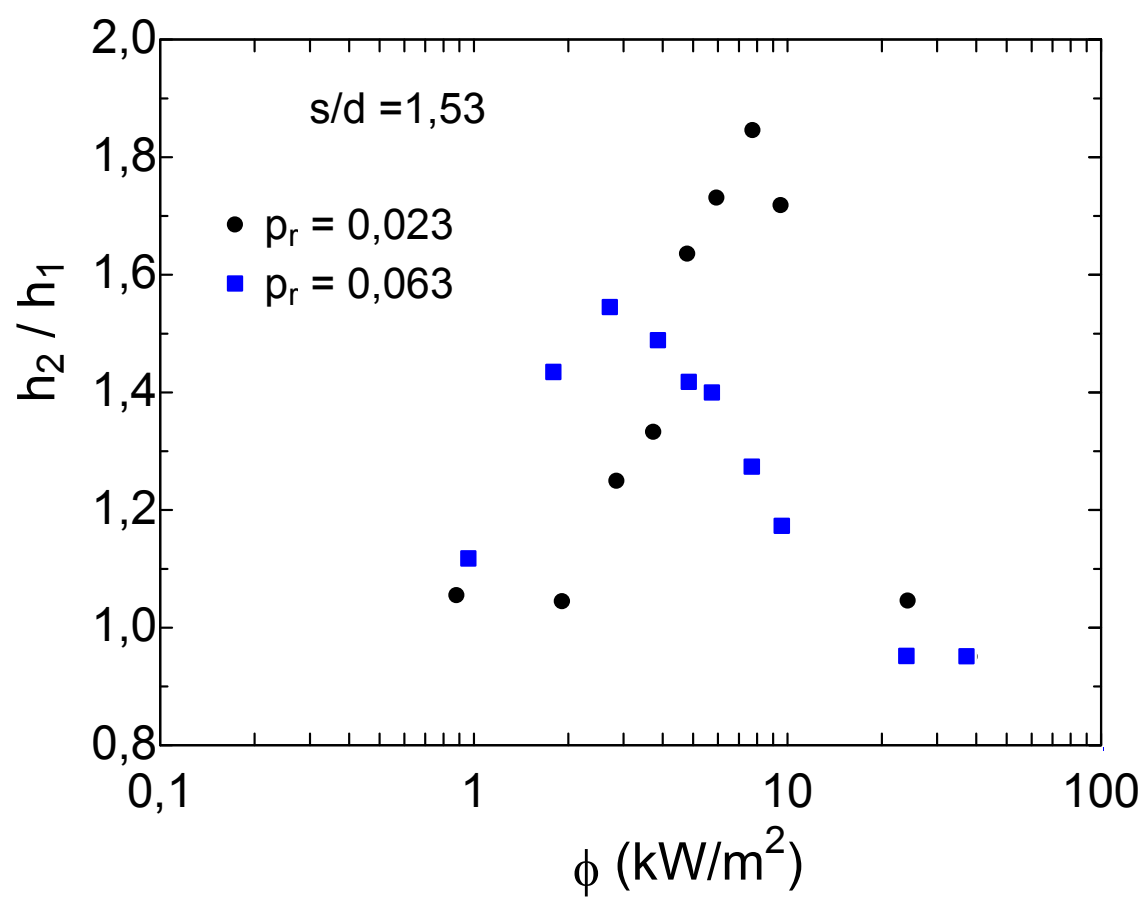

Figura 4.10 Relação entre coeficientes de transferência de calor do tubo superior $\left(\mathrm{h}_{2}\right)$ e inferior $\left(\mathrm{h}_{1}\right)$ em função da pressão reduzida $\left(\mathrm{p}_{\mathrm{r}}\right)$ e fluxo de calor $(\phi)$. R-123, Tubos de latão, $\mathrm{s} / \mathrm{d}=1,53$.

\subsubsection{3 - Influência do posicionamento dos tubos}

Conforme mostrado na revisão bibliográfica, como regra geral, o coeficiente de transferência de calor (h) aumenta no sentido ascendente nas fileiras de tubos em 
ebulição parcial. Para ebulição nucleada plenamente desenvolvida, o desempenho térmico é aproximadamente similar aquele observado em um único tubo aquecido isoladamente.

Inicialmente foram obtidas curvas do coeficiente de transferência de calor (h) versus fluxo de calor específico $(\phi)$ para 2 tubos aquecidos simultaneamente e, posteriormente, para 3 tubos, conforme mostrado nas Figs.(4.6) e (4.7) apresentadas anteriormente. De acordo com estas figuras, especialmente em ebulição parcial, o coeficiente de transferência de calor aumenta com o posicionamento do tubo no sentido ascendente. Para elevados fluxos de calor (regime de ebulição nucleada plenamente desenvolvida) não ocorre influência das bolhas formadas nos tubos inferiores sobre os superiores, independentemente do posicionamento. Para regime de ebulição parcial, definida pela região onde ocorre formação de bolhas esparsas deve ocorrer intensa influência na transferência de calor dos tubos superiores até um determinado posicionamento. As bolhas formadas nos tubos inferiores devem influenciar a região dos tubos superiores onde ainda não ocorre nucleação e formação de bolhas, contribuindo, com isso, para o incremento do coeficiente de transferência de calor. No entanto, a relação entre o coeficiente de transferência de calor do tubo superior e imediatamente inferior diminui no sentido ascendente, conforme ilustrado na Fig. (4.11). Este comportamento sugere que existirá uma fileira $(\mathrm{N})$, no sentido ascendente, a partir da qual a relação entre o coeficiente de transferência de calor da mesma e do tubo inferior $\left(\mathrm{h}_{\mathrm{N}} / \mathrm{h}_{1}\right)$ permanecerá constante. Este valor pode ser estimado e será mostrado no capítulo 5 .

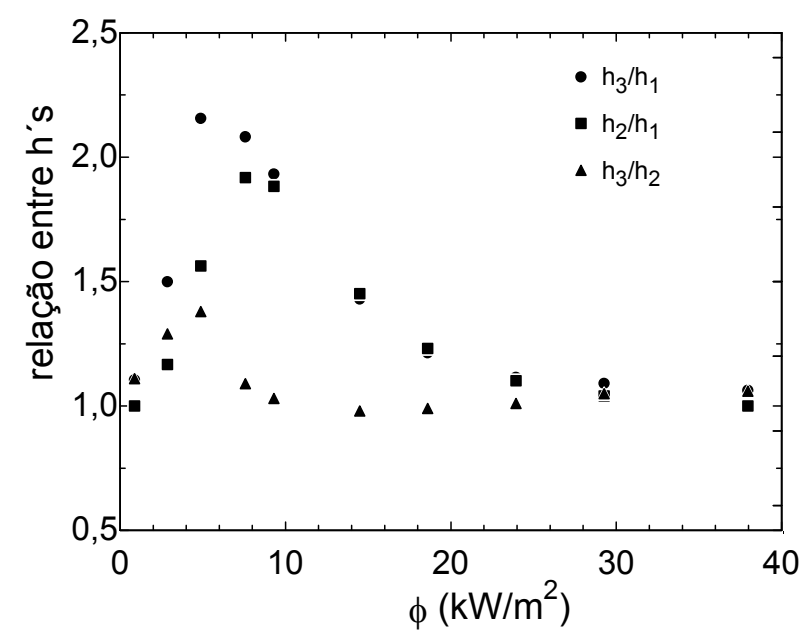

Figura 4.11 Relação entre coeficientes de transferência de calor versus fluxo de calor específico 


\subsubsection{4 - Influência do espaçamento entre tubos}

Como observado na revisão bibliográfica, apesar de diversos autores (Wallner (1971), Muller (1986), Hahne et al (1991), Gupta et al (1995) e Liu e Qiu (2002)) terem investigado a influência do espaçamento entre tubos, geralmente representado pela relação (s/d), no coeficiente de transferência de calor (h), ainda existem contradições e lacunas a serem pesquisadas. Entre tais contradições, destaca-se o fato de alguns autores considerarem que o coeficiente de transferência de calor aumenta com s/d e outros sugerirem o inverso. Através de uma análise dos resultados experimentais, envolvendo valores de (s/d) de 1,32, 153 e 2,00, observou-se que a influência do espaçamento é limitada. No entanto, a análise deste parâmetro, possibilitou a obtenção de informações relevantes sobre o fenômeno da ebulição em banco de tubos.

Através da Fig.(4.12) constata-se que o coeficiente de transferência de calor é pouco influenciado pelo espaçamento entre tubos, quando comparado com o efeito do posicionamento. Este resultado pode estar relacionado à reduzida faixa de espaçamentos utilizados (s/d entre 1,32 e 2,00). Uma redução mais pronunciada na relação s/d poderia proporcionar uma influência do espaçamento mais significativa na transferência de calor, conforme mostrado recentemente por Liu e Qiu (2002).

Na revisão bibliográfica e na seção 4.3.2.3 observa-se que a relação entre os coeficientes de transferência de calor do tubo intermediário e inferior $\left(\mathrm{h}_{2} / \mathrm{h}_{1}\right)$ é afetada pelo regime de ebulição, apresentando valor máximo em condições de ebulição parcial. Através dos resultados experimentais, foi possível concluir que nesse regime de ebulição, a relação entre o coeficiente de transferência de calor do tubo intermediário e inferior $\left(\mathrm{h}_{2} / \mathrm{h}_{1}\right)$, aquecidos simultaneamente com o mesmo fluxo de calor, apresenta uma inversão de comportamento associado ao espaçamento entre tubos. Até um determinado fluxo de calor específico $\left(\phi \approx 7 \mathrm{~kW} / \mathrm{m}^{2}\right)$ a relação $\left(\mathrm{h}_{2} / \mathrm{h}_{1}\right)$ é maior para a configuração com s/d =2,0. Para valores superiores de fluxo de calor específico $\left(\phi>7 \mathrm{~kW} / \mathrm{m}^{2}\right)$, a relação torna-se superior para $\mathrm{s} / \mathrm{d}=1,32$, tendendo à unidade para elevados fluxos de calor $\left(\phi>30 \mathrm{~kW} / \mathrm{m}^{2}\right)$, conforme mostrado na Fig. (4.12). É interessante observar, ainda, que para $\mathrm{s} / \mathrm{d}=1,53$, a relação $\left(\mathrm{h}_{2} / \mathrm{h}_{1}\right)$ apresenta 
sempre um valor intermediário entre os obtidos para $\mathrm{s} / \mathrm{d}=1,32$ e 2,00 , sugerindo que os resultados são consistentes.

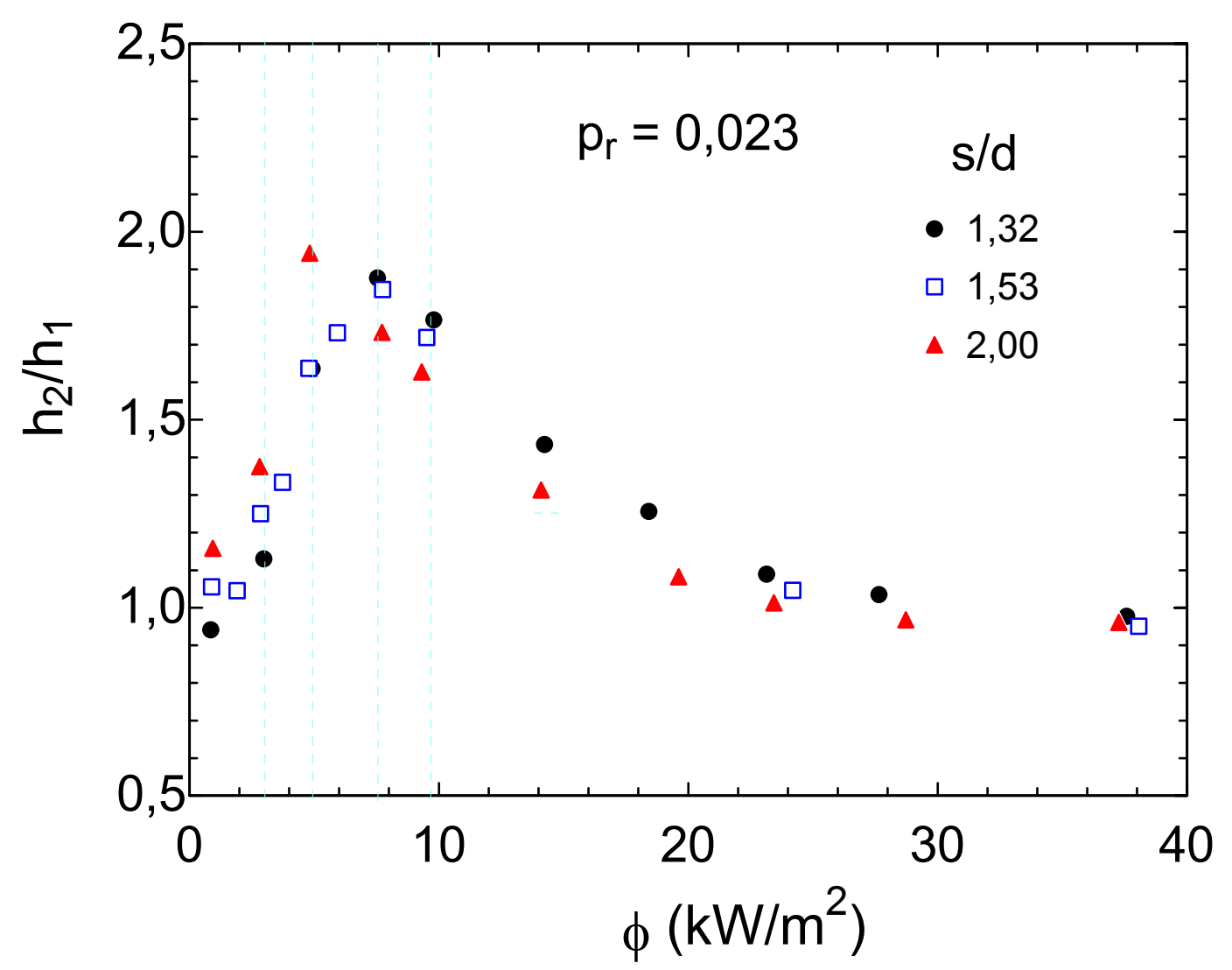

Figura 4.12 - Relação entre coeficientes de transferência de calor do tubo intermediário $\left(\mathrm{h}_{2}\right)$ e inferior $\left(\mathrm{h}_{1}\right)$ versus fluxo de calor.

Os resultados mostrados no parágrafo anterior podem ser explicados, com o auxílio da Fig. (4.13), que ilustra a diferença entre a temperatura da parede do tubo superior desligado (que pode ser aproximada à temperatura do fluido junto à parede do tubo) e do fluido saturado distante dos tubos. Conforme mostrado na Fig. (4.13), a temperatura do fluido junto à parede do tubo é maior quando os tubos inferiores são aquecidos com reduzidos fluxos de calor, sendo esta diferença de temperaturas $\left(\Delta \mathrm{T}_{\text {desligado }}\right)$ mais pronunciada para a configuração com relação de espaçamentos ( $\left.\mathrm{s} / \mathrm{d}\right)$ igual a 1,32. Para reduzidos fluxos de calor predomina o mecanismo de transferência de calor por convecção natural, ocorrendo o movimento do líquido aquecido nos tubos inferiores no sentido ascendente. Ao longo do percurso, este líquido com temperatura superior vai se misturando e trocando calor com o líquido (frio) afastado 
dos tubos, conseqüentemente, resfriando-se. Com isso, para a configuração com $\mathrm{s} / \mathrm{d}=2,0$, o fluido próximo a parede do tubo superior(desligado) apresenta uma temperatura menor que para configuração com $\mathrm{s} / \mathrm{d}=1,32$. Para fluxos de calor elevados, ocorre uma formação de bolhas mais intensa nos tubos inferiores, responsáveis pela agitação e circulação do líquido, suprimindo os efeitos de convecção natural. Com isso o fluido em contato com o tubo superior (desligado), apresenta uma temperatura superior ao fluido distante dos tubos, mas inferior àquela em condições de convecção natural. Portanto, para elevados fluxos de calor, as diferenças de temperaturas no tubo superior (desligado) são aproximadamente iguais, independentemente da configuração.

Seguindo o mesmo raciocínio, pode-se afirmar que para reduzidos fluxos de calor específico $\left(\phi<7 \mathrm{~kW} / \mathrm{m}^{2}\right) \quad$ (com o tubo inferior e intermediário aquecidos simultaneamente), o tubo intermediário na configuração com s/d=1,32 sofrerá maior influência em relação a configuração com $\mathrm{s} / \mathrm{d}=2,0$, onde predomina o mecanismo de convecção natural. Como observado na revisão bibliográfica, o tubo inferior apresenta desempenho semelhante a um único tubo, independentemente da configuração e espaçamentos. Com isso, conclui-se que, para reduzidos fluxos de calor, o coeficiente de transferência de calor do tubo intermediário, na configuração com $\mathrm{s} / \mathrm{d}=2,0$, é superior ao daquela em que $\mathrm{s} / \mathrm{d}=1,32$. Este efeito está relacionado ao menor gradiente de temperatura existente na região junto à parede do tubo para configuração com $\mathrm{s} / \mathrm{d}=1,32$ quando comparada à $\mathrm{s} / \mathrm{d}=2,0$. Este menor gradiente de temperatura ocasiona uma menor transferência de calor e conseqüentemente menor coeficiente de transferência de calor.

Para fluxos de calor específico intermediários $\left(7<\phi>20 \mathrm{~kW} / \mathrm{m}^{2}\right)$ o mecanismo de transferência de calor passa a ser afetado pela ebulição do tubo inferior, responsável pela agitação e movimentação do líquido junto a superfície dos tubos. Para a configuração com espaçamento maior $(\mathrm{s} / \mathrm{d}=2,0)$ ocorre uma maior dispersão das bolhas formadas no tubo inferior antes de atingirem as proximidades do tubo superior, resultando numa menor influência daquelas na transferência de calor do mesmo, quando comparada com a configuração com s/d=1,32. Com isso, para fluxos de calor intermediários a relação entre os coeficientes de transferência de calor do tubo intermediário e inferior $\left(\mathrm{h}_{2} / \mathrm{h}_{1}\right)$ é superior para a configuração com 
$\mathrm{s} / \mathrm{d}=1,32$. Para elevados fluxos de calor $\left(\phi>20 \mathrm{~kW} / \mathrm{m}^{2}\right)$, a formação de bolhas é intensa em ambos os tubos, sendo a influência do tubo inferior sobre o superior pouco significativa. Com isso, a relação entre os coeficientes de transferência de calor do tubo intermediário e inferior $\left(\mathrm{h}_{2} / \mathrm{h}_{1}\right)$ é aproximadamente unitária independentemente do espaçamento entre tubos.

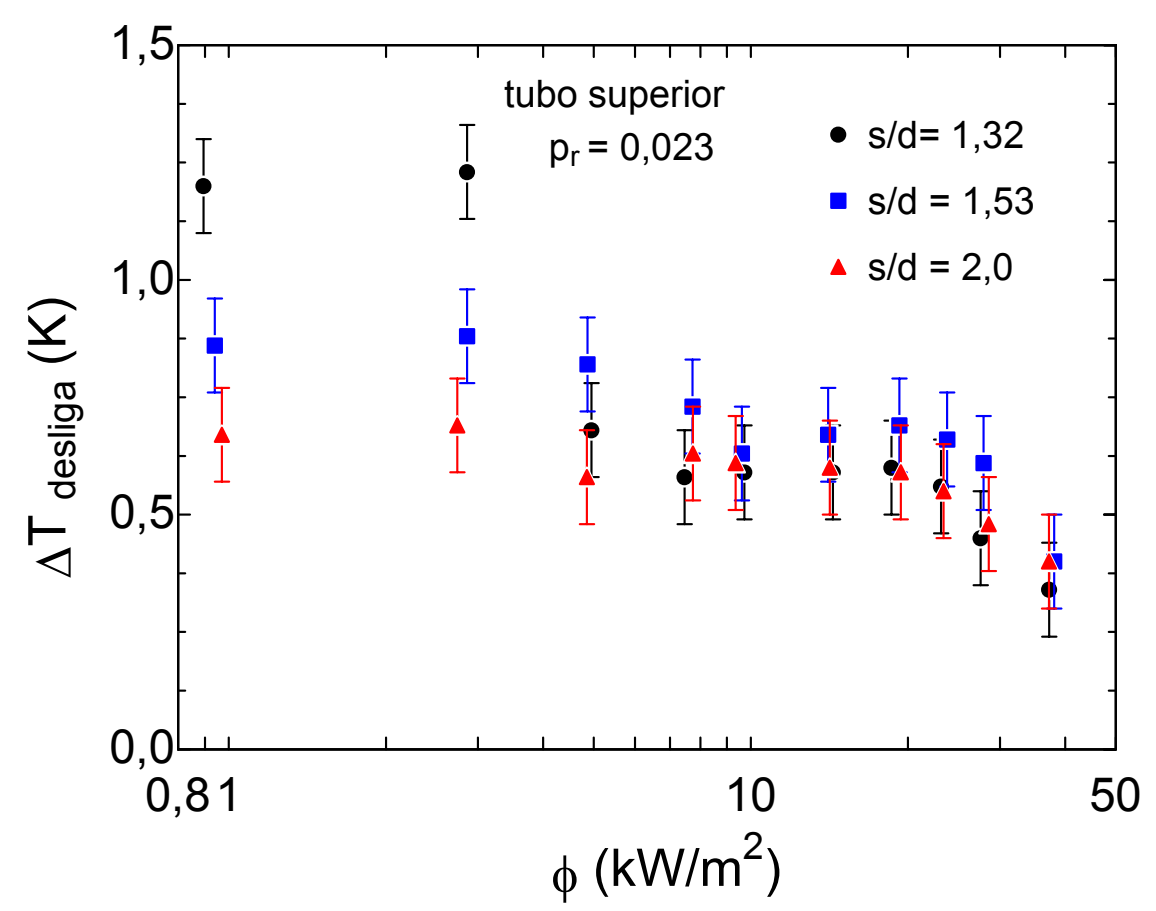

Figura 4.13 - Diferença entre a temperatura do fluido junto à superfície do tubo superior (desligado) e fluido afastado dos tubos (saturado) em função do fluxo de calor aplicado nos tubos inferior e intermediário, e relação de espaçamentos entre tubos $(\mathrm{s} / \mathrm{d})$.

\subsection{Conclusões}

Com base nos resultados experimentais obtidos, foi possível extrair as seguintes conclusões:

- O acabamento superficial apresenta grande influência no coeficiente de transferência de calor em ebulição nucleada até um determinado valor de rugosidade média aritmética. A partir de um determinado valor (acima de 3,5 $\mu \mathrm{m})$ foi verificada uma diminuição no coeficiente de transferência de calor. 
- Para faixa de diâmetros investigados (entre 12,5 e 22,0 mm), a influência deste parâmetro no coeficiente de transferência de calor em ebulição nucleada, pode ser considerada desprezível.

- Em banco de tubos, para fluxos de calor relativamente reduzidos (entre 5 a 10 $\mathrm{kW} / \mathrm{m}^{2}$, para o R-123) ou regime de ebulição nucleada parcial, a diferença entre desempenho dos tubos depende consideravelmente do posicionamento. Neste regime o tubo superior apresentou coeficiente de transferência de calor consideravelmente superior (até 2 vezes) ao do tubo inferior.

- Com o aumento do fluxo de calor, diminui a diferença entre os coeficientes de transferência de calor dos tubos superior e inferior.

- Com o aumento da pressão, apesar do coeficiente de transferência de calor ser superior em todos os tubos, diminui a relação entre os coeficientes de transferência de calor dos tubos superior e inferior.

- Tubos de fileiras superiores apresentam um melhor desempenho (maior coeficiente de transferência de calor) que tubos de fileiras inferiores. Esta melhora relativa de desempenho tende a diminuir com o número de fileiras e o fluxo de calor.

- A influência do espaçamento entre tubos no coeficiente de transferência de calor médio é menor quando comparada com a influência do posicionamento dos tubos.

- Para o R-123, em reduzidos fluxos de calor $\left(\phi<7 \mathrm{~kW} / \mathrm{m}^{2}\right)$, a relação entre o coeficiente de transferência de calor do tubo intermediário e inferior (aquecidos simultaneamente com mesmo fluxo de calor) é superior para a configuração com maior espaçamento entre tubos $(\mathrm{s} / \mathrm{d}=2,0)$. Para fluxos de calor intermediários $\left(7<\phi<20 \mathrm{~kW} / \mathrm{m}^{2}\right)$, este comportamento é inverso, ou seja, a relação entre os coeficientes de transferência de calor do tubo intermediário e o do inferior é maior para a configuração com menor espaçamento entre tubos $(\mathrm{s} / \mathrm{d}=1,32)$. Para elevados fluxos de calor $(\phi>20$ $\left.\mathrm{kW} / \mathrm{m}^{2}\right)$, a relação $\left(\mathrm{h}_{2} / \mathrm{h}_{1}\right)$ é aproximadamente igual a 1 , ou seja, a influência do tubo inferior sobre o intermediário é desprezível, independentemente do espaçamento entre tubos. 


\section{5- Desenvolvimento de uma correlação}

$\mathrm{Na}$ revisão bibliográfica foram introduzidas diversas correlações da literatura para a ebulição em banco de tubos. Tais correlações são geralmente semi-empíricas, incorporando parâmetros relacionados aos fenômenos físicos intervenientes e ajustados através de coeficientes e expoentes empíricos, sendo assim, válidas para uma faixa de operação restrita.

A correlação proposta no presente trabalho toma por base o efeito dos tubos inferiores sobre os superiores, resultando uma expressão para os coeficientes de transferência de calor dos tubos superiores $\left(\mathrm{h}_{2}, \mathrm{~h}_{3}, \ldots, \mathrm{h}_{\mathrm{n}}\right)$ em relação ao tubo inferior $\left(h_{1}\right)$, como função dos principais parâmetros que afetam a transferência de calor em banco de tubo (fluxo de calor específico, pressão reduzida e posicionamento). A correlação proposta é extensiva a várias condições e exclui a necessidade de utilização de tabelas para os coeficientes empíricos. O coeficiente de transferência de calor do tubo inferior pode ser obtido mediante correlações da literatura para um único tubo 


\section{1 - Correlação para relação $h_{2} / h_{1}$}

Conforme mostrado nos Capítulos 2 e 4, que envolvem, respectivamente, a análise de correlações para ebulição nucleada e resultados experimentais, verificouse que o coeficiente de transferência de calor em tubos superiores de um banco de tubos em relação àquele relativo a um único tubo apresenta diferenças resultantes do posicionamento dos tubos, da faixa de fluxo de calor (região de ebulição nucleada parcial), pressão e, em menor grau, do espaçamento entre tubos. Através dos resultados experimentais, para dois tubos aquecidos simultaneamente com aproximadamente o mesmo fluxo de calor, foram obtidas as relações entre os coeficientes de transferência de calor do tubo superior e inferior $\left(\mathrm{h}_{2} / \mathrm{h}_{1}\right)$ versus fluxo de calor específico $(\phi)$, conforme mostrado nas Figs. (5.1) a (5.3).

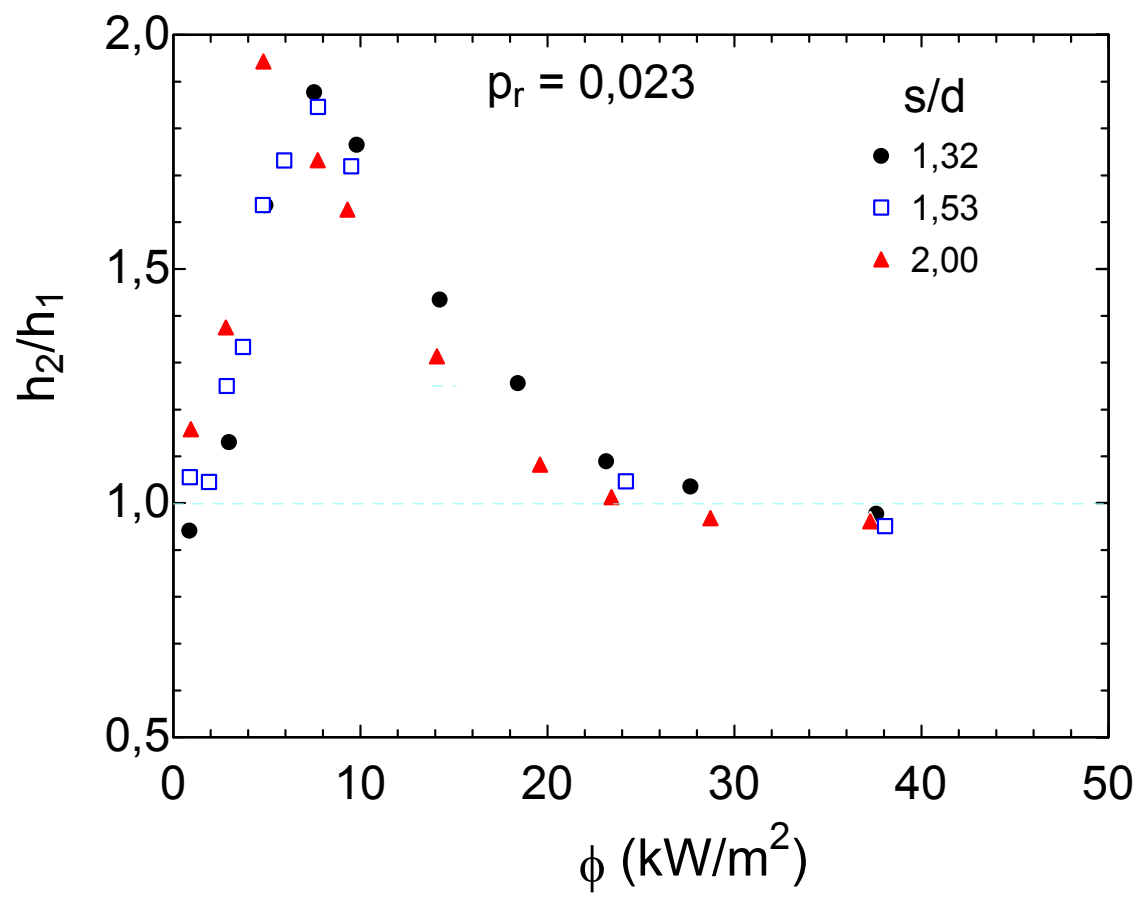

Figura 5.1 - Relação entre coeficientes de transferência de calor do tubo superior e inferior $\left(\mathrm{h}_{2} / \mathrm{h}_{1}\right)$ versus fluxo de calor específico $(\phi)$. R-123, $\mathrm{p}_{\mathrm{r}}=0,023$ 


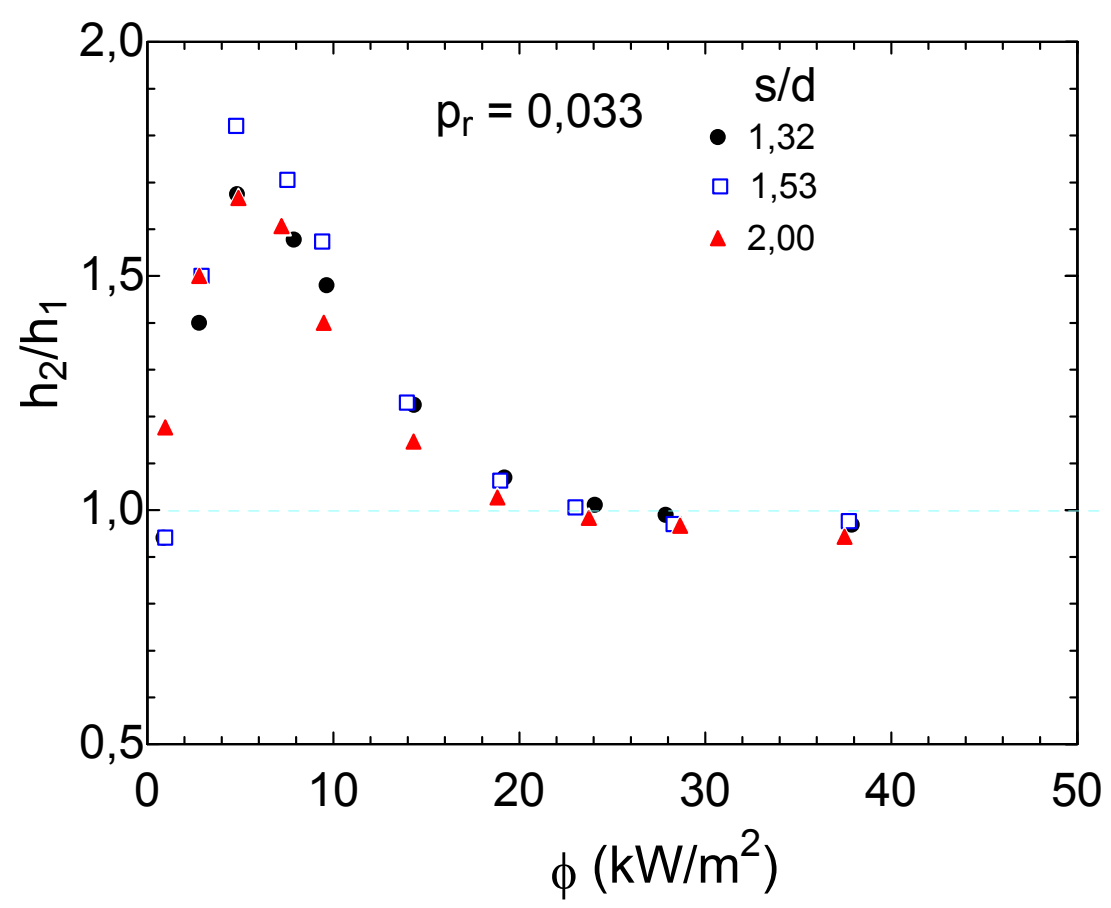

Figura 5.2 - Relação entre coeficientes de transferência de calor do tubo superior e inferior $\left(\mathrm{h}_{2} / \mathrm{h}_{1}\right)$ versus fluxo de calor específico $(\phi) . \mathrm{R}-123, \mathrm{p}_{\mathrm{r}}=0,033$

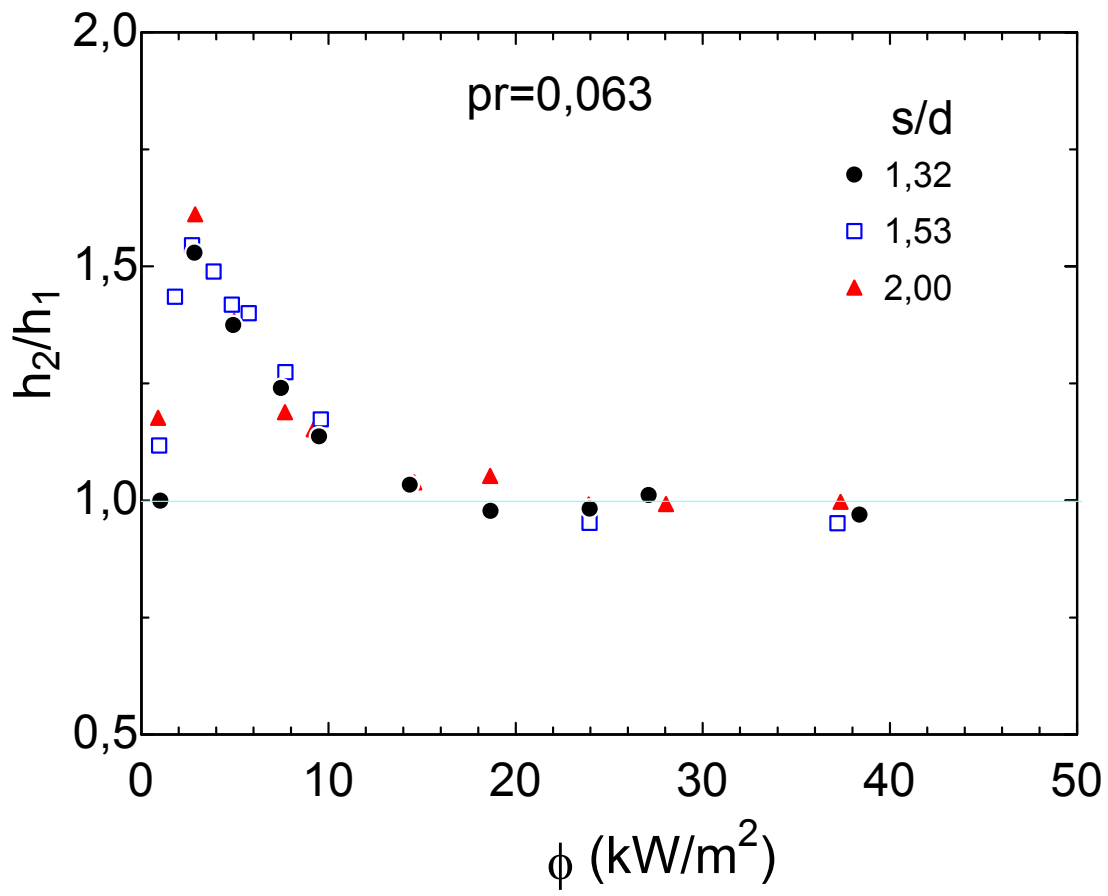

Figura 5.3 - Relação entre coeficientes de transferência de calor do tubo superior e inferior $\left(h_{2} / h_{1}\right)$ versus fluxo de calor específico $(\phi) . R-123, p_{r}=0,063$ 
Nas curvas das Fig. (5.1) a (5.3), verifica-se que a relação $h_{2} / h_{1}$ aumenta com o fluxo de calor até um determinado valor, a partir do qual diminui assintoticamente. Este comportamento ilustra os efeitos das bolhas formadas no tubo inferior sobre o tubo superior, sendo mais pronunciado para região de ebulição parcial, caracterizada por formação de bolhas esparsas na superfície aquecida. Observa-se, ainda, que o máximo da relação $h_{2} / h_{1}$ e o correspondente valor do fluxo de calor específico diminuem com a pressão. As curvas das Figs. (5.1) a (5.3) podem ser razoavelmente reproduzidas pela função matemática logarítmica normal, cuja expressão é a seguinte:

$$
\frac{h_{2}}{h_{1}}=A_{0}+\frac{A}{\sqrt{2 \pi} \cdot w \cdot \phi} \exp \left(\frac{-\left(\ln \left(\phi / \phi_{c}\right)\right)^{2}}{2 w^{2}}\right)
$$

onde $h_{l}$ é o coeficiente de transferência de calor para um único tubo ou tubo inferior e $A_{0}, A, w$ e $\phi_{c}$ são coeficientes que podem ser obtidos através do ajuste dos resultados experimentais, mediante a utilização de algumas condições de contorno, conforme será mostrado adiante.

\subsection{1 - Análise dos coeficientes}

Os coeficientes da Eq. (5.1) foram obtidos com o auxílio de um programa para computador, "Origin Pro Lab", que ajusta os resultados experimentais, sendo os valores resultantes mostrados na Tabela 5.1. Estes coeficientes poderiam, ainda, ser obtidos analiticamente através da utilização de algumas condições de contorno associadas ao problema físico da ebulição em banco de tubos. No entanto, com o fim de facilitar o procedimento e reduzir os desvios em relação aos resultados experimentais, utilizou-se o referido programa de ajuste.

As Figuras (5.1) a (5.3) permitem propor as seguintes condições de contorno relacionadas ao comportamento físico:

- A relação $h_{2} / h_{1}$ tende à unidade para elevados fluxos de calor específico. Este comportamento está relacionado à reduzida influência do tubo inferior sobre o tubo superior na região de ebulição nucleada plenamente desenvolvida (região de elevados fluxos de calor). Nesta região, a formação de bolhas no tubo superior é tão intensa que as bolhas formadas no tubo inferior não 
afetam a superfície superior e, conseqüentemente, o coeficiente de transferência de calor do tubo superior é aproximadamente igual ao do tubo inferior.

- A relação $h_{2} / h_{1}$ atinge um valor máximo para determinado fluxo de calor específico, aqui designado por $\phi_{c}$. $\mathrm{O}$ máximo valor da relação $\mathrm{h}_{2} / \mathrm{h}_{1}$ dependente da pressão e espaçamento entre tubos. No entanto, o efeito deste último parâmetro pode ser considerado desprezível. O valor da máxima relação $\mathrm{h}_{2} / \mathrm{h}_{1}$ estaria relacionado aos coeficientes $A$ e $w$, conforme será mostrado adiante.

Tabela 5.1 - Coeficientes da Eq.5.1 em função da pressão reduzida ajustada a partir dos resultados experimentais

\begin{tabular}{|cccc|}
\hline \hline $\mathbf{p}_{\mathbf{r}}$ & $\boldsymbol{\phi}_{\mathbf{c}}\left(\mathbf{k W} / \mathbf{m}^{2}\right)$ & $\boldsymbol{A}$ & $\boldsymbol{w}$ \\
\hline 0,023 & 10,2 & 10,3 & 0,53 \\
\hline 0,033 & 7,96 & 7,04 & 0,61 \\
\hline 0,063 & 4,98 & 3,15 & 0,66 \\
\hline
\end{tabular}

\section{Interpretação do coeficiente $\boldsymbol{A}_{o}$}

As Figuras. (5.1) a (5.3) permitem concluir que para elevados fluxos de calor específico $\left(\phi \approx 20\right.$ e $\left.25 \mathrm{~kW} / \mathrm{m}^{2}\right), p_{\mathrm{r}}=0,023$ a 0,063 , respectivamente, a relação $\mathrm{h}_{2} / \mathrm{h}_{1}$ tende assintoticamente para um. Através da Eq. (5.1) mostra-se que com o aumento do fluxo de calor específico, o segundo termo do lado direito da equação tende a zero e, conseqüentemente, a relação $\mathrm{h}_{2} / \mathrm{h}_{1}$ tende ao valor do coeficiente $A_{0}$. Com isso $A_{0}$ pode ser considerado igual a $1\left(\mathrm{~h}_{2}\right.$ igual $\mathrm{h}_{1}$, não ocorrendo influência de um tubo sobre o outro) para elevados fluxos de calor $\left(\phi>40 \mathrm{~kW} / \mathrm{m}^{2}\right)$. 


\section{Interpretação do coeficiente $\phi_{c}$}

A partir dos resultados experimentais, mostrou-se que $\mathrm{h}_{2} / \mathrm{h}_{1}$ é mínimo quando for igual ao coeficiente $A_{0}$. Com isso, a relação $A / \sqrt{2 \pi}$.w. $\phi$ deverá necessariamente ser positiva. A relação $\mathrm{h}_{2} / \mathrm{h}_{1}$ será máxima quando o termo $\left\{-\left[\left(\ln \left(\phi / \phi_{c}\right)\right)^{2} / 2 w^{2}\right]\right\}$ for igualmente máximo. Este termo é sempre menor ou igual a zero, portanto, seu máximo algébrico é zero. Para ser igual a zero, $\phi_{\mathrm{c}}$ deve ser igual $\phi$ ou $w$ tender ao infinito. Se o coeficiente $w$ tendesse ao infinito, a Eq. (5.1) não reproduziria os resultados experimentais. Portanto, necessariamente $\phi$ deve ser igual $\phi_{\mathrm{c}}$. Com isso, $\phi_{c}$, correspondente ao fluxo de calor específico para o qual a relação $h_{2} / h_{1}$ é máxima. Destaca-se que este coeficiente sempre diminui com a pressão reduzida, conforme mostrado na Tabela (5.1). Este resultado ilustra o fato de que, com o aumento da pressão, diminui o valor do fluxo de calor específico para o qual a relação $h_{2} / h_{1}$ atinge seu máximo. Este comportamento está relacionado à curva de ebulição (mostrada no Cap.2) sofrer o deslocamento para a esquerda com o aumento da pressão, devido ao incremento no número de cavidades ativas e bolhas formadas. Com isso, a faixa de fluxos de calor correspondente à ebulição parcial (onde ocorre a máxima relação $h_{2} / h_{1}$ ) corresponde a menores fluxos de calor com o aumento da pressão. Observa-se, ainda, nas Figs.(5.1) a (5.3), que o coeficiente $\phi_{\mathrm{c}}$ não apresenta uma tendência clara com o espaçamento entre tubos. Portanto, este efeito será considerado desprezível em comparação aos de pressão reduzida. A partir dos resultados, mostrados na Tabela (5.1), foi possível obter uma curva relacionando o coeficiente $\phi_{c}$ e a pressão reduzida, conforme mostrado na Fig. (5.4). Esta curva pode ser expressa pela seguinte relação:

$\phi_{c}=0,73 \cdot p_{r}^{-0,7}$ 


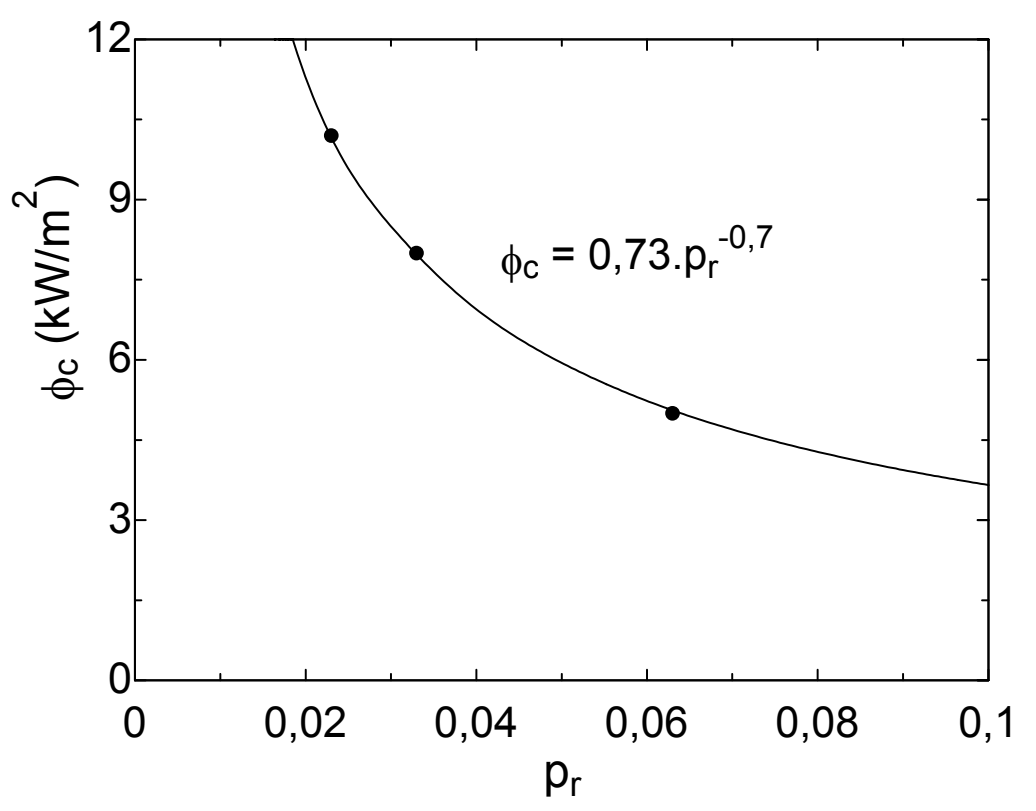

Figura 5.4 - Variação do coeficiente $\phi_{c}$ com a pressão reduzida

O coeficiente $\phi_{\mathrm{c}}$ poderia ser utilizado para caracterizar o regime de transição de ebulição parcial para ebulição nucleada plenamente desenvolvida em banco de tubos. Esta transição seria dependente da pressão reduzida associada a uma determinada faixa de fluxos de calor. A partir da pressão reduzida, poderia se determinar o valor correspondente do coeficiente $\phi_{c}$ e, conseqüentemente, do fluxo de calor para transição entre referidos regimes. Conforme será mostrado adiante, o valor de $\phi_{\mathrm{c}}$ diminui com o número de fileiras verticais do banco de tubos.

\section{Interpretação dos coeficientes $A$ e $w$}

Conforme mostrado anteriormente, o máximo valor de $h_{2} / h_{1}$ ocorre quando $\phi$ é aproximadamente igual a $\phi_{c}$. Nesta situação o termo exp $\left\{-\left[\left(\ln \left(\phi / \phi_{c}\right)\right)^{2} / 2 w^{2}\right]\right\}$ será igual a 1 e a Eq.(5.1) será expressa por:

$$
\left(\frac{h_{2}}{h_{1}}\right)_{\max }-1=\frac{A}{2,5 \cdot w \cdot \phi_{c}},
$$

O coeficiente $A$ está relacionado ao máximo valor que a relação $\mathrm{h}_{2} / \mathrm{h}_{1}$ pode atingir, independendo do fluxo de calor em que ocorre este máximo. Mantendo-se 
todos os demais coeficientes constantes, as curvas de $\mathrm{h}_{2} / \mathrm{h}_{1}$ vs $\phi$ para distintos valores de $A$ assumirão o valor máximo para um mesmo fluxo de calor, como ilustrado na Fig. (5.5).

O coeficiente $w$ é o responsável pelo ajuste do posicionamento da curva $h_{2} / h_{1}$ vs $\phi$ para se atingir $\left(\mathrm{h}_{2} / \mathrm{h}_{1}\right)_{\max }$ correspondente ao fluxo de calor específico $\phi_{c}$. Este comportamento é ilustrado na Fig. (5.6), onde o valor de $w$ é variado mantendo-se fixos os valores dos demais coeficientes da Eq. (5.1).

Com o aumento da pressão reduzida a relação $\left(\mathrm{h}_{2} / \mathrm{h}_{1}\right)_{\max }$ diminui e, conseqüentemente, o coeficiente $A$ deve diminuir. Ao contrário, o coeficiente $w$ deve aumentar para que o valor correspondente de $\phi_{c}$ seja inferior com o aumento da pressão. Através da comparação das Fig. (5.5) e (5.6) com as Figs. (5.1) a (5.3) é possível observar que o coeficiente $A$ deve diminuir e o $w$ aumentar com a pressão reduzida. Este comportamento é confirmado através dos resultados ilustrados na Tabela (5.1) para $A$ e $w$ em função de $\mathrm{p}_{\mathrm{r}}$.

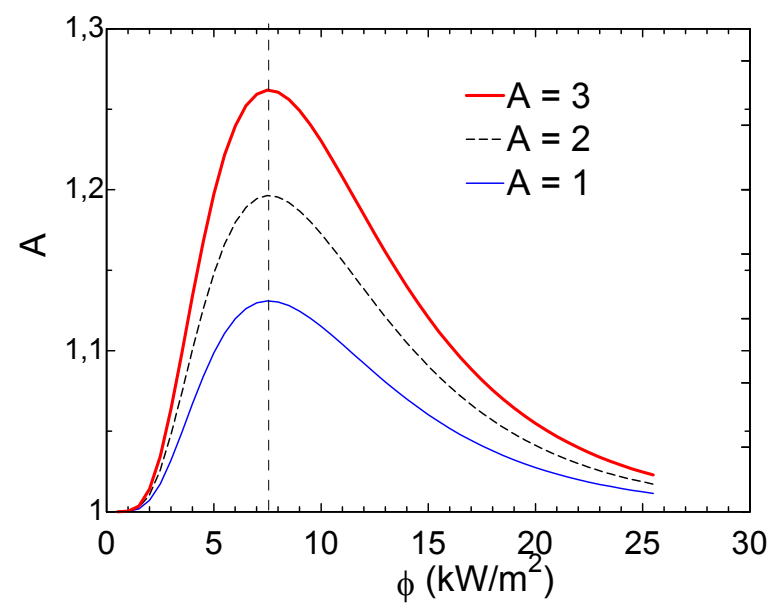

Figura 5.5 - Variação de $A \operatorname{com} \phi$

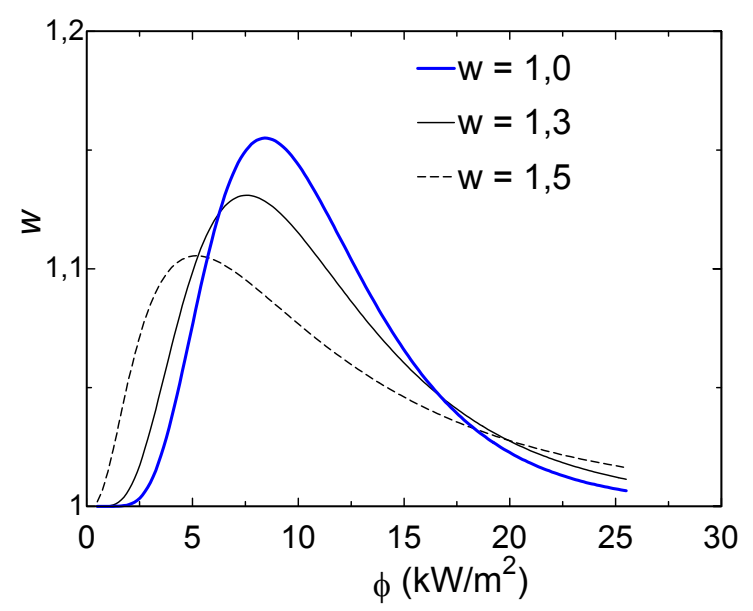

Figura 5.6 - Variação de $w \operatorname{com} \phi$

As curvas dos coeficientes $A$ e $w$ versus a pressão reduzida são ilustradas nas Figs (5.7) e (5.8). Estas curvas podem ser expressas pelas seguintes relações: $A=0,113 \cdot p_{r}^{-1,2}$

$w=1,16 \cdot p_{r}^{0,2}$ 


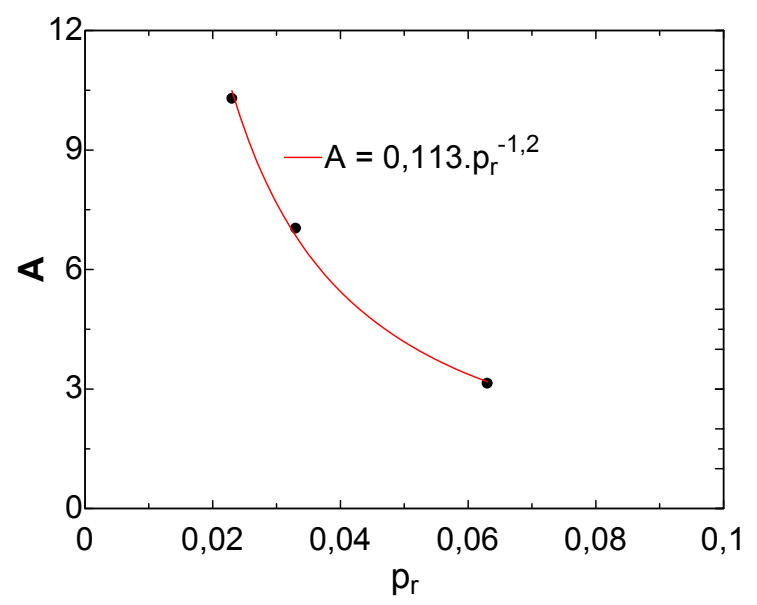

Figura 5.7 - Relação entre $A$ e $\mathrm{p}_{\mathrm{r}}$

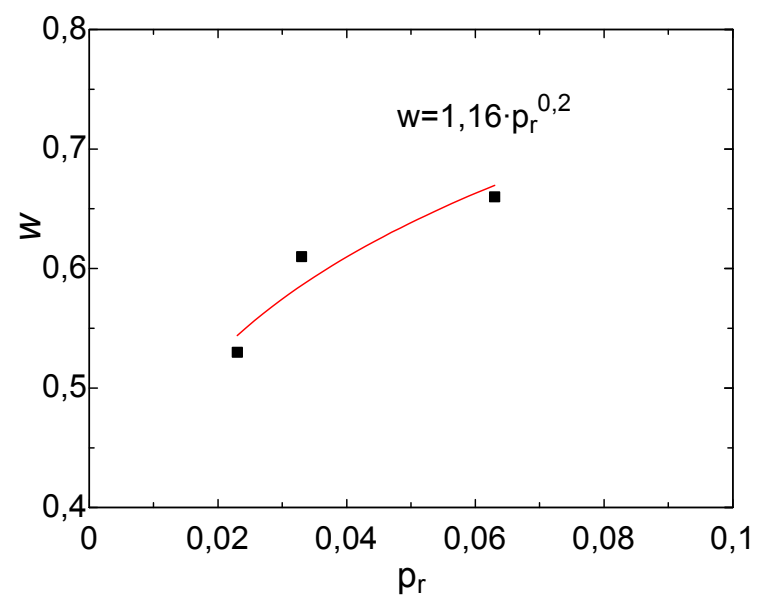

Figura 5.8 - Relação entre $w$ e $p_{\mathrm{r}}$

\subsection{Correlação para 2 tubos}

A partir das Eqs. (5.2), (5.4) e (5.5), obtidas para os coeficientes da Eq. (5.1), obteve-se a seguinte correlação para $h_{2} / h_{1}$, envolvendo a ebulição do refrigerante R-123 em dois tubos aquecidos simultaneamente com mesmo fluxo de calor:

$\frac{h_{2}}{h_{1}}=1+0,345 \cdot C_{A} \cdot p_{r}^{-1,4} \cdot \phi^{-1} \cdot \exp \left\{-0,37 \cdot p_{r}^{-0,4}\left[\ln \left(\phi / \phi_{c}\right)\right]^{2}\right\}$

onde: $\quad C_{A}=0,113 \mathrm{e}$

$\phi_{c}=C_{\phi} \cdot p_{r}^{-0,7}$

$C_{\phi}=0,73$

\section{3 - Correlação para relação $h_{3} / h_{1}$}

$\mathrm{O}$ procedimento para a obtenção da correlação para a relação $\mathrm{h}_{3} / \mathrm{h}_{1}$ é semelhante ao utilizado para $h_{2} / h_{1}$. As relações de $h_{3} / h_{1}$ versus $\phi$ para 3 tubos aquecidos simultaneamente com igual fluxo de calor são mostradas nas Figs. (5.9) a (5.11). 


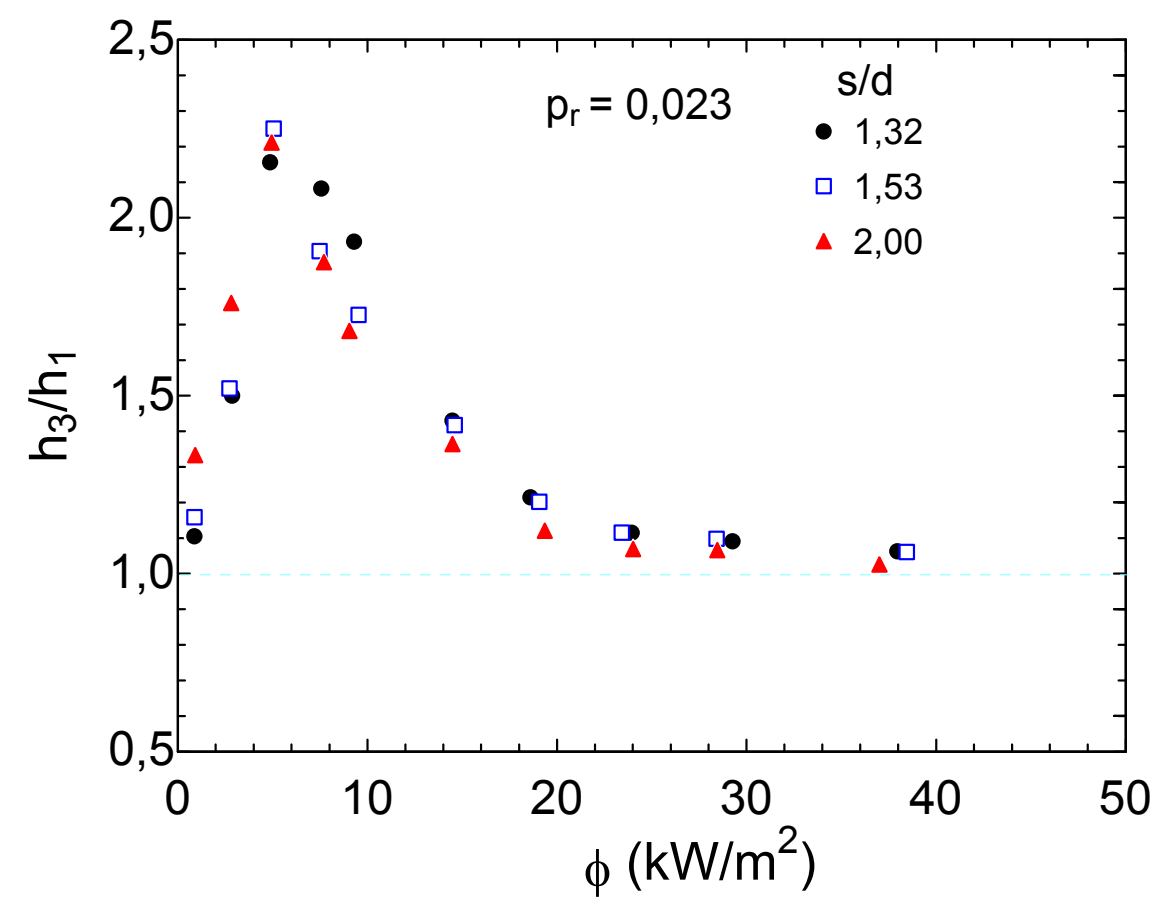

Figura 5.9 - Relação entre coeficientes de transferência de calor do tubo superior e inferior $\left(h_{3} / h_{1}\right)$ versus fluxo de calor específico $(\phi)$. R-123, $\mathrm{p}_{\mathrm{r}}=0,023$

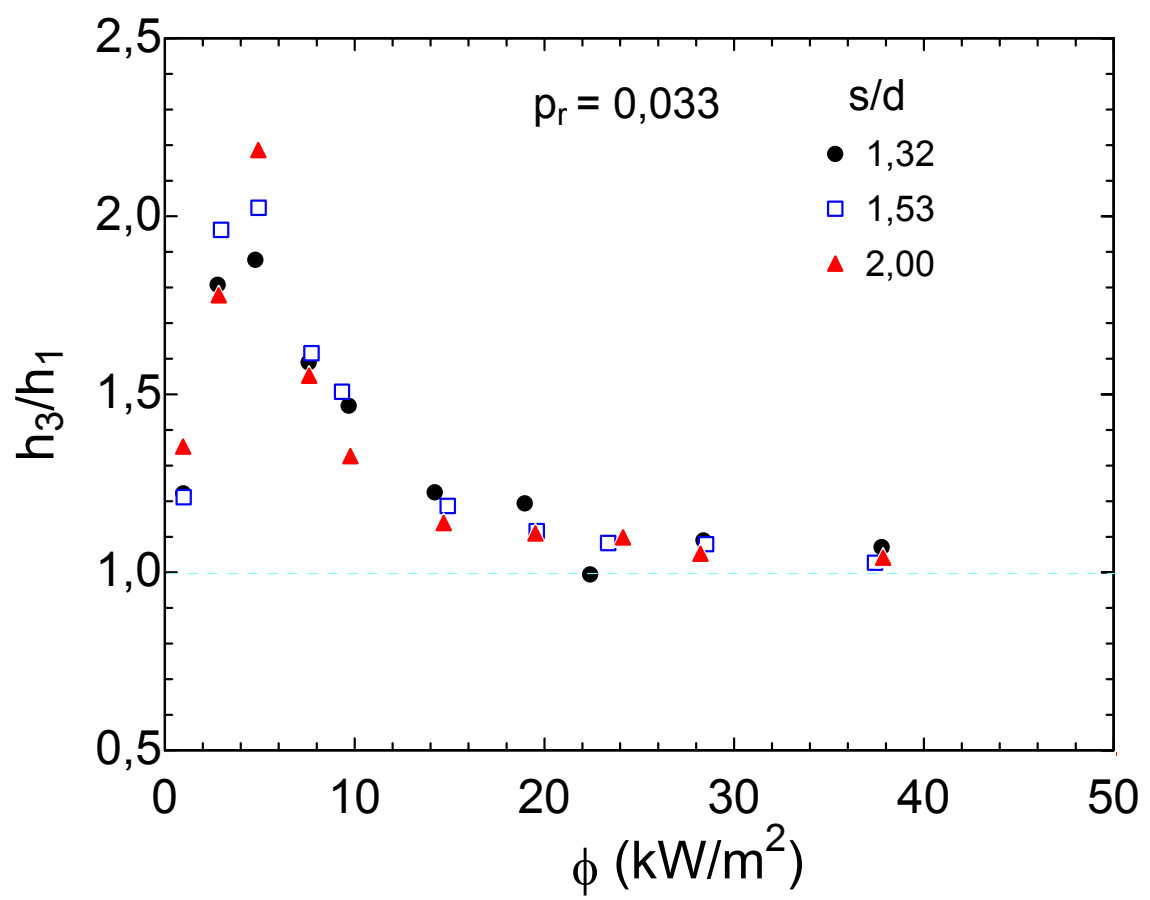

Figura 5.10 - Relação entre coeficientes de transferência de calor do tubo superior e inferior $\left(\mathrm{h}_{3} / \mathrm{h}_{1}\right)$ versus fluxo de calor específico $(\phi)$. R-123, $\mathrm{p}_{\mathrm{r}}=0,033$ 


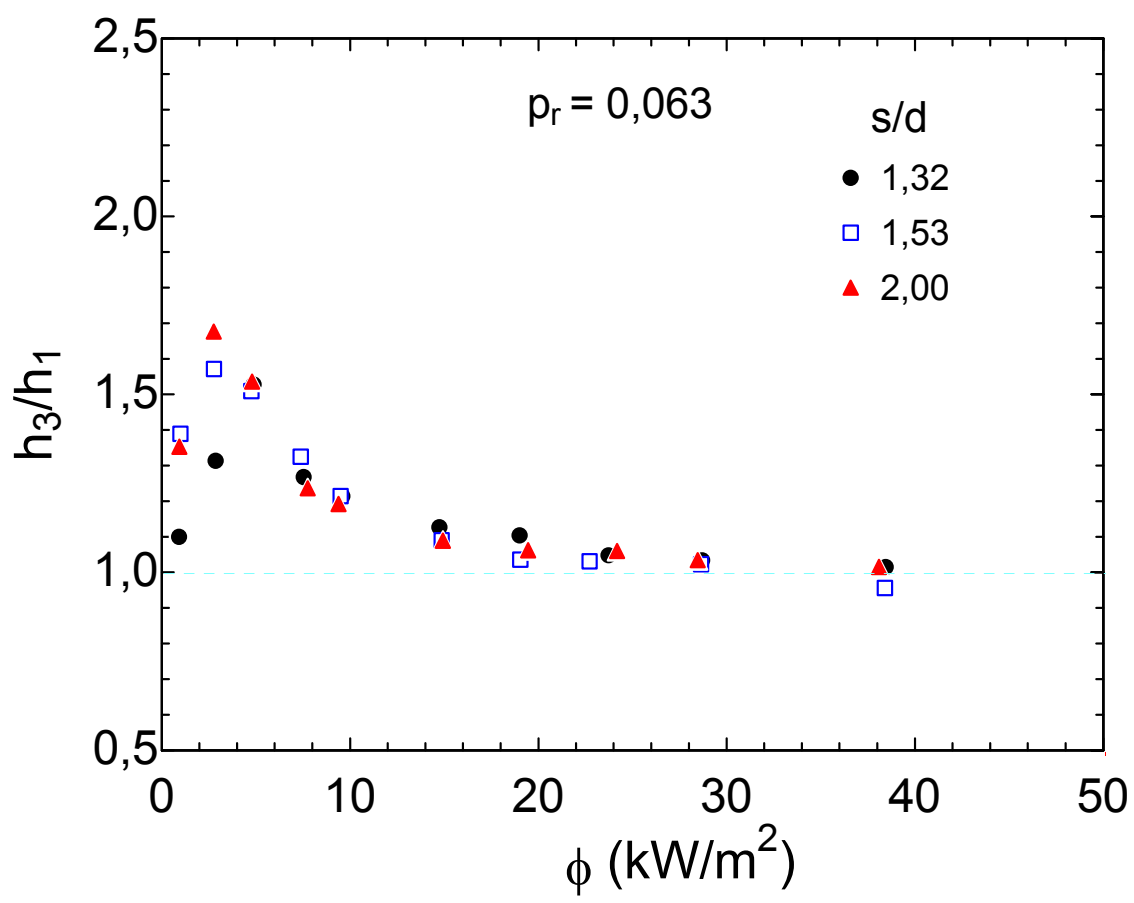

Figura 5.11 - Relação entre coeficientes de transferência de calor do tubo superior e inferior $\left(h_{3} / h_{1}\right)$ versus fluxo de calor específico $(\phi)$. R-123, $\mathrm{p}_{\mathrm{r}}=0,063$

As Figs. (5.9) a (5.11) permitem constatar que a relação $h_{3} / h_{1}$ pode, também, ser expressa pela mesma função logarítmica normal do caso anterior: $\frac{h_{3}}{h_{1}}=A_{03}+\frac{A_{3}}{\sqrt{2 \pi} \cdot w_{3} \cdot \phi} \exp \left(\frac{-\left(\ln \left(\phi / \phi_{c 3}\right)\right)^{2}}{2 w_{3}^{2}}\right)$

Comparando-se as Figs. (5.1) a (5.3) e Figs. (5.9) a (5.11), podem-se obter algumas conclusões associadas ao mecanismo físico em questão que servirão de base para obtenção de uma correlação generalizada para ampla faixa de fileiras de tubos. Entre tais observações, destacam-se as seguintes:

1) Como observado para $h_{2} / h_{1}$, a relação $h_{3} / h_{1}$ tende assintoticamente para 1 . Portanto para a Eq. (5.7) o coeficiente $A_{03}$ pode ser considerado igual a 1 .

2) O máximo valor de $h_{3} / h_{1}$ é superior ao máximo obtido para $h_{2} / h_{1}$. No entanto, a relação $h_{3} / h_{2}$ é inferior a $h_{2} / h_{1}$. Este comportamento sugere que a relação $\mathrm{h}_{\mathrm{n}} / \mathrm{h}_{1}$ aumenta com o número de fileiras (n) até um determinado valor, a partir do qual deve se manter aproximadamente constante. 
3) O fluxo de calor específico correspondente ao máximo de $\mathrm{h}_{3} / \mathrm{h}_{1}\left(\phi_{c 3}\right)$ é inferior ao correspondente $\mathrm{a} \mathrm{h}_{2} / \mathrm{h}_{1}$. Portanto, o valor de $\phi_{c}$ deve diminuir com o número de fileiras. No entanto, este valor deve atingir um mínimo. Este mínimo corresponderia ao limite superior da faixa de fluxos de calor em que se verifica convecção natural, condição em que tem início a formação da primeira coluna de bolhas.

4) O deslocamento e "abertura" das curvas, associados aos coeficientes $A$ e $w$ da função logarítmica normal, apresentam comportamentos próximos para ambas relações $h_{2} / h_{1}$ e $h_{3} / h_{1}$.

A partir das curvas mostradas das Figs. (5.9) a (5.11) foi possível obter os coeficientes $A_{3}, w_{3}$ e $\phi_{c 3}$ em função da pressão reduzida $\left(\mathrm{p}_{\mathrm{r}}\right)$, sendo os mesmos apresentados na Tabela 5.2.

Tabela 5.2 - Coeficientes da Eq.5.7 em função da pressão reduzida

\begin{tabular}{|cccc|}
\hline \hline $\mathbf{p}_{\mathbf{r}}$ & $\boldsymbol{\phi}_{c 3}\left(\mathbf{k W} / \mathbf{m}^{\mathbf{2}}\right)$ & $\boldsymbol{A}_{\mathbf{3}}$ & $\boldsymbol{w}_{\mathbf{3}}$ \\
\hline 0,023 & 7,70 & 11,2 & 0,55 \\
\hline 0,033 & 5,90 & 7,70 & 0,59 \\
\hline 0,063 & 4,30 & 4,30 & 0,67 \\
\hline
\end{tabular}

Comparando os valores obtidos para os coeficientes da Eq. (5.7) (mostrados na Tablea 5.2) com aqueles da Eq. (5.1) (mostrados na Tabela 5.1), e de acordo com as observações enumeradas anteriormente, mostra-se que:

- Os valores dos coeficientes $A_{3}$ são superiores aos correspondentes $A$. Este comportamento confirma a observação (2).

- O fluxo de calor específico correspondente ao máximo $h_{3} / h_{1}$, representado pelo coeficiente $\phi_{c 3}$ é inferior a $\phi_{c}$ para uma mesma pressão reduzida. Este comportamento esperado confirma a observação (3).

- Os coeficientes $w_{3}$ foram aproximadamente iguais aos correspondentes à Eq. (5.1). Portanto, este coeficiente pode ser considerado independente do posicionamento e número de tubos, dependendo exclusivamente da pressão reduzida. 
Através dos resultados obtidos para os coeficientes da Eq.(5.7), foram traçadas curvas dos mesmos em termos da pressão reduzida, conforme mostrado nas Figs. (5.12) a (5.14). Estas curvas podem ser expressas pelas seguintes relações:

$$
\begin{aligned}
& A_{3}=0,125 \cdot p_{r}^{-1,2} \\
& \phi_{c 3}=0,56 \cdot p_{r}^{-0,7} \\
& w_{3}=1,16 \cdot p_{r}^{0,2}
\end{aligned}
$$

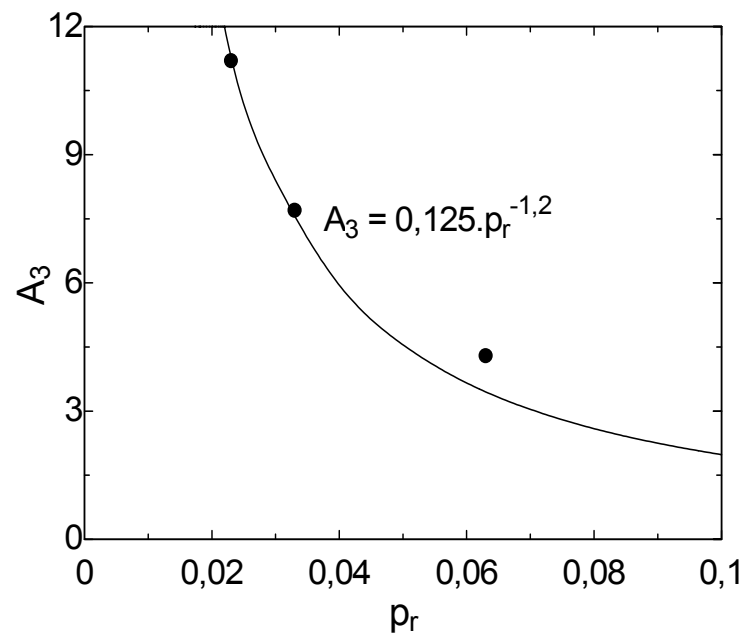

Figura 5.12 - Variação de $A_{3}$ com $\mathrm{p}_{\mathrm{r}}$

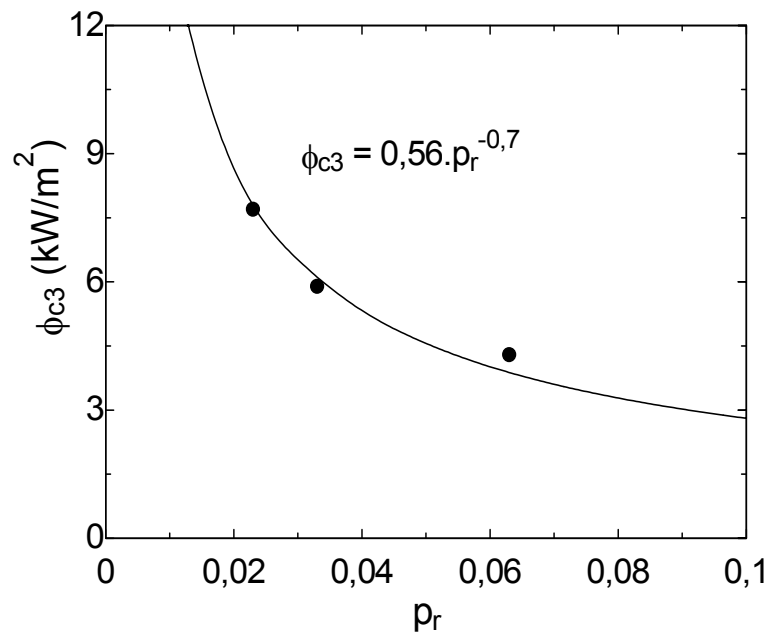

Figura 5.13 - Variação de $\phi_{c 3}$ com $p_{\mathrm{r}}$

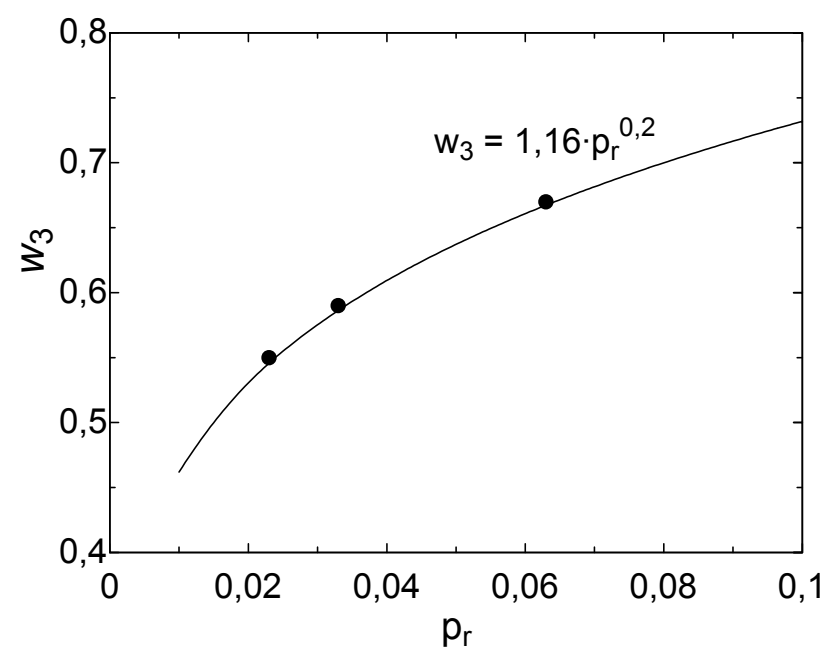

Figura 5.14 - Variação de $w_{3}$ com a $p_{r}$ 
A correlação final para $h_{3} / h_{1}$ pode, assim, ser expressa pela seguinte relação:

$\frac{h_{3}}{h_{1}}=1+0,345 \cdot C_{A} \cdot p_{r}^{-1,4} \cdot \phi^{-1} \cdot \exp \left\{-0,37 \cdot p_{r}^{-0,4}\left[\ln \left(\phi / \phi_{c}\right)\right]^{2}\right\}$

onde: $\quad C_{A}=0,125$

$\phi_{c}=C_{\phi} \cdot p_{r}^{-0,7}$

$C_{\phi}=0,56$

Observa-se que os expoentes da pressão reduzida $\left(0,2\right.$ para $w,-0,7$ para $\phi_{c}$ e -1,2 para $A$ ) são iguais aos obtidos para o caso de 2 tubos aquecidos. Observa-se, ainda, que o coeficiente de $w$ é o mesmo, tanto para dois tubos quanto para três; verificando-se variações somente nos coeficientes $C_{A}$ e $C_{\phi}$.

\subsection{Extensão da Correlação para vários tubos $\left(h_{n} / h_{1}\right)$}

Nas seções precedentes verificou-se que as expressões para $h_{2} / h_{1}$ e $h_{3} / h_{1}$ são semelhantes, diferindo apenas nos coeficientes $C_{A}$ e $C_{\phi}$. Estes podem ser relacionados ao número de fileiras do banco de tubos. No entanto, na presente pesquisa, foram levantados dados para 2 e 3 fileiras de tubos, conforme se ilustra na Tabela 5.3. Danilova et al (1992) propuseram uma correlação empírica para a ebulição nucleada do refrigerante R-22 em um banco com 55 tubos. Tal correlação permitiria obter uma estimativa dos coeficientes $C_{A}$ e $C_{\phi}$ extensivos a um banco de tubos com número de fileiras igual a $N$. Tal estimativa tomou por base hipóteses e argumentos apresentados a seguir.

Tabela 5.3 - Coeficientes da Eq.5.1 ou 5.7 em função do número de tubos

\begin{tabular}{|ccc|}
\hline \hline $\begin{array}{c}\text { Número de tubos } \\
(\boldsymbol{N})\end{array}$ & $\boldsymbol{C}_{\boldsymbol{\phi}}\left(\mathbf{k W} / \mathbf{m}^{\mathbf{2}}\right)$ & $\boldsymbol{C}_{\boldsymbol{A}}$ \\
\hline 2 & 0,73 & 0,113 \\
\hline 3 & 0,56 & 0,125 \\
\hline
\end{tabular}


Na Tabela 5.3 observa-se que $C_{\phi}$ diminui com o número da fileira, $N$. No entanto, o coeficiente $\phi_{c}$, e conseqüentemente $C_{\phi}$, devem tender assintoticamente para um valor mínimo com o número de fileiras $(N)$. Este valor mínimo, por hipótese, será considerado o fluxo de calor máximo correspondente à condição em que se forma a primeira coluna de bolhas no tubo inferior (transição entre regime de convecção natural e ebulição nucleada). Através desta consideração, supõe-se que existirá uma fileira $(N)$, no sentido ascendente, a partir da qual a relação $h_{n} / h_{1}$ permanecerá constante. Com o aumento do fluxo de calor nos tubos inferiores e conseqüentemente o aumento no número de bolhas, o tubo superior não mais será influenciado pelas bolhas adicionais formadas nos tubos inferiores. Como $\mathrm{h}_{1}$ aumenta com o fluxo de calor, a relação $\mathrm{h}_{\mathrm{n}} / \mathrm{h}_{1}$ diminuirá. $\mathrm{O}$ valor do fluxo de calor de transição do regime de convecção natural para ebulição nucleada depende da pressão reduzida e pode ser estimado a partir do tubo inferior ou um único tubo aquecido isoladamente. Para o caso do refrigerante R-123 à pressão reduzida de 0,023, o fluxo de calor específico mínimo $\left(\phi_{\mathrm{cmin}}\right)$ para transição de convecção natural para ebulição nucleada foi, arbitrariamente admitido igual a $0,9 \mathrm{~kW} / \mathrm{m}^{2}$. Como conseqüência, $C_{\phi}$ resultará igual a 0,065 para particular fileira. Estes valores foram obtidos empiricamente através da observação de fotografias. Estas ilustraram que, na faixa de fluxos de calor específicos entre 0,8 e $1,0 \mathrm{~kW} / \mathrm{m}^{2}$, só ocorria transferência de calor por convecção natural (ausência de bolhas). Com isso, o valor de $C_{\phi}$ correspondente a $n$ na Tabela 5.3 será estimado igual a 0,065 , valor limite.

Para estimar a fileira $(N)$ a partir da qual não ocorreria mais influência adicional das bolhas formadas nos tubos inferiores ou para a qual a relação $h_{n} / h_{1}$ permaneceria constante com o número de tubos, utilizou-se à correlação de Danilova et al (1992). Apesar do fluido utilizado ser o refrigerante R-22, a correlação é expressa em termos da pressão reduzida. Com isso, pode ser aproximada para outros refrigerantes halogenados, mediante a utilização deste parâmetro. A correlação de Danilova et al (1992) é expressa por:

$$
h_{n}=A \cdot \phi^{C_{1}} \cdot N_{r}^{C_{2}} \cdot p_{r}^{C_{3}} \cdot n^{B}
$$


onde $A, C_{1}, C_{2} e C_{3}$ são constantes; $N_{r}$ e $n$ representam, respectivamente, o número de fileiras do banco e a fileira em análise do banco de tubos; e $B=0,31-0,3 \cdot p_{r}-2 \times 10^{-4} \cdot N_{r}$

A partir da Eq. (2.64), fazendo $N_{r}=n$, obtém-se a seguinte expressão:

$\frac{h_{n}}{h_{1}}=n^{\left(0,26-7,6 \cdot 10^{-6} \cdot \phi-1,3 \cdot 10^{-3} n\right)}$

Através da Eq.(5.12) foi traçada a curva de $\mathrm{h}_{\mathrm{n}} / \mathrm{h}_{1}$ versus $n$, conforme mostrado na Fig.(5.15), sendo, assim, obtida a fileira $(n)$, a partir da qual a relação $h_{n} / h_{1}$ não mais varia; o valor de $n$ resulta, aproximadamente, igual a 40 .

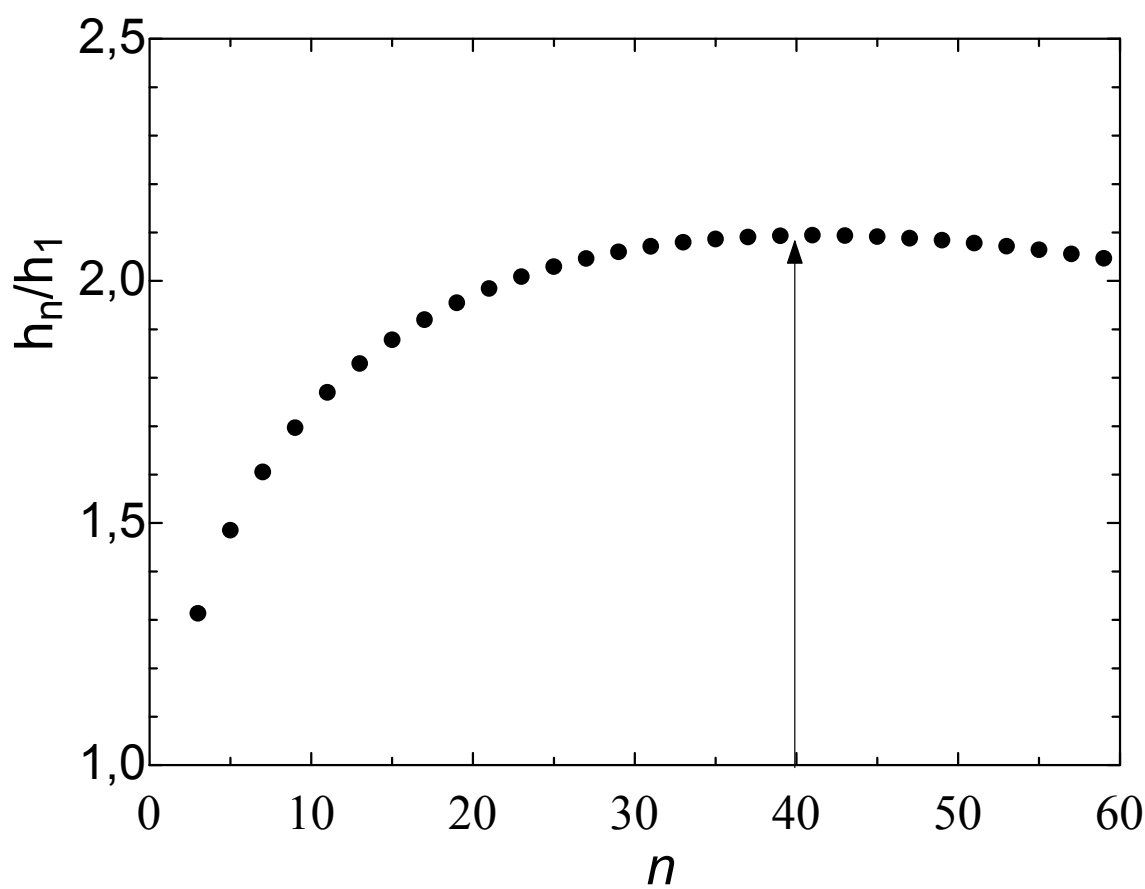

Figura 5.15 - Curva de $\mathrm{h}_{\mathrm{n}} / \mathrm{h}_{1}$ versus $n$

A partir do resultado obtido para $C_{\phi}$, correspondente a $n=40$, e os demais valores obtidos empiricamente, traçou-se a curva de $C_{\phi}$ versus $n$, conforme ilustrada na Fig.(5.16), expressa pela seguinte relação:

$C_{\phi}=0,065+1,2 \cdot \exp (-0,3 . n)$ 


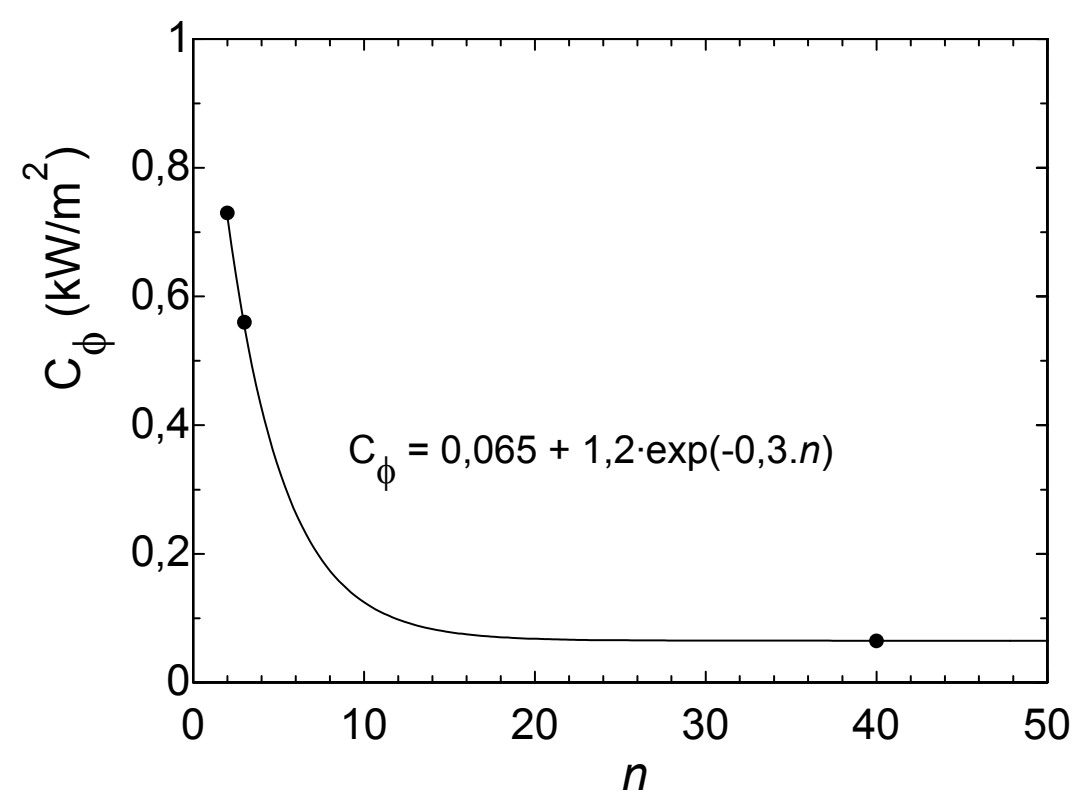

Figura 5.16 - Curva de $C_{\phi}$ versus $n$

$\mathrm{O}$ valor de $C_{A}$ correspondente a $40^{\mathrm{a}}$ fileira de tubos pode ser estimado a partir de uma função de $C_{A} \operatorname{com} C_{\phi}$. Como $C_{A}$ e $C_{\phi}$ são dependentes somente do número de fileiras de tubos e se tem somente 2 valores obtidos empiricamente para os mesmos, obteve-se uma relação linear entre estes coeficientes, resultando na seguinte expressão:

$C_{A}=0,165-0,0701 . C_{\phi}$

ou

$C_{A}=0,16-0,0852 \cdot \exp (-0,3 . n)$

A partir destas considerações pode-se acrescentar a Tabela 5.3 os constantes $C_{A}$ e $C_{\phi}$, correspondentes a $N=40$, resultando, respectivamente, 0,160 e 0,065

Com as expressões para $C_{A}$ e $C_{\phi}$ e a Eq. (5.11) pode ser expressa da seguinte maneira:

$\frac{h_{n}}{h_{1}}=1+0,345 \cdot C_{A} \cdot p_{r}^{-1,4} \cdot \phi^{-1} \cdot \exp \left\{-0,37 \cdot p_{r}^{-0,4}\left[\ln \left(\phi / \phi_{c}\right)\right]^{2}\right\}$

onde: $\quad C_{A}=0,16-0,0852 \cdot \exp (-0,3 . n)$

$\phi_{c}=C_{\phi} \cdot p_{r}^{-0,7}$

$C_{\phi}=0,065+1,2 \cdot \exp (-0,3 \cdot n)$ 
Foram traçadas curvas das relações $h_{n} / h_{1}$ versus fluxo de calor específico mediante a utilização da Eq. (5.16), conforme ilustrado nas Figs. 5.17 (a) e (b). Mostra-se que, para $n>20$, o máximo valor atingido por $h_{n} / h_{1}$ permanece aproximadamente constante com a fileira. Deve-se salientar que estas curvas foram obtidas através das considerações feitas no desenvolvimento da relação generalizada de $h_{n} / h_{1}$. No entanto, devido ao reduzido número de dados experimentais (obtidos somente para 2 e 3 tubos) disponíveis, as expressões para os coeficientes $C_{A}$ e $C_{\phi}$ devem ser admitidas e utilizadas com certo cuidado. A correlação proposta teve por objetivo ilustrar algumas tendências que poderão ser úteis para o ajuste de resultados envolvendo um número maior de fileiras do banco de tubos que o utilizado no presente estudo.

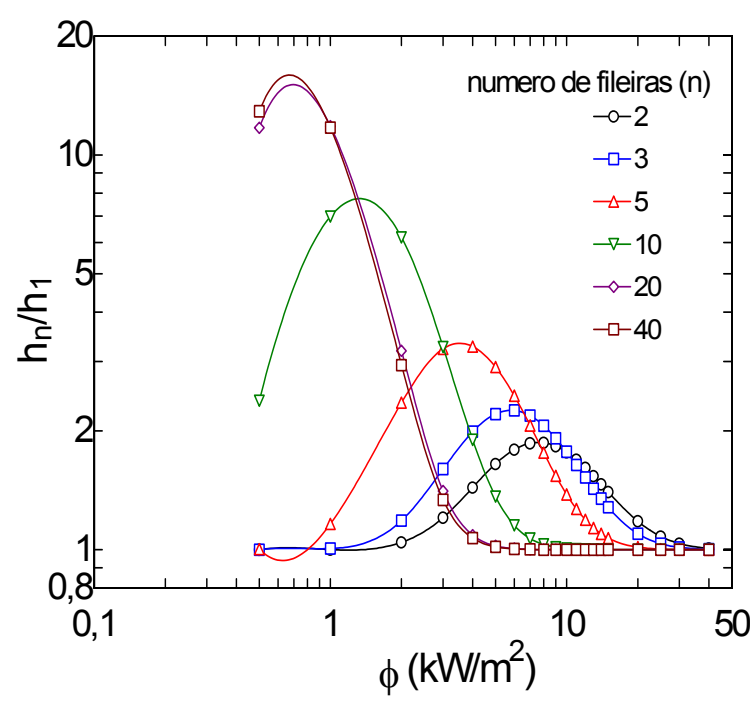

(a) $p_{\mathrm{r}}=\mathbf{0 , 0 2 3}$

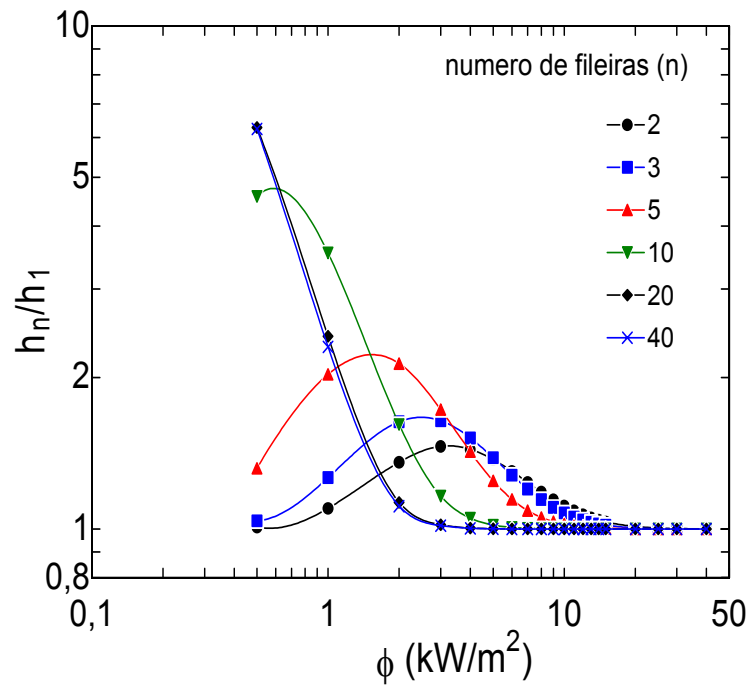

(b) $p_{r}=0,063$

Figura 5.17 - Relações entre coeficientes de transferência de calor do n-ésimo tubo e inferior $\left(h_{n} / h_{1}\right)$ correlacionadas versus fluxo de calor específico $(\phi)$. 


\section{5 - Análise dos desvios médios e resíduos}

A análise dos desvios médios e resíduos tem por objetivo verificar a adequação da correlação proposta face aos resultados experimentais levantados. A análise envolve a comparação dos resultados experimentais com aqueles resultantes da Eq. (5.16). Ressalta-se que esta análise não busca a validação da correlação proposta, mas sim verificar a adequação de seus resultados aos levantados experimentalmente.

O desvio médio absoluto é definido pela seguinte expressão:

$\lambda_{\text {absoluto }}=\frac{\sum_{1}^{m}\left|\frac{\left(h_{n} / h_{1}\right)_{\exp }-\left(h_{n} / h_{1}\right)_{\text {corr }}}{\left(h_{n} / h_{1}\right)_{\exp }}\right|}{m}$

onde $m$ representa o número de pontos experimentais e $n$ representa a fileira analisada no sentido ascendente

Os valores dos desvios médios absolutos para cada condição são mostrados nas Tabelas (5.4) a (5.6) que apresentam, respectivamente, resultados para as relações $h_{2} / h_{1}$ (2 tubos aquecidos), $h_{2} / h_{1}$ (3 tubos aquecidos) e $h_{3} / h_{1}$ (3 tubos aquecidos).

O resíduo relativo para cada ponto experimental é definido como:

Re síduo $=100 \times\left(\frac{\left(h_{n} / h_{1}\right)_{\exp }-\left(h_{n} / h_{1}\right)_{\text {corr }}}{\left(h_{n} / h_{1}\right)_{\exp }}\right)[\%]$

Os resíduos dos resultados são mostrados na Fig (5.18) e a comparação dos resultados experimentais com os proporcionados pela Eq. (5.16) são ilustrados na Fig. (5.19). Estes resultados ilustram que os valores correlacionados encontram-se em sua maioria entre $\pm 10 \%$ dos valores experimentais. É interessante destacar que para reduzidos fluxo de calor $\left(\phi<5 \mathrm{~kW} / \mathrm{m}^{2}\right)$ e pressão reduzida $(0,023)$, e elevado espaçamento $(\mathrm{s} / \mathrm{d}=2,0)$ os resíduos e desvios são mais acentuados. Tal comportamento se justifica através de três aspectos. $\mathrm{O}$ primeiro relacionado às 
incertezas dos resultados experimentais, que se elevam com a redução do fluxo de calor. O segundo estaria relacionado a instabilidade na ativação e desativação de cavidades que forma $\mathrm{m}$ bolhas em regiões de reduzida pressão e fluxo de calor. Por fim, o espaçamento estaria relacionado à não incorporação deste parâmetro na Eq. (5.16).

Tabela 5.4 - Desvios médios absolutos para a relação $\mathrm{h}_{2} / \mathrm{h}_{1} \operatorname{com} 2$ tubos aquecidos.

\begin{tabular}{|c|c|c|c|c|}
\hline \hline $\mathbf{s} / \mathbf{d} / \mathbf{p}_{\mathbf{r}}$ & $\mathbf{0 , 0 2 3}$ & $\mathbf{0 , 0 3 3}$ & $\mathbf{0 , 0 6 3}$ & TOTAL \\
\hline \hline $\mathbf{1 , 3 2}$ & 2,35 & 2,39 & 2,36 & 2,37 \\
\hline $\mathbf{1 , 5 3}$ & 4,28 & 5,06 & 4,47 & 4,60 \\
\hline $\mathbf{2 , 0 0}$ & 11,27 & 5,44 & 2,79 & 6,50 \\
\hline TOTAL & 5,97 & 4,30 & 3,21 & $\mathbf{4 , 5 0}$ \\
\hline
\end{tabular}

Tabela 5.5 - Desvios médios absolutos para a relação $h_{2} / h_{1} \operatorname{com} 3$ tubos aquecidos.

\begin{tabular}{|c|c|c|c|c|}
\hline \hline $\mathbf{s} / \mathbf{d} / \mathbf{p}_{\mathbf{r}}$ & $\mathbf{0 , 0 2 3}$ & $\mathbf{0 , 0 3 3}$ & $\mathbf{0 , 0 6 3}$ & TOTAL \\
\hline \hline $\mathbf{1 , 3 2}$ & 0,95 & 3,64 & 3,66 & 2,75 \\
\hline $\mathbf{1 , 5 3}$ & 4,23 & 2,78 & 4,36 & 3,79 \\
\hline $\mathbf{2 , 0 0}$ & 8,37 & 6,72 & 3,25 & 6,11 \\
\hline TOTAL & 4,52 & 4,38 & 3,76 & $\mathbf{4 , 2 2}$ \\
\hline
\end{tabular}

Tabela 5.6 - Desvios médios absolutos para a relação $h_{3} / h_{1} \operatorname{com} 3$ tubos aquecidos.

\begin{tabular}{|c|c|c|c|c|}
\hline \hline $\mathbf{s} / \mathbf{d} / \mathbf{p}_{\mathbf{r}}$ & $\mathbf{0 , 0 2 3}$ & $\mathbf{0 , 0 3 3}$ & $\mathbf{0 , 0 6 3}$ & TOTAL \\
\hline \hline $\mathbf{1 , 3 2}$ & 5,07 & 6,73 & 9,14 & 6,98 \\
\hline $\mathbf{1 , 5 3}$ & 7,03 & 5,97 & 6,22 & 6,41 \\
\hline $\mathbf{2 , 0 0}$ & 8,07 & 6,48 & 5,41 & 6,65 \\
\hline TOTAL & 6,72 & 6,39 & 6,92 & $\mathbf{6 , 6 8}$ \\
\hline
\end{tabular}




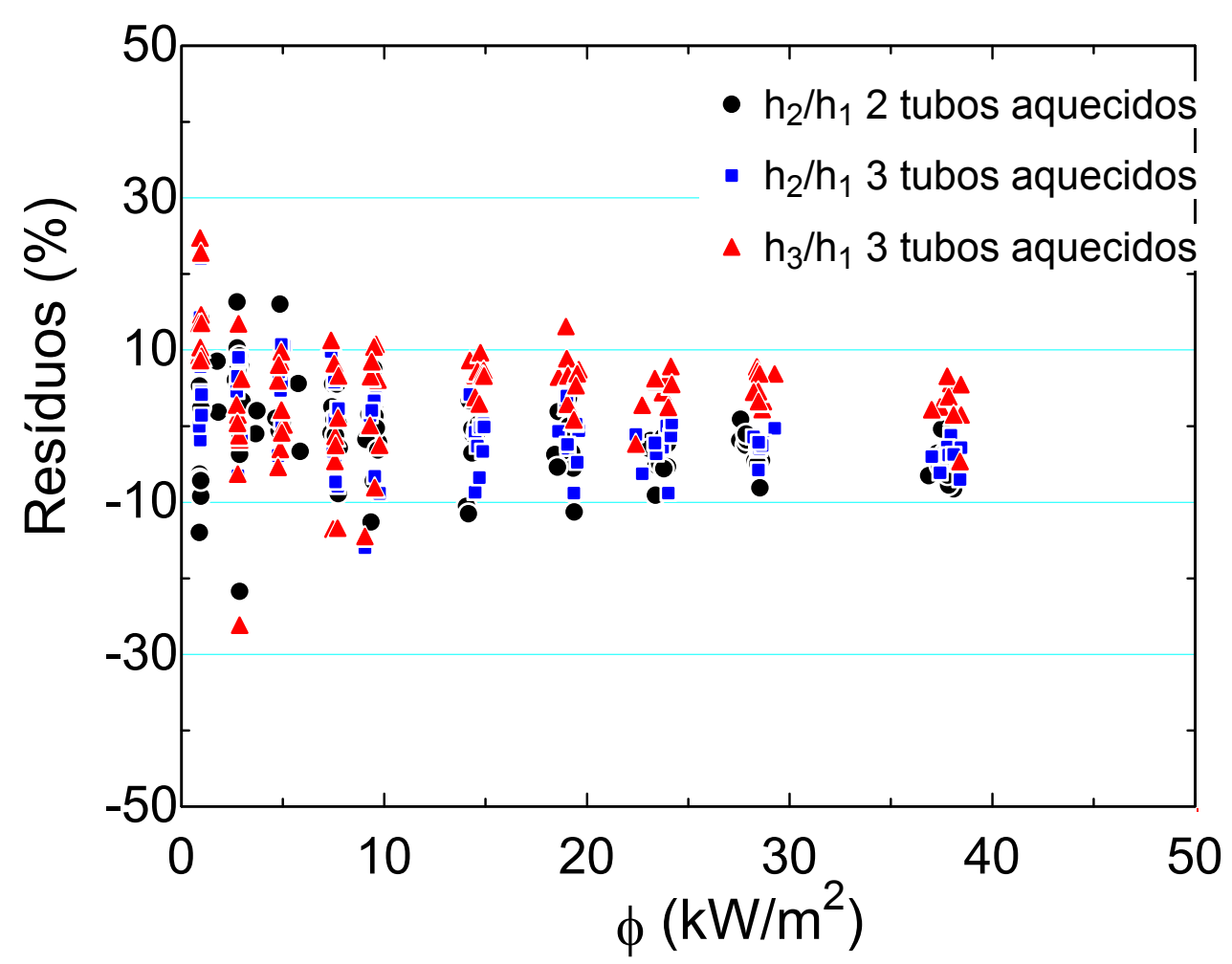

Figura 5.18 Resíduos para os resultados apresentados pela Eq. (5.16) em relação ao banco de dados experimentais

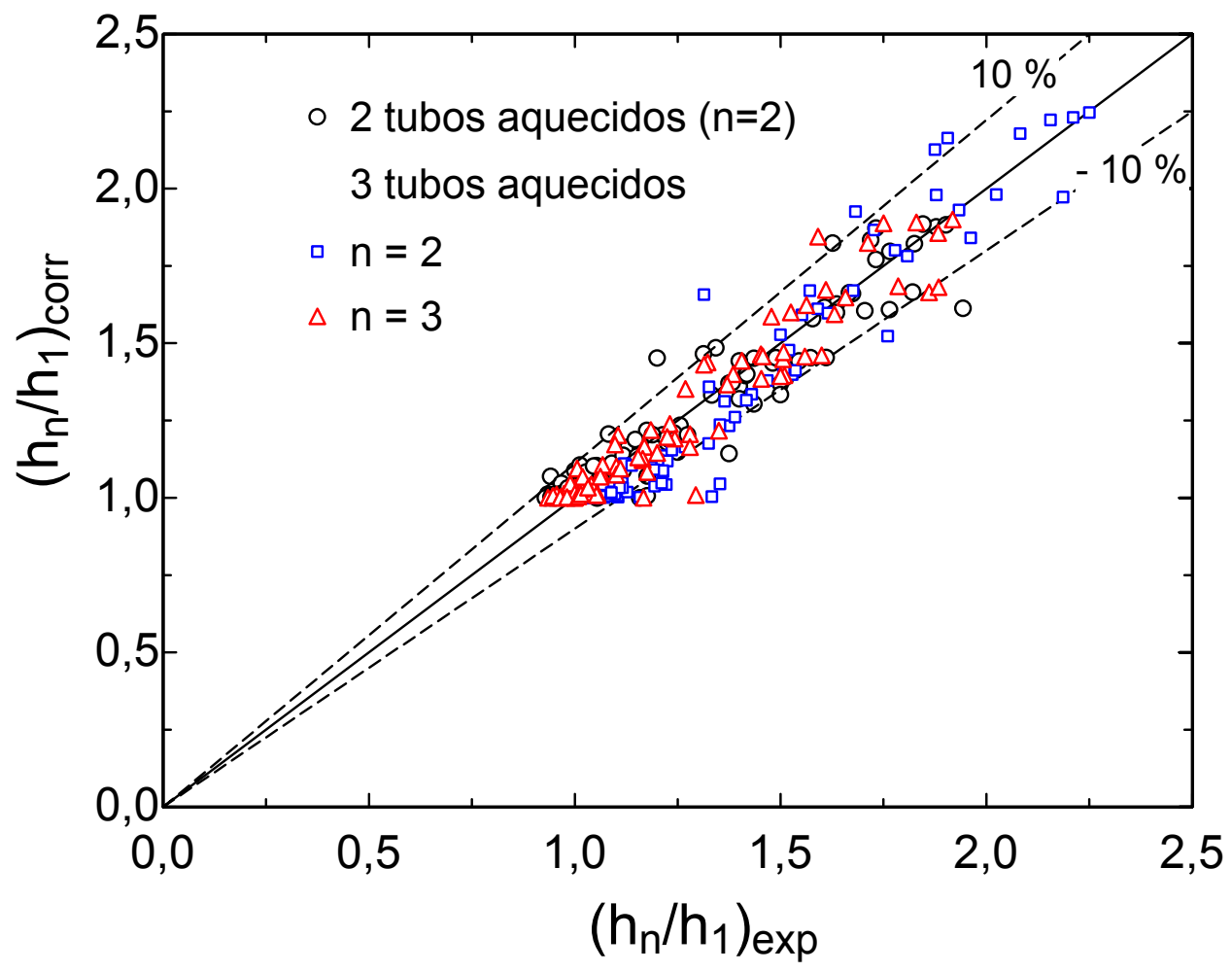

Figura 5.19 Curva comparativa dos resultados experimentais com os proporcionados pela Eq. (5.16) 


\section{6 - Comparação com resultados da literatura}

Foi elaborada uma análise comparativa de resultados da literatura, envolvendo dados experimentais e correlações para refrigerantes halogenados (R-11 e R-134a) e água, com os obtidos através da Eq. (5.16). A presente análise revelou algumas discrepâncias de caráter quantitativo cujos resultados podem ser observados nas Figs.(5.20) a (5.22) e serão comentadas sucintamente a seguir.

As curvas da Figura (5.20) ilustram que há diferença entre $h_{2} / h_{1}$ obtidos da Eq. (5.16) e da correlação de Kumar et al (1992), sendo mais acentuada para região de reduzidos fluxos de calor específico. Este comportamento pode estar associado à correlação de Kumar et al (1992) ter sido proposta somente para região de ebulição nucleada, não envolvendo a região onde predomina o mecanismo de transferência de calor por convecção natural $\left(\phi<5 \mathrm{~kW} / \mathrm{m}^{2}\right.$, para água a $\left.\mathrm{P}=100 \mathrm{kPa}\right)$. Com o incremento do fluxo de calor, ambas as curvas tendem assintoticamente para valores próximos de 1 . No entanto a diferença entre as mesmas é razoavelmente elevada. Com isso, não é aconselhável a utilização da Eq. (5.16) envolvendo a água.

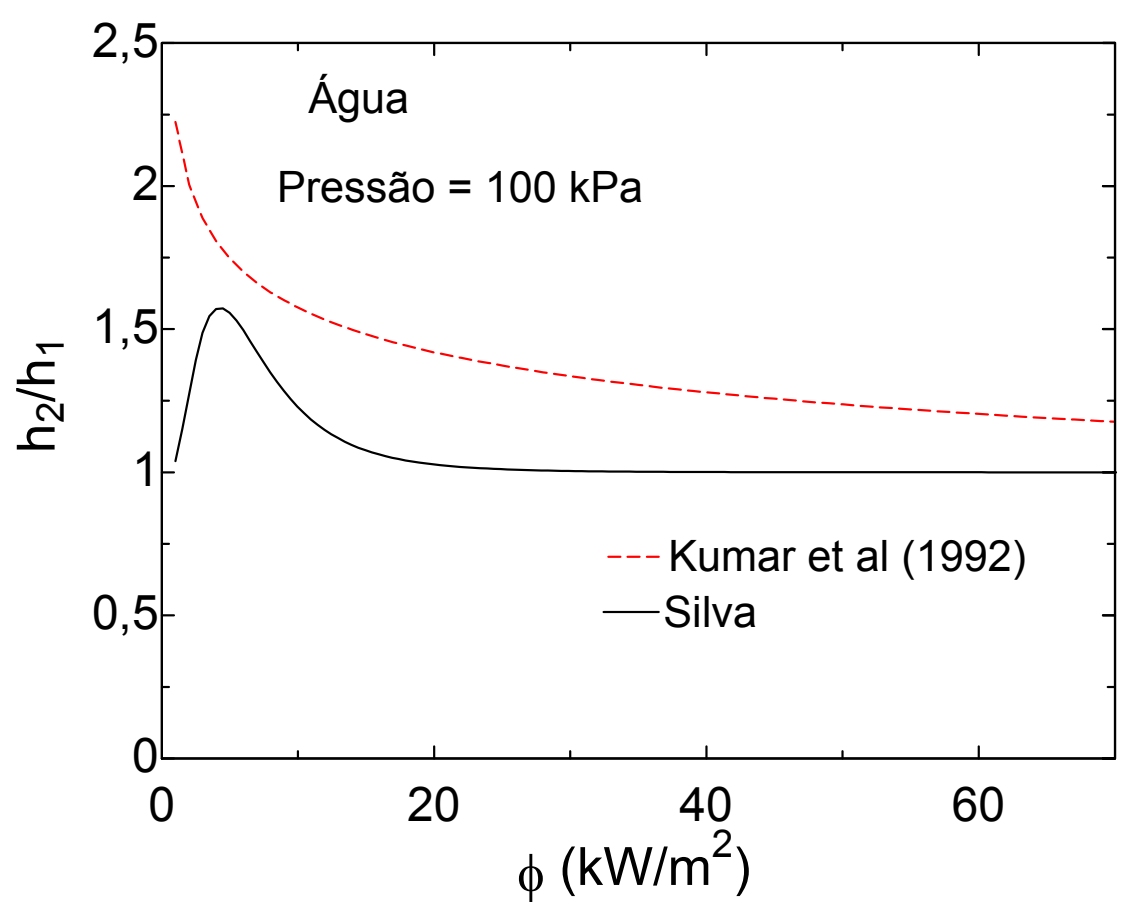

Figura 5.20 - Comparação da correlação de Kumar et al (1992) com a Eq. (5.16); Água, $\mathrm{P}_{\mathrm{sat}}=100 \mathrm{kPa}$. 
A Figura (5.21) ilustra a comparação entre resultados experimentais obtidos por Hsieh et al (2003) para o R-134a e as curvas obtidas da Eq. (5.16). Os resultados experimentais para $h_{2} / h_{1}$, na região de reduzidos e intermediários fluxos de calor $(\phi<$ $3 \mathrm{~kW} / \mathrm{m}^{2}$ ), são superiores aos obtidos da Eq. (5.16). Este comportamento pode estar relacionado às incertezas de medidas nesta região que são mais pronunciadas ou ao acabamento superficial. Semelhante à influência da pressão, o coeficiente de transferência de calor deve aumentar com o acabamento superficial em ambos os tubos, no entanto deve diminuir a relação $\mathrm{h}_{2} / \mathrm{h}_{1}$. Os resultados de Hsieh et al (2003) foram para $\mathrm{Ra}=0,06 \mu \mathrm{m}$, ao passo que a Eq. (5.16) foi obtida a partir de resultados para tubos com $\mathrm{Ra}=0,12 \mu \mathrm{m}$. Para elevados fluxos de calor os resultados experimentais e correlacionados são próximos e $\mathrm{h}_{2} / \mathrm{h}_{1}$ tende para 1 . Portanto, nesta região o acabamento superficial não deve influenciar na relação $h_{2} / h_{1}$.

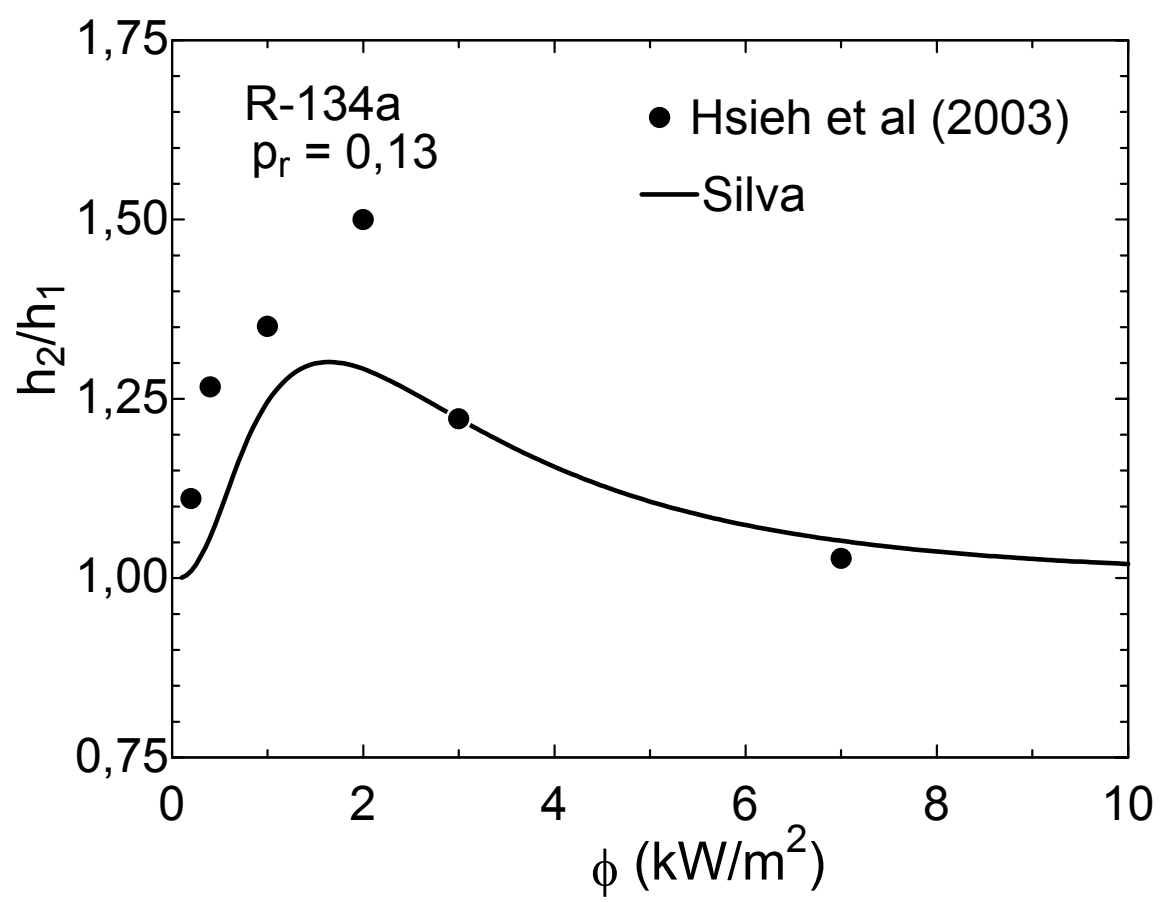

Figura 5.21 - Comparação de resultados experimentais obtidos por Hsieh et al (2003) com a Eq. (5.16) 
As Figuras 5.22 (a) e (b) ilustram curvas obtidas da correlação de Muller (1986) para tubos ranhurados e da Eq. (5.16) para, respectivamente, $h_{3} / h_{1}$ e $h_{5} / h_{1}$. Verifica-se que em ambas figuras, o máximo valor destas relações são superiores para as obtidas da Eq. (5.16). Observa-se, ainda, que o valor deste máximo corresponde a um menor fluxo de calor para os valores obtidos da correlação de Muller (1986). Este comportamento pode estar relacionado ao acabamento superficial. As superfícies ranhuradas apresentam coeficiente de transferência de calor superior às lisas devido a um maior número de cavidades ativas, no entanto a relação $h_{n} / h_{1}$ deve diminuir e ocorrer com um menor fluxo de calor. Com o aumento no número de fileiras (de 3 para 5) a diferença entre as curvas se acentua. Este comportamento pode estar relacionado à estimativa na obtenção dos coeficientes $C_{A}$ e $C_{\phi}$ da Eq. (5.16).

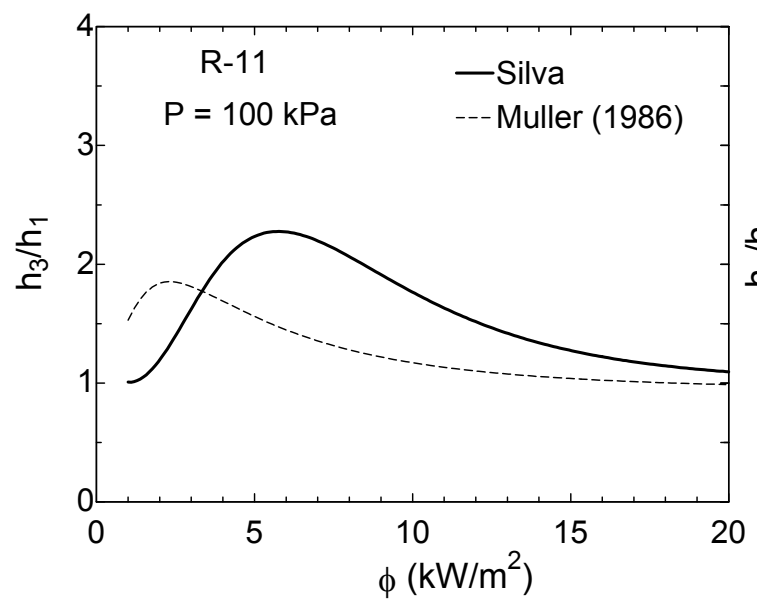

(a)

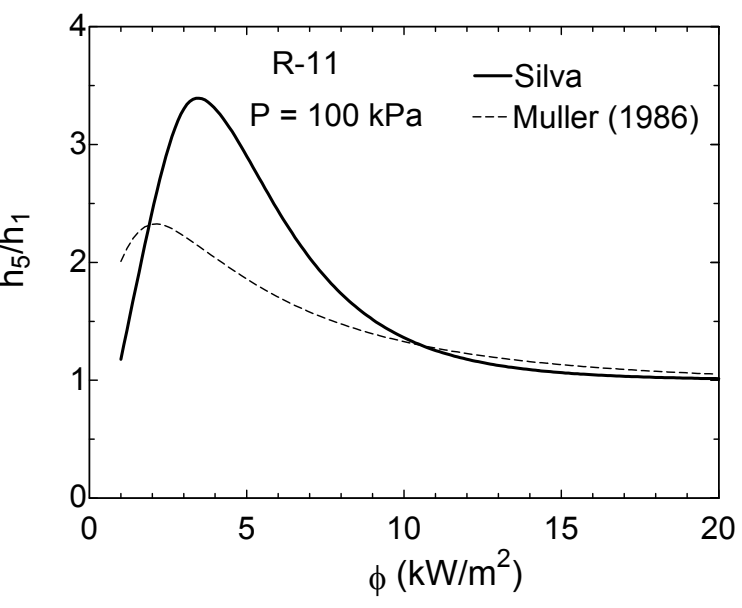

(b)

Figura 5.22 Comparação da correlação de Muller et al (1986) com a Eq. (5.16); $\mathrm{R} 11, \mathrm{P}_{\text {sat }}=100 \mathrm{kPa}, \mathrm{s} / \mathrm{d}=1,6$. 


\section{6 - Conclusões e Recomendações}

Foi levantada e analisada uma extensa bibliografia referente à ebulição nucleada, sendo dada ênfase à relacionada com banco de tubos. Procurou-se elucidar os diversos parâmetros que podem afetar o mecanismo de transferência de calor. Entre estes parâmetros destacam-se a configuração do banco, posição e espaçamento relativo entre os tubos, fluxo de calor, pressão e efeitos convectivos. Os testes experimentais foram realizados em 3 distintas etapas. $\mathrm{Na}$ primeira etapa foram obtidos resultados para um único tubo e diâmetro, com distintos acabamentos superficiais, investigando-se, sucintamente, os efeitos da rugosidade no coeficiente de transferência de calor. Na segunda etapa, foram realizados ensaios com tubos de 3 diâmetros distintos, ensaiado um por vez, analisando-se o efeito deste parâmetro. $\mathrm{Na}$ terceira, e mais importante etapa, foram obtidos resultados para dois e três tubos aquecidos com igual diâmetro e rugosidade. Nesta última etapa analisou-se os parâmetros que influenciam na ebulição em banco de tubos e foi proposta uma correlação baseada na relação entre os coeficientes de transferência de calor dos tubos superiores e inferior. 


\section{1 - Conclusões}

A seguir são apresentadas as principais conclusões deste trabalho:

- O acabamento superficial (representado pela rugosidade média aritmética, Ra) afeta significativamente o coeficiente de transferência de calor, que aumenta até um máximo, a partir do qual diminui com a rugosidade.

- Para diâmetros de tubos entre 12,5 e $22,0 \mathrm{~mm}$, este parâmetro não afeta significativamente o coeficiente de transferência de calor em ebulição nucleada, podendo ser considerado desprezível quando comparado com a influência do acabamento superficial.

- Em banco de tubos, para fluxos de calor relativamente reduzidos (entre 5 a 10 $\mathrm{kW} / \mathrm{m}^{2}$, para o R-123) ou região de ebulição nucleada parcial, o coeficiente de transferência de calor depende consideravelmente do posicionamento. Nesta região o tubo superior apresentou coeficiente de transferência de calor consideravelmente superior (até 2 vezes) em relação ao tubo inferior.

- O aumento do fluxo de calor diminui a diferença entre os coeficientes de transferência de calor dos tubos superior e inferior.

- Com o aumento da pressão, apesar de aumentar o coeficiente de transferência de calor em todos os tubos, diminui a relação entre os coeficientes de transferência de calor dos tubos superiores e inferior. Este efeito, provavelmente, se deve a menor influência das bolhas formadas nos tubos inferiores sobre os tubos superiores e ao aumento do número de cavidades ativas com a pressão.

- O coeficiente de transferência de calor aumenta com as fileiras de tubos no sentido ascendente. Este aumento tende a diminuir com o número de fileiras e o fluxo de calor.

- A influência do espaçamento entre tubos no coeficiente de transferência de calor é menor quando comparada com a influência do posicionamento dos tubos.

- Para o R-123, em reduzidos fluxos de calor específico $\left(\phi<7 \mathrm{~kW} / \mathrm{m}^{2}\right)$, a relação entre o coeficiente de transferência de calor do tubo intermediário e inferior $\left(h_{2} / h_{1}\right)$ é superior para a configuração com maior espaçamento entre 
tubos $(\mathrm{s} / \mathrm{d}=2,0)$. Para fluxos de calor intermediários $\left(7<\phi<20 \mathrm{~kW} / \mathrm{m}^{2}\right)$ este comportamento é inverso, ou seja, a relação entre os coeficiente de transferência de calor do tubo intermediário e inferior é superior para a configuração com menor espaçamento entre tubos $(\mathrm{s} / \mathrm{d}=1,32)$. Para elevados fluxos de calor $\left(\phi>20 \mathrm{~kW} / \mathrm{m}^{2}\right)$ a relação $\mathrm{h}_{2} / \mathrm{h}_{1}$ é aproximadamente igual a 1 , independentemente do espaçamento. Este comportamento pode estar relacionado ao regime de ebulição.

- Com base nos resultados experimentais foi desenvolvida uma correlação para a ebulição de refrigerantes halogenados em banco de tubos, Eq. (5.16). Esta correlacionou satisfatoriamente estes resultados, apresentando um desvio médio de 4,5\% e 6,7\% para 2 e 3 tubos, respectivamente. A correlação desenvolvida alia simplicidade e facilidade de uso, requerendo apenas o conhecimento da pressão reduzida, posicionamento do tubo e fluxo de calor.

\section{2 - Recomendações para Futuros Trabalhos}

Com base nos resultados experimentais levantados e objetivando a continuidade da presente pesquisa, as seguintes sugestões para futuros trabalhos podem ser enumeradas:

- Levantamento experimental envolvendo uma única superfície com ampla faixa de diâmetros, destacando-se tubos com diâmetros externos variando entre $0,5 \mathrm{~mm}$ até $100 \mathrm{~mm}$.

- Obtenção de resultados para um banco com elevado número de fileiras de tubos para refinamento da correlação proposta na presente pesquisa.

- Levantamento experimental e investigação da ebulição nucleada envolvendo banco de tubos com ampla faixa de rugosidades $(0,1<\mathrm{Ra}<10 \mu \mathrm{m})$ e superfícies intensificadoras.

- Levantamento de resultados experimentais para misturas de refrigerantes.

- Utilização de uma câmera de alta velocidade de captura de imagens para verificação da interação de bolhas formadas em tubos inferiores sobre os tubos superiores. 


\section{Referências Bibliográficas}

Abernethy R. B.; Thompson J. W. (1973), Handbook, Uncertainty in Gas Turbine Measurements. Arnold Engineering Development Center, Arnold Air Force Station, tenesse.

Arai, N.; Fukushima, T.; Arai, A.; Tadakatsu, N.; Fujie, K.; Nakayama, Y. (1977). Heat transfer tubes enhancing boiling and condensation in heat exchangers of a refrigerating machine. ASHRAE Transactions, v. 83, part II, p. 58-70.

Browne, M. W.; Bansal, P. K. (1999) Heat transfer characteristics of boiling phenomenon in flooded refrigerant evaporators. Applied Thermal Engineering, v. 19 p. $595-624$.

Chan, A. M.; Shoukri, M. (1987). Boiling characteristics of small multitube bundles. Journal of Heat Transfer, v.109, p.753-760.

Chen, J. C. (1966) Correlation for boiling heat transfer to saturaded fluids in convective flow. I\&EC Process Design and Development, p. 322-329

Cheung, K. H.; Ohadi, M. M.; Dessiatoun, S. (1995) Compound enhancement of boiling heat transfer of R-134a in a tube bundle. ASHRAE Transaction, v.101.

Collier, J. G.; Thome, J. R. (1996). Convective boiling and condensation. 3. ed. New York, Oxford University Press

Cooper, M. G. (1984) Heat flow rates in saturated nucleate pool boiling - A wide ranging examination using reduced properties. Advances in Heat Transfer, v.16, p.157-238.

Cornwell, K.; Schüller, R. B. (1982). A study of boiling outside a tube bundle using high speed photography. Int. J. Heat and Mass Transfer, v.25, p.683-690.

Cornwell, K. (1990) The role of sliding bubbles in boiling on tube bundles. Proc. 9th Int. heat transfer conference. P. 455-460.

Czikk, A. M.; Gottzmann, C. F.; Ragi, E. G.; Withers, J.G.; Habdas, E. P. (1970). Performance of advanced heat transfer tubes in refrigerant-flooded liquid coolers. ASHRAE Transactions, v. 76, part. I, p. 96-109. 
Danilova, G. N.; Dyundin, V. A. (1972). Heat Transfer with freons 12 and 22 boiling at bundles of finned tubes. Heat Transfer-Soviet Research, v. 4, p. 48-54.

Danilova, G. N.; Dyundin, V. A.; Soloviyov, A. G. (1992). Heat transfer in boiling of R-717 and R-22 refrigerants on multirow tube bundles. Heat Transfer Research, v. 24, p. $889-893$.

Foster, H. K.; Zuber, N. (1955). Bubble dynamics and boiling heat transfer. AIChe Journal, v.1, p.531-535.

Fujita, Y.; Ohta, H.; Hoshida, K.; Hidaka, S.; Toyama, Y. (1987a) Boiling heat transfer on horizontal tube bundles. Heat Transfer Science and Technology, p.393-400.

Fujita, Y.; Ohta, H.; Hoshida, K.; Hidaka, S. (1987b) Heat transfer in nucleate boiling outside horizontal tube bundles, part 2 - prediciton for tube bundle effect. Trans, JSME, v.53, p. 528-535.

Gorenflo, D.; Luke, A.; Künstler, W.; Buschmeier, M. (1994). Prediction of pool boiling heat transfer with new refrigerants. In : $C f c$ 's the day after, Padova, spt. 21-23, p.557-563.

Gupta, A.; Saini, J.S.; Varma, H. K. (1995) Boiling heat transfer in small horizontal tube bundles at low cross-flow velocities. International Journal of Heat and Mass Transfer, v. 38, p. 599-605.

Gupte, N. S. (1992). Simulation of boiling in flooded refrigerant evaporators. University Park. 264p. Tese (doutorado) - Departament of Mechanical Engineering, Pennsylvania State University.

Hahne, E.; Müller, J. (1983). Boiling on a finned tube and a finned tube bundle. Int. J. Heat Mass Transfer, v.26, p.849-859.

Hahne, E.; Qiu-Rong, C.; Windisch, R. (1991) Pool boiling heat transfer on finned tubes - an experimental and theoretical study. International Journal of Heat and Mass Transfer, v. 34, n.8, p.2071-2079.

Han, C. Y.; Griffith, P. (1965a). The Mechanism of heat transfer in nucleate pool boiling - part. I. Int. J. Heat Mass Transfer, v.8, p.887-904. 
Han, C. Y.; Griffith, P. (1965b). The Mechanism of heat transfer in nucleate pool boiling - part. II. Int. J. Heat Mass Transfer, v.8, p.905-914.

Hsieh, S. S.; Huang, G. Z.; Tsai, H. H. (2003) Nucleate pool boiling characteristics from coated tube bundles in saturated R-134a. International Journal of Heat and Mass Transfer, v. 46, p. 1223-1239.

Hwang, T. H.; Yao, S. C. (1986a). Crossflow boiling heat transfer in tube bundles, Int. Comm. Heat Mass Transfer, v.13, p.493-502.

Hwang, T. H.; Yao, S. C. (1986b) Forced convective boiling in horizontal tube bundles. International Journal of Heat and Mass Transfer, v. 29, p.785-795.

Jensen, M. K.; Hsu, J. T. (1988). A parametric study of boiling heat transfer in a horizontal tube bundle. Journal of Heat Transfer, v.110, p.976-981.

Kudristskii, G. R.; Kolomiets, E. A. (1995). Effect of geometric characteristics of heating surfaces on heat transfer and the onset of boiling of heat transfer agent. Heat Transfer Research, v. 16, p.18-21.

Kurihara, H. M. (1956). Fundamental factors affecting boiling coefficients. Lafayette, Indiana. 130p. Tese (doutorado) - Department of Chemical Engineering, Purdue University.

Kumar, S.; Mohanty, B.; Gupta, S.C. (2002) Boiling heat transfer from a vertical row of horizontal tubes. International Journal of Heat and Mass Transfer, v.45, p.3857-3864.

Leiner, W. (1994). Heat Transfer by nucleate pool boiling - general correlation based on thermodynamic similarity. Int. J. Heat Mass Transfer, v. 37, p. 763-769.

Li, Z.; Hahne, E. (1995). Boiling heat transfer on finned tube bundle with lower tubes heated with constant heat flux. Experimental Thermal and Fluid Science, v. 11, p. 174-180.

Liu, Z. H.; Qiu, Y.H. (2002) Enhanced boiling heat transfer in restricted spaces of a compact tube bundle with enhanced tubes. Applied Thermal Engineering, v. 22, p. 1931-1941.

Marto, P. J.; Anderson, C. L. (1992). Nucleate boiling characteristics of R-113 in a small tube bundle. Journal of Heat Transfer, v.114, p. 425-433. 
Memory, S. B.; Chilman, S. V.; Marto, P. J. (1994). Nucleate pool boiling of a Turbo-B bundle in R-113. Journal of Heat Transfer, v. 116, p. 670-678.

Memory, S. B.; Akcasayar, N.; Eraydin, H.; Marto, P. J. (1995b). Nucleate pool boiling of R-114 and R-114-oil mixtures from smooth and enhanced surfaces-II . Tube bundles. Int. J. Heat Mass Transfer, v.38, p.1363-1376.

Mikic, B. B.; Rohsenow, W. M. (1969). A new correlation of pool-boiling data including the effect of heating surface characteristics. Journal of Heat Tranfer, v.91, p.245-250.

Müller, J. (1986) Boiling heat transfer on finned Tube Bundle - the effect of tube position and intertube spacing. Proc. 8th Int. Heat Transfer Conference, v.4, p.2111-2116.

Nakajima, K.; Shiozawa, A. (1975) Na experimental study on the performance of a flooded type evaporator. Heat transfer-Japanese research, v.4, n.3, p.49-66.

Nukiyama, S. (1934) reeditado em (1966). The maximum and minimum values of the heat $\mathrm{Q}$ transmitted from metal to boiling water under atmospheric pressure. Int. J. Heat Mass Transfer, v.9, p.1419-1433.

Palen, J.W.; Taborek, J.J. (1962) Refinery kettle reboilers - proposed method for design and optimization. Chemical Engineering Progress. V.58, n.7, p.37-46.

Rebrov, P. N.; Bukin, V. G.; Danilova, G. N. (1989) A correlation for local coefficients of heat transfer in boiling of R-12 and R-22 refrigerants on multirow bundles of smooth tubes. Heat Transfer Soviet Research, v.21, n.4, p. 543-548.

Ribatski, G. (2002) Análise teórica e experimental da ebulição nucleada de refrigerantes halogenados. Escola de Engenharia de São Carlos - USP. Departamento de Engenharia Mecânica. Tese de doutorado. São Carlos S.P. Brasil.

Rohsenow, W. M. (1952) A method correlating heat-transfer data for surface boiling of liquids. Trans. Amer. Soc. Mech. Engrs., v.74, p.969-976

Roser, R.; Thonon, B.; Mercier, P. (1999) Experimental investigations on boiling of n-pentane across a horizontal tube bundle: two-phase flow and heat transfer characteristics. Int. J. Refrig., v.22, p. 536-547. 
Saiz Jabardo, J. M. (1988) Transferência de calor em escoamentos bifásicos. Notas de aula. Departamento de Engenharia Mecânica, Escola Politécnica, Universidade de São Paulo.

Saiz Jabardo, J. M.; Silva C. L. (1991) Modeling of the nucleate boiling of refrigerant-oil mixtures. In: $18^{\text {th }}$ International Congress of Refrigeration, Montreal, Canada.

Silva E. F. (2002) Análise experimental da ebulição nucleada de hidrocarbonetos halogenados de baixa e média pressão em tubos horizontais. Escola de Engenharia de São Carlos - USP. Departamento de Engenharia Mecânica. Dissertação de mestrado.São Carlos S.P. Brasil.

Stelute E. B. (2004) Efeito da rugosidade superficial na ebulição nucleada de refrigerantes halogenados em tubos horizontais. Escola de Engenharia de São Carlos - USP. Departamento de Engenharia Mecânica. Dissertação de mestrado.São Carlos S.P. Brasil.

Wallner, R. (1971) Heat transfer in flooded shell and tube evaporators. 13 th. Int. Congress of Refrigeration, p.214-217.

Webb, R. L.; Chien, L. H. (1994). Correlation of convective vaporization on banks of plain tubes using refrigerants. Heat Transfer Engineering, v. 15, p. 57-69.

Zuber, N. (1963). Nucleate boiling. The region of isolated bubbles and the similarity with natural convection. Int. J. Heat Mass Transfer, v.6, p.53-78. 


\section{APÊNDICE I - INCERTEZAS}

A análise de incertezas possibilita a validação em comparações entre as variáveis experimentais envolvidas no mecanismo físico. Utilizando o método de propagação da soma quadrática dos efeitos de uma das variáveis, proposto por Kline \& McClintock apud Holman (1989), pode-se obter as incertezas nas medidas associadas às variáveis envolvidas na transferência de calor através do mecanismo de ebulição nucleada.

\section{Método de propagação da soma quadrática dos efeitos de uma das variáveis.}

O método consiste no cálculo das incertezas associadas as variáveis experimentais. Para uma função $R$ em função das variáveis $x_{1}, x_{2}, x_{3}, \ldots, x_{n}$, ou seja: $R=R\left(x_{1}, x_{2}, x_{3}, \ldots, x_{n}\right)$

As incertezas associadas as variáveis, podem ser escritas como:

$i\left(x_{1}\right), i\left(x_{2}\right), i\left(x_{3}\right), \ldots, i\left(x_{n}\right)$

Sendo todas varáveis independentes, a incerteza associada a $R$ segundo Kline e McClintock apud Holman(1989) será dada por:

$$
\frac{i(R)}{R}=\left[\left(\frac{\partial R}{\partial x_{1}} \frac{i\left(x_{1}\right)}{R}\right)^{2}+\left(\frac{\partial R}{\partial x_{2}} \frac{i\left(x_{2}\right)}{R}\right)^{2}+\left(\frac{\partial R}{\partial x_{3}} \frac{i\left(x_{3}\right)}{R}\right)^{2}+\ldots \ldots+\left(\frac{\partial R}{\partial x_{n}} \frac{i\left(x_{n}\right)}{R}\right)^{2}\right]^{1 / 2}
$$




\section{Incertezas associadas as variáveis na transferência de calor em ebulicãa nucleada}

Para o caso da ebulição nucleada, as variáveis envolvidas são: temperatura do banho e dos termopares, tensão e corrente elétrica na resistência alojada na superfície cilíndrica, área externa, comprimento e temperatura da parede da superfície aquecida. Outras variáveis envolvidas no estudo da ebulição nucleada em piscina são dependentes destas. Estas variáveis são: fluxo de calor $(\phi)$ dependente da área, tensão e corrente da resistência elétrica; o superaquecimento da parede $\left(T_{p}-T_{s a t}\right)$ depende das temperaturas da parede e do fluido no estado saturado; o coeficiente de transferência de calor $(h)$ dependente do $\phi$ e $\left(T_{p}-T_{\text {sat }}\right)$.

\section{Incerteza na Área da secão de teste}

A área considerada é dada por:

$A=\pi \cdot D \cdot L$

onde: $D$ é o diâmetro externo da superfície de teste que envolve a resistência elétrica.

$L$ é o comprimento da resistência elétrica.

A incerteza na área da superfície aquecida está associada à incerteza na medida do diâmetro e do comprimento do tubo. Estes foram medidos utilizando-se um paquímetro com precisão de $0,05 \mathrm{~mm}$.

Com isso:

$D=19 \pm 0,05 \mathrm{~mm}$

$L=210 \pm 0,05 \mathrm{~mm}$

Utilizando-se a Eq.(A1.2) tem-se:

$$
\begin{aligned}
& \frac{i(A)}{A}=\left[\left(\frac{i(D)}{D}\right)^{2}+\left(\frac{i(L)}{L}\right)^{2}\right]^{1 / 2} \\
& \frac{i(A)}{A}=\left[\left(\frac{0,05}{19}\right)^{2}+\left(\frac{0,05}{210}\right)^{2}\right]^{1 / 2}=0,0026=0,26 \%
\end{aligned}
$$




\section{Incertezas na medida do Fluxo de Calor $(\phi)$}

O fluxo de calor é expresso em termos da tensão, corrente e área sendo expresso da seguinte maneira:

$\phi=\frac{Q}{A}=\frac{V . I}{A}$

Para o voltímetro e amperímetro, as incertezas nas leituras foram consideradas respectivamente de $0,1 \mathrm{~V}$ e $0,05 \mathrm{~A}$, valores estes fornecidos pelo fabricante.

Utilizando a Eqs.(A1.6) e (A1.2) tem-se:

$\frac{i(\phi)}{\phi}=\left[\left(\frac{i(V)}{V}\right)^{2}+\left(\frac{i(I)}{I}\right)^{2}+\left(\frac{i(A)}{A}\right)^{2}\right]^{1 / 2}$

Como $\frac{i(V)}{V}$ e $\left(\frac{i(I)}{I}\right)$ dependem da tensão e corrente aplicada foram calculados alguns valores de $\frac{i(\phi)}{\phi}$ para os respectivos fluxos de calor. A Fig.A1 apresenta as incertezas associadas aos fluxos de calor aplicados.

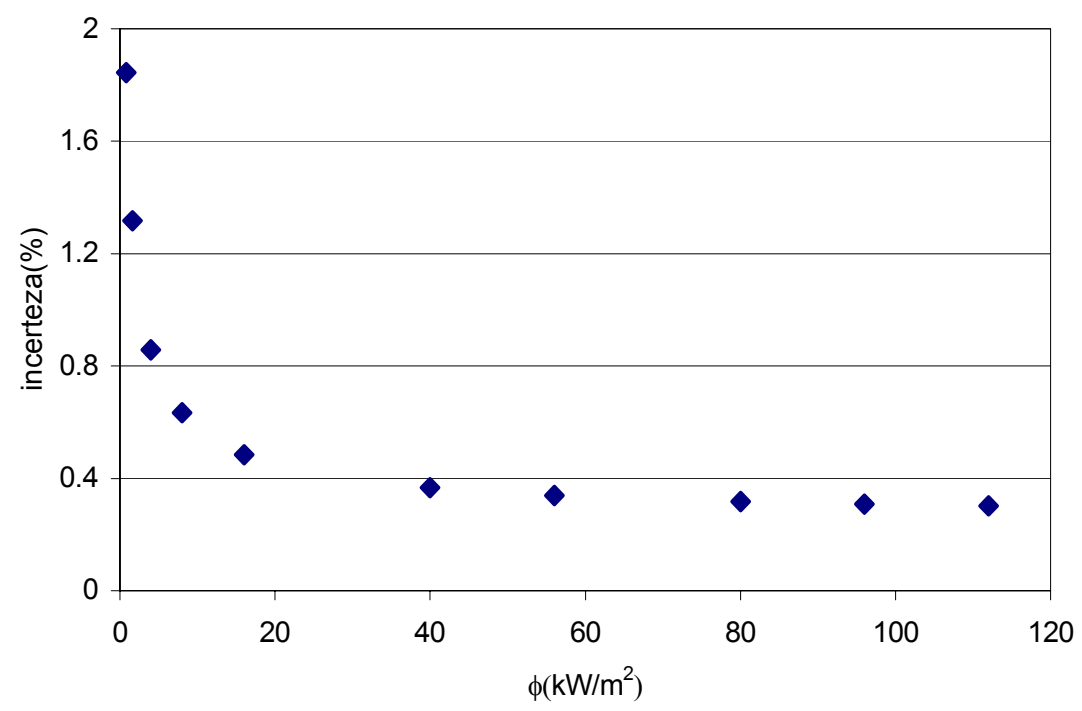


Figura A1 Incertezas associadas ao fluxo de calor

Equipamentos utilizados na medida do fluxo de calor:

Voltímetro digital

Fabricante/Modelo: Hewlett Packard/3457A

Resolução: $0.01 \mathrm{~V}$

Faixa de utilização: 0 a $220 \mathrm{~V}$.

\section{Amperímetro digital}

Fabricante/Modelo: Minipa/ET2700

Resolução: $0.01 \mathrm{~A}$

Faixa de utilização: 0 a 20 A

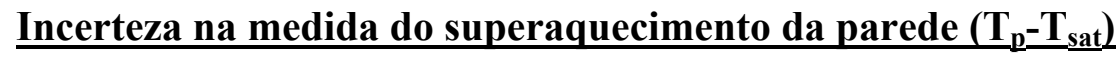

A temperatura na parede da superfície de testes e no banho são medidas com termopares que apresentam uma precisão de $0,20 \mathrm{~K}$.

A temperatura na parede foi medida com um termopar posicionado a aproximadamente 1,0 $\mathrm{mm}$ do diâmetro externo do tubo. Pode-se estimar a incerteza da medida da temperatura superficial utilizando a Lei de Fourier para superfícies cilíndricas, dada por:

$$
T_{p}=T_{T}+\frac{\phi \cdot(D / 2)}{k} \cdot \ln \left(\frac{D}{D_{T}}\right)
$$

onde $T_{T}$ é a temperatura medida no termopar fixo na parte superior da ranhura.

Foram desprezadas as incertezas associadas à condutividade térmica(tabelada) e do diâmetro, que assumiu valores inferiores a $0,25 \%$.

Utilizando as Eqs.(A1.8) e (A1.2) obtém-se a seguinte expressão para a incerteza associada ao superaquecimento da parede:

$$
\frac{i\left(T_{p}-T_{\text {sat }}\right)}{\left(T_{p}-T_{\text {sat }}\right)}=\left[\left(\frac{i(\phi)}{\phi}\right)^{2}+\frac{\left(i\left(T_{p}\right)\right)^{2}+\left(i\left(T_{\text {sat }}\right)\right)^{2}}{\left(T_{p}-T_{\text {sat }}\right)^{2}}\right]^{1 / 2}
$$




\section{Incerteza na medida do coeficiente de transferência de calor (h).}

O coeficiente de transferência de calor $(h)$ é calculado por:

$$
h=\frac{\phi}{\left(T_{p}-T_{\text {sat }}\right)}
$$

Com isso, das Eqs. (A1.10) e (A1.2) a incerteza é dada por:

$$
\frac{i(h)}{h}=\left[\left(\frac{i(\phi)}{\phi}\right)^{2}+\left(\frac{i\left(T_{p}-T_{\text {sat }}\right)}{\left(T_{p}-T_{\text {sat }}\right)}\right)^{2}\right]^{1 / 2}=\left[2 \cdot\left(\frac{i(\phi)}{\phi}\right)^{2}+\frac{\left.\left((i(T))^{2}\right)+\left(i\left(T_{\text {sat }}\right)\right)^{2}\right)}{\left(T_{p}-T_{\text {sat }}\right)^{2}}\right]^{1 / 2}
$$

A incerteza na medida do coeficiente de transferência de calor(h) depende das incertezas de medida do fluxo de calor e do superaquecimento da parede, variando, assim, com as condições experimentais.

A Tabela A1.1 apresenta as incertezas dos parâmetros medidos.

Tabela A1.1 - Incerteza dos parâmetros medidos

\section{Parâmetros}

\section{Incertezas}

\begin{tabular}{ll}
\hline \hline fluxo mínimo de calor $\phi=0,6 \mathrm{~kW} / \mathrm{m}^{2}$ & $\pm 1,78 \%$
\end{tabular}

fluxo máximo de calor $\phi=120 \mathrm{~kW} / \mathrm{m}^{2} \quad \pm 0,30 \%$

superaquecimento da parede, $\left(T_{p}-T_{\text {sat }}\right)$, para o fluxo mínimo de $\pm 0,3 \mathrm{~K}$ calor
superaquecimento da parede, $\left(T_{p}-T s_{a t}\right)$, para o fluxo máximo de $\pm 0,3 \mathrm{~K}$ calor

temperatura de saturação

$$
\pm 0,2 \mathrm{~K}
$$




\section{Calibração dos Termopares}

Os termopares utilizados foram calibrados para uma faixa de temperaturas entre -10 e $60^{\circ} \mathrm{C}$, utilizando como referência termômetros de imersão de precisão, $1 / 20^{\circ} \mathrm{C}$ (com rastreabilidade NIST). No processo de calibração, inseriram-se os termopares e o termômetro em um banho termostático. Desse modo, levantou-se, para a faixa de temperatura de ensaio, as diferenças entre as temperaturas medidas nos termopares, determinadas através do conjunto termopar, sistema de aquisição de dados e computador pessoal, e a fornecida pelo termômetro, que foi considerada como sendo a temperatura real. Foram levantadas curvas de calibração partindo-se de $-10{ }^{\circ} \mathrm{C}$ até $60^{\circ} \mathrm{C}$. Após atingir a temperatura de $60^{\circ} \mathrm{C}$, reduzia-se seu valor até -10 ${ }^{\circ} \mathrm{C}$. As diferenças entre as temperaturas indicadas pelos termopares e a dos termômetros foram determinadas dentro desta faixa a cada intervalo de $10^{\circ} \mathrm{C}$. Seguindo este procedimento foram levantadas 3 curvas de calibração. A partir das curvas foram obtidas equações do tipo:

$T_{\text {termômetro }}=A \cdot T_{\text {termopar }}+B$

onde $A$ e $B$ são constantes obtidas para cada canal do sistema de aquisição.

Com isso, pode-se inserir no programa de aquisição de dados as equações e diminuir o erro de cada canal e termopar na leitura das temperaturas. Após este ajuste preliminar as incertezas relativas as medidas foram determinadas através do procedimento sugerido por Abernethy e Thompson (1973), resultando para um intervalo de confiança de $95 \%$ igual a $\pm 0,16{ }^{\circ} \mathrm{C}$.

Tal procedimento consistiu em levantar distintas curvas de calibração com a elevação gradual do parâmetro de leitura até um máximo seguido de sua redução até o valor inicial. Este procedimento, segundo os autores, objetiva incorporar ao processo de determinação das incertezas efeitos de não linearidade e histerese relacionados a efetuação da medida. Com base nos resultados levantados experimentalmente determinou-se o desvio padrão para cada nível do parâmetro medido, neste caso a temperatura, definido como: 


$$
s_{i}=\sqrt{\frac{\sum_{j=1}^{n}\left(\bar{T}_{j}-\bar{T}\right)}{n-1}}
$$

onde

$n$ é o número de curvas de calibração levantadas.

$\bar{T}_{j}=\frac{T(\text { temperatura curva incremento })+Y(\text { temperatura curva decréscimo })}{2}$ para a $j$ curva de calibração.

$\bar{T}$ média aritmética de todas as temperaturas medidas naquele nível de temperatura

O desvio padrão total foi determinado por:

$$
s=i \sqrt{\sum_{i=1}^{k} s_{i}^{2}}
$$

onde $\mathrm{k}$ é o número de níveis de temperaturas

O número de graus de liberdade para determinação do valor do $t$ de student foi obtido segundo o método de Welch-Satterthwaite, através da seguinte equação:

$$
g l=\frac{\left(\sum_{i=1}^{k} s_{i}^{2}\right)^{2}}{\sum_{i=1}^{k} \frac{s_{i}^{4}}{g l_{i}}}
$$

onde $g l_{i}$ é o número de graus de liberdade em cada nível de temperatura dado pelo número de curvas levantadas menos 1

Finalmente, conhecendo-se o número de graus de liberdade total, determinase o valor do $t$ de Student obtendo-se a incerteza total na medida da temperatura com um intervalo de confiança de $95 \%$ dada por $t_{95}{ }^{\circ} \mathrm{s}$. 


\section{APÊNDICE II - RESULTADOS EXPERIMENTAIS - 1 ÚNICO TUBO AQUECIDO}

$R-123$ - Tubo de latão aquecido isoladamente, $R a=0,16 \mu \mathrm{m}$.

\begin{tabular}{|c|c|c|c|}
\hline $\mathbf{p r}_{\mathbf{r}}$ & $\begin{array}{c}\text { Tubo Latão } \\
\text { D }_{\text {ext }(\mathrm{mm})}\end{array}$ & $\phi\left(\mathbf{k W} / \mathbf{m}^{2}\right)$ & $\begin{array}{c}\Delta \text { Tmenor } \\
(\mathbf{K})\end{array}$ \\
\hline \multirow{12}{*}{0,023} & \multirow{32}{*}{12,5} & 38,68 & 13,44 \\
\hline & & 34,21 & 13,11 \\
\hline & & 25,12 & 12,80 \\
\hline & & 17,42 & 12,48 \\
\hline & & 14,44 & 12,26 \\
\hline & & 11,35 & 12,06 \\
\hline & & 8,61 & 11,77 \\
\hline & & 6,52 & 11,56 \\
\hline & & 4,46 & 11,09 \\
\hline & & 2,88 & 9,52 \\
\hline & & 1,70 & 6,82 \\
\hline & & 0,76 & 3,61 \\
\hline \multirow{10}{*}{0,034} & & 39,53 & 11,56 \\
\hline & & 35,14 & 11,21 \\
\hline & & 24,75 & 10,57 \\
\hline & & 17,60 & 10,21 \\
\hline & & 14,01 & 9,93 \\
\hline & & 11,27 & 9,77 \\
\hline & & 8,75 & 9,61 \\
\hline & & 4,73 & 9,14 \\
\hline & & 1,62 & 6,61 \\
\hline & & 0,74 & 3,69 \\
\hline \multirow{10}{*}{0,063} & & 39,23 & 8,95 \\
\hline & & 34,37 & 8,60 \\
\hline & & 24,78 & 7,95 \\
\hline & & 18,76 & 7,45 \\
\hline & & 11,72 & 6,86 \\
\hline & & 8,14 & 6,66 \\
\hline & & 6,43 & 6,59 \\
\hline & & 4,52 & 6,37 \\
\hline & & 3,07 & 6,22 \\
\hline & & 0,71 & 3,63 \\
\hline
\end{tabular}


$R-123$ - Tubo de latão aquecido isoladamente, $R a=0,16 \mu \mathrm{m}$.

\begin{tabular}{|c|c|c|c|}
\hline$p_{r}$ & $\begin{array}{c}\text { Tubo Latão } \\
D_{\text {ext }(\mathbf{m m})}\end{array}$ & $\phi\left(\mathbf{k W} / \mathbf{m}^{2}\right)$ & $\begin{array}{l}\Delta \text { Tmenor } \\
(\mathbf{K})\end{array}$ \\
\hline \multirow{10}{*}{0,023} & \multirow{29}{*}{22,0} & 44,36 & 14,31 \\
\hline & & 33,10 & 13,31 \\
\hline & & 22,59 & 12,07 \\
\hline & & 14,53 & 10,60 \\
\hline & & 10,99 & 9,96 \\
\hline & & 8,27 & 9,47 \\
\hline & & 5,70 & 8,58 \\
\hline & & 3,63 & 7,59 \\
\hline & & 1,98 & 5,69 \\
\hline & & 0,90 & 4,37 \\
\hline \multirow{9}{*}{0,035} & & 43,88 & 12,68 \\
\hline & & 32,76 & 11,43 \\
\hline & & 22,56 & 10,20 \\
\hline & & 14,68 & 9,14 \\
\hline & & 10,90 & 8,35 \\
\hline & & 8,26 & 7,83 \\
\hline & & 5,63 & 7,07 \\
\hline & & 3,71 & 6,42 \\
\hline & & 1,34 & 3,97 \\
\hline \multirow{10}{*}{0,063} & & 43,34 & 10,44 \\
\hline & & 33,08 & 9,43 \\
\hline & & 22,29 & 8,21 \\
\hline & & 14,63 & 6,98 \\
\hline & & 10,90 & 6,32 \\
\hline & & 8,34 & 5,99 \\
\hline & & 5,60 & 5,29 \\
\hline & & 3,70 & 4,74 \\
\hline & & 2,06 & 4,11 \\
\hline & & 0,95 & 3,61 \\
\hline
\end{tabular}

$R-123$ - Tubo de latão aquecido isoladamente no banco de tubos/ $D_{\text {ext }}=19 \mathrm{~mm}$.

\begin{tabular}{|c|c|c|c|c|c|c|}
\hline $\mathbf{p}_{\mathbf{r}}$ & $\begin{array}{c}\text { Tubo/ } \\
\operatorname{Ra}(\mu \mathrm{m})\end{array}$ & $\begin{array}{c}\phi \\
\left(\mathrm{kW} / \mathrm{m}^{2}\right)\end{array}$ & $\begin{array}{c}\Delta \mathrm{T} 1 \\
(\mathbf{K})\end{array}$ & $\begin{array}{c}\Delta \mathrm{T} 2 \\
(\mathrm{~K})\end{array}$ & $\begin{array}{c}\Delta \mathrm{T3} \\
(\mathrm{K})\end{array}$ & $\begin{array}{c}\Delta \mathrm{T} 4 \\
(\mathrm{~K})\end{array}$ \\
\hline \multirow{10}{*}{$\mathbf{0 , 0 2 3}$} & \multirow{10}{*}{$\begin{array}{c}\text { Inferior } \\
0,12\end{array}$} & 38,44 & 16,21 & 15,59 & 16,23 & 17,34 \\
\hline & & 27,95 & 15,41 & 14,79 & 15,42 & 16,09 \\
\hline & & 23,53 & 14,91 & 14,32 & 15,04 & 15,51 \\
\hline & & 18,71 & 14,22 & 13,79 & 14,69 & 14,81 \\
\hline & & 14,61 & 13,61 & 13,51 & 14,63 & 14,23 \\
\hline & & 9,51 & 12,96 & 13,18 & 14,19 & 13,60 \\
\hline & & 7,56 & 12,83 & 13,08 & 13,78 & 13,60 \\
\hline & & 4,86 & 10,62 & 10,74 & 10,95 & 10,88 \\
\hline & & 2,69 & 5,02 & 5,03 & 5,10 & 5,02 \\
\hline & & 0,86 & 5,73 & 5,75 & 5,84 & 5,74 \\
\hline
\end{tabular}


$R-123$ - Tubo de latão aquecido isoladamente no banco de tubos/ $D_{\text {ext }}=19 \mathrm{~mm}$.

\begin{tabular}{|c|c|c|c|c|c|c|}
\hline $\mathbf{p}_{\mathbf{r}}$ & $\begin{array}{c}\text { Tubo/ } \\
\operatorname{Ra}(\mu \mathbf{m})\end{array}$ & $\begin{array}{c}\phi \\
\left(k \mathbf{k} / \mathbf{m}^{2}\right)\end{array}$ & $\begin{array}{c}\Delta \mathrm{T} 1 \\
(\mathrm{~K})\end{array}$ & $\begin{array}{c}\Delta \mathrm{T} 2 \\
(\mathrm{~K})\end{array}$ & $\begin{array}{l}\Delta \mathrm{T3} \\
(\mathrm{K})\end{array}$ & $\begin{array}{c}\Delta \mathrm{T} 4 \\
(\mathrm{~K})\end{array}$ \\
\hline \multirow{10}{*}{$\mathbf{0 , 0 3 3}$} & \multirow{20}{*}{$\begin{array}{c}\text { Inferior } \\
0,12\end{array}$} & 37,39 & 13,57 & 13,12 & 13,63 & 14,98 \\
\hline & & 27,97 & 12,84 & 12,37 & 12,74 & 13,79 \\
\hline & & 23,85 & 12,37 & 11,87 & 12,31 & 13,12 \\
\hline & & 19,32 & 11,97 & 11,46 & 12,10 & 12,49 \\
\hline & & 14,21 & 11,08 & 10,67 & 11,47 & 11,52 \\
\hline & & 9,48 & 10,08 & 10,00 & 10,79 & 10,41 \\
\hline & & 7,53 & 9,99 & 9,98 & 10,75 & 10,35 \\
\hline & & 4,77 & 9,66 & 9,92 & 10,35 & 9,83 \\
\hline & & 2,97 & 9,42 & 9,63 & 9,89 & 9,66 \\
\hline & & 1,00 & 5,70 & 5,75 & 5,78 & 5,68 \\
\hline \multirow{10}{*}{0,063} & & 37,64 & 10,90 & 10,68 & 11,06 & 12,52 \\
\hline & & 28,67 & 10,37 & 10,04 & 10,43 & 11,53 \\
\hline & & 23,38 & 10,04 & 9,66 & 10,09 & 10,89 \\
\hline & & 18,82 & 9,67 & 9,27 & 9,77 & 10,30 \\
\hline & & 14,61 & 9,18 & 8,87 & 9,44 & 9,61 \\
\hline & & 9,93 & 8,32 & 8,24 & 8,89 & 8,63 \\
\hline & & 7,82 & 8,03 & 8,05 & 8,69 & 8,34 \\
\hline & & 4,84 & 7,65 & 7,72 & 8,26 & 7,89 \\
\hline & & 2,83 & 7,23 & 7,33 & 7,69 & 7,47 \\
\hline & & 0,92 & 5,05 & 5,13 & 5,11 & 5,02 \\
\hline \multirow{10}{*}{$\mathbf{0 , 0 2 3}$} & \multirow{30}{*}{$\begin{array}{c}\text { Central/ } \\
0,12\end{array}$} & 37,30 & 18,12 & 17,15 & 16,25 & 15,92 \\
\hline & & 27,98 & 17,37 & 16,17 & 15,33 & 15,02 \\
\hline & & 23,78 & 16,98 & 15,82 & 15,26 & 14,68 \\
\hline & & 18,64 & 16,29 & 15,27 & 14,80 & 14,20 \\
\hline & & 14,45 & 15,57 & 15,00 & 14,27 & 13,83 \\
\hline & & 9,20 & 14,52 & 14,35 & 13,74 & 13,29 \\
\hline & & 7,77 & 14,03 & 13,86 & 13,36 & 13,17 \\
\hline & & 5,01 & 12,72 & 12,62 & 12,15 & 12,12 \\
\hline & & 2,93 & 10,31 & 10,31 & 9,79 & 9,81 \\
\hline & & 0,94 & 5,30 & 5,36 & 5,16 & 5,11 \\
\hline \multirow{10}{*}{$\mathbf{0 , 0 3 3}$} & & 37,98 & 15,61 & 14,84 & 14,11 & 14,04 \\
\hline & & 27,45 & 14,57 & 13,65 & 12,83 & 12,76 \\
\hline & & 23,42 & 14,14 & 13,20 & 12,34 & 12,27 \\
\hline & & 18,66 & 13,34 & 12,48 & 11,67 & 11,60 \\
\hline & & 14,28 & 12,51 & 11,70 & 11,09 & 10,99 \\
\hline & & 9,83 & 11,68 & 11,18 & 10,65 & 10,42 \\
\hline & & 7,60 & 10,96 & 10,56 & 10,14 & 10,01 \\
\hline & & 4,73 & 10,00 & 9,82 & 9,48 & 9,33 \\
\hline & & 2,99 & 9,23 & 9,08 & 8,85 & 8,90 \\
\hline & & 0,91 & 5,10 & 5,16 & 5,00 & 4,96 \\
\hline \multirow{10}{*}{0,063} & & 37,64 & 12,67 & 11,99 & 11,08 & 10,98 \\
\hline & & 28,67 & 12,11 & 11,28 & 10,32 & 10,22 \\
\hline & & 23,38 & 11,60 & 10,77 & 9,75 & 9,66 \\
\hline & & 18,82 & 11,03 & 10,26 & 9,24 & 9,14 \\
\hline & & 14,61 & 10,31 & 9,64 & 8,75 & 8,59 \\
\hline & & 9,93 & 9,46 & 8,94 & 8,18 & 7,99 \\
\hline & & 7,82 & 8,92 & 8,52 & 7,95 & 7,66 \\
\hline & & 4,84 & 8,05 & 7,80 & 7,45 & 7,21 \\
\hline & & 2,83 & 7,41 & 7,33 & 6,99 & 6,83 \\
\hline & & 0,92 & 5,24 & 5,20 & 4,96 & 5,00 \\
\hline
\end{tabular}


$R-123$ - Tubo de latão aquecido isoladamente no banco de tubos/ $D_{\text {ext }}=19 \mathbf{m m}$.

\begin{tabular}{|c|c|c|c|c|c|c|}
\hline $\mathbf{p}_{\mathbf{r}}$ & $\begin{array}{c}\text { Tubo/ } \\
\operatorname{Ra}(\mu \mathbf{m})\end{array}$ & $\begin{array}{c}\phi \\
\left(\mathrm{kW} / \mathrm{m}^{2}\right)\end{array}$ & $\begin{array}{c}\Delta \mathrm{T} 1 \\
(\mathrm{~K})\end{array}$ & $\begin{array}{c}\Delta \mathrm{T} 2 \\
(\mathbf{K})\end{array}$ & $\begin{array}{c}\Delta \mathrm{T3} \\
(\mathbf{K})\end{array}$ & $\begin{array}{c}\Delta \mathrm{T} 4 \\
(\mathrm{~K})\end{array}$ \\
\hline \multirow{10}{*}{$\mathbf{0 , 0 2 3}$} & \multirow{30}{*}{$\begin{array}{c}\text { Superior/ } \\
0,14\end{array}$} & 39,50 & 17,14 & 16,57 & 15,87 & 14,15 \\
\hline & & 28,86 & 16,34 & 15,52 & 14,93 & 13,49 \\
\hline & & 24,24 & 15,95 & 15,05 & 14,62 & 13,23 \\
\hline & & 19,83 & 15,47 & 14,69 & 14,22 & 12,97 \\
\hline & & 14,89 & 14,76 & 14,22 & 13,73 & 12,73 \\
\hline & & 9,95 & 13,74 & 13,72 & 13,27 & 12,37 \\
\hline & & 7,94 & 13,44 & 13,48 & 13,12 & 12,42 \\
\hline & & 4,69 & 12,67 & 12,94 & 12,30 & 11,72 \\
\hline & & 2,94 & 11,21 & 11,45 & 10,78 & 10,53 \\
\hline & & 1,08 & 6,00 & 6,02 & 5,73 & 5,78 \\
\hline \multirow{10}{*}{$\mathbf{0 , 0 3 3}$} & & 38,15 & 14,62 & 14,32 & 13,66 & 11,89 \\
\hline & & 28,75 & 14,06 & 13,46 & 12,77 & 11,38 \\
\hline & & 23,86 & 13,51 & 12,80 & 12,24 & 10,98 \\
\hline & & 19,47 & 12,91 & 12,15 & 11,57 & 10,54 \\
\hline & & 14,36 & 12,14 & 11,38 & 10,91 & 10,08 \\
\hline & & 9,29 & 11,03 & 10,69 & 10,40 & 9,53 \\
\hline & & 7,76 & 10,72 & 10,57 & 10,19 & 9,37 \\
\hline & & 5,07 & 9,99 & 9,92 & 9,68 & 9,12 \\
\hline & & 2,90 & 9,18 & 9,11 & 8,74 & 8,56 \\
\hline & & 0,97 & 5,88 & 5,91 & 5,70 & 5,70 \\
\hline \multirow{10}{*}{0,063} & & 39,40 & 12,18 & 11,94 & 11,08 & 9,58 \\
\hline & & 28,41 & 11,30 & 10,90 & 10,00 & 8,86 \\
\hline & & 23,16 & 10,69 & 10,16 & 9,31 & 8,35 \\
\hline & & 18,64 & 10,20 & 9,59 & 8,83 & 8,02 \\
\hline & & 13,98 & 9,49 & 8,89 & 8,35 & 7,56 \\
\hline & & 9,61 & 8,59 & 8,03 & 7,74 & 7,09 \\
\hline & & 7,83 & 8,18 & 7,70 & 7,50 & 6,88 \\
\hline & & 5,19 & 7,54 & 7,28 & 7,15 & 6,67 \\
\hline & & 3,06 & 6,93 & 6,82 & 6,67 & 6,44 \\
\hline & & 0,91 & 5,46 & 5,47 & 5,28 & 5,25 \\
\hline
\end{tabular}


Banco de tubos de latão, 2 tubos aquecidos, $s / d=2,0 . d_{\text {ext }}=19 \mathrm{~mm}$

\begin{tabular}{|c|c|c|c|c|c|c|c|c|c|c|c|c|c|c|c|}
\hline & \multicolumn{5}{|c|}{ Tubo superior } & \multicolumn{5}{|c|}{ Tubo central } & \multicolumn{5}{|c|}{ Tubo inferior } \\
\hline $\mathbf{p}_{\mathbf{r}}$ & $\phi_{1}$ & $\Delta \mathrm{T11}$ & $\Delta \mathrm{T12}$ & $\Delta \mathrm{T13}$ & $\Delta \mathrm{T14}$ & $\phi_{2}$ & $\Delta \mathrm{T} 21$ & $\Delta \mathrm{T22}$ & $\Delta \mathrm{T} 23$ & $\Delta \mathrm{T} 24$ & $\phi_{3}$ & $\Delta \mathrm{T31}$ & $\Delta \mathrm{T32}$ & $\Delta \mathrm{T33}$ & $\Delta \mathrm{T34}$ \\
\hline \multirow{10}{*}{$\mathbf{0 , 0 2 3}$} & 0,00 & 0,25 & 0,29 & 0,33 & 0,29 & 38,41 & 18,38 & 17,79 & 16,35 & 16,28 & 38,02 & 16,46 & 15,89 & 16,40 & 17,57 \\
\hline & 0,00 & 0,27 & 0,31 & 0,35 & 0,32 & 28,78 & 17,79 & 16,97 & 15,15 & 15,34 & 28,50 & 15,86 & 15,23 & 15,98 & 16,59 \\
\hline & 0,00 & 0,28 & 0,32 & 0,37 & 0,34 & 23,16 & 17,21 & 16,38 & 14,15 & 14,34 & 23,68 & 15,35 & 14,78 & 15,77 & 15,99 \\
\hline & 0,00 & 0,31 & 0,35 & 0,40 & 0,36 & 19,06 & 15,86 & 15,18 & 12,79 & 12,97 & 19,06 & 14,61 & 14,34 & 15,69 & 15,34 \\
\hline & 0,00 & 0,29 & 0,34 & 0,38 & 0,35 & 14,43 & 13,50 & 13,12 & 10,84 & 10,94 & 14,57 & 14,02 & 14,07 & 15,55 & 14,87 \\
\hline & 0,00 & 0,29 & 0,31 & 0,33 & 0,31 & 9,71 & 10,48 & 10,24 & 8,53 & 8,54 & 9,58 & 13,48 & 13,70 & 15,07 & 14,58 \\
\hline & 0,00 & 0,28 & 0,32 & 0,32 & 0,31 & 7,72 & 9,17 & 9,05 & 7,51 & 7,49 & 7,74 & 13,45 & 13,58 & 14,81 & 14,65 \\
\hline & 0,00 & 0,31 & 0,33 & 0,34 & 0,34 & 4,83 & 7,73 & 7,53 & 6,58 & 6,53 & 4,89 & 13,55 & 13,76 & 14,53 & 14,47 \\
\hline & 0,00 & 0,36 & 0,37 & 0,39 & 0,38 & 2,77 & 8,74 & 8,95 & 8,30 & 8,12 & 2,80 & 11,47 & 11,58 & 11,73 & 11,68 \\
\hline & 0,00 & 0,44 & 0,48 & 0,47 & 0,48 & 0,95 & 4,68 & 4,75 & 4,58 & 4,53 & 0,97 & 5,55 & 5,57 & 5,65 & 5,56 \\
\hline \multirow{10}{*}{$\mathbf{0 , 0 3 3}$} & 0,00 & 0,27 & 0,29 & 0,32 & 0,30 & 37,39 & 15,90 & 15,18 & 13,88 & 14,00 & 37,42 & 14,13 & 13,63 & 14,09 & 15,43 \\
\hline & 0,00 & 0,29 & 0,30 & 0,34 & 0,32 & 28,53 & 15,22 & 14,45 & 13,02 & 13,11 & 27,19 & 13,52 & 12,89 & 13,32 & 14,28 \\
\hline & 0,00 & 0,30 & 0,32 & 0,36 & 0,34 & 23,56 & 14,75 & 14,02 & 12,36 & 12,48 & 23,91 & 13,12 & 12,51 & 13,02 & 13,71 \\
\hline & 0,00 & 0,31 & 0,33 & 0,37 & 0,36 & 18,48 & 13,94 & 13,27 & 11,44 & 11,55 & 18,80 & 12,47 & 11,96 & 12,45 & 12,88 \\
\hline & 0,00 & 0,33 & 0,35 & 0,38 & 0,37 & 14,35 & 12,49 & 11,96 & 10,01 & 10,16 & 13,91 & 11,71 & 11,43 & 12,22 & 12,14 \\
\hline & 0,00 & 0,35 & 0,37 & 0,40 & 0,39 & 10,06 & 10,60 & 10,22 & 8,42 & 8,58 & 9,77 & 11,22 & 11,19 & 12,26 & 11,73 \\
\hline & 0,00 & 0,29 & 0,30 & 0,33 & 0,32 & 7,69 & 8,71 & 8,45 & 6,97 & 7,07 & 7,47 & 10,84 & 10,88 & 11,64 & 11,25 \\
\hline & 0,00 & 0,45 & 0,47 & 0,49 & 0,48 & 4,81 & 8,27 & 8,24 & 7,08 & 7,00 & 4,84 & 10,83 & 11,13 & 11,75 & 11,12 \\
\hline & 0,00 & 0,44 & 0,46 & 0,48 & 0,47 & 3,03 & 8,25 & 8,28 & 7,70 & 7,54 & 2,86 & 10,37 & 10,55 & 10,86 & 10,70 \\
\hline & 0,00 & 0,79 & 0,82 & 0,83 & 0,84 & 0,93 & 4,97 & 5,00 & 4,80 & 4,77 & 0,92 & 5,49 & 5,53 & 5,57 & 5,48 \\
\hline \multirow{10}{*}{0,063} & 0,00 & 0,34 & 0,33 & 0,36 & 0,37 & 36,73 & 12,54 & 11,87 & 10,79 & 10,92 & 37,14 & 10,80 & 10,58 & 10,90 & 12,36 \\
\hline & 0,00 & 0,35 & 0,36 & 0,38 & 0,38 & 29,14 & 11,85 & 11,15 & 10,02 & 10,11 & 28,36 & 10,20 & 9,90 & 10,24 & 11,32 \\
\hline & 0,00 & 0,32 & 0,31 & 0,35 & 0,35 & 24,06 & 11,40 & 10,69 & 9,51 & 9,57 & 24,19 & 9,92 & 9,59 & 9,94 & 10,88 \\
\hline & 0,00 & 0,39 & 0,39 & 0,41 & 0,42 & 18,73 & 10,81 & 10,09 & 8,85 & 8,96 & 18,97 & 9,58 & 9,21 & 9,59 & 10,21 \\
\hline & 0,00 & 0,38 & 0,39 & 0,41 & 0,43 & 14,33 & 10,14 & 9,47 & 8,17 & 8,33 & 14,59 & 9,06 & 8,75 & 9,21 & 9,49 \\
\hline & 0,00 & 0,41 & 0,41 & 0,44 & 0,44 & 9,80 & 9,29 & 8,78 & 7,35 & 7,58 & 9,77 & 8,48 & 8,34 & 8,90 & 8,80 \\
\hline & 0,00 & 0,42 & 0,42 & 0,45 & 0,46 & 7,77 & 8,61 & 8,13 & 6,75 & 7,00 & 7,67 & 8,09 & 8,02 & 8,53 & 8,36 \\
\hline & 0,00 & 0,43 & 0,42 & 0,45 & 0,46 & 4,91 & 7,02 & 6,71 & 5,68 & 5,86 & 4,82 & 7,66 & 7,73 & 8,23 & 7,85 \\
\hline & 0,00 & 0,46 & 0,46 & 0,48 & 0,49 & 2,90 & 5,99 & 5,80 & 5,13 & 5,20 & 2,90 & 7,42 & 7,48 & 7,94 & 7,74 \\
\hline & 0,00 & 0,70 & 0,70 & 0,72 & 0,73 & 0,95 & 4,69 & 4,68 & 4,45 & 4,49 & 0,95 & 5,23 & 5,32 & 5,33 & 5,23 \\
\hline
\end{tabular}


Banco de tubos de latão, 3 tubos aquecidos, $s / d=2,0 . d_{\text {ext }}=19 \mathrm{~mm}$

\begin{tabular}{|c|c|c|c|c|c|c|c|c|c|c|c|c|c|c|c|}
\hline & \multicolumn{5}{|c|}{ Tubo superior } & \multicolumn{5}{|c|}{ Tubo central } & \multicolumn{5}{|c|}{ Tubo inferior } \\
\hline $\mathbf{p}_{\mathbf{r}}$ & $\phi_{1}$ & $\Delta \mathrm{T11}$ & $\Delta \mathrm{T12}$ & $\Delta \mathrm{T} 13$ & $\Delta \mathrm{T} 14$ & $\phi_{2}$ & $\Delta \mathrm{T} 21$ & $\Delta \mathrm{T} 22$ & $\Delta \mathrm{T} 23$ & $\Delta \mathrm{T} 24$ & $\phi_{3}$ & $\Delta \mathrm{T31}$ & $\Delta \mathrm{T32}$ & $\Delta \mathrm{T33}$ & $\Delta \mathrm{T34}$ \\
\hline \multirow{10}{*}{$\mathbf{0 , 0 2 3}$} & 38,47 & 17,18 & 17,16 & 15,22 & 13,98 & 37,11 & 18,46 & 17,86 & 16,43 & 16,41 & 37,87 & 16,53 & 16,02 & 16,51 & 17,65 \\
\hline & 29,02 & 16,23 & 16,20 & 13,62 & 12,77 & 28,47 & 17,90 & 17,04 & 15,28 & 15,49 & 28,23 & 15,82 & 15,24 & 15,94 & 16,49 \\
\hline & 24,21 & 15,71 & 15,55 & 12,86 & 12,28 & 23,33 & 17,27 & 16,44 & 14,18 & 14,41 & 23,26 & 15,27 & 14,74 & 15,80 & 15,90 \\
\hline & 18,82 & 14,56 & 14,32 & 11,60 & 11,30 & 18,35 & 15,43 & 14,84 & 12,48 & 12,58 & 18,22 & 14,40 & 14,12 & 15,34 & 15,05 \\
\hline & 14,57 & 12,60 & 12,52 & 10,09 & 9,89 & 14,06 & 13,00 & 12,64 & 10,42 & 10,47 & 14,18 & 13,87 & 13,93 & 15,28 & 14,67 \\
\hline & 9,78 & 9,42 & 9,26 & 7,64 & 7,66 & 9,53 & 10,21 & 9,93 & 8,34 & 8,40 & 9,48 & 13,45 & 13,55 & 14,94 & 14,64 \\
\hline & 7,93 & 8,18 & 8,26 & 6,75 & 6,53 & 7,80 & 9,27 & 9,19 & 7,65 & 7,50 & 7,67 & 13,47 & 14,11 & 14,91 & 14,30 \\
\hline & 5,06 & 6,20 & 6,23 & 5,27 & 5,05 & 4,75 & 7,85 & 7,83 & 6,92 & 6,75 & 4,88 & 13,25 & 13,55 & 14,03 & 13,94 \\
\hline & 2,94 & 5,80 & 6,01 & 5,59 & 5,35 & 2,84 & 8,92 & 9,00 & 8,52 & 8,41 & 2,91 & 11,81 & 12,00 & 12,24 & 12,16 \\
\hline & 0,97 & 4,02 & 4,09 & 3,87 & 3,91 & 0,86 & 4,31 & 4,38 & 4,25 & 4,19 & 0,91 & 5,10 & 5,15 & 5,24 & 5,13 \\
\hline \multirow{10}{*}{$\mathbf{0 , 0 3 3}$} & 38,24 & 14,77 & 14,58 & 13,21 & 11,82 & 37,20 & 15,90 & 15,23 & 13,85 & 13,95 & 38,12 & 14,05 & 13,53 & 13,94 & 15,28 \\
\hline & 28,25 & 13,85 & 13,53 & 11,85 & 10,88 & 28,34 & 15,20 & 14,36 & 12,95 & 13,11 & 28,06 & 13,41 & 12,78 & 13,19 & 14,16 \\
\hline & 24,67 & 13,25 & 12,95 & 11,14 & 10,41 & 23,97 & 14,66 & 13,87 & 12,23 & 12,39 & 23,78 & 13,03 & 12,40 & 12,81 & 13,61 \\
\hline & 20,13 & 12,68 & 12,35 & 10,43 & 9,94 & 18,97 & 13,86 & 13,20 & 11,26 & 11,41 & 19,45 & 12,45 & 11,90 & 12,45 & 12,98 \\
\hline & 15,18 & 11,81 & 11,51 & 9,47 & 9,24 & 14,29 & 12,44 & 11,90 & 9,89 & 10,05 & 14,59 & 11,76 & 11,38 & 12,09 & 12,23 \\
\hline & 9,72 & 9,16 & 9,04 & 7,45 & 7,37 & 9,71 & 10,01 & 9,71 & 7,94 & 8,03 & 9,89 & 11,06 & 11,00 & 11,95 & 11,62 \\
\hline & 7,83 & 8,05 & 7,89 & 6,65 & 6,65 & 7,38 & 8,75 & 8,46 & 6,92 & 7,06 & 7,59 & 10,91 & 10,91 & 11,84 & 11,44 \\
\hline & 5,02 & 5,64 & 5,59 & 4,80 & 4,76 & 4,94 & 7,00 & 6,85 & 5,73 & 5,79 & 4,82 & 10,57 & 10,89 & 11,55 & 11,02 \\
\hline & 2,81 & 5,99 & 6,18 & 5,66 & 5,47 & 2,87 & 8,10 & 8,24 & 7,58 & 7,32 & 2,81 & 10,12 & 10,36 & 10,58 & 10,36 \\
\hline & 0,90 & 3,93 & 4,00 & 3,77 & 3,81 & 1,05 & 5,00 & 5,06 & 4,78 & 4,74 & 0,92 & 5,45 & 5,48 & 5,53 & 5,43 \\
\hline \multirow{10}{*}{$\mathbf{0 , 0 6 3}$} & 38,05 & 11,91 & 11,74 & 10,58 & 9,23 & 37,77 & 12,60 & 11,93 & 10,75 & 10,91 & 38,69 & 10,81 & 10,59 & 10,93 & 12,42 \\
\hline & 29,44 & 11,05 & 10,77 & 9,54 & 8,50 & 28,09 & 11,99 & 11,21 & 10,01 & 10,10 & 28,03 & 10,32 & 9,98 & 10,35 & 11,47 \\
\hline & 23,91 & 10,56 & 10,20 & 8,98 & 8,14 & 23,78 & 11,53 & 10,74 & 9,48 & 9,53 & 24,24 & 10,05 & 9,66 & 10,04 & 10,92 \\
\hline & 19,70 & 10,06 & 9,68 & 8,47 & 7,74 & 18,93 & 11,03 & 10,25 & 8,91 & 9,03 & 19,22 & 9,67 & 9,25 & 9,69 & 10,30 \\
\hline & 13,87 & 9,20 & 8,80 & 7,53 & 7,11 & 14,28 & 10,25 & 9,55 & 8,18 & 8,36 & 14,22 & 9,05 & 8,77 & 9,28 & 9,43 \\
\hline & 9,28 & 8,07 & 7,76 & 6,52 & 6,42 & 9,53 & 9,11 & 8,58 & 7,10 & 7,34 & 9,77 & 8,45 & 8,30 & 8,88 & 8,73 \\
\hline & 7,90 & 7,27 & 7,02 & 5,90 & 5,85 & 8,03 & 8,55 & 8,04 & 6,58 & 6,87 & 7,59 & 7,99 & 7,92 & 8,47 & 8,26 \\
\hline & 4,92 & 5,97 & 5,77 & 4,96 & 5,00 & 5,14 & 6,98 & 6,70 & 5,60 & 5,75 & 5,00 & 7,70 & 7,75 & 8,33 & 7,91 \\
\hline & 2,77 & 4,79 & 4,74 & 4,29 & 4,20 & 2,57 & 5,33 & 5,18 & 4,54 & 4,58 & 2,92 & 7,46 & 7,56 & 7,99 & 7,72 \\
\hline & 0,88 & 4,28 & 4,30 & 4,12 & 4,16 & 0,89 & 5,00 & 5,01 & 4,78 & 4,78 & 0,96 & 5,63 & 5,73 & 5,72 & 5,59 \\
\hline
\end{tabular}


Banco de tubos de latão, 2 tubos aquecidos, $s / d=1,53$. $d_{\text {ext }}=19 \mathrm{~mm}$

\begin{tabular}{|c|c|c|c|c|c|c|c|c|c|c|c|c|c|c|c|}
\hline & \multicolumn{5}{|c|}{ Tubo superior } & \multicolumn{5}{|c|}{ Tubo central } & \multicolumn{5}{|c|}{ Tubo inferior } \\
\hline $\mathbf{p}_{\mathbf{r}}$ & $\phi_{1}$ & $\Delta \mathrm{T11}$ & $\Delta \mathrm{T} 12$ & $\Delta \mathrm{T13}$ & $\Delta \mathrm{T14}$ & $\phi_{2}$ & $\Delta \mathrm{T} 21$ & $\Delta \mathrm{T} 22$ & $\Delta T 23$ & $\Delta \mathrm{T} 24$ & $\phi_{3}$ & $\Delta \mathrm{T31}$ & $\Delta \mathrm{T32}$ & $\Delta \mathrm{T33}$ & $\Delta \mathrm{T34}$ \\
\hline \multirow{10}{*}{$\mathbf{0 , 0 2 3}$} & 0,00 & 0,31 & 0,36 & 0,40 & 0,38 & 37,52 & 19,60 & 19,26 & 16,68 & 16,84 & 38,06 & 17,76 & 18,40 & 16,19 & 16,28 \\
\hline & 0,00 & 0,40 & 0,46 & 0,50 & 0,46 & 23,76 & 17,86 & 17,00 & 13,90 & 14,18 & 24,19 & 17,24 & 17,00 & 15,54 & 15,42 \\
\hline & 0,00 & 0,38 & 0,42 & 0,44 & 0,43 & 9,42 & 9,99 & 9,70 & 8,01 & 7,99 & 9,51 & 15,72 & 15,45 & 14,67 & 14,66 \\
\hline & 0,00 & 0,39 & 0,43 & 0,46 & 0,45 & 7,83 & 9,41 & 9,10 & 7,69 & 7,67 & 7,74 & 15,53 & 15,25 & 14,66 & 14,71 \\
\hline & 0,00 & 0,53 & 0,59 & 0,61 & 0,58 & 5,79 & 8,47 & 8,60 & 7,90 & 7,71 & 5,93 & 11,85 & 11,76 & 11,15 & 11,22 \\
\hline & 0,00 & 0,39 & 0,42 & 0,45 & 0,43 & 4,87 & 9,76 & 9,40 & 7,48 & 7,64 & 4,79 & 13,47 & 12,86 & 12,23 & 12,40 \\
\hline & 0,00 & 0,40 & 0,42 & 0,44 & 0,42 & 3,60 & 8,44 & 8,15 & 6,63 & 6,73 & 3,73 & 13,15 & 12,58 & 12,03 & 12,24 \\
\hline & 0,00 & 0,41 & 0,44 & 0,45 & 0,43 & 2,75 & 7,73 & 7,65 & 6,61 & 6,50 & 2,85 & 12,68 & 12,36 & 11,89 & 12,09 \\
\hline & 0,00 & 0,46 & 0,48 & 0,50 & 0,48 & 1,72 & 7,81 & 7,91 & 7,21 & 7,25 & 1,91 & 11,52 & 11,42 & 10,89 & 11,01 \\
\hline & 0,00 & 1,35 & 1,44 & 1,51 & 1,43 & 0,91 & 6,17 & 6,24 & 5,95 & 5,94 & 0,88 & 5,58 & 5,58 & 5,44 & 5,38 \\
\hline \multirow{10}{*}{$\mathbf{0 , 0 3 3}$} & 0,00 & 0,27 & 0,30 & 0,34 & 0,31 & 38,60 & 17,04 & 16,46 & 14,79 & 14,91 & 37,71 & 15,31 & 16,14 & 13,84 & 14,11 \\
\hline & 0,00 & 0,34 & 0,38 & 0,41 & 0,38 & 28,28 & 16,38 & 15,56 & 13,71 & 13,97 & 28,28 & 15,03 & 15,22 & 13,28 & 13,56 \\
\hline & 0,00 & 0,40 & 0,43 & 0,47 & 0,43 & 23,16 & 15,80 & 14,94 & 12,80 & 13,06 & 23,01 & 14,82 & 14,67 & 13,02 & 13,27 \\
\hline & 0,00 & 0,42 & 0,46 & 0,50 & 0,46 & 19,15 & 14,94 & 14,19 & 11,66 & 11,93 & 18,97 & 14,55 & 14,16 & 12,71 & 12,97 \\
\hline & 0,00 & 0,40 & 0,45 & 0,48 & 0,44 & 14,45 & 12,91 & 12,44 & 9,83 & 10,01 & 13,95 & 14,10 & 13,47 & 12,32 & 12,58 \\
\hline & 0,00 & 0,39 & 0,42 & 0,45 & 0,43 & 9,58 & 9,74 & 9,38 & 7,45 & 7,62 & 9,39 & 13,45 & 12,83 & 12,21 & 12,38 \\
\hline & 0,00 & 0,40 & 0,42 & 0,44 & 0,42 & 7,40 & 8,42 & 8,13 & 6,61 & 6,71 & 7,53 & 13,13 & 12,56 & 12,01 & 12,22 \\
\hline & 0,00 & 0,41 & 0,44 & 0,45 & 0,43 & 4,91 & 7,72 & 7,64 & 6,59 & 6,49 & 4,76 & 12,67 & 12,35 & 11,88 & 12,08 \\
\hline & 0,00 & 0,46 & 0,48 & 0,50 & 0,48 & 2,93 & 7,80 & 7,90 & 7,21 & 7,24 & 2,91 & 11,52 & 11,42 & 10,89 & 11,00 \\
\hline & 0,00 & 1,35 & 1,44 & 1,51 & 1,43 & 0,96 & 6,17 & 6,24 & 5,95 & 5,94 & 0,96 & 5,58 & 5,58 & 5,44 & 5,37 \\
\hline \multirow{10}{*}{0,063} & 0,00 & 0,35 & 0,35 & 0,39 & 0,39 & 37,61 & 13,42 & 13,11 & 11,61 & 11,48 & 37,20 & 11,58 & 12,72 & 10,62 & 10,66 \\
\hline & 0,00 & 0,38 & 0,37 & 0,41 & 0,42 & 23,63 & 12,54 & 11,84 & 10,28 & 10,28 & 23,95 & 11,12 & 11,48 & 9,81 & 9,99 \\
\hline & 0,00 & 0,46 & 0,46 & 0,49 & 0,50 & 9,75 & 9,82 & 9,17 & 7,24 & 7,66 & 9,59 & 10,16 & 9,79 & 8,99 & 8,98 \\
\hline & 0,00 & 0,47 & 0,47 & 0,49 & 0,51 & 7,63 & 8,71 & 8,19 & 6,44 & 6,77 & 7,69 & 9,83 & 9,46 & 8,94 & 8,90 \\
\hline & 0,00 & 0,48 & 0,49 & 0,50 & 0,49 & 5,79 & 7,60 & 7,20 & 5,78 & 6,03 & 5,74 & 9,48 & 9,23 & 8,78 & 8,68 \\
\hline & 0,00 & 0,50 & 0,50 & 0,50 & 0,49 & 4,47 & 6,73 & 6,44 & 5,29 & 5,40 & 4,84 & 9,30 & 9,08 & 8,70 & 8,59 \\
\hline & 0,00 & 0,49 & 0,48 & 0,48 & 0,48 & 3,60 & 6,21 & 6,00 & 5,08 & 5,11 & 3,86 & 8,97 & 8,87 & 8,53 & 8,46 \\
\hline & 0,00 & 0,52 & 0,52 & 0,52 & 0,53 & 2,62 & 5,77 & 5,65 & 4,96 & 4,91 & 2,71 & 8,50 & 8,48 & 8,19 & 8,23 \\
\hline & 0,00 & 0,66 & 0,64 & 0,67 & 0,69 & 1,74 & 5,64 & 5,57 & 5,14 & 5,15 & 1,79 & 7,93 & 7,93 & 7,69 & 7,70 \\
\hline & 0,00 & 1,15 & 1,17 & 1,22 & 1,19 & 0,97 & 5,44 & 5,41 & 5,10 & 5,14 & 0,96 & 5,74 & 5,77 & 5,60 & 5,54 \\
\hline
\end{tabular}


Banco de tubos de latão, 3 tubos aquecidos, $s / d=1,53 . d_{\text {ext }}=19 \mathrm{~mm}$

\begin{tabular}{|c|c|c|c|c|c|c|c|c|c|c|c|c|c|c|c|}
\hline & \multicolumn{5}{|c|}{ Tubo superior } & \multicolumn{5}{|c|}{ Tubo central } & \multicolumn{5}{|c|}{ Tubo inferior } \\
\hline $\mathbf{p}_{\mathbf{r}}$ & $\phi_{1}$ & $\Delta \mathrm{T11}$ & $\Delta \mathrm{T12}$ & $\Delta \mathrm{T} 13$ & $\Delta \mathrm{T14}$ & $\phi_{2}$ & $\Delta \mathrm{T} 21$ & $\Delta \mathrm{T} 22$ & $\Delta \mathrm{T} 23$ & $\Delta \mathrm{T} 24$ & $\phi_{3}$ & $\Delta \mathrm{T31}$ & $\Delta \mathrm{T32}$ & $\Delta \mathrm{T33}$ & $\Delta \mathrm{T34}$ \\
\hline \multirow{10}{*}{$\mathbf{0 , 0 2 3}$} & 39,21 & 17,41 & 17,22 & 15,22 & 14,00 & 37,68 & 19,16 & 18,67 & 16,54 & 16,60 & 38,44 & 17,60 & 18,29 & 15,99 & 16,26 \\
\hline & 28,86 & 16,46 & 16,28 & 13,50 & 12,72 & 28,36 & 18,66 & 17,69 & 15,18 & 15,53 & 28,01 & 17,31 & 17,38 & 15,57 & 15,75 \\
\hline & 23,73 & 15,70 & 15,48 & 12,67 & 11,99 & 23,14 & 17,39 & 16,50 & 13,61 & 13,87 & 23,36 & 17,02 & 16,78 & 15,28 & 15,38 \\
\hline & 19,36 & 14,19 & 13,90 & 11,31 & 10,81 & 18,71 & 15,09 & 14,41 & 11,77 & 11,97 & 19,11 & 16,76 & 16,29 & 14,97 & 15,08 \\
\hline & 14,77 & 11,85 & 11,69 & 9,47 & 9,03 & 14,45 & 12,77 & 12,33 & 9,89 & 9,96 & 14,57 & 16,26 & 15,71 & 14,74 & 14,90 \\
\hline & 9,66 & 9,20 & 8,89 & 7,35 & 7,30 & 9,36 & 9,70 & 9,34 & 7,69 & 7,76 & 9,58 & 15,59 & 15,16 & 14,08 & 14,13 \\
\hline & 7,49 & 7,94 & 7,84 & 6,54 & 6,41 & 7,35 & 8,62 & 8,43 & 7,18 & 7,02 & 7,59 & 15,23 & 14,83 & 14,03 & 13,94 \\
\hline & 5,15 & 6,83 & 6,87 & 5,76 & 5,47 & 5,02 & 8,19 & 8,34 & 7,28 & 6,85 & 4,98 & 14,43 & 14,35 & 13,58 & 13,47 \\
\hline & 2,63 & 7,11 & 7,24 & 6,76 & 6,57 & 2,66 & 9,25 & 9,35 & 8,89 & 8,78 & 2,88 & 11,76 & 11,68 & 11,16 & 11,32 \\
\hline & 0,89 & 4,09 & 4,19 & 3,98 & 3,97 & 0,76 & 4,06 & 4,17 & 4,02 & 3,95 & 0,96 & 5,07 & 5,08 & 4,94 & 4,86 \\
\hline \multirow{10}{*}{$\mathbf{0 , 0 3 3}$} & 37,49 & 15,39 & 15,01 & 13,50 & 12,16 & 36,73 & 16,89 & 16,23 & 14,55 & 14,62 & 38,05 & 15,32 & 16,32 & 13,94 & 14,17 \\
\hline & 28,86 & 14,45 & 14,07 & 12,21 & 11,25 & 28,58 & 16,38 & 15,54 & 13,70 & 13,94 & 28,12 & 14,94 & 15,15 & 13,20 & 13,50 \\
\hline & 23,51 & 13,89 & 13,51 & 11,43 & 10,70 & 23,46 & 15,79 & 14,90 & 12,75 & 13,02 & 23,09 & 14,66 & 14,55 & 12,91 & 13,14 \\
\hline & 19,79 & 13,28 & 12,88 & 10,73 & 10,29 & 19,61 & 15,07 & 14,24 & 11,71 & 12,05 & 19,36 & 14,50 & 14,11 & 12,64 & 12,90 \\
\hline & 15,10 & 11,79 & 11,57 & 9,52 & 9,10 & 14,35 & 12,49 & 11,96 & 9,49 & 9,70 & 15,25 & 14,18 & 13,65 & 12,39 & 12,63 \\
\hline & 9,47 & 9,04 & 8,82 & 7,41 & 7,17 & 9,26 & 9,89 & 9,46 & 7,52 & 7,70 & 9,25 & 13,34 & 12,76 & 11,97 & 12,16 \\
\hline & 7,59 & 7,80 & 7,68 & 6,41 & 6,21 & 7,76 & 8,59 & 8,34 & 6,75 & 6,77 & 7,83 & 13,07 & 12,49 & 11,84 & 12,05 \\
\hline & 5,02 & 6,30 & 6,42 & 5,31 & 5,04 & 4,92 & 7,33 & 7,38 & 6,33 & 6,02 & 4,85 & 12,35 & 12,01 & 11,33 & 11,52 \\
\hline & 3,07 & 6,13 & 6,23 & 5,76 & 5,70 & 2,98 & 8,59 & 8,77 & 8,11 & 7,97 & 2,84 & 11,15 & 11,05 & 10,54 & 10,68 \\
\hline & 0,96 & 4,09 & 4,16 & 3,96 & 3,95 & 1,01 & 5,18 & 5,28 & 4,98 & 4,95 & 0,98 & 5,29 & 5,31 & 5,17 & 5,09 \\
\hline \multirow{10}{*}{$\mathbf{0 , 0 6 3}$} & 38,25 & 12,90 & 12,63 & 11,45 & 10,00 & 38,34 & 13,37 & 13,12 & 11,71 & 11,60 & 38,60 & 11,55 & 12,82 & 10,70 & 10,71 \\
\hline & 28,83 & 11,68 & 11,27 & 10,11 & 9,00 & 29,00 & 12,63 & 12,10 & 10,77 & 10,76 & 28,09 & 11,09 & 11,78 & 9,97 & 10,09 \\
\hline & 23,06 & 10,85 & 10,42 & 9,22 & 8,35 & 22,25 & 11,95 & 11,27 & 9,90 & 9,94 & 22,84 & 10,73 & 11,08 & 9,46 & 9,63 \\
\hline & 18,79 & 10,34 & 9,88 & 8,62 & 7,95 & 19,27 & 11,79 & 11,02 & 9,55 & 9,68 & 19,06 & 10,65 & 10,76 & 9,32 & 9,48 \\
\hline & 15,02 & 9,74 & 9,28 & 7,99 & 7,56 & 14,65 & 11,29 & 10,43 & 8,71 & 9,05 & 14,91 & 10,49 & 10,30 & 9,11 & 9,26 \\
\hline & 9,61 & 8,39 & 8,10 & 6,82 & 6,60 & 9,45 & 9,57 & 8,97 & 7,12 & 7,49 & 9,43 & 10,03 & 9,62 & 8,85 & 8,91 \\
\hline & 7,36 & 7,52 & 7,28 & 6,15 & 6,07 & 7,67 & 8,63 & 8,11 & 6,45 & 6,80 & 7,10 & 9,61 & 9,26 & 8,68 & 8,66 \\
\hline & 4,88 & 6,51 & 6,36 & 5,58 & 5,40 & 4,79 & 7,01 & 6,70 & 5,56 & 5,71 & 4,58 & 9,06 & 8,90 & 8,50 & 8,41 \\
\hline & 2,77 & 5,23 & 5,27 & 4,68 & 4,47 & 2,69 & 5,80 & 5,69 & 5,05 & 5,00 & 2,84 & 8,49 & 8,44 & 8,12 & 8,12 \\
\hline & 1,00 & 4,08 & 4,08 & 3,93 & 3,92 & 0,99 & 4,96 & 4,95 & 4,72 & 4,76 & 0,96 & 5,51 & 5,53 & 5,36 & 5,31 \\
\hline
\end{tabular}


Banco de tubos de latão, 2 tubos aquecidos, $s / d=1,32 . d_{\text {ext }}=19 \mathrm{~mm}$

Tubo superior

Tubo central

Tubo inferior

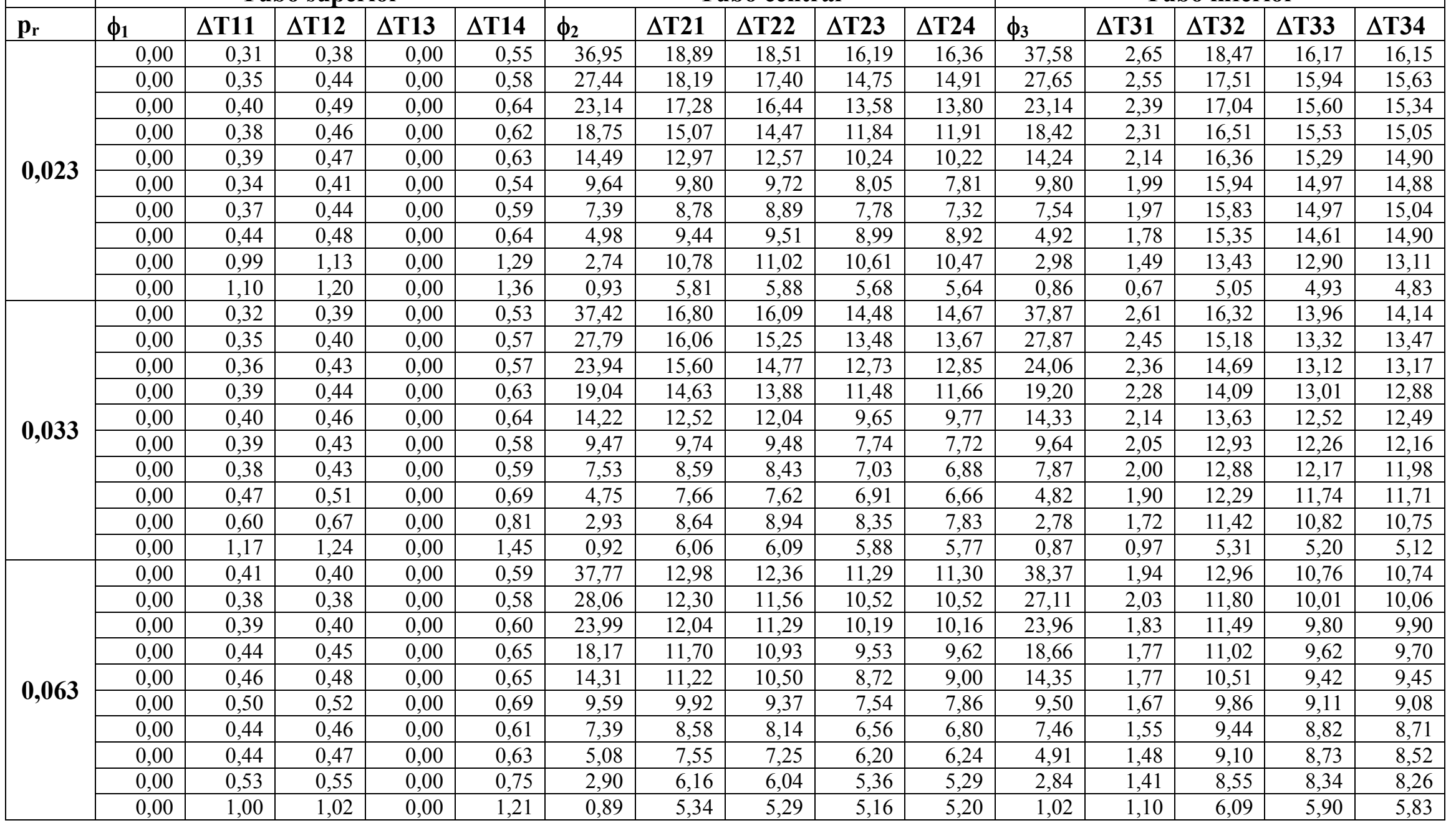


Banco de tubos de latão, 3 tubos aquecidos, $s / d=1,32 . d_{e x t}=19 \mathrm{~mm}$

\begin{tabular}{|c|c|c|c|c|c|c|c|c|c|c|c|c|c|c|c|}
\hline & \multicolumn{5}{|c|}{ Tubo superior } & \multicolumn{5}{|c|}{ Tubo central } & \multicolumn{5}{|c|}{ Tubo inferior } \\
\hline $\mathbf{p}_{\mathbf{r}}$ & $\phi_{1}$ & $\Delta \mathrm{T11}$ & $\Delta \mathrm{T} 12$ & $\Delta \mathrm{T} 13$ & $\Delta \mathrm{T14}$ & $\phi_{2}$ & $\Delta \mathrm{T} 21$ & $\Delta \mathrm{T} 22$ & $\Delta \mathrm{T} 23$ & $\Delta \mathrm{T} 24$ & $\phi_{3}$ & $\Delta \mathrm{T31}$ & $\Delta \mathrm{T32}$ & $\Delta \mathrm{T33}$ & $\Delta \mathrm{T34}$ \\
\hline \multirow{10}{*}{$\mathbf{0 , 0 2 3}$} & 38,40 & 17,52 & 17,34 & desliga & 14,23 & 37,96 & 18,92 & 18,67 & 16,31 & 16,55 & 37,49 & 2,57 & 18,48 & 16,23 & 16,22 \\
\hline & 29,44 & 16,64 & 16,33 & desliga & 13,04 & 29,39 & 18,43 & 17,68 & 15,11 & 15,30 & 28,94 & 2,37 & 17,64 & 15,93 & 15,68 \\
\hline & 23,86 & 15,78 & 15,40 & desliga & 12,06 & 24,37 & 17,67 & 16,79 & 13,91 & 14,14 & 23,58 & 2,23 & 17,02 & 15,61 & 15,31 \\
\hline & 18,57 & 13,87 & 13,47 & desliga & 10,66 & 18,42 & 14,68 & 14,08 & 11,46 & 11,54 & 18,82 & 2,11 & 16,36 & 15,33 & 15,04 \\
\hline & 14,77 & 12,07 & 11,76 & desliga & 9,36 & 14,45 & 12,66 & 12,25 & 9,88 & 9,89 & 14,22 & 2,02 & 16,03 & 15,11 & 14,78 \\
\hline & 9,51 & 8,86 & 8,68 & desliga & 7,16 & 9,23 & 9,41 & 9,27 & 7,67 & 7,48 & 9,15 & 1,89 & 15,71 & 15,07 & 14,94 \\
\hline & 7,81 & 8,10 & 8,05 & desliga & 6,81 & 7,40 & 8,75 & 8,85 & 7,65 & 7,24 & 7,50 & 1,81 & 15,76 & 14,93 & 15,05 \\
\hline & 5,16 & 7,55 & 7,79 & desliga & 7,04 & 4,69 & 9,70 & 9,86 & 9,19 & 9,05 & 4,76 & 1,60 & 15,17 & 14,47 & 14,78 \\
\hline & 2,92 & 8,09 & 8,44 & desliga & 8,15 & 2,90 & 10,68 & 10,88 & 10,29 & 10,22 & 2,78 & 1,19 & 11,66 & 11,15 & 11,32 \\
\hline & 0,90 & 4,21 & 4,27 & desliga & 4,26 & 0,89 & 4,79 & 4,87 & 4,64 & 4,57 & 0,82 & 0,48 & 4,46 & 4,40 & 4,27 \\
\hline \multirow{9}{*}{$\mathbf{0 , 0 3 3}$} & 38,28 & 15,03 & 14,85 & desliga & 12,20 & 37,58 & 16,75 & 16,10 & 14,47 & 14,68 & 37,45 & 2,43 & 16,19 & 13,83 & 14,06 \\
\hline & 28,75 & 14,23 & 13,90 & desliga & 11,36 & 28,20 & 16,17 & 15,38 & 13,54 & 13,76 & 28,20 & 2,16 & 15,29 & 13,43 & 13,57 \\
\hline & 20,02 & 12,80 & 12,43 & desliga & 9,98 & 23,76 & 15,59 & 14,80 & 12,66 & 12,77 & 23,46 & 2,12 & 14,65 & 13,12 & 13,16 \\
\hline & 19,90 & 13,06 & 12,62 & desliga & 10,30 & 18,55 & 14,48 & 13,80 & 11,23 & 11,41 & 18,42 & 2,03 & 14,06 & 12,78 & 12,81 \\
\hline & 14,25 & 11,44 & 11,19 & desliga & 8,91 & 14,10 & 12,22 & 11,81 & 9,35 & 9,48 & 14,31 & 1,97 & 13,57 & 12,48 & 12,53 \\
\hline & 9,70 & 9,23 & 9,22 & desliga & 7,31 & 9,74 & 9,86 & 9,64 & 7,76 & 7,74 & 9,63 & 1,78 & 13,03 & 12,31 & 12,29 \\
\hline & 4,93 & 6,74 & 6,94 & desliga & 5,64 & 4,55 & 7,51 & 7,52 & 6,75 & 6,46 & 4,83 & 1,58 & 12,14 & 11,57 & 11,66 \\
\hline & 2,85 & 6,05 & 6,41 & desliga & 5,78 & 2,69 & 8,24 & 8,61 & 7,99 & 7,59 & 2,80 & 1,47 & 11,31 & 10,72 & 10,78 \\
\hline & 0,90 & 4,07 & 4,12 & desliga & 4,09 & 1,10 & 5,80 & 5,89 & 5,63 & 5,57 & 0,90 & 0,76 & 5,20 & 5,06 & 4,98 \\
\hline \multirow{10}{*}{0,063} & 39,73 & 12,67 & 12,55 & desliga & 10,10 & 37,68 & 13,00 & 12,37 & 11,27 & 11,32 & 37,93 & 1,95 & 12,88 & 10,72 & 10,71 \\
\hline & 29,22 & 11,58 & 11,28 & desliga & 9,13 & 28,42 & 12,36 & 11,64 & 10,59 & 10,54 & 28,45 & 1,90 & 11,99 & 10,10 & 10,16 \\
\hline & 24,19 & 11,06 & 10,68 & desliga & 8,74 & 23,38 & 12,04 & 11,30 & 10,16 & 10,10 & 23,61 & 1,80 & 11,51 & 9,81 & 9,92 \\
\hline & 19,29 & 10,48 & 10,01 & desliga & 8,26 & 19,36 & 11,78 & 10,99 & 9,61 & 9,67 & 18,39 & 1,77 & 11,01 & 9,57 & 9,70 \\
\hline & 15,10 & 9,76 & 9,28 & desliga & 7,76 & 14,45 & 11,17 & 10,44 & 8,61 & 8,88 & 14,69 & 1,74 & 10,56 & 9,40 & 9,44 \\
\hline & 9,79 & 8,48 & 8,16 & desliga & 6,85 & 9,40 & 9,53 & 9,01 & 7,14 & 7,44 & 9,59 & 1,52 & 9,88 & 9,11 & 9,06 \\
\hline & 7,66 & 7,93 & 7,73 & desliga & 6,47 & 7,42 & 8,49 & 8,10 & 6,50 & 6,69 & 7,54 & 1,46 & 9,60 & 9,04 & 8,89 \\
\hline & 5,15 & 6,69 & 6,64 & desliga & 5,67 & 4,89 & 7,31 & 7,06 & 6,03 & 6,04 & 4,60 & 1,35 & 9,00 & 8,66 & 8,52 \\
\hline & 2,83 & 5,20 & 5,28 & desliga & 7,84 & 2,80 & 5,51 & 5,41 & 4,84 & 4,76 & 2,96 & 1,26 & 8,67 & 8,33 & 8,30 \\
\hline & 0,99 & 4,45 & 4,47 & desliga & 4,56 & 0,93 & 5,54 & 5,48 & 5,28 & 5,35 & 0,84 & 1,06 & 5,29 & 5,17 & 5,09 \\
\hline
\end{tabular}



